\author{
UNIVERSIDADE DE SÃO PAULO \\ INSTITUTO DE FÍSICA DE SÃO CARLOS
}

ATÍLIO TOMAZINI JÚNIOR

Estudos de proteômica, estruturais e funcionais de proteínas envolvidas na degradação da biomassa lignocelulósica: expansinas microbianas e hidrolases de glicosídeos termofílicas.

São Carlos

2016 



\section{ATÍLIO TOMAZINI JÚNIOR}

Estudos de proteômica, estruturais e funcionais de proteínas envolvidas na degradação da biomassa lignocelulósica: expansinas microbianas e hidrolases de glicosídeos termofílicas.

Tese apresentada ao Programa de PósGraduação em Física do Instituto de Física de São Carlos da Universidade de São Paulo, para obtenção do título de Doutor em Ciências.

Área de concentração: Física Aplicada Opção: Física Biomolecular Orientador: Prof. Dr. Igor Polikarpov

Versão Corrigida

(Versão original disponível na Unidade que aloja o Programa)

São Carlos

2016 


\section{AUTORIZO A REPRODUÇÃO E DIVULGAÇÃO TOTAL OU PARCIAL DESTE TRABALHO, POR QUALQUER MEIO CONVENCIONAL OU ELETRÔNICO PARA FINS DE ESTUDO E PESQUISA, DESDE QUE CITADA A FONTE.}

Ficha catalográfica revisada pelo Serviço de Biblioteca e Informação do IFSC, com os dados fornecidos pelo(a) autor(a)

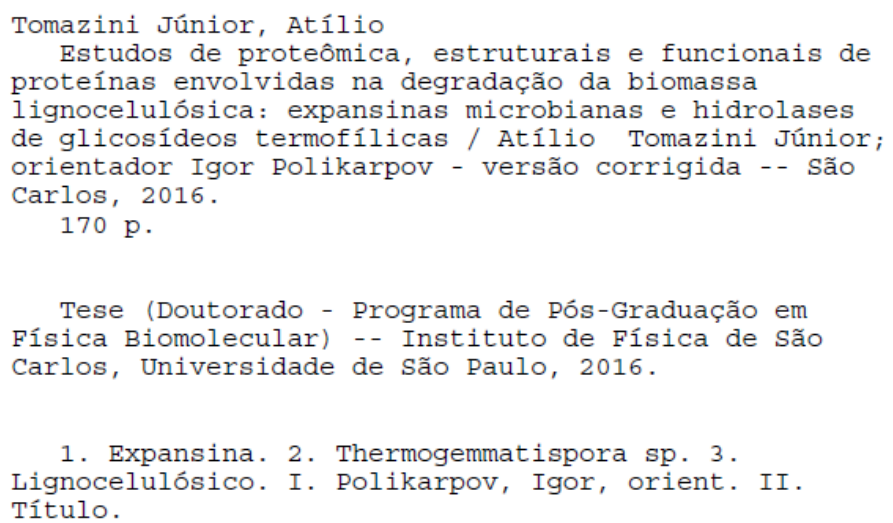


A meus pais Atílio e Fátima, pelo apoio, confiança e amor.

Dedico. 



\section{AGRADECIMENTOS}

A Deus, pela vida e pelas pessoas que Ele colocou em meu caminho;

Aos meus pais Atílio e Fátima, aos meus irmãos Daniela e Maico e minhas sobrinhas Yasmin e Helena, pelo apoio e carinho em todos os momentos;

A Helena Judith minha avó, Fabiana Tomazini, Mayara, Milena e Ivi em nome das quais agradeço a todos meus familiares;

Ao Prof. Dr. Igor Polikarpov, pela confiança, pelas discussões sempre construtivas e pelo apoio na realização deste trabalho;

Aos amigos Caio V. dos Reis, Ivan R e Silva, Geraldo R. Sartori e Rodrigo Berté pela constante ajuda, discussões e inestimável amizade.

Aos amigos Ivoney G. Queiroz, Vera, Marina, Bia e Raquel;

Aos professores David B. Levin e Richard Sparling pela oportunidade do estágio na Universidade de Manitoba, Winnipeg - Canadá;

Aos amigos Livia R. Manzine Margarido e Josimar Sartori pelo companheirismo e aprendizado.

Aos amigos Alessandro Machado, Luisa Anastácio, Ártemis e Rogério B. pela inestimável amizade.

Aos amigos da reunião secreta Marco A. S. Kadovak, Mariana Ortiz e Mariana Zulian pela constante ajuda, discussões e inestimável amizade.

Aos amigos Júlio Dadalt, Priscilla J., Ana Paula, Andréia, Dimas, Ericka, Alan, Tingting e Thinesh ; 
Aos amigos Joci Neuby Alves Macedo, Andressa Patrícia A. Pinto, Derminda Isabel de Morais (Bel), Fernando, Suzana e José Luiz.

Aos amigos de graduação: Wagner, Hilde, Victor H. (B2), Luciano, Paulinha, Ricardo, Gustavo (Udi), Erica, Cauê, Ila, Alexandre e Vitor (Wally);

As Profas. Ana Paula Ullian de Araújo, Nelma Segnini Bosolam e Leila Beltramini e ao Prof. Antonio José da Costa Filho (Jabah) pela prestatividade;

A Silvio Athayde pela dedicação, atenção e apoio em nome do qual agradeço a todos do departamento acadêmico;

A Elizabeth Conti pelo constante apoio nos assuntos acadêmicos desde a graduação;

Aos amigos de laboratório Evandro, Hévila, Vássia, Vanessa, Melissa, Andre, Amanda, Danilo, Graziele, Andreia, Aline, Ana, Renata, Marina, Bruno, Erick, Heloisa, João e Karina ;

Aos técnicos do Grupo de Biotecnologia Molecular Maria e João;

A Daniele Santini, Cristina Silva, Edvane e Italo em nome dos quais agradeço a todos os funcionários do IFSC;

Às funcionárias do serviço de Biblioteca e Informação do IFSC-USP, pela prestatividade em todos os momentos em especial Neusa e Cris;

À Universidade de São Paulo e o Instituto de Física de São Carlos, por oferecer toda a estrutura necessária para realização deste trabalho;

A Capes, pela concessão da bolsa de doutorado e CNPQ pela bolsa de doutorado sanduíche.

Enfim, a todos que contribuíram de forma direta ou indireta para a realização deste trabalho. 
"Uma grande descoberta envolve a solução de um grande problema, mas há uma semente de descoberta na solução de qualquer problema. Seu problema pode ser modesto porém, se ele desafiar sua curiosidade e fizer funcionar sua capacidade inventiva, e caso você o resolva sozinho, então poderá experimentar a tensão e o prazer do triunfo da descoberta" 



\section{RESUMO}

TOMAZINI JUNIOR, A. Estudos de proteômica, estruturais e funcionais de proteínas envolvidas na degradação da biomassa lignocelulósica: expansinas microbianas e hidrolases de glicosídeos termofílicas. 2016. 170 p. Tese (Doutorado em Ciências) Instituto de Física de São Carlos, Universidade de São Paulo, São Carlos, 2016.

O Brasil possui uma posição privilegiada quando se refere à produção de etanol. Por questões históricas e geográficas o país é responsável por mais de 30 \% da produção mundial de etanol, com uma produção nacional de mais de 28 bilhões de litros em 2014. Para maximizar o rendimento desse processo, está em desenvolvimento a tecnologia associada ao etanol de segunda geração ou etanol lignocelulósico. Os principais desafios desta tecnologia são: melhorar a eficiência de conversão do substrato em produto e a produção em grande escala utilizando substratos de baixo custo. Com o objetivo de melhorar a eficiência do processo de conversão foram estudadas proteínas auxiliares (expansinas) que, em conjunto com celulases, melhoram a despolimerização de biomassa lignocelulósica em açúcares fermentescíveis. Além disso, realizou-se também a caracterização de enzimas ativas de carboidratos (CAZymes) de origem termofílica do organismo Thermogemmatispora $s p$. T81, devido a capacidade que estas proteínas apresentam de manter a atividade e conformação estrutural em altas temperaturas por um prolongado período de tempo. A partir de análises utilizando bioinformática, os genes que codificam para expansinas de Xanthomonas campestris, Bacillus licheniformis e Trichoderma reesei foram clonados e expressos em E. coli, e seus produtos gênicos (as expansinas) tiveram seus índices de sinergismo (devido atuação conjunta com coquetéis comerciais) e atividade catalítica determinados. Adicionalmente, dispondo de alinhamentos estruturais, foi proposto um mecanismo hidrolítico para elas. Em relação à bactéria Thermogemmatispora $s p$. T81, foram realizadas análises genômicas e proteômicas, a fim de selecionar enzimas superexpressas em meio celulósico. Seus genes foram clonados heterologamente em E. coli e o produto de expressão caracterizado bioquimicamente (cromatografia, ensaios de atividade e perfil de hidrólise) e estruturalmente (SAXS e dicroísmo circular). Os índices de sinergismo determinados foram de 2,47; 1,96 e 2,44 para as expansinas de Xanthomonas campestris, Bacillus licheniformis e Trichoderma reesei, respectivamente. A partir dos alinhamentos estruturais foi proposto a díade Asp/Glu como sitio catalítico em expansinas. As análises de proteômica possibilitaram a seleção de quatro alvos de clonagem, por apresentarem alto índice de expressão quando a bactéria foi cultivada em meio celulósico. Estas proteínas foram caracterizadas quanto a atividade e apresentaram um perfil comum: temperatura ótima de ação (de 70 a $75^{\circ} \mathrm{C}$ ), pH ótimo de 5 , e hidrolisam preferencialmente substratos hemicelulósicos (xilano). A porcentagem de estruturais secundárias das proteínas em estudo foram confirmadas com predições teóricas ao se utilizar a técnica de dicroísmo circular. Desta maneira, os objetivos iniciais propostos neste projeto foram concluídos com a determinação do grau de sinergismo das proteínas expansinas em estudo e a proposição de um mecanismo de hidrólise para as mesmas, considerando que tais proteínas por mais de 20 anos tiveram sua atividade definida exclusivamente como acessória. Além disso, este estudo contribui com a identificação e seleção de genes para CAZymes termofilícas com aplicação biotecnológica devido às propriedades termoestáveis apresentadas.

Palavras-chave: Expansina. Thermogemmatispora sp.. Lignocelulósico. 



\begin{abstract}
TOMAZINI JUNIOR, A. Proteomic, structural and functional studies of lignocellulosic biomass degradation: microbial expansins and thermophilic glycosyl hydrolases. 2016. 170 p. Tese (Doutorado em Ciências) - Instituto de Física de São Carlos, Universidade de São Paulo, São Carlos, 2016.

Brazil holds a privileged position regarding the production of ethanol. Due to geographical and historical reasons the country produces more than $30 \%$ of the world's ethanol, with a national yield of more than 28 billion liters in 2014 alone. To further increase gain in production, technology related to second generation (or lignocellulosic) ethanol is currently under development. The main challenges of this technology are: to improve the substrate-product conversion and large-scale production using low-cost substrates. In order to improve the efficiency of the former, auxiliary proteins (expansins), which enhance lignocellulosic biomass depolymerization to fermentable sugars when associated to celullases, were studied. Besides, due to structural and catalytic resilience when subjected to high temperature, the characterization of carbohydrate-active enzymes (CAZymes) of thermophilic origin from Thermogemmatispora sp. T81 organism was performed. Through the application of bioinformatics, genes coding for Xanthomonas campestris, Bacillus licheniformis e Trichoderma reesei expansins were cloned and expressed in E. coli, being the products assessed regarding their synergism (due to joint action with commercially available enzyme cocktails) and catalytic activity. Additionally, a hydrolytic mechanism was proposed based on structural alignments. Concerning the Thermogemmatispora sp. T81 bacteria, genomic and proteomic analysis were performed in order to select overexpressed enzymes in cellulosic medium. The heterologous cloning of the respective genes was then performed in E. coli, being the products characterized biochemically (utilizing chromatography, activity assay and hydrolysis profile) and structurally (through SAXS and circular dichroism). Determined synergistic indices were 2.47; 1.96 and 2.44 for Xanthomonas campestris, Bacillus licheniformis e Trichoderma reesei expansins, respectively. From structural alignments, the dyad Asp/Glu was proposed as the catalytic site in expansins. Proteomic analysis allowed the selection of four proteins for cloning, due to high expression levels when the bacteria were cultivated in a cellulosic medium. These proteins were characterized based on their activity and showed similar trends: optimal functional temperature $\left(70-75^{\circ} \mathrm{C}\right)$, optimal $\mathrm{pH}$ of 5 , and preferential hydrolysis of hemicellulosic substrates (xylan). Theoretical predictions of secondary structure percentages of studied proteins were confirmed through circular dichroism technique. Therefore, the initially proposed objectives in this project were accomplished with the determination of synergistic level and proposed hydrolytic mechanism for the expansins, considering that the role of these proteins were deemed marginal for over 20 years. In addition, this study contributes with the identification and selection of genes of thermophilic CAZymes with biotechnological applications due to shown thermostability properties.
\end{abstract}

Keywords: Expansins. Thermogemmatispora sp.. Lignocellulosic. 



\section{LISTA DE FIGURAS}

Figura 1 - Componentes da parede celular vegetal.

Figura 2 - Modelo de M. Himmel para a ação de hidrolases de glicosídeos. Sendo R: extremidades com terminais redutores e NR: extremidades sem terminais redutores.

Figura 3 - Mecanismos bioquímico e microbiológico da quebra de fibras de algodão 30

Figura 4 - A- Estrutura do xilano e os sítios de seu ataque pelas enzimas xilanolíticas Bhidrólise de xilo-oligossacarídeo por $\beta$-xilosidase.

Figura 5 - Mecanismo de retenção e inversão proposto por Koshland. 34

Figura 6 Mecanismo de ação por retenção (A) e inversão (B) por uma $\beta$-glicosidase. 35

Figura 7- Mapa do vetor LIC, pET Trx_1a.

Figura 8- Espectro típico das principais estruturas secundárias em proteínas.

Figura 9 - Esquema do experimento de SAXS com a transformada de Fourier do espaço real para o recíproco.

Figura 10 - Teste de expressão, perfil eletroforético em SDS-PAGE 15\%. M: marcador de massa molecular, 1: extrato bruto e 2: pós-indução de Rare lipoprotein de $T$. harzianum.; 3: extrato bruto e 4: pós-indução de Gras transcriptor de T. harzianum; 5: extrato bruto e 6: pós-indução da SWO1 de T. harzianum; 7 extrato bruto e 8: pós indução da SWO1-domínio catalítico de T. harzianum.

Figura 11 - Perfil eletroforético SDS-PAGE 15\%. A) Expansin-like de Bacillus licheniformis, B) Expansin-like de Xanthomonas campestris, C) Swo-domínio catalítico de Trichoderma reesei e D) Domínio de Rare lipoprotein de Trichoderma reesei. Para todas as amostras apresentadas, a ordem das linhas nos géis de poliacrilamida é: M: marcador de massa molecular, 1: fração pré-indução, 2: fração pós-indução, 3: "pellet" do precipitado celular, 4: fração sobrenadante, 5: primeira eluição $(200 \mathrm{mM}$ imidazol) e 6: segunda eluição $(500 \mathrm{mM})$ de imidazol..

Figura 12- Perfil eletroforético da purificação das espansinas em gel SDS-PAGE $15 \%$. M: marcador de massa molecular, 1: Expansina de Bacillus licheniformis, 2: SWO1domínio catalítico de Trichoderma reesei, 3: Rare lipoprotein de Trichoderma reesei e 4: expansina de Xanthomonas campestris ....

Figura 13-Avaliação da atividade relativa entre a ação do coquetel (Accellerase 1500) atuando sozinho e em conjunto com expansinas sobre papel filtro $\mathrm{N}^{\circ} 1$ da Whatman.

Figura 14 - Atividade hidrolítica das expansinas sobre xilano $(1 \% \mathrm{~m} / \mathrm{V})$ por $24 \mathrm{~h}, 50^{\circ} \mathrm{C}$ e 1000rpm. Utilizando por reação de SWO1 d. catalítico T. reesei, Expansina de $B$. licheniformis ou Expansina de $X$. campestris $0,08 \mathrm{mg}(=33 \mu \mathrm{M})$ de proteína e para a reação de Rare lipoprotein de $T$. reesei $0,02 \mathrm{mg}(=18 \mu \mathrm{M})$ de proteína. 
Figura 15- Visão estéreo da sobreposição entre a estrutura dos modelos obtidos por cristalografia e homologia, dando enfoque para a conservação do domínio 1 (Rare lipoprotein) conservado em expansinas e nas GH45 da família C. A - PDB 3X2M (alaranjado) e os modelos cristalográficos de expansinas bacterianas: Xanthmonas campestris (PDBid 3D30) e modelo por homologia de Bacillus licheniformis em gradiente de cinza. B - PDB 3X2M (alanranjado) e os modelos cristalográficos de expansinas fúngicas: modelo estrutural por homologia para SWO1-domínio catalítico Trichoderma reesei, modelo estrutural por homologia de Rare lipoprotein de Trichoderma reesei e PDBid 1N10 em gradiente de cinza. 88

Figura 16 -Árvore de identidade sequencial obtida com o algoritmo Neighbour-joining para expansina (Expansin-like) de Bacillus lichenisformis e Xanthomonas campestris, SWO1-sítio catalítico de Trichoderma reesei e a GH45 de Phanerochaete chrysosporium. Testes com 10000 repetições foram conduzidos com um grupo controle para examinar a qualidade do modelo. 89

Figura 17 - Alinhamento sequencial para SWO1-domínio catalítico de Trichoderma reesei com a GH45 de Phanerochaete chrysosporium, em destaque os aminoácidos catalítico da GH45 e os possíveis aminoácidos catalítcos das expansinas. Obtidos com o servidor T-Coffee. ${ }^{40}$ 91

Figura 18 - Alinhamento sequencial para Expansin-like de Bacillus subtillis, Bacillus licheniformis, Xanthomonas campestris e a GH45 de Phanerochaete chrysosporium, em destaque os aminoácidos catalítico da GH45 e os possíveis aminoácidos catalítcos das expansinas. Obtidos com o servidor T-Coffee. ${ }^{40}$....... 92

Figura 19 - Sobreposição estrutural da expansina (Expansin-like) de Xanthomonas campestris em cor ciano com a PcCel45A em cor alaranjada.

Figura 20 - Sobreposição estrutural da Expansin-like de Xanthomonas campestris em cor ciano com a PcCel45A em cor alaranjado, destacando em vermelho os resíduos catalíticos da GH45 de Phanerochaete chrysosporium e em verde os resíduos propostos como catalíticos em Xanthomonas campestris. 94

Figura 21 - Cromatografia em camada delgada do perfil de degradação dos oligossacarídeos para as expansinas. Cada linha corresponde: M, marcadores de oligossacarídeos, X1 (xilose), X2 (xilobiose), X3( xilotriose), X4 (xilotetraose), X5(xilopentaose) e X6 (xilohexaose), 1: Expansin-like de Xanthomonas campestris, 2: Expansin-like de Bacillus licheniformis, 3: SWO-domínio catalítico de Trichoderma reesei, 4: Rare lipoprotein de Trichoderma reesei e B: branco, substrato da reação 95

Figura 22 - Espectros de CD das proteínas similar a expansina de Xanthomonas campestris (ExX), proteína similar a expansina de Trichoderma reesei (ExT) e a proteína similar a expansina de Bacillus licheniformis $(\mathrm{ExB})$

Figura 23 - Imagens da bactéria Thermogemmatispora sp. cepa T81. A) Imagem de microscopia óptica sem corantes ou fixadores, B) em meio líquido AOM1 com $20 \mathrm{~g} / \mathrm{L}$ de extrato de levedura. 102

Figura 24 - Árvore filogenética utilizando o algoritmo Neighbour-joining com base nas sequências do gene cpn60 para as espécies selecionadas. Testes com 10000 
repetições foram conduzidos para examinar a confiabilidade dos ramos interiores.

Figura 25 - SDS-PAGE das amostras da fase Mid-log (exponencial) e estacionária dos substratos avaliados como fonte de carbono, em A as amostras correspondentes a $\alpha$ celulose e em B as correspondentes ao extrato de levedura e glicose, as letras A e B junto ao exponencial e estacionário referem-se a cada duplicata do experimento. 116

Figura 26 - Perfil eletroforético SDS-PAGE 15\% referente às etapas de purificação. A (T81_46750 GH6), B (T81_30480 GH30_7), C (T81_30480 domínio CBM) D (T81_30480, domínio catalítico) E (T81_22550, GT4) e F ( T81_14280 GH5_22). Para todas as amostras apresentadas, a ordem das linhas nos géis de poliacrilamida é a seguinte: M: marcador de massa molecular, 1: fração antes de indução, 2: fração pós-indução, 3: “pellet” precipitado celular, 4: fração sobrenadante, 5: primeira eluição (200mM imidazol) e 6: segunda eluição (500mM) de imidazol. 123

Figura 27 - Perfil eletroforético em SDS-PAGE 15\% dos alvos purificados 123

Figura 28 - A, Varredura de temperaturas de ação do coquetel de T81 sobre CMC, B, Varredura de pHs de ação do coquetel de T81 sobre Xilano de faia. 124

Figura 29 - Varredura de substratos para ação do coquetel T81. 125

Figura 30 - A, Atividade do coquetel recém produzido e do coquetel armazenado por 6 meses $\mathrm{B}$, Atividade das enzimas secretadas ao longo do período de crescimento da cultura de T81. 126

Figura 31 - Painel de substratos para as enzimas clonadas de T81: A ( T81_46750 GH6), B (T81_30480 GH30_7), C (T81_30480, domínio catalítico) e E ( T81_14280 GH5 22) foram utilizadas as concentrações de 4,3; 5,6; 6,2 e 12,5 $\mu \mathrm{M}$, respectivamente, reações por $120 \mathrm{~min}$ a $60^{\circ} \mathrm{C}, 1000 \mathrm{rpm}$ e para a enzima $\mathrm{D}$ (T81_05390, GT4) na concentração de $7 \mu \mathrm{M}, 720 \mathrm{~min}$ a $60^{\circ} \mathrm{C}$, com rotação de 1000 rpm. 130

Figura 32 - Avaliação dos substratos para a enzima (T81_30480 GH30_7): A, temperatura ótima e $\mathrm{B}, \mathrm{pH}$. 130

Figura 33 - Avaliação das condições ótimas para a enzima C (T81_30480 GH30_7 domínio catalítico). A, temperatura e B, pH. 131

Figura 34 - Determinação da concentração ideal de enzima e do tempo reacional para a enzima GH30_7 domínio catalítico (T81_30480).

Figura 35 - Gráfico da velocidade de formação de xilose em função da concentração de xilano para a enzima GH30_7 domínio catalítico (T81_30480)

Figura 36 - Perfil eletroforético em gel nativo da enzima GH30_7 domínio catalítico (T81_40520). Gel nativo (gradiente de 8-25\%), M: corresponde ao padrão de massa molecular, 1: corresponde a proteína.

Figura 37 - Cromatografia em camada delgada do perfil de degradação dos oligossacarídeos para GH30_7 domínio catalítico (T81_30180). Cada linha corresponde: M, 
marcadores de oligossacarídeos, X1 (xilose), X2 (xilobiose), X3( xilotriose), X4 (xilotetraose), X5(xilopentaose) e X6 (xilohexaose), 1: tempo de 2,5 min e B: branco, substrato da reação................................................................................ 135

Figura 38 - Atividade relativa do CBM2, reação 24h, 70 ${ }^{\circ} \mathrm{C}$, 100rpm................................ 136

Figura 39 - Espectros de CD obtidos para as proteínas p1( T81_46750 GH6), p2 (T81_30480 GH30_7), p3 (T81_30480, domínio CBM), p5 (T81_30480, domínio catalítico), p7(T81_22550, GT4) e p8( T81_14280 GH5_22).

Figura 40 - A, Monitoramento em 208nm para a proteína p5 (T81_30480), B, Monitoramento em 222nm para a proteína p5 (T81_30480).............................. 139

Figura 41 - Espectro de dicroísmo circular da p5 em $25^{\circ} \mathrm{C}$ inicial, $75^{\circ} \mathrm{C}$ e $25^{\circ} \mathrm{C}$ pós desnaturação térmica. .................................................................................. 140

Figura 42 - Imagem estéreo do modelo para GH30_7 domínio catalítico obtido por

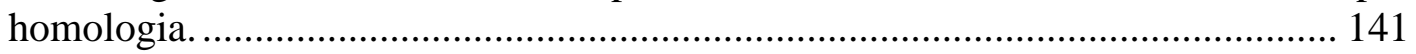

Figura 43 - Obtenção do raio de giro pelo método de Guinier ............................................ 142

Figura 44 - Função de distribuição de distâncias para os dados experimentais da GH30_7 domínio catalítico.

Figura 45 - Curva de espalhamento de raios-X a baixo ângulo da proteína GH30_7 domínio catalítico. Para o modelo de envelope molecular, DAM (Dammin), modelo cristalográfico por homologia e para a curva experimental. 144

Figura 46 - Sobreposição do DAM para GH30_7 com o modelo por homologia. A partir do modelo central temos: a imagem a direita provinda de uma rotação de $90^{\circ}$ no eixo $\mathrm{x}$ e a da esquerda a partir de uma rotação de $90^{\circ}$ com relação ao eixo y. Tomando como coordenadas o plano cartesiano xyz. 145

Figura 47 - Cristais do sítio catalítico da GH30_7 de T81. 146 


\section{LISTA DE TABELAS}

Tabela 1 - Descrição de xilanases quanto a família de hidrolases de glicosídeos, enovelamento estrutural, mecanismo e resíduos catalíticos 31

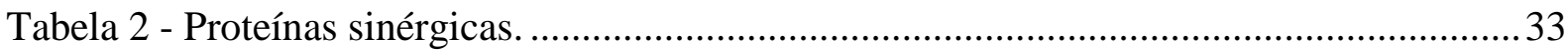

Tabela 3- Reação de amplificação do vetor de clonagem. ....................................................... 46

Tabela 4 - Oligonucleotídeos utilizados na amplificação dos genes das expansinas. ..............46

Tabela 5 - Reação de tratamento com T4 DNA polimerase.................................................. 47

Tabela 6 - Reação de amplificação para cada um dos genes.................................................56

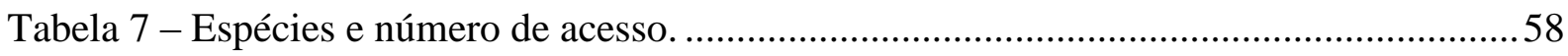

Tabela 8 - Oligonucleotídeos utilizados na amplificação dos genes selecionados de T81 ......64

Tabela 9 - Parâmetros moleculares e de clonagem das expansinas........................................ 80

Tabela 10 - Grau de sinergismo das expansinas em duas concentrações diferentes. ..............85

Tabela 11 - Proporção de estruturas secundárias obtidas a partir dos espectros de CD,

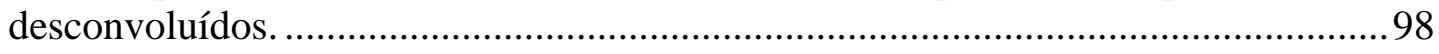

Tabela 12 - Concentração de $\mathrm{CO}_{2}$ medida utilizando a cromatografia gasosa........................ 101

Tabela 13 - Características gerais dos genomas de Thermogemmatispora sp. T81 e de outras bactérias do grupo Chloroflexi (em ordem ascendente de tamanho do genoma). ... 105

Tabela 14 - Analise comparativa do número de CAZymes por família codificada pelo grupo

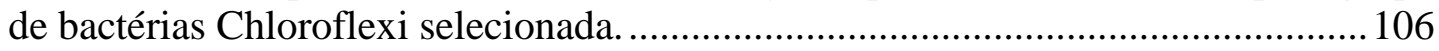

Tabela 15 - CAZymes extracelulares preditas para Thermogemmatispora sp. T81 .............. 108

Tabela 16 - Distribuição das famílias de hidrolases de glicosídeos nos genomas das bactérias do grupo Chloroflexi

Tabela 18 - Tabela de Hidrolases de Glicosídeos identificadas no proteôma da bactéria Thermogemmatispora sp. cepa T81. Os níveis de expressão é listado para cada um dos substratos. AC: $\alpha$-celulose, Gli: glicose e EL: extrato de levedura. 119

Tabela 19 - Tabela de Transferases de glicosídeos identificadas no proteôma da bactéria Thermogemmatispora sp. cepa T81. Os níveis de expressão é listado para cada um dos substratos. AC: $\alpha$-celulose, Gli: glicose e EL: extrato de levedura.

Tabela 20 - Tabela de Esterase de Carboidratos identificadas no proteôma da bactéria da bactéria Thermogemmatispora sp.cepa T81. Os níveis de expressão é listado para cada um dos substratos.AC: $\alpha$-celulose, Gli:glicose e EL: extrato de levedura....... 120 
Tabela 21 - Tabela de Proteínas Multidomínio identificadas no proteôma da bactéria Thermogemmatispora sp. cepa T81. Os níveis de expressão é listado para cada um dos substratos. AC: $\alpha$-celulose, Gli: glicose e EL: extrato de levedura.

Tabela 22 - Alvos selecionados para estudo com caracterização baseada no Swiss-Prot (http://web.expasy.org/protparam/) e Protein Data Bank (PDB;

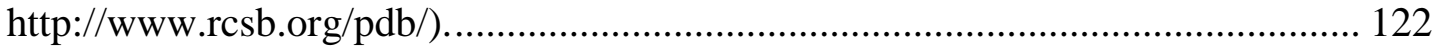

Tabela 23 - Parâmetros cinéticos de caracterização da enzima GH30_7 domínio catalítico (T81_30480). 134

Tabela 24 - Proporção de estruturas secundárias obtidas para os dados (CD) deconvoluidos. 138

Tabela 25 - Parâmetros estruturais da GH30_7 domínio catalítico, obtidos por SAXS. 144 


\section{LISTA DE ABREVIATURAS E SIGLAS}

ATCC

ATP

BLAST

CAZy

$\mathrm{CD}$

$D_{\text {máx }}$

ExPASy

I

IPTG

LB

LNLS

MM, M

NCBI

ORF

$\mathrm{p}(\mathrm{r})$

PCR

PDB

pI

q

$\mathrm{R}_{\mathrm{g}}$

SAXS

$\mathrm{Tm}$

$\mathrm{Xcc}$
American Type Culture Collection

Adenosina-5'-trifosfato

Basic Local Aligment Sequence Tool

Carbohydrate-Active enZYmes Database

Circular Dichroism

Dimensão máxima de uma proteína

Expert Protein Analysis System

Intensidade de espalhamento de raios-X

Isopropil-tio-B-D-galactopiranosídeo

Luria-Bertani

Laboratório Nacional de Luz Síncrotron

Massa molecular

National Center for Biotechnology Information

Fase aberta de leitura, do inglês Open Reading Frame

Função de distribuição de distâncias de centros espalhadores de raios-X

Reação em cadeia da polimerase

Protein Data Bank

Ponto isoelétrico

Vetor de espalhamento de raios-X

Raio de giro

Espalhamento de Raios-X a baixo ângulo, do inglês Small angle X-ray scattering

Melting Temperature

Xanthomonas campestris 



\section{SUMÁRIO}

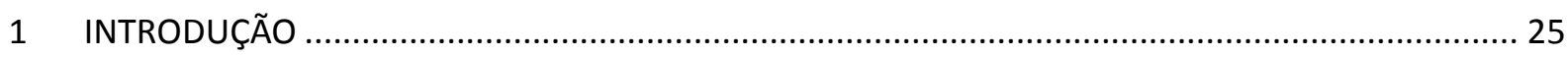

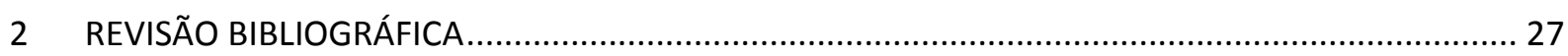

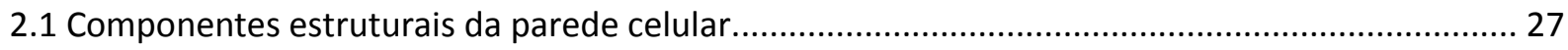

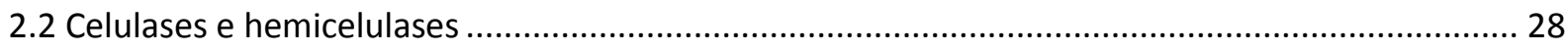

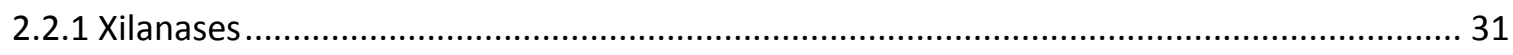

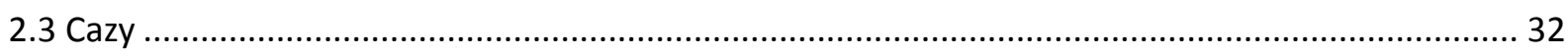

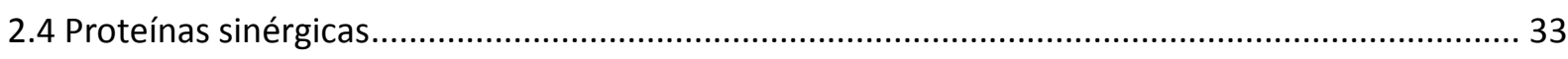

2.5 Mecanismos de hidrólise de ligações glicosídeos. ....................................................................... 34

2.6 Organismos fonte das sequências gênicas de expansinas para estudo......................................... 36

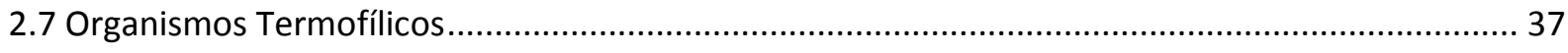

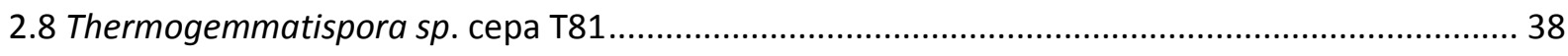

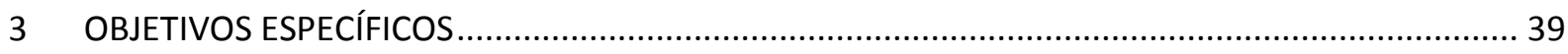

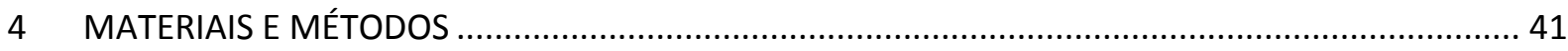

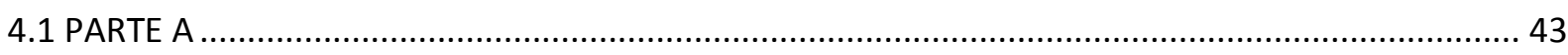

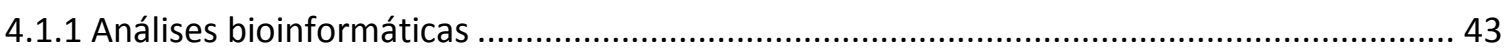

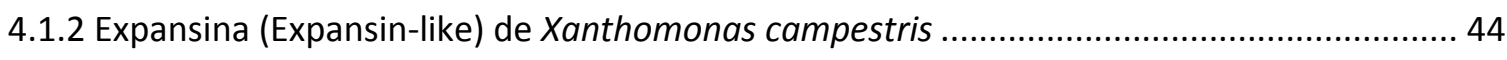

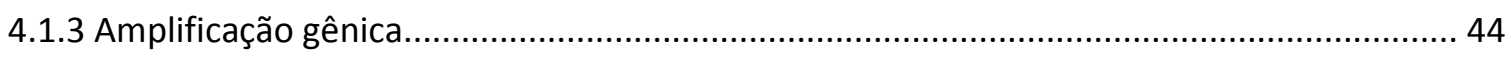

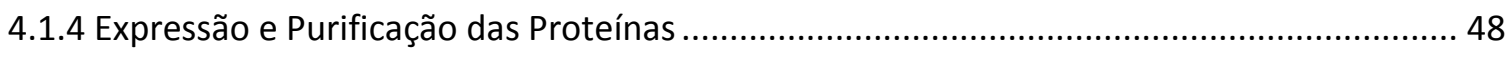

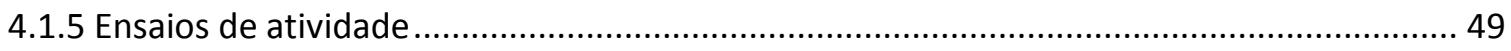

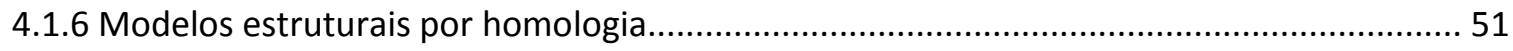

4.1.7 Cromatografia em camada delgada (CCD ou TLC (Thin-layer chromatography)) ................. 52

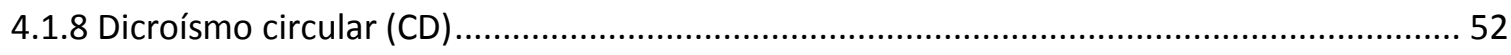

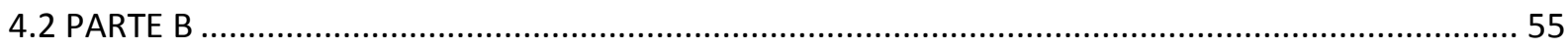

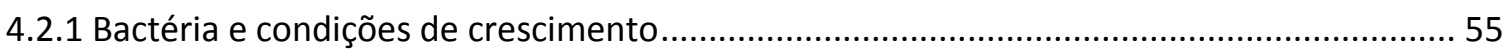

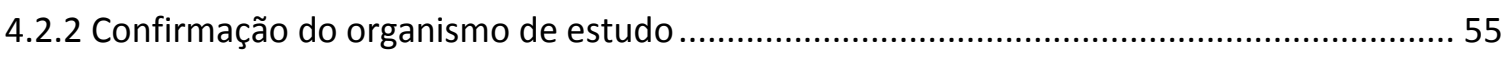

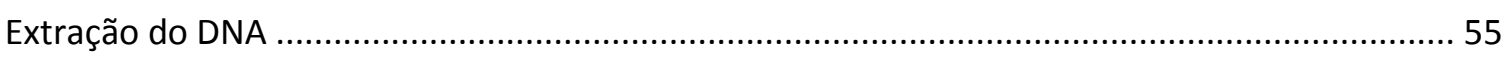

PCR utilizando oligonucleotídeos universais para a sequência CPN60 …................................... 55

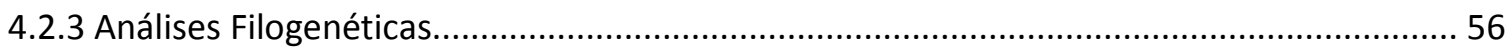

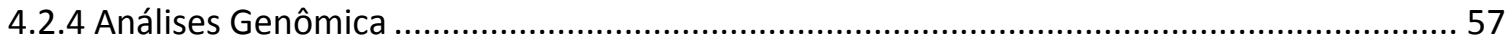

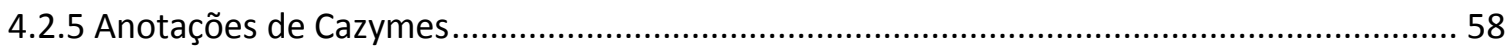

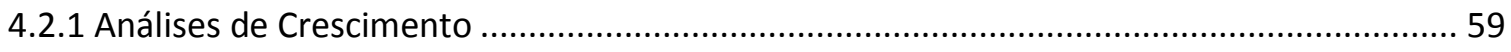




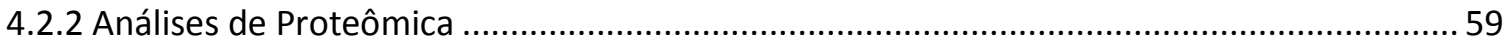

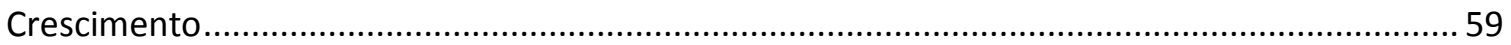

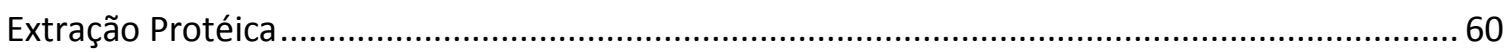

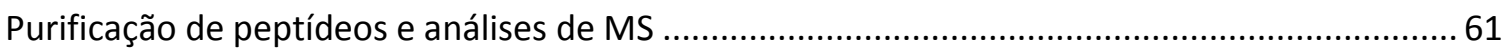

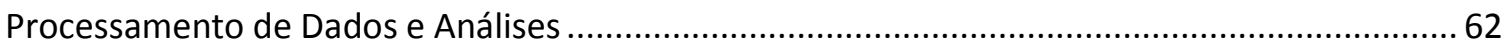

4.2.3 Seleção de candidatos para expressão heteróloga utilizando o processamento de dados, desenho dos oligonucleotídeos, amplificação gênica e clonagem..................................................63

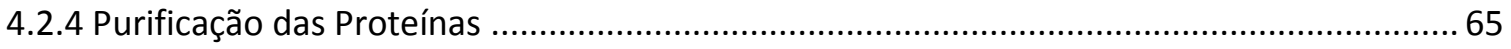

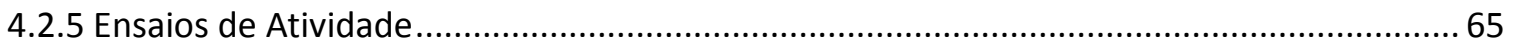

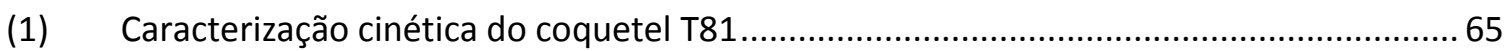

Avaliação da atividade das enzimas secretadas pela bactéria T81 no meio de cultura: Coquetel T81

(2) Caracterização cinética das enzimas clonadas a partir dos dados de proteômica ............67

Cromatografia em camada delgada (CCD ou TLC (Thin-layer chromatography)) para o............... 70

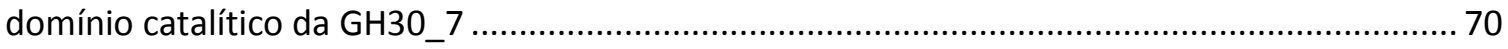

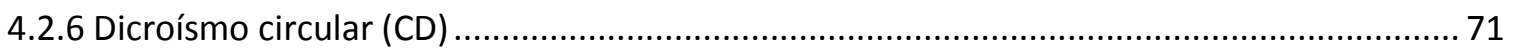

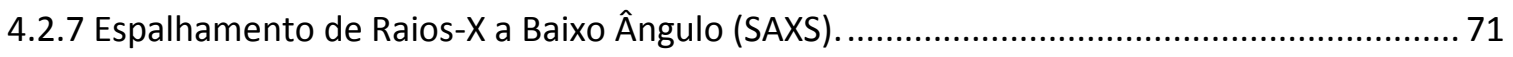

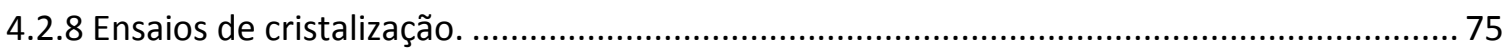

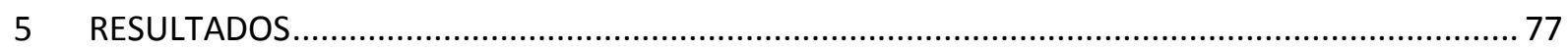

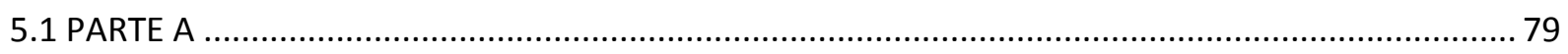

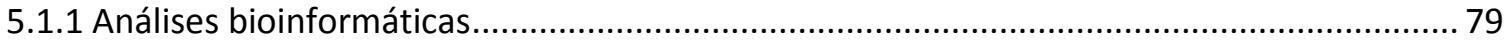

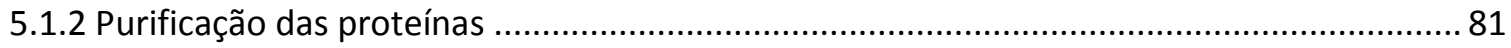

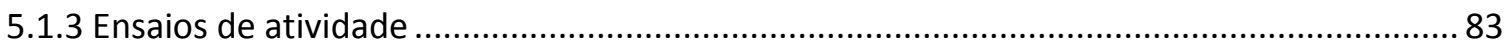

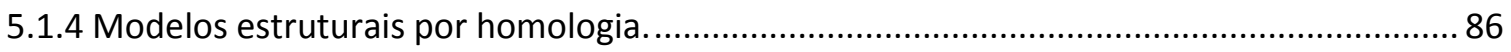

5.1.1 Cromatografia em camada delgada (CCD) ou Thin-layer chromatography (TLC) ................95

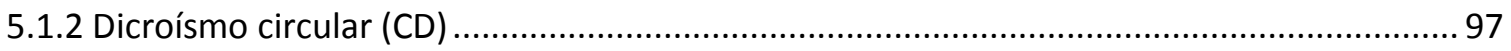

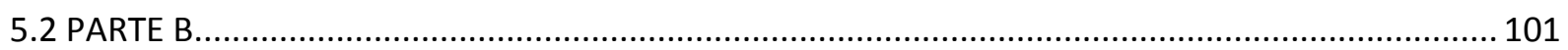

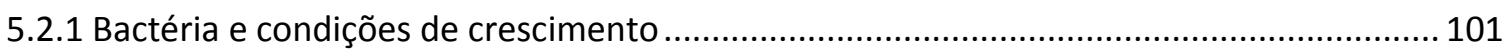

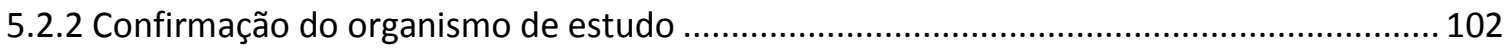

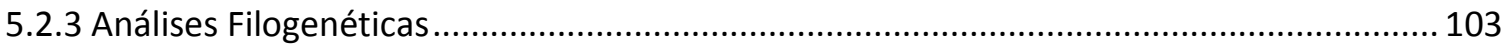

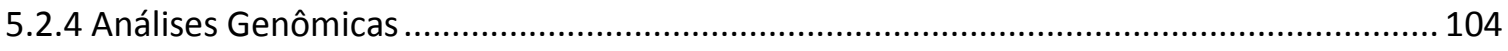

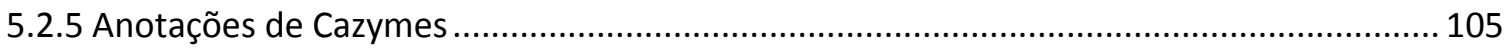

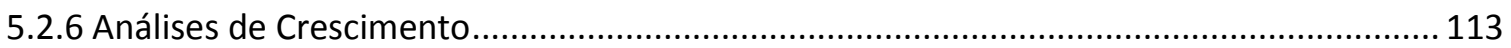

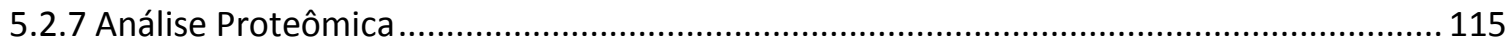

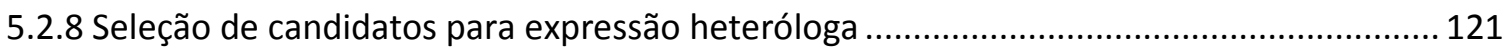




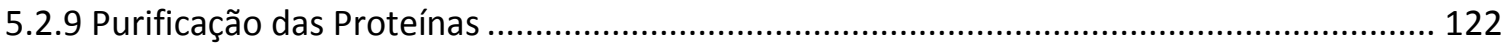

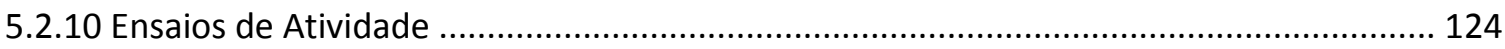

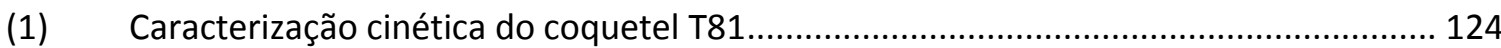

(2) Caracterização cinética das enzimas clonadas a partir dos dados de proteôma ............. 127

Cromatografia em camada delgada (CCD) ou Thin-layer chromatography (TLC) para o domínio

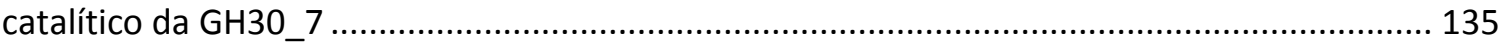

5.2.11 Espectroscopia de CD - proteínas de T81 ................................................................. 136

5.2.12 Modelo por homologia da proteína T81_30480_domínio catalítico ................................. 140

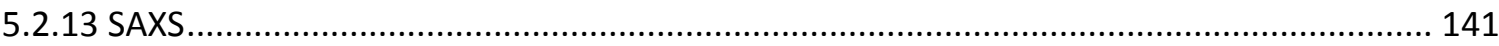

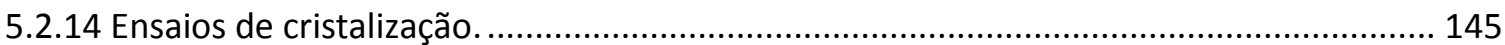

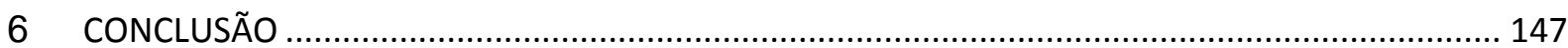

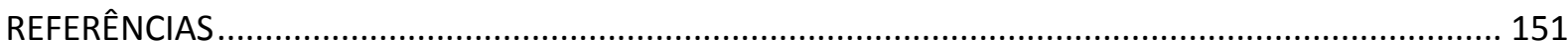

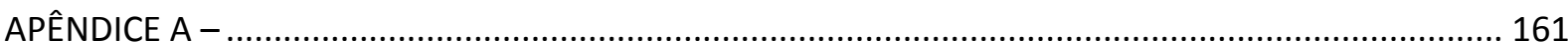





\section{INTRODUÇÃO}

O aumento no consumo de combustíveis e a conscientização da população a respeito da questão ambiental decorrente do uso excessivo de combustíveis fósseis têm como consequência a necessidade de novas fontes de energia. Dessa maneira, o consumo de etanol combustível é crescente em todo o mundo.

O Brasil possui uma posição privilegiada quando se refere à produção de etanol. Por questões históricas e geográficas o país é responsável por mais de $30 \%$ da produção mundial de etanol com uma produção nacional de mais de 28 bilhões de litros em 2014. ${ }^{1}$ Para maximizar o rendimento desse processo, esta em desenvolvimento a tecnologia associada ao etanol de segunda geração ou etanol lignocelulósico.

Os materiais lignocelulósicos geram açúcares fermentescíveis: hexoses e pentoses, após passarem por um pré-tratamento químico e por hidrólise enzimática. O produto da conversão destes açúcares recebe o nome de etanol de segunda geração. Cujos principais desafios são: melhorar a eficiência de conversão do substrato em produto (ação de enzimas e proteínas auxiliares) e a produção em grande escala utilizando substratos de baixo custo. 


\section{REVISÃO BIBLIOGRÁFICA}

\subsection{Componentes estruturais da parede celular.}

Os principais componentes da parede celular vegetal (Figura 1) são: celulose (formada por fibras insolúveis com ligação $\beta$-1,4-glucano), hemicelulose (polissacarídeos não celulósicos incluindo xiloglucanos, glucanos, arabinoxilano, manano e xilanos), pectinas (arabinano, galactano, homogalaturonano) e lignina (complexa estrutura poli-fenólica). ${ }^{2}$

A composição exata da parede celular vegetal depende de sua fonte, no entanto, as composições percentuais típicas são de 35-50\% de celulose, de 20-35\% para a hemicelulose e de $15-30 \%$ para a lignina. ${ }^{3}$

Além disso, a parede celular é classificada em dois principais tipos: primária e secundárias. A parede celular primária é formada durante o crescimento das células que são geralmente consideradas sem especialização e com arquitetura molecular similar, já a parede celular secundária é formada quando o crescimento celular cessou-se estando as células altamente especializadas em relação a suas estruturas e composições, o que refleti o estado de diferenciação de cada célula. ${ }^{4}$ 


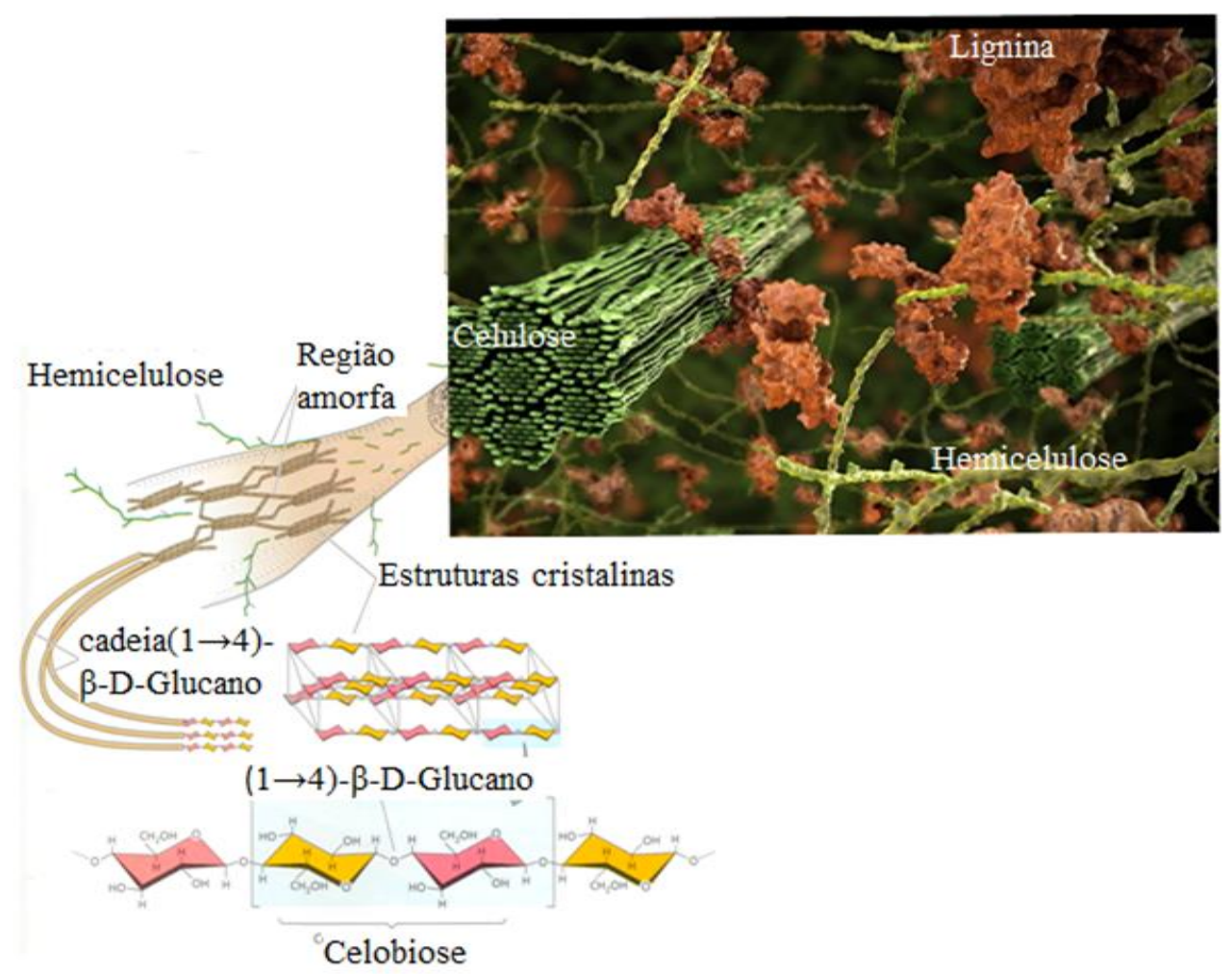

Figura 1 - Componentes da parede celular vegetal

Fonte: Adaptado de TAIZ ;ZEIGER ${ }^{4}$; SCISTYLE $^{5}$.

\subsection{Celulases e hemicelulases}

As enzimas do complexo celulolítico são hidrolases que clivam ligações O-glicosídicas. A classificação das celulases respeita o local de atuação no substrato celulósico, dividindo-as em três grupos (Figura 2): endoglucanases (EnG), que clivam ligações internas da fibra celulósica; exoglucanases (ExG), que atuam nas extremidades da celulose; e $\beta$-glicosidases (BG), que hidrolisam oligossacarídeos solúveis em glicose. ${ }^{6}$

As hemicelulases hidrolisam polímeros da hemicelulose. Dentre as mais conhecidas estão as xilanases, $\beta$-xilosidases, mananases, $\alpha$-arabinofuranosidases e as $\alpha$-galactosidases. Elas atuam de maneira cooperativa e sinérgica no processo de despolimerização da celulose e hemicelulose. 
O fluxograma na Figura 3 mostra o mecanismo bioquímico e microbiológico de quebra da celulose contida nas fibras de algodão à glicose, indicando as reações intra e extracelulares envolvidas neste processo.

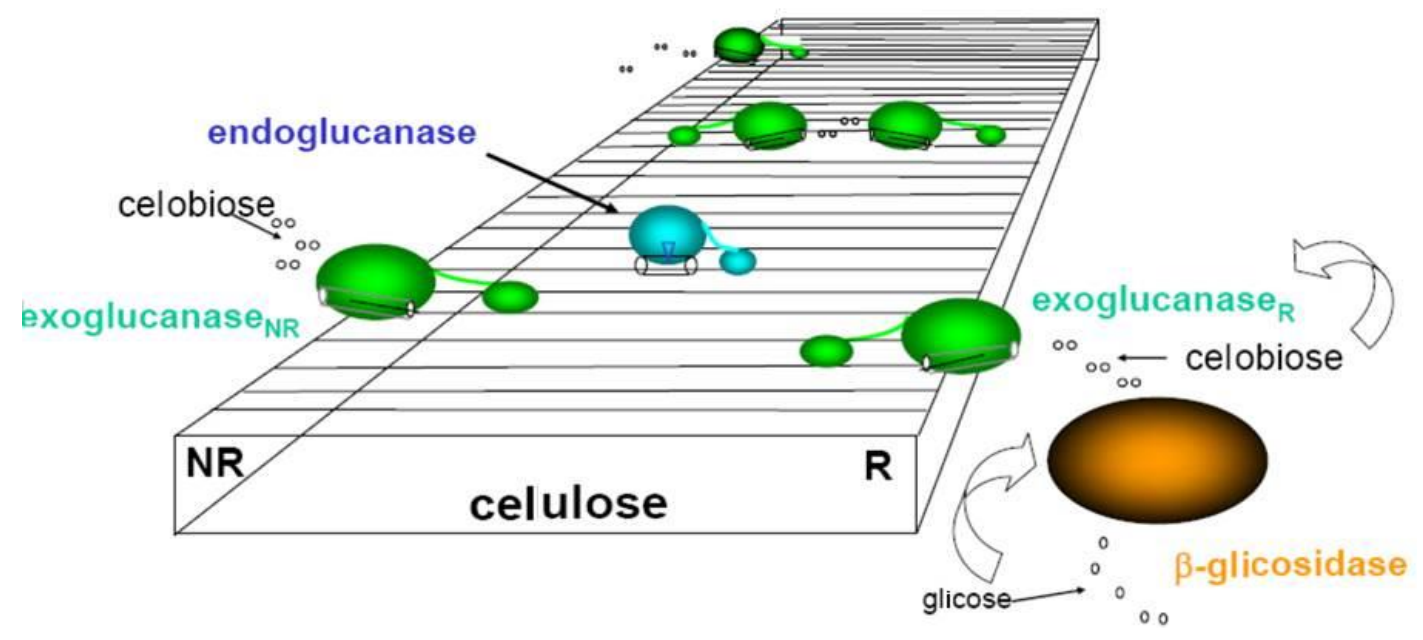

Figura 2 - Modelo de M. Himmel para a ação de hidrolases de glicosídeos. Sendo R: extremidades com terminais redutores e NR: extremidades sem terminais redutores.

Fonte: Adaptado de HIMMEL. ${ }^{7}$

O estudo dos agentes microbiológicos responsáveis por este processo hidrolítico seja como fonte direta de enzimas ou como fonte de sequências gênicas para utilização da técnica do DNA recombinante são determinantes para o desenvolvimento de coquetéis enzimáticos capazes de degradar o material lignocelulósico a açúcares fermentescíveis e para o próprio entendimento da ação de cada agente (enzimas e/ou proteínas auxiliares) envolvidos neste processo. 


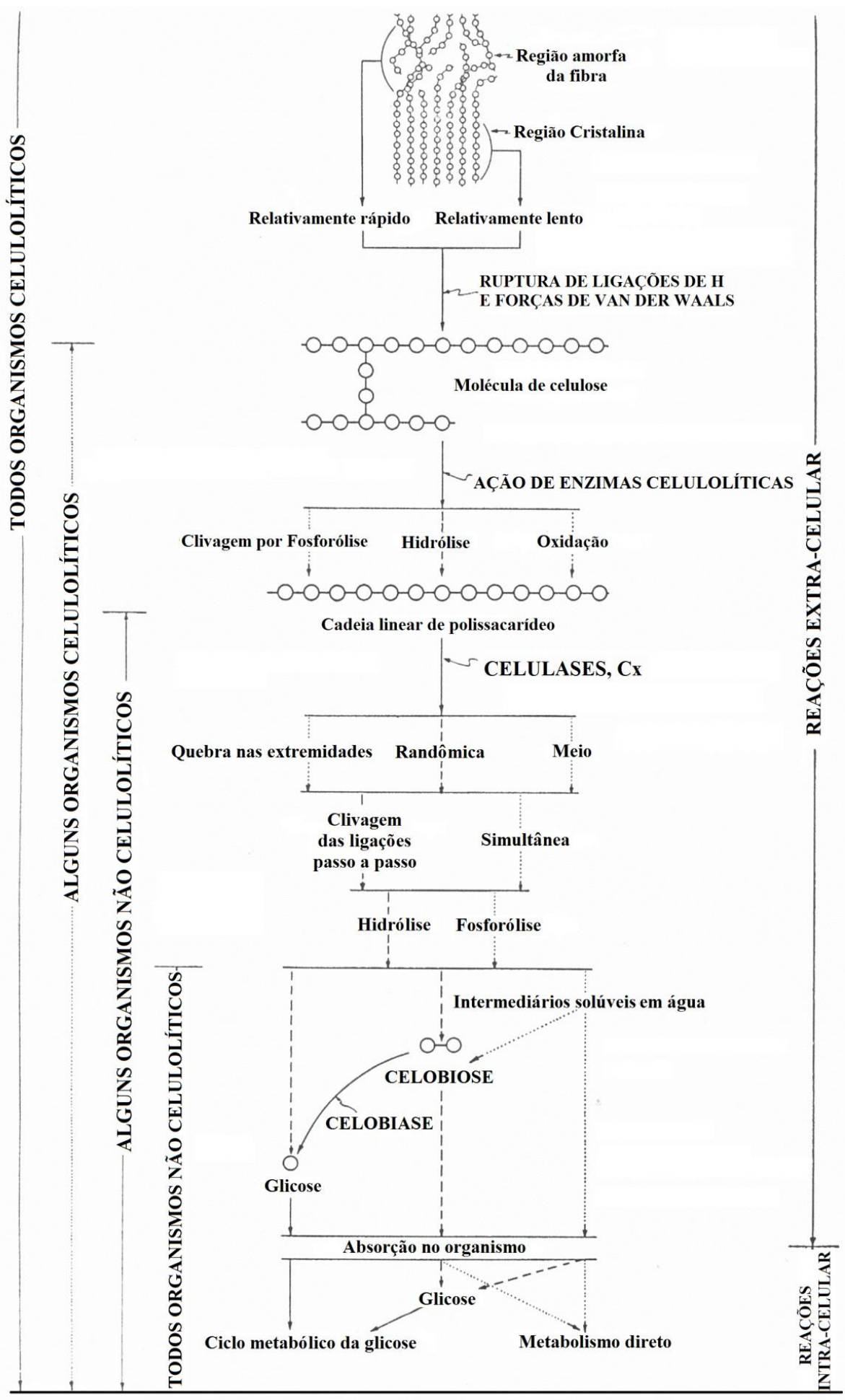

Figura 3 - Mecanismos bioquímico e microbiológico da quebra de fibras de algodão. Fonte: Adaptado de SIU ${ }^{8}$ 


\subsubsection{Xilanases}

Outra classe de hidrolases de glicosídeos que mereceu destaque nesta pesquisa foram as xilanases, uma vez que várias das enzimas identificadas a partir dos estudos de proteômica como as de maior índice de expressão pertenciam a classe das xilanases; estas catalisam a endo hidrólise em cadeias de xilano de ligações do tipo 1,4- $\beta$-D-xilosídica sendo nomeadas 1,4- $\beta$ xilosidases $^{9}$. Devido à complexidade da cadeia de xilano (Figura 4 A) é necessária uma complexa variedade de enzimas para hidrolisar o mesmo. As endo-1,4- $\beta$-D-xilanases clivam randomicamente a cadeia de xilano, $\beta$-D-xilanosidades clivam extremidades não redutoras de xilo-oligossacarídeos e xilobiose, enquanto a $\alpha$-L-arabinofuranosidase hidrolisam cadeias laterais do xilano9 (Figura 4 A e B).

A maior parte das xilanases descritas na literatura pertence às famílias GH10 e GH11, contudo algumas estão descritas nas famílias 5, 7, 8, 30 e 43. 10;95 A Tabela 1 mostra a identificação do enovelamento típico de cada grupo de xilanases bem como o mecanismo e os aminoácidos catalíticos de cada família.

Tabela 1 - Descrição de xilanases quanto a família de hidrolases de glicosídeos, enovelamento estrutural, mecanismo e resíduos catalíticos.

\begin{tabular}{ccclc}
\hline $\begin{array}{c}\text { Família de } \\
\text { hidrolases de } \\
\text { glicosídeos } \\
5\end{array}$ & Enovelamento & $\begin{array}{c}\text { Mecanismo } \\
\text { catalítico }\end{array}$ & $\begin{array}{c}\text { Resíduo } \\
\text { ácido/base }\end{array}$ & $\begin{array}{c}\text { Base } \\
\text { nucleófilica }\end{array}$ \\
7 & $(\beta / \alpha)_{8}$ & Retenção & Glutamato & Glutamato \\
8 & $\begin{array}{c}\beta \text {-Jelly roll }(\beta- \\
\text { rocambole }) \\
(\beta / \alpha)_{6}\end{array}$ & Retenção & Glutamato & Glutamato \\
10 & $(\beta / \alpha)_{6}$ & Inversão & Glutamato* & Aspartato* \\
11 & $\beta$ - rocambole & Retenção & Glutamato & Glutamato \\
30 & Retenção & Glutamato & Glutamato \\
43 & Retenção & Glutamato & Glutamato \\
& $\begin{array}{c}\text { 5-blade } \beta \text {-propeller } \\
(\text { hélice de5 folhas } \beta)\end{array}$ & Inversão & Glutamato* & Aspartato* \\
\hline
\end{tabular}

*Sugeridos como catalíticos.

Fonte: Adaptada de COLLINS; GERDAY; FELLER. ${ }^{9}$ 


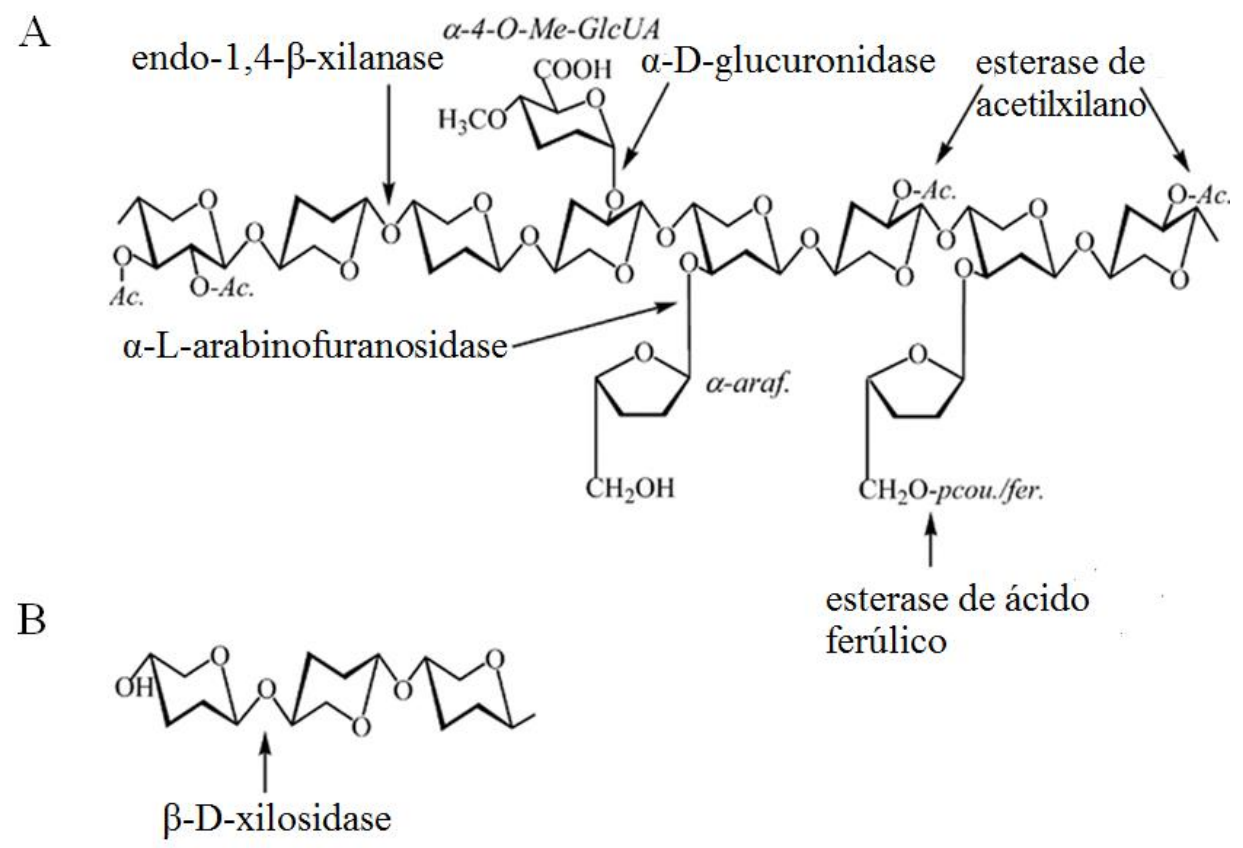

Figura 4 - A- Estrutura do xilano e os sítios de seu ataque pelas enzimas xilanolíticas, B- hidrólise de xilooligossacarídeo por $\beta$-xilosidase.

Fonte: Adaptada de COLLINS; GERDAY; FELLER. ${ }^{9}$

\subsection{Cazy}

O banco de dados Carbohydrate-Active Enzyme (Cazy) descreve as famílias de proteínas estruturalmente relacionadas à atividade catalítica ou de ligação a carboidratos que sejam capazes de degradar, modificar ou criar ligações glicosídicas. ${ }^{11}$ Este banco de dados utiliza a sequência de aminoácidos para correlacionar os mecanismos de ação e enovelamentos protéicos em famílias distintas. O CAZy abrange os seguintes grupos de proteínas: hidrolases de glicosídeos (GH), transferases de glicosídeos (GT), liases de polissacarídeos (PL), esterase de carboidrato (CE), enzimas com atividade auxiliar (AA) e módulo de ligação a carboidrato (CBM). ${ }^{11}$ 


\subsection{Proteínas sinérgicas}

Proteínas sinérgicas aumentam a atividade de celulases sem promover hidrólise significativa da mesma, sendo que, as proteínas sinérgicas promovem sua atividade a partir de mudanças estruturais na celulose. ${ }^{12}$ Entre as proteínas sinérgicas podemos citar: os módulos de ligação à celulose (CBM), expansinas de microrganismos (proteínas semelhantes à expansinas) de bactérias (Expansin-like) e fungos (swoleninas). Na Tabela 2, adaptado de Kim et al. ${ }^{12}$ apresentamos uma síntese da função biológica destas proteínas.

Tabela 2 - Proteínas sinérgicas.

\begin{tabular}{|c|c|c|c|}
\hline Classe & Tipo & Função molecular ou biológica & $\begin{array}{c}\text { Condições com } \\
\text { sinergismo descrito }\end{array}$ \\
\hline $\mathrm{CBM}$ & Tipo A, B e C & $\begin{array}{l}\text { Ligação à celulose: proximidade, } \\
\text { afrouxando e perturbação da estrutura } \\
\text { celulósica. }\end{array}$ & $\begin{array}{l}\text { Em celulose cristalina } \\
\text { atuam no aumento da } \\
\text { atividade total de celulases. }\end{array}$ \\
\hline $\begin{array}{l}\text { Expansinas de } \\
\text { plantas }\end{array}$ & Expansina & $\begin{array}{l}\text { Extensão, afrouxamento, e ruptura da } \\
\text { parede celular vegetal, envolvida no } \\
\text { processo de crescimento da parede } \\
\text { celular vegetal. }\end{array}$ & $\begin{array}{l}\text { Sinergismo sobre celulose } \\
\text { cristalina, CMC, pectina e } \\
\text { lignocelulose pré-tratada. }\end{array}$ \\
\hline \multirow[t]{2}{*}{$\begin{array}{l}\text { Expansinas de } \\
\text { microrganismos }\end{array}$} & $\begin{array}{c}\text { Expansinas } \\
\text { bacterianas } \\
\text { (Expansin-like) }\end{array}$ & $\begin{array}{l}\text { Ligação, afrouxamento e distensão da } \\
\text { parede celular; facilitam a interação de } \\
\text { microrganismos e plantas. }\end{array}$ & $\begin{array}{l}\text { Sinergismo sobre papel } \\
\text { filtro, xilano de aveia e } \\
\text { lignocelulose pré-tratada. }\end{array}$ \\
\hline & $\begin{array}{l}\text { Expansinas } \\
\text { fungicas } \\
\text { (Swoleninas) }\end{array}$ & $\begin{array}{l}\text { Incham ("swell" em inglês) fibras de } \\
\text { algodão, afrouxam a celulose e parede } \\
\text { celular. }\end{array}$ & Sinergismo sobre Avicel. \\
\hline AA & AA9 e AA10 & $\begin{array}{l}\text { Clivagem oxidativa de celulose } \\
\text { cristalina (requer doador de elétron) }\end{array}$ & $\begin{array}{l}\text { Sinergismo em celulose } \\
\text { pura ou lignocelulose pré- } \\
\text { tratada. }\end{array}$ \\
\hline
\end{tabular}

Fonte: Adaptada de KIM et al. ${ }^{12}$. 


\subsection{Mecanismos de hidrólise de ligações glicosídicas.}

Os dois principais mecanismos de hidrólise de ligações glicosídicas foram propostos por Koshland (Figura 5) onde $\mathrm{X}$ representa o carbono assimétrico que será substituído pelo grupo $\mathrm{Y}$, sendo estereoquimicamente em duas condições com manutenção da mesma (mecanismo de retenção) ou inversão da estereoquimica (mecanismo de inversão). No mecanismo de retenção o processo ocorre em duas etapas e envolve um intermediário covalente e no mecanismo de inversão a inversão da configuração anomérica de $\mathrm{C}$ ocorre em uma única etapa.

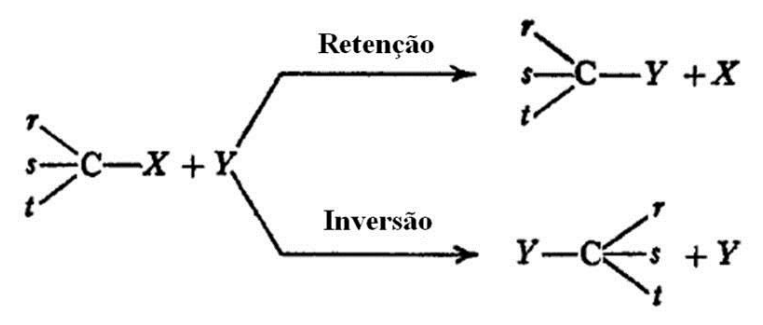

Figura 5 - Mecanismo de retenção e inversão proposto por Koshland.

Fonte: Adaptado de KOSHLAND. ${ }^{13}$

O mecanismo acima proposto explica o modo de ação da maior parte das hidrolases de glicosídeos. Recentemente foram descritas várias enzimas que não respeitam este mecanismo envolvendo no mesmo, reações de eliminação e/ou de hidratação. ${ }^{14}$

A Figura 6, ilustra um esquema adaptado de T. Collins et al. ${ }^{9}$ sobre o mecanismo de retenção e inversão aplicada a atividade de uma $\beta$-glicosidase. Seja no mecanismo de retenção ou inversão a posição do doador de prótons é a mesma, ou seja, muito próxima a ligação do oxigênio da ligação glicosídica. 

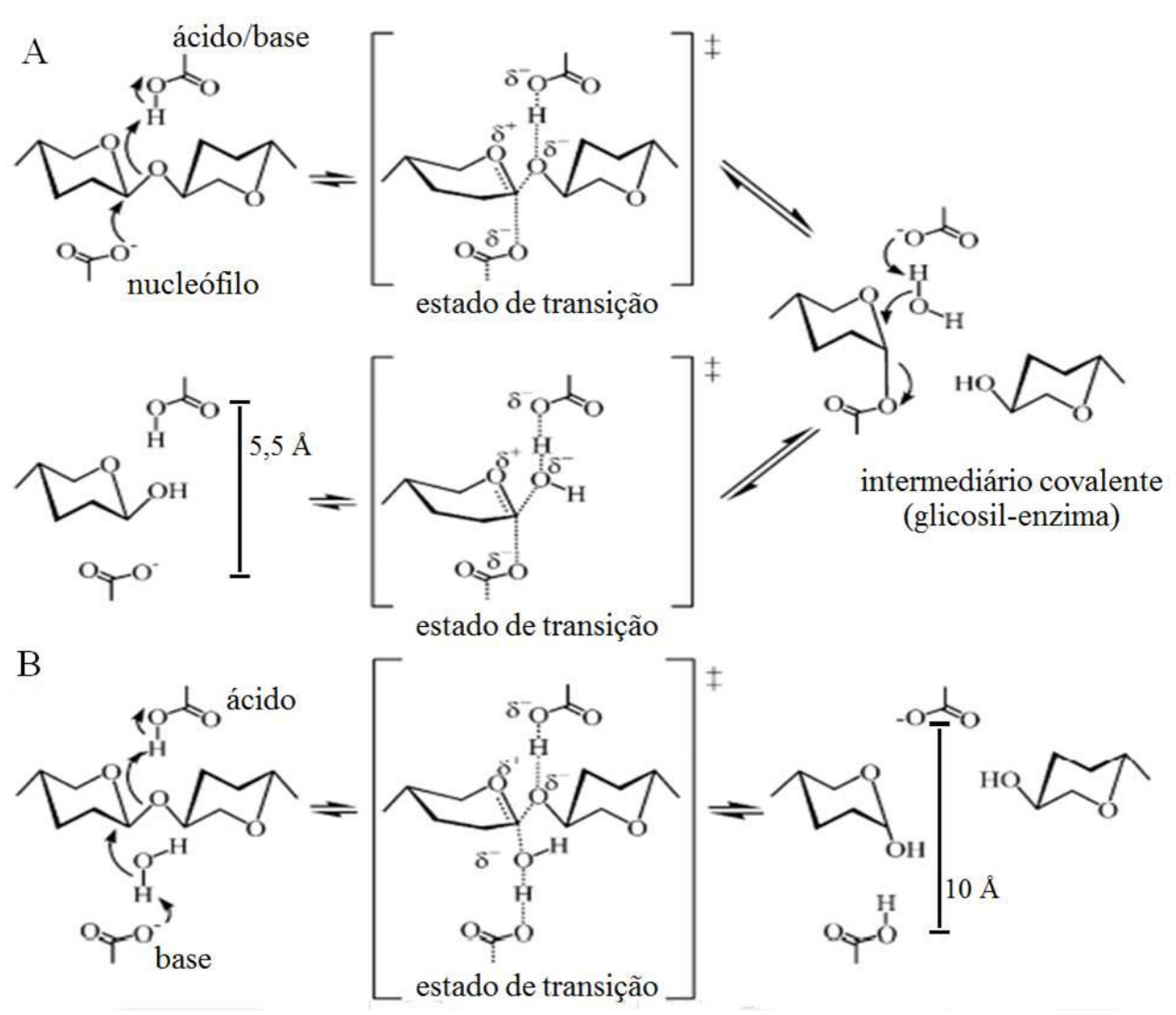

Figura 6 - Mecanismo de ação por retenção (A) e inversão (B) por uma $\beta$-glicosidase.

Fonte: Adaptada de COLLINS; GERDAY; FELLER ${ }^{5}$; DAVIES ${ }^{9}$; HENRISSAT. ; $^{\text {; }} 15$

Em enzimas que realizam o mecanismo de retenção, a base catalítica nucleofílica está muito próxima ao carbono anomérico do substrato (ligação glicosídica) enquanto que, para enzimas que realizam a inversão, esta base está mais distante ao substrato permitindo acomodar uma molécula de água. Devido a isto, a distância entre os resíduos catalíticos em enzimas que realizam o mecanismo de retenção é de aproximadamente 5,5 $\mathrm{A}$, enquanto que nas que aplicam inversão a distância é de aproximadamente $10 \AA^{15}$ 


\subsection{Organismos fonte das sequências gênicas de expansinas para estudo}

Foram selecionadas para caracterização estrutural e funcional expansinas de bactérias e fungos. Cujos organismos fonte das sequências gênicas foram: Xanthomonas campestris, Trichoderma reesei, Bacillus licheniformis e Trichoderma harzianum.

Xanthomonas campestris é uma bactéria gram negativa encontrada no solo, na água e em tecidos vegetais, sendo conhecida por ser cultivada comercialmente para produção da goma xantana, um exopolissacarídeos usado para controlar a viscosidade e como um agente estabilizador em muitos setores industriais. ${ }^{16}$

Bacillus licheniformis é uma bactéria gram positiva, comumente encontrada no solo. Sua temperatura ótima de crescimento é de aproximadamente $30^{\circ} \mathrm{C}$, embora possa sobreviver a temperaturas mais elevadas. Esta bactéria é utilizada na indústria de fermentação para a produção de proteases, amilases, antibióticos e produtos químicos. ${ }^{17 ; 18}$

O gênero Trichoderma inclui fungos capazes de colonizar diferentes substratos e em diversas condições ambientais. Um dos nichos ecológicos mais significantes ocupados pelas espécies de Trichoderma sp. é a rizosfera, a qual é colonizada efetivamente devido à capacidade destes fungos em interagir com plantas e outros organismos do solo. A atividade de controle biológico, fortemente característica desse fungo, depende da versatilidade metabólica e do potencial secretor, os quais são responsáveis pela produção de uma grande quantidade de enzimas altamente hidrolíticas envolvidas na degradação da parede celular. ${ }^{19}$ 


\subsection{Organismos Termofílicos}

Organismos que apresentam atividade metabólica e crescimento sob condições não usuais e extremas (da perspectiva humana) são nomeados extremófilos, sendo portanto organismos capazes de produzir enzimas que podem mudar a interpretação da biocatálise.

Microrganismos que crescem em temperaturas de 50 a $60^{\circ} \mathrm{C}$ (termofílicos) já eram conhecidos há várias décadas, mas foi na década de 1960 que as pesquisas em biocatálise iniciaram um novo período de descobertas na área de biomoléculas. Em 1968, Thomas D. Brock, isolou uma bactéria que crescia a $70^{\circ} \mathrm{C} .^{20}$ Esta bactéria era a Thermus aquaticus, da qual foi isolada a enzima termoestável DNA polimerase utilizada na reação de amplificação gênica, Polymerase Chain Reaction (PCR).

$\mathrm{Na}$ década de 1980 foram isolados microrganismos que cresciam acima de $80^{\circ} \mathrm{C}$ e continuamente novos organismos foram isolados, sendo que, aqueles que vivem sob condições mais extremas são as bactérias extremófilas (hipertermofílicas), como por exemplo, Pyrolobus fumarii, que cresce a $113^{\circ} \mathrm{C}$ e a Methanopyrus kandleri, que cresce a $122^{\circ} \mathrm{C}$.

A termoestabilidade é definida como a capacidade de uma enzima manter sua atividade e conformação estrutural em altas temperaturas por um prolongado período de tempo. ${ }^{21}$ Enzimas termoestáveis apresentam uma série de vantagens potenciais no processo de hidrólise de material lignocelulósico: 1) aumentam a solubilidade de produtos e reagentes, resultando no aumento da velocidade das reações; 2) reduzem o intervalo de reação; 3) diminuem o risco de contaminação por contaminantes e aumentam a produtividade; 4) facilitam a recuperação de produtos voláteis e reduzem custos com energia para resfriamento e pré-tratamentos térmicos. ${ }^{21}$; 


\subsection{Thermogemmatispora sp. cepa T81}

A bactéria Thermogemmatispora sp. da cepa T81 (ICMP 18709) ${ }^{23}$ é um organismo termofílico, aeróbico, Gram-positivo, filamentoso e formador de micélios com células de 0,2 a $0,4 \mu \mathrm{m}$ de largura. Apresenta crescimento em pHs de 3.1 a 7.5 e entre temperatura de $40^{\circ} \mathrm{C}$ a $75^{\circ} \mathrm{C}^{23 ; 24}$

Esta bactéria pertence ao filo Chloroflexi, que contém seis Classes: a Anaerolineae (Ordem Anaerolineales), a Caldilineae (Ordem Caldilineales), a Chloroflexia (Ordem Chloroflexales e Ordem Herpetosiphonales), a Dehalococcoidia (Ordem Dehalococcoidales), a Ktedonobacteria (Ordem Ktedonobacterales e Ordem Thermogemmatispora sp.les), e a Thermomicrobia (Ordem Sphaerobacterales e Ordem Thermomicrobiales). ${ }^{25}$ Thermogemmatispora sp. cepa T81 é classificada como pertencente a Classe Ktedobacteria (Ordem, Thermogemmatispora sp.les) a qual possui apenas duas linhagens descritas: Thermogemmatispora sp. onikobensis e Thermogemmatispora sp. foliorum.

A linhagem T81 possui um nome proposto por M. Stott como Thermogemmatispora sp. tikiterensis. Esta linhagem difere das demais do gênero pelo conteúdo guanina-citosina, morfologia e a tolerância salina, além da utilização de diversos substratos como fontes de nutrientes. $^{26}$ 


\section{OBJETIVOS ESPECÍFICOS}

- Análises de bioinformática: seleção do gene de interesse dentro do contexto de hidrólise e disponibilização de polissacarídeos para fermentação bem como análise de domínios conservados.

- Clonagem do gene: extração do DNA genômico, amplificação por PCR, clonagem em vetor de propagação, clonagem em vetor de expressão e sequênciamento.

- Purificação das proteínas: superexpressão em Escherichia coli, purificação por métodos cromatográficos.

- Análises em genômica e proteômica buscando potenciais hidrolases de glicosídeos com aplicação biotecnológica.

- Caracterização estrutural: CD, espalhamento de raios-X a baixo ângulo (SAXS), cristalização e estudos de difração de raios-X.

\section{Observação:}

As seções seguintes: materiais, métodos e resultados estarão divididas em:

PARTE A: referente aos estudos estruturais e funcionais de expansinas.

PARTE B: referente a análise proteômica da bactéria termofílica e lignocelulolítica, Thermogemmatispora sp. cepa T81, bem como a clonagem e caracterização de alguns genes selecionados. 
4 MATERIAIS E MÉTODOS 


\subsection{PARTE A}

\subsubsection{Análises bioinformáticas}

Voesenek e colaboradores ${ }^{27}$ definiram um padrão de nomenclatura para tratar as protéinas com efeitos de afrouxamento sobre material celulósico. De acordo com o proposto, o termo expansina (Expansin) é reservado às proteínas de origem vegetal, para as de origem bacteriana indica-se o termo proteína semelhante à expansina (Expansin-like) e para as de origem fúngica, o termo swoleninas (Swolenin). Nesta pesquisa por simplicidade no uso de termos, trataremos as expansinas bacterianas e fúngicas como SWO1, ou de maneira geral como expansinas.

A seleção de expansinas para estudo, sendo proteínas semelhantes às expansinas (Expansin-like) e swoleninas (SWO1) tiveram como modelo de busca a expansina (Expansinlike) de Bacillus subtillis BsEXLX1 ${ }^{28}$ e a expansina (Expansin-like) de Xanthomonas campestris XcEXLX1 ${ }^{29 ;} 30$ (AAM\#42805.1) cujas sequências de aminoácidos foram confrontadas com as bases de dados do NCBI $^{31}$ e CAZy ${ }^{11}$ para a seleção dos alvos.

A partir da análise por sequências gênicas homólogas foram selecionados os seguintes produtos gênicos dos seguintes microrganismos: Bacillus licheniformis GI\#763044428, T. reesei GI:589114404, T.harzianum jgi\#484109, T.harzianum jgi\#484109, T.harzianum jgi 498030. O programa Domain-Fish $^{32}$ foi utilizado para identificação das regiões de clonagem delimitando as mesmas seja em Expansin-like e SWO1 ou sub domínios (SWO1 - domínio catalítico, Rare lipoprotein, Cerato-platanin e GRAS transcription factor). Alinhamentos múltiplos das sequências gênicas selecionadas para estudos foram realizados por meio do programa Clustal $^{33} \mathrm{e}$ análises qualitativas das sequências foram procedidas utilizando a plataforma do ProtParam. ${ }^{34}$ 


\subsubsection{Expansina (Expansin-like) de Xanthomonas campestris}

A descrição referente a clonagem e caracterização bioquímica e estrutural desta proteína encontra-se no APÊNDICE A - "Xanthomonas campestris expansin-like X domain is a structurally disordered beta-sheet macromolecule capable of synergistically enhancing enzymatic efficiency of cellulose hydrolysis".

\subsubsection{Amplificação gênica}

O sistema de clonagem independente de ligase, LIC (do inglês, Ligase Independent Cloning $)^{35}$ foi escolhido para a clonagem dos genes de estudo. Este sistema não requer a etapa de formação de extremidades coesivas advinda da digestão com enzimas endonucleases e tão pouco da etapa de ligação com o uso da enzima DNA ligase como ocorre no método clássico de clonagem.

Os genes selecionados para estudo foram amplificados utilizando PCR e inseridos no vetor IPTG induzível pET Trx-1a/Lic (gentilmente cedido pelo Dr. Arie Geerlof do Laboratório de Biologia Molecular Europeu (EMBL)). Os oligonucleotídeos utilizados para a amplificação das regiões codificadoras de genes (do inglês Open reading frame ORF) foram sintetizados pela Exxtend Biotecnologia Ltda e estão apresentados na Tabela 4. As bases sublinhadas referem-se à região de ligação ao inserto. O vetor pET Trx-1a/Lic (Figura 7) é originado de uma modificação do vetor pETM20. 


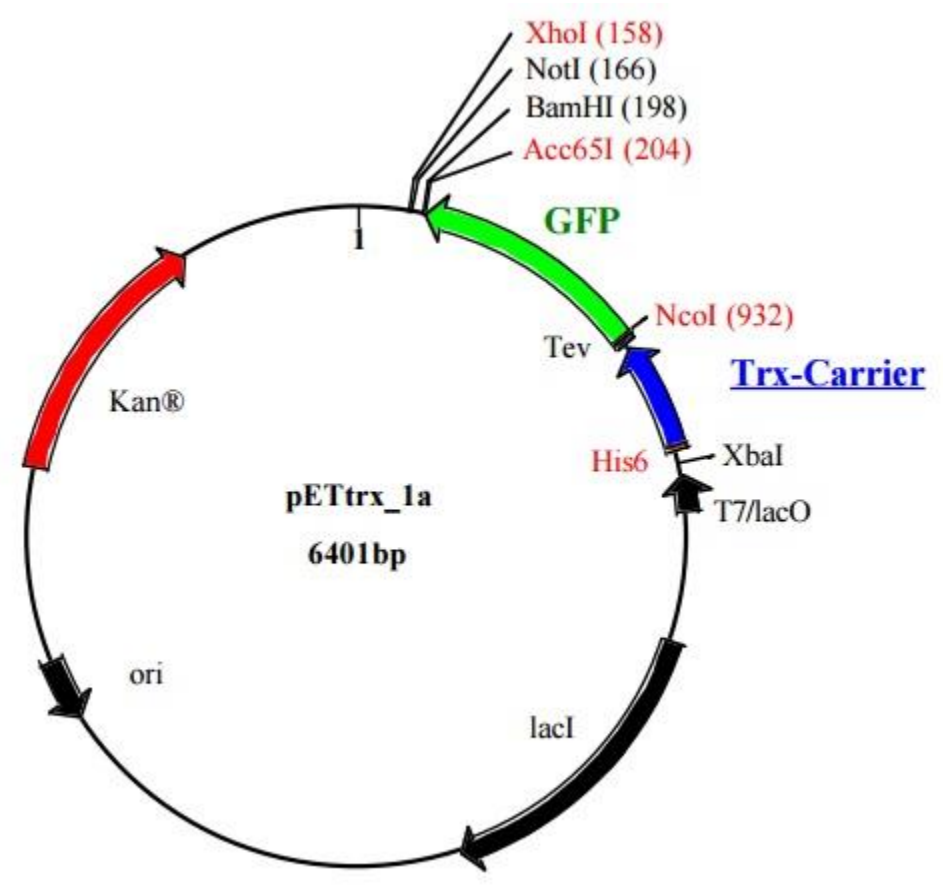

Figura 7- Mapa do vetor LIC, pET Trx_1a.

Fonte:_http://babel.ucmp.umu.se/cpep/web_content/pdf/vector\%20maps/pETtrx1.pdf (acessado em 30 de Janeiro de 2015).

Para a amplificação da região de clonagem no vetor, excluindo a região de GFP (Green Fluorescent Protein) utilizando o método de reação em cadeia da polimerase (PCR), foram utilizados os oligonucleotídeos Trx/Lic fita direta -TGG CGC CCT GAA AAT AAA G- e Trx/LIC fita reversa -CCG CGT CGG GTC AC- de maneira complementar a ligação aos genes, empregando-se a enzima Phusion High Fidelity DNA Polimerase (NEB -M05301-500U), reação descrita na Tabela 3 e seguindo-se o ciclo: primeiro passo $98^{\circ} \mathrm{C}$ por $30 \mathrm{~s}$, segundo passo (35 ciclos: $98^{\circ} \mathrm{C}$ por $10 \mathrm{~s}, 65^{\circ} \mathrm{C}$ por $30 \mathrm{~s} \mathrm{e} 72^{\circ} \mathrm{C}$ por $1 \mathrm{~min} 45 \mathrm{~s}$ ), terceiro passo $72^{\circ} \mathrm{C}$ por $10 \mathrm{~min} \mathrm{e}$ posteriormente à $4^{\circ} \mathrm{C}$ por $1 \mathrm{~min}$. Após a reação de PCR, adicionou-se 1 ul da enzima Dpn1 à reação (50ul) e deixou-se por $16 \mathrm{~h}$ a $37^{\circ} \mathrm{C}$, seguido de eletroforese em gel de agarose e recuperação do vetor utilizando PCR Clean-Up System (Promega). 
Tabela 3- Reação de amplificação do vetor de clonagem.

\begin{tabular}{cc}
\hline Reação de amplificação & $\begin{array}{c}\text { Concentração } \\
\text { final }\end{array}$ \\
Tampão da enzima Phusion $[5 \mathrm{X}]$ & $1 \mathrm{X}$ \\
$\mathrm{dNTP}[10 \mathrm{mM}] \quad(\mathrm{N}=\mathrm{A}, \mathrm{G}, \mathrm{C}, \mathrm{T})$ & $0,2 \mathrm{mM}$ \\
& $0,5 \mu \mathrm{M}$ \\
Oligonucleotídeo $[25 \mu \mathrm{M}]\left(5^{\prime}\right.$ 'do gene $)$ & $0,5 \mu \mathrm{M}$ \\
Oligonucleotídeo $[25 \mu \mathrm{M}]\left(3^{\prime}\right.$ do gene $)$ & $2,5 \mathrm{ng}$ \\
DNA & $0,05 \mathrm{U} / \mu \mathrm{L}$ \\
Enzima Phusion $\mathrm{HF}$ & \\
$\mathrm{H}_{2} \mathrm{O}$ milli-Q para completar o volume de $50 \mu \mathrm{L}$ & \\
\hline
\end{tabular}

Fonte: Elaborada pelo autor.

Tabela 4 - Oligonucleotídeos utilizados na amplificação dos genes das expansinas.

\begin{tabular}{|c|c|c|}
\hline Organismo & Proteína & Oligonocleotideos \\
\hline Bacillus & Domínio semelhante & Sequência direta: \\
\hline licheniformis & $\begin{array}{l}\text { a expansina } \\
\text { (Expansin-like) }\end{array}$ & $\begin{array}{l}\text { CAGGGCGCCATGGCGTACAACTCACTGCATACG } \\
\text { Sequência reversa: }\end{array}$ \\
\hline $\begin{array}{l}\text { Trichoderma } \\
\text { harzianum JGI } \\
\quad \# 484109\end{array}$ & SWO1-Swolenina & $\begin{array}{l}\text { GACCCGACGCGGTTAGTCAGGGAACTGTACTTT TCCC } \\
\text { Sequência direta: } \\
\text { CAGGGCGCCATGTTATTTGGCCAATGTGGAG } \\
\text { Sequência reversa: }\end{array}$ \\
\hline $\begin{array}{l}\text { Trichoderma } \\
\text { harzianum JGI } \\
\quad \text { \#48.4109 }\end{array}$ & $\begin{array}{l}\text { SWO1- domínio } \\
\text { catalítica (Domínio } \\
\text { homologo à } \\
\text { expansina) }\end{array}$ & $\begin{array}{c}\text { Sequência direta: } \\
\begin{array}{c}\text { CAGGGCGCCATGCCAGGAGCCCTAGATAACTACCTG } \\
\text { Sequência }\end{array} \\
\text { reversa:GACCCGACGCGGTTAGTTTTGACTAAACT } \\
\text { GTACGCC }\end{array}$ \\
\hline $\begin{array}{r}\text { Trichoderma } \\
\text { reesei } 12.3992 \text { - }\end{array}$ & $\begin{array}{l}\text { SWO1- domínio } \\
\text { catalítica (Domínio } \\
\text { homólogo à } \\
\text { expansina) }\end{array}$ & $\begin{array}{c}\text { Sequência direta: } \\
\text { CAGGGCGCCATGCCAGGAGCCCTCGATAACTAC } \\
\text { Sequência reversa: } \\
\text { GACCCGACGCGGTTATCAATTCTGGCTAAACTGCAC }\end{array}$ \\
\hline $\begin{array}{l}\text { Trichoderma } \\
\text { reesei } 71390\end{array}$ & $\begin{array}{l}\text { Domínio Rare } \\
\text { lipoprotein A de } \\
\text { SWO1 T. reesei }\end{array}$ & $\begin{array}{c}\text { Sequência direta: } \\
\text { CAGGGCGCCATGGCTCCCACCGAGCCC } \\
\text { Sequência reversa: } \\
\text { GACCCGACGCGGCTAAGCCCACTCCCAAGAAG }\end{array}$ \\
\hline $\begin{array}{c}\text { T. harzianum } \\
498030\end{array}$ & $\begin{array}{l}\text { Domínio Cerato- } \\
\text { platanin e GRAS } \\
\text { transcription factor }\end{array}$ & $\begin{array}{c}\text { Sequência direta: } \\
\text { CAGGGCGCCATGGCTGTCCTCCCTCCCG } \\
\text { Sequência reversa: } \\
\text { GACCCGACGCGGTTACGCAGCCGCGAC }\end{array}$ \\
\hline $\begin{array}{c}\text { T. harzianum } \\
87202\end{array}$ & $\begin{array}{l}\text { Domínio Rare } \\
\text { lipoprotein A de } \\
\text { SWO1 T. harzianum }\end{array}$ & $\begin{array}{c}\text { Sequência direta: } \\
\text { CAGGGCGCCATGCTCCCCGAGCCTCCTTC } \\
\text { Sequência reversa: } \\
\text { GACCCGACGCGGTTAGCACTGGCCGTTCTC }\end{array}$ \\
\hline
\end{tabular}

Fonte: Elaborada pelo autor. 
A amplificação dos fragmentos gênicos de interesse utilizando o sistema LIC foi realizada utilizando o método de reação em cadeia da polimerase (PCR), a partir dos oligonucleotídeos descritos na Tabela 4 e do DNA genômico de Trichoderma reesei, Trichoderma harzianum e Bacillus licheniformis seguindo a reação descrita na Tabela 6. A quantidade de DNA para a amplificação dos produtos gênicos foi de 5 ng por reação de acordo com o ciclo: primeiro passo $98^{\circ} \mathrm{C}$ por 30 s, segundo passo $\left(35\right.$ ciclos: $98^{\circ} \mathrm{C}$ por $10 \mathrm{~s}, 65^{\circ} \mathrm{C}$ por $30 \mathrm{~s} \mathrm{e} 72^{\circ} \mathrm{C}$ por $1 \mathrm{~min} 45 \mathrm{~s}$ ), terceiro passo $72^{\circ} \mathrm{C}$ por $10 \mathrm{~min}$ e posteriormente à $4{ }^{\circ} \mathrm{C}$ por $1 \mathrm{~min}$. Posteriormente, seguiu-se a eletroforese em gel de agarose e recuperação do amplificado gênico utilizando PCR Clean-Up System (Promega).

O vetor pET Trx 1a/Lic tratado com Dpn1 e os amplificados gênicos foram quantificados utilizando o espectrofotômetro (Nanodrop 2000 Thermo Scientific) e tratados com T4 DNA polimerase (Fermentas) seguindo a reação descrita na Tabela 5, sendo que para o vetor foi utilizado $500 \mathrm{ng}$ e para o amplificado gênico $200 \mathrm{ng}$.

Tabela 5 - Reação de tratamento com T4 DNA polimerase.

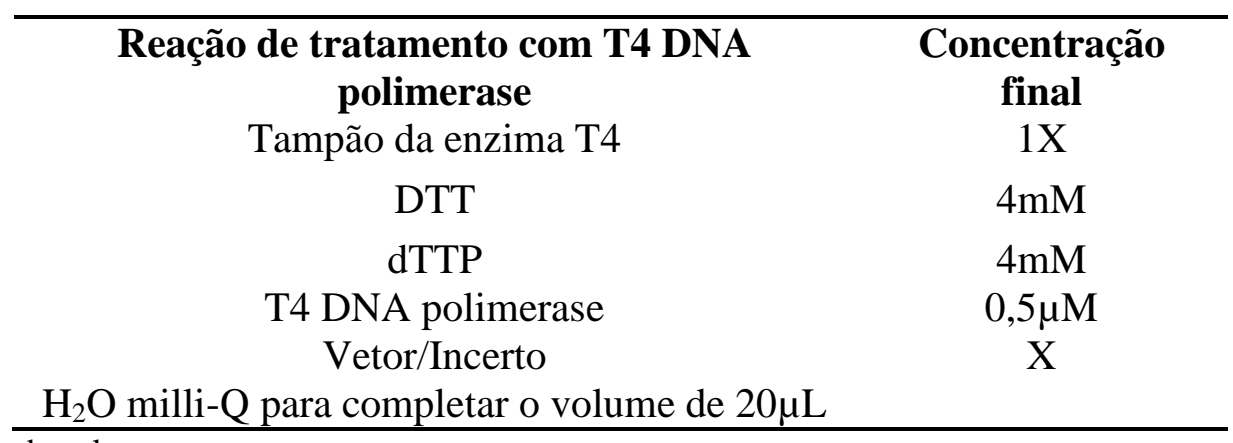

Fonte: Elaborada pelo autor. 
A última etapa deste processo foi a de anelamento, na qual para cada $0,02 \mathrm{pmol}$ de incerto foi utilizado de 25 a $50 \mathrm{ng}$ do vetor LIC tratado. Ou seja, para cada 0,02 pmol de incerto foi utilizado $0,01 \mathrm{pmol}$ do vetor o que equivale a $35 \mathrm{ng}$. Foi adicionado o incerto ao vetor e deixou-se em temperatura ambiente por 30 min para o processo de anelamento.

Os plasmídeos resultantes gene-pET Trx-1a/LIC foram inseridos em células de propagação Escherichia coli $\mathrm{DH} 10 \mathrm{~B}$ quimio-competentes por transformação do tipo choque térmico com posterior transformação em células de expressão E. coli Rosetta (DE3).

\subsubsection{Expressão e Purificação das Proteínas}

A cultura de E. coli Rosetta (DE3) foi mantida em crescimento por 16h em meio LuriaBertani (10 g/L triptona, $5 \mathrm{~g} / \mathrm{L}$ extrato de levedura, $5 \mathrm{~g} / \mathrm{L} \mathrm{NaCl}, \mathrm{pH} 7,5)$ à $37^{\circ} \mathrm{C}$. O inóculo foi então diluído na proporção de 1:100 em $1000 \mathrm{~mL}$ meio de cultura $\mathrm{LB}$ em frascos de $2 \mathrm{~L}$, à $37^{\circ} \mathrm{C}$ e sob agitação de $160 \mathrm{rpm}$ até atingir a $\mathrm{DO}_{600 \mathrm{~nm}}$ de 0,6 quando a expressão foi estimulada pela adição de $1 \mathrm{mM}$ de IPTG e incubada a $18^{\circ} \mathrm{C}, 160 \mathrm{rpm}$ por $16 \mathrm{~h}$.

As células foram sedimentadas por centrifugação e a fração líquida descartada. $\mathrm{O}$ sedimentado foi ressuspenso em tampão Tris- $\mathrm{HCl}$ (50 mM Tris, $150 \mathrm{mM} \mathrm{NaCl}, 5 \%$ glicerol, pH 7,5) e a ele foi adicionado $10 \mathrm{mM}$ de $\beta$ - mercaptoetanol, $1 \mathrm{mM}$ PMSF, $1 \mathrm{mM}$ DTT, na proporção de $10 \mathrm{~mL}$ de tampão por litro de meio de cultura sedimentado. As células sofreram desruptura por sonicação e posterior centrifugação a $6500 \mathrm{xg}$ por $30 \mathrm{~min}$ a $4^{\circ} \mathrm{C}$. O sobrenadante foi recolhido e aplicado em $5 \mathrm{~mL}$ de resina Ni-NTA Agarose (Qiagen) previamente equilibrada com 5 volumes de coluna de tampão Tris- $\mathrm{HCl}$ e incubado por $60 \mathrm{~min}$.

$\mathrm{Na}$ etapa seguinte, a resina foi lavada com 10 volumes de coluna de tampão Tris- $\mathrm{HCl}$ acrescido de $20 \mathrm{mM}$ de imidazol e por fim, a proteína foi removida (eluída) da coluna em duas etapas: primeira um volume de coluna de Tris- $\mathrm{HCl}$ em $200 \mathrm{mM}$ de imidazol e na segunda por um volume de coluna de Tris- $\mathrm{HCl}$ em $500 \mathrm{mM}$ de imidazol. A proteína eluída foi dialisada para a remoção do imidazol utilizando concentradores Vivaspin 20 (GE Healthcare) e a concentração 
da solução protéica foi determinada utilizando o Nanodrop espectrofotômetro (Thermo Scientific).

A thireodoxina-his-tag foi clivada utilizando-se a TEV protease numa relação de (1:50), a $8^{\circ} \mathrm{C}$, durante 18 horas. Após a clivagem a solução protéica foi carregada em $5 \mathrm{~mL}$ de resina Ni-NTA Agarose (Qiagen) previamente equilibrada com 5 volumes de coluna do tampão Tris$\mathrm{HCl}$, mantido sob incubação por $60 \mathrm{~min}$, e em seguida a fração não ligada na resina foi recolhida. A pureza da preparação protéica foi analisada por SDS-PAGE (Sodium Dodecyl Sulfate - Polyacrylamide Gel Electrophoresis) $15 \%$, sob condições desnaturantes. ${ }^{36}$

\subsubsection{Ensaios de atividade}

A definição de unidade de atividade enzimática (U) que foi empregada corresponde a quantidade de proteína capaz de liberar $1 \mu \mathrm{mol}$ de açúcares redutores, por minuto. A medida da atividade enzimática foi avaliada a partir da quantificação de açúcar liberado pelo método de DNS (ácido dinitrosalicílico), que se baseia na reação entre o açúcar redutor e o ácido 3,5dinitrosalicílico (Miller, 1959) sendo mensurado no espectrofotômetro de microplaca (Thermo Scientific) à $535 \mathrm{~nm}$. Todos os experimentos foram realizados em triplicatas.

As curvas padrão utilizadas foram obtidas a partir de soluções estoque de glicose (Sigma) ou xilose (Sigma) a $100 \mathrm{mg} \cdot \mathrm{mol} \mathrm{L}^{-1}$. A diluição do estoque de glicose ou xilose foi em tampão ácido cítrico-citrato de sódio para concentrações finais de 5, 10, 15, 20, e $30 \mathrm{mmol} \mathrm{L}^{-1}$. 
Avaliação da atividade sinérgica das expansinas: Expansin-like (Xanthomonas campestris, Bacillus licheniformis) SWO1-dominio catalítico (Trichoderma reesei), domínio de Rare lipoprotein (Trichoderma reesei) e CBM2 (Thermogemmatispora sp. T81) associada ao coquetel enzimático Accellerase 1500 (DuPont Industrial Biosciences) sobre o papel filtro $\mathrm{N}^{\circ} 1$ Whatman.

A reação de hidrólise contendo $(0.06 \mathrm{~mL})$ com $3,3 \mathrm{mg}$ de papel filtro $\mathrm{N}^{\circ} 1$ Whatman em tampão $20 \mathrm{mM}$ citrato de sódio-ácido cítrico $\mathrm{pH} \mathrm{5,0,06} \mathrm{FPU/g} \mathrm{de} \mathrm{substrato} \mathrm{do} \mathrm{composto}$ celulósico/hemicelulósico (Accellerase 1500) e 303 e $30 \mu \mathrm{g} / \mathrm{g}$ de substrato das proteínas Expansin-like de Bacillus licheniformis e Xanthomonas campestris, SWO1-domínio catalítico domínio Trichoderma reesei, domínio Rare lipoprotein de Trichoderma reesei e CBM2 de Thermogemmatispora sp. T81 (clonagem descrita na seção B). As reações em triplicata foram incubadas a $50^{\circ} \mathrm{C}$ por $12 \mathrm{~h}$.

O cálculo do grau de sinergismo (Degree of Synergism = DS) foi determinado segundo a equação 1, como descrito por Liu et al. ${ }^{96}$ Valores de DS abaixo de 1: indicam inibição, igual a 1: que não interfere no rendimento e acima de 1: que o processo é cooperativo.

$$
\mathrm{DS}=\frac{\text { Açúcar redutor liberado pela cellulase em conjunto com a proteína acessória }\left(\frac{\mathbf{g}}{\mathbf{L}}\right)}{\text { Açúcar redutor liberado pela cellulase sozinha }\left(\frac{\mathbf{g}}{\mathbf{L}}\right)}
$$

Avaliação da atividade hidrolítica das expansinas: Expansin-like (Xanthomonas campestris, Bacillus licheniformis) SWO1-dominio catalítico (Trichoderma reesei) e domínio de Rare lipoprotein (Trichoderma reesei). 
A atividade catalítica das expansinas foi avaliada sobre substratos celulósicos (papel filtro, CMC, Sigmacell e Avicel) e hemicelulósicos (xilano e xiloglucano) em tampão $20 \mathrm{mM}$ citrato de sódio - ácido cítrico, pH 5, sendo que para cada reação foi utilizado 3,3 mg de papel filtro e $0,4 \mathrm{mg}$ dos demais substratos.

Cada expansina foi avaliada independentemente numa reação contendo $(0,1 \mathrm{~mL})$ sendo utilizado $80 \mu \mathrm{g}$ de Expansin-like ou SWO1-domínio catalítico e $20 \mu \mathrm{g}$ de domínio Rare lipoprotein por reação. As reações em triplicata foram incubadas a $50^{\circ} \mathrm{C}, 1000 \mathrm{rpm}$ por $24 \mathrm{~h}$. $\mathrm{O}$ açúcar liberado foi mensurado no espectrofotômetro de microplaca (Thermo Scientific) a 535 $\mathrm{nm}$, utilizando o ácido dinitrosalicílico (DNS). ${ }^{37}$ Para curva padrão foram utilizadas glicose (Sigma) e xilose (Sigma).

\subsubsection{Modelos estruturais por homologia.}

A partir da sequência de aminoácidos de todas as proteínas de estudo, foram gerados modelos estruturais por homologia utilizando o servidor Phyre $2^{38}$ para modelagem, predição e análises estruturais de proteínas. Além disso, para a correlação evolutiva entre os organismos fontes das proteínas de estudo, utilizamos o programa de análise molecular evolutiva Mega $6^{39} \mathrm{e}$ para alinhamento sequencial das proteínas combinando as sequências de amínoácidos com informação estrutural foi utilizado o servidor T-Coffee. ${ }^{40}$

Os PDBs 3D30 (Expansin-like de Bacillus subtillis) e 3X2M (GH 45 Phanerochate chrysosporium) foram utilizados como modelos de referência. $\mathrm{O}$ primeiro pela identidade com as expansinas em estudo e o segundo pela identificação nesta estrutura do sítio catalítico das GH45 sub-família C que apresentam homologia estrutural com o domínio de Rare lipoprotein típico em expansinas. 


\subsubsection{Cromatografia em camada delgada (CCD ou TLC (Thin-layer chromatography))}

A cromatografia em camada delgada tem como princípio a separação de uma mistura sólido-líquido, na qual a fase móvel migra sobre a fase estacionária do adsorvente retido na camada delgada. A separação está fundamentada no fenômeno de adsorção.

Os carboidratos em geral, por serem extremamente hidrófilos, requerem eluentes polares, que apresentam migração lenta. Para a análise da composição química dos biopolímeros foram utilizadas placas de sílica gel 60 F254 (Merck) empregando como eluente a mistura de solventes: butanol: ácido acético: água, 20:10:10 (v/v/v). ${ }^{41}$

Como padrão foi utilizado uma mistura de xilo-oligossacarídeos (xilose, xilobiose, xilotriose, xilotetraose, xilopentaose e xilohexaose) (Megazyme). As amostras e a mistura de padrões foram aplicadas a $1 \mathrm{~cm}$ da parte inferior da placa, com aplicações sucessivas de $1 \mathrm{uL}$ (20 aplicações) a uma distância de 1,5 cm entre cada amostra. A placa foi inserida em um béquer com a mistura de solventes suficiente para cobrir $0,5 \mathrm{~cm}$ da parte inferior da placa. Após o solvente ascender ao topo da mesma, a placa foi seca e novamente submetida ao processo de ascensão do solvente para uma melhor separação dos oligossacarídeos. A revelação das amostras foi realizada com o borrifamento de solução $5 \%$ de ácido sulfúrico em etanol seguido pelo aquecimento em estufa a $105^{\circ} \mathrm{C}$ por $30 \mathrm{~min}$.

\subsubsection{Dicroísmo circular (CD)}

Para a caracterização biofísica das proteínas foi utilizada a técnica de espectroscopia de dicroísmo circular utilizando o espectropolarímetro Jasco J-815 (Jasco, Tokyo, Japan) com cubetas de quartzo de caminho óptico igual a $0,1 \mathrm{~cm}$. Os espectros das proteínas foram coletados em tampão 20mM fosfato de sódio, pH 7,5 variando-se o comprimento de onda de 190 a 280 $\mathrm{nm}$, com sensibilidade de $100 \mathrm{~nm} \cdot \mathrm{min}^{-1}$,tempo médio igual a $10 \mathrm{~s}$, largura de banda de $1 \mathrm{~nm}$ e tempo de resposta de $0,5 \mathrm{~s}$. 
As contribuições de tampão foram subtraídas dos espectros experimentais e os dados obtidos foram convertidos para elipticidade molar usando a seguinte relação:

$$
\theta(\text { graus })=\frac{100}{l c}(180)(\ln 10)(\Delta A / 4 \pi)
$$

Onde $\Delta A$ corresponde à variação de absorbância da luz circularmente polarizada à esquerda e à direita, $l$ corresponde ao caminho óptico e $c$ a concentração da amostra. Para a deconvolução dos espectros de CD foi empregado o servidor Dichroweb ${ }^{42}$ obtendo dessa forma, as percentagens de estrutura secundária das proteínas (Figura 8).

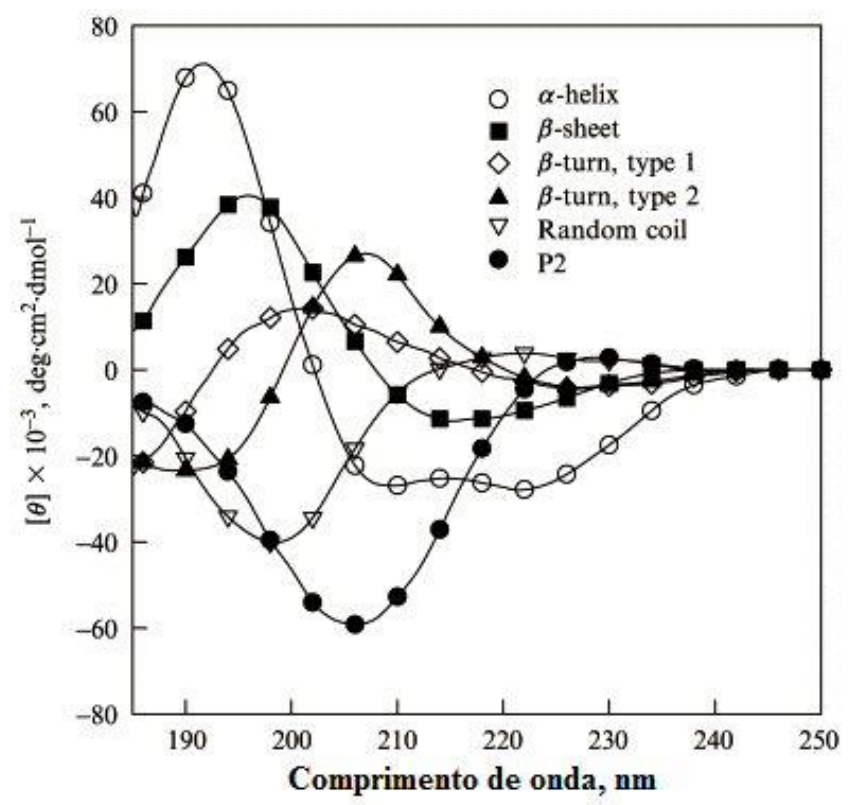

Figura 8- Espectro típico das principais estruturas secundárias em proteínas.

Fonte: Adaptado de GREENFIELD. ${ }^{43}$ 


\subsection{PARTE B}

\subsubsection{Bactéria e condições de crescimento}

Estoques independentes da bactéria Thermogemmatispora sp. cepa T81 (T81) foram mantidos a $4^{\circ} \mathrm{C}$, sendo que, para cada experimento foram reavivadas triplicatas experimentais. A cultura estoque foi cultivada em meio mínimo de crescimento Ammonium Oxidation Medium (AOM1) a $60^{\circ} \mathrm{C}$ conforme descrito previamente na literatura ${ }^{24}$ e também em meio AOM1 sólido com fitagel (Sigma) a 8g/L. Além disso, testes foram realizados utilizando Ágar a 8g/L.

\subsubsection{Confirmação do organismo de estudo}

\section{Extração do DNA}

A extração do DNA genômico da Thermogemmatispora sp. cepa T81 foi realizado utilizando-se $5 \mathrm{~mL}$ de cultura seguindo os procedimentos descritos no protocolo da Charge Switch gDNA Mini Bacteria Kit (Life Technologies) com a seguinte adaptação: na etapa pós ressuspensão do maciço celular com o tampão de ressuspensão adicionou-se $10 \mu \mathrm{L}$ de $V W R$ BeadsZirconMolBio $200 \mathrm{M}$ e por 45 segundos a amostra foi exposta ao Mini beadbeater (BioSpec) onde foi aplicado um processo de desruptura celular sob alta energia. Após esta etapa, o protocolo Charge Switch gDNA Mini Bacteria foi realizado como descrito pelo fabricante.

\section{PCR utilizando oligonucleotídeos universais para a sequência CPN60}

Análises da sequência gênica para chaperonina 60 (GroEL) foram realizadas a fim de confirmar a linhagem da bactéria em estudo. Os genes GroEL codificam proteínas altamente 
conservadas que auxiliam no processo de enovelamento (também conhecidas como chaperoninas). ${ }^{44}$ Para a amplificação da sequência gênica utilizando o método de reação em cadeia da polimerase (PCR), foram utilizados os oligonucleotídeos H729 fita direta CGCCAGGGTTTTCCCAGTCACGACGAIIIIGCIGGI GAYGGIACIACIAC- e H730 fita reversa -AGCGGATAACAATTTCACACAGGAYKIY KITCICCRAAICCIGGIGCYTTT-, empregando-se as condições descritas na Tabela 6 e seguindo-se o ciclo: primeiro passo $95^{\circ} \mathrm{C}$ por $2 \mathrm{~min}$, segundo passo ( 39 ciclos: $95^{\circ} \mathrm{C}$ por $45 \mathrm{~s}, 55^{\circ} \mathrm{C}$ por 1 min e $72^{\circ} \mathrm{C}$ por $1 \mathrm{~min}$ ), terceiro passo $72^{\circ} \mathrm{C}$ por 7 min e posteriormente à $4^{\circ} \mathrm{C}$ por $1 \mathrm{~min}$.

Tabela 6 - Reação de amplificação para cada um dos genes.

\begin{tabular}{cc}
\hline Reação de amplificação & Concentração final \\
Tampão (20mM Tris-HCl pH 8,4,50mM KCl) $10 \mathrm{X}$ & $1 \mathrm{X}$ \\
dNTP $[10 \mathrm{mM}](\mathrm{N}=\mathrm{A}, \mathrm{G}, \mathrm{C}, \mathrm{T})$ & $0,2 \mathrm{mM}$ \\
$\mathrm{MgCl}_{2}[25 \mathrm{mM}]$ & $2,5 \mathrm{mM}$ \\
Oligonucleotídeo $[25 \mu \mathrm{M}]\left(5^{\prime}\right.$ do gene $)$ & $0,5 \mu \mathrm{M}$ \\
Oligonucleotídeo $[25 \mu \mathrm{M}]\left(3^{\prime}\right.$ do gene $)$ & $0,5 \mu \mathrm{M}$ \\
DNA genômico & $17 \mathrm{ng}$ \\
Taq DNA Polimerase $(5 \mathrm{U} / \mu \mathrm{L})$ & $0,05 \mathrm{U} / \mu \mathrm{L}$ \\
$\mathrm{H}_{2} \mathrm{O}$ milli-Q para completar o volume de $25 \mu \mathrm{L}$ & \\
\hline
\end{tabular}

Fonte: Elaborada pelo autor.

O produto da amplificação gênica foi purificado utilizando-se Charge Switch PCR Clean-up Kit (Invitrogen) e quantificado com o espectrofotômetro NanoDrop 1000 (Therno Scientific). As amostras foram sequênciadas pela Macrogen Corporation (Maryland, USA).

\subsubsection{Análises filogenéticas}

As análises filogenéticas foram realizadas para determinar a relação entre Thermogemmatispora sp. T81 com outros membros do filo Chloroflexi com base na proteína chaperonina 60 (cpn60; também conhecida como a GroEL ou HSP60). A GroEL fornece informações melhor apuradas e filogeneticamente mais robustas do que a utilização de sequências de DNA $16 \mathrm{~S} .^{45}$ 
Sequências de nucleotídeo para o gene universal cpn60 (cpn60 UT) de T81 foram aplicadas no servidor NCBI BLASTP. ${ }^{31}$

As sequências homólogas de Chloroflexi foram exportadas como arquivo fasta e usadas como arquivo de entrada para o alinhamento múltiplo utilizando o programa CLUSTAL. ${ }^{33}$

As árvores de sequências de aminoácidos foram obtidas a partir dos algoritmos de junção de vizinhos (neighbour-joining) e alinhamentos com máxima parcimônia (maximum-parsimony) utilizando o programa MEGA, versão 6.06.

Testes com 1000 repetições foram conduzidos para examinar a confiabilidade dos ramos interiores das árvores filogenéticas.

\subsubsection{Análises genômicas}

Análises utilizando o genoma da Thermogemmatispora sp. cepa T81 foram realizadas por meio da plataforma Joint Genome Institute's Integrated Microbial Genome's, Expert-Review (IMG-ER) ${ }^{46}$, sendo o genoma do organismo disponível publicamente sob o número de acesso 2995. Comparações com outros organismos do filo Chloroflexi foram conduzidas com genomas disponíveis no GenBank (Tabela 7). 
Tabela 7 - Espécies e número de acesso.

\begin{tabular}{lc}
\hline \multicolumn{1}{c}{ Espécie } & Número de acesso \\
Chloroflexus sp Y-400-fl & CP001364.1 \\
Chloroflexus aggregans DSM 9485 & CP001337.1 \\
Roseiflexus castenholzii DSM 13941 & CP000804.1 \\
Thermobaculum terrenum ATCC BAA-798 & CP001825.1 \\
Sphaerobacter thermophilus DSM 20745 & CP001823.1 \\
Thermomicrobium roseum DSM 5159 & CP001275.1 \\
Anaerolinea thermophila UNI-1 & AP012029.1 \\
Caldilinea aerophila DSM 14535 & AP012337.1 \\
Thermogemmatispora sp. T81 & \\
Thermus thermophilus JL-18 & CP003252.1 \\
Thermotoga maritima MSB8 & AE000512.1 \\
Escherichia coli K-12 subst.MG1655 & U00096.3 \\
Clostridium thermocellum ATCC 27405 & CP000568.1 \\
Ktedonobacter racemifer & GCA_000178855.1 \\
\hline
\end{tabular}

Fonte: Elaborada pelo autor.

\subsubsection{Anotações de Cazymes}

Análises específicas por CAZymes foram gentilmente realizadas por Bernard Henrissat (Le laboratoire Architecture et Fonction des Macromolécules Biologiques, Marseille, France) utilizando as sequências protéicas traduzidas a partir do genoma da Thermogemmatispora $s p$. cepa T81 e do CAZy pipeline. ${ }^{11}$ Além disso, as sequências FASTA das proteínas determinadas como CAZymes foram aplicadas no programa PSORTb 3.0 possibilitando uma predição da localização subcelular das mesmas. ${ }^{47}$ 


\subsubsection{Análises de crescimento}

A determinação da curva de crescimento da bactéria Thermogemmatispora sp. cepa T81 (fase inicial, exponencial e estacionária) foi avaliada sob o meio mínimo AOM1 suprido pelas fontes de carbono glicose, $\alpha$-celulose e extrato de levedura na concentração final de $2 \mathrm{~g} / \mathrm{L}$.

$\mathrm{O}$ estoque da bactéria foi mantido em meio AOM1 suprido com extrato de levedura como fonte de carbono. Para que a interferência de fontes diferentes de carbono fosse eliminada, realizou-se um primeiro crescimento da bactéria no meio com a fonte de carbono de interesse para estudo, numa relação de 10\% [vol/vol] para o inóculo inicial, para só então proceder com a inoculação experimental avaliando a fonte de carbono desejada respeitando a mesma relação.

A relação de crescimento foi obtida a partir da concentração total de proteína extraída como descrito: centrifugou-se $5 \mathrm{~mL}$ da cultura a 6500 xg por 10min, separou-se o sobrenadante do precipitado celular e ressuspendeu-se o precipitado em $0,9 \%$ de $\mathrm{NaCl}$ para lavagem. Em seguida, descartou-se o sobrenadante após centrifugação, ressuspendeu-se com $1 \mathrm{~mL}$ da solução de $\mathrm{NaOH} 0,2 \mathrm{~N}$, colocou-se em água fervente por $45 \mathrm{~min}$ e centrifugou-se por $5 \mathrm{~min}$. O sobrenadante foi utilizado para mensurar a concentração total proteica pelo método de Bradford $^{48}$ e cada substrato de estudo foi avaliado em triplicatas biológicas.

\subsubsection{Análises de proteômica}

\section{Crescimento}

O meio de cultura AOM1 foi preparado com adição de glicose, extrato de levedura e $\alpha$ celulose na concentração final de 2g/L e em duplicatas biológicas (amostra A e B) para serem coletadas ao atingir metade da fase exponencial de crescimento em um período de 10 horas após este momento, ou seja, duplicatas biológicas para cada fase de crescimento analisado.

As amostras foram centrifugadas a 4,700 x g por 10min, o precipitado celular foi lavado por três vezes em $5 \mathrm{~mL}$ de tampão fosfato $\left(\mathrm{NaCl}, 8 \mathrm{~g} / \mathrm{L} ; \mathrm{KCl}, 0,2 \mathrm{~g} / \mathrm{L} ; \mathrm{NaHPO}_{4}, 1,44 \mathrm{~g} / \mathrm{L}\right.$; 
$\left.\mathrm{KH}_{2} \mathrm{PO}_{4}, 0,24 \mathrm{~g} / \mathrm{L}, \mathrm{pH} 7,4\right)$, o sobrenadante foi descartado e as amostras foram mantidas a $-80^{\circ} \mathrm{C}$ até a extração protéica.

\section{Extração protéica}

A extração protéica foi conduzida da seguinte maneira: colocou-se as amostras em banho de água fervente; adicionou-se $350 \mu \mathrm{L}$ de água para ressuspensão de cada precipitado celular; preparou-se 2X SDT tampão de lise (8 g SDS e 200 mM Tris-HCl em 100 mL de água, pH 7,6); preparou-se SDT com DTT utilizando-se a seguinte proporção: 48mg DTT para 1,5 mL SDT; adicionou-se $1 \mathrm{~mL}$ de SDT com DTT em cada amostra, ressuspendeu-se as células e dividiu-se

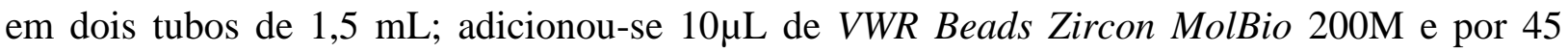
segundos a amostra foi exposta ao Mini beadbeater (BioSpec); centrifugou-se à $16000 \mathrm{x}$ g por $20 \mathrm{~min}$; transferiu-se o sobrenadante para filtros concentradores Amicon Ultra-15 10K (Milipore, Billerica,MA); lavou-se o sobrenadante por duas vezes em $12 \mathrm{~mL}$ de solução de uréia ( $8 \mathrm{M}$ de uréia em $0,1 \mathrm{M}$ Tris- $\mathrm{HCl}, \mathrm{pH} 8,5$ ), sendo que para cada lavagem foi utilizada uma rotação de $4000 \mathrm{x} \mathrm{g}$ à $25^{\circ} \mathrm{C}$ por ao menos $30 \mathrm{~min}$, até que o volume restante no concentrador fosse inferior a $1 \mathrm{~mL}$.

Em seguida, para cada $1 \mathrm{~mL}$ de solução protéica no filtro concentrador adicionou-se $1 \mathrm{~mL}$ de solução $50 \mathrm{mM}$ de iodoacetamida preparada em solução de uréia ( $8 \mathrm{M}$ de uréia e $0,1 \mathrm{M}$ Tris-HCl, pH 8,5), incubando-se no escuro por 10 min. Após incubação centrifugou-se por 5 min à $4000 \mathrm{x} \mathrm{g}, 25^{\circ} \mathrm{C}$, descartando-se o filtrado e repetindo-se por duas vezes o seguinte procedimento: adicionação de $12 \mathrm{~mL}$ de solução de uréia ( $8 \mathrm{M}$ de uréia em $0,1 \mathrm{M}$ Tris- $\mathrm{HCl}, \mathrm{pH}$ $8,5)$ para cada filtro concentrador, homogeneização com o uso de pipeta e centrifugação por 45 min, $4000 \mathrm{xg}$ à $25^{\circ} \mathrm{C}$ até o volume final de $1 \mathrm{~mL}$.

Uma alíquota de $50 \mu \mathrm{L}$ de cada concentrador foi retirada para avaliar a concentração protéica utilizando-se ensaio de ácido bicinconínico (BCA) (Pierce chemical Co., Rockford, IL). ${ }^{49} \mathrm{O}$ filtro concentrador foi então lavado por duas vezes com $10 \mathrm{~mL}$ de $50 \mathrm{mM}$ de bicarbonato de amônio em água, centrifugado à 4000 x g por 30 min numa temperatura de $25^{\circ} \mathrm{C}$. Após a centrifugação, com um volume de aproximadamente $1 \mathrm{~mL}$ em cada filtro 
concentrador, foi adicionada tripsina (Promega, Madison, WI) para a digestão por $18 \mathrm{~h} \mathrm{em}$ temperatura ambiente (relação tripsina / concentração de proteína, $1 \mu \mathrm{g}: 100 \mu \mathrm{g}$ ). A unidade filtro foi transferida para um novo tubo coletor e centrifugada a $4000 \mathrm{x}$ g por $15 \mathrm{~min}$ a $25^{\circ} \mathrm{C}$; em seguida adicionou-se $1 \mathrm{~mL}$ de $0,5 \mathrm{M}$ de $\mathrm{NaCl}$ em água e centrifugou-se por $15 \mathrm{~min}, 4000 \mathrm{x} \mathrm{g}$ a $25^{\circ} \mathrm{C}$

\section{Purificação de peptídeos e análises de MS}

A concentração dos peptídeos resultantes da clivagem foi verificada utilizado o espectrofotômetro NanoDrop 1000 (Thermo Scientific). As amostras foram liofilizadas utilizando-se Savant SpeedVac Plus Model SC110A Concentrator (Savant) e em seguida ressuspensas em $300 \mu \mathrm{L}$ de $0,1 \%$ de ácido trifluoroacético (TFA) apresentando massa entre 60 a $180 \mu \mathrm{g}$ de peptídeos. As amostras foram purificadas no sistema HPLC Agilent 1100 (Agilent Technologies, Santa Clara, CA) utilizando uma coluna 1-/-100-mm C18 (5- um Luna C18; Phenomenex, Torrance, CA) e eluídas com acetonitrila a $80 \%$ (v/v).

As alíquotas purificadas foram liofilizadas e ressuspensas em tampão $(0,1 \%$ de ácido fórmico em água) para subsequente análise por cromatografia líquida de massas (LC-MS). Um sistema ultra 2D LC (Eksigent, Dublin, CA) com um nano divisor de fluxo (splitless nano-flow) apresentando um volume de injeção de amostra de $10 \mu \mathrm{L}$ via coluna PepMap100 de $300 \mu \mathrm{m} \times 5 \mathrm{~mm}$ e uma coluna analítica Luna $5 \mu \mathrm{m}$ C18 (Phenomenex, Torrance, CA) com $100 \mu \mathrm{m} \times 200 \mathrm{~mm}$ foram utilizadas para a separação no LC. Os eluentes A (água) e B (acetonitrila) continham $0,1 \%$ de ácido fórmico como modificador de emparelhamento de elétrons.

Três diferentes gradientes lineares de 0,33, 0,66 e $1 \%$ de acetonitrila por minuto foram empregados para separar a mistura de peptídeos. Os digestos trípticos foram separados utilizando-se um gradiente de $0,33 \%$ de acetonitrila seguido por um passo de lavagem de $5 \mathrm{~min}$ com 90\% tampão A e 8 min de equilíbrio iniciando-se o gradiente com $0,5 \%$ correspondente a 120 minutos de tempo de uso do instrumento LC-MS. Todas as separações foram realizadas em temperatura ambiente. Um espectrômetro de massa Triplo TOF5600 (ABSciex, Concord, ON) 
foi utilizado no modo de aquisição dependente de dados MS / MS padrão. Com $250 \mathrm{~ms}$ de levantamento, os espectros de MS foram coletados (m/z 300-1500), seguido por até 20 MS/MS medições sobre os íons mais intensos gerados (com limiar de medida de 300 contagens/ s,+ 2 +4 de estado de carga, m/z 100 - 1500 faixa de massa de MS/MS, a $100 \mathrm{~ms} \mathrm{cada).}$

Íons marcados previamente foram excluídos da aquisição repetidamente MS/MS por $12 \mathrm{~s}$ (com tolerância de massa de $50 \mathrm{mDa}$ ). Arquivos de espectros brutos foram convertidos no formato de arquivos genéricos Mascote (MGF) para identificação de peptídeos e proteína. Os seguintes parâmetros de busca foram utilizados: 20 ppm, 0,1 Da de tolerância para geradores de massa e fragmento de íons, respectivamente; constantes modificações de Cys com iodo acetamida. Nenhuma variável de modificação foi permitida e a expectativa do valor de corte foi de $\log (e)<-3$.

\section{Processamento de dados e análises}

Os peptídeos foram identificados a partir dos espectros MS/MS obtidos utilizando-se uma unidade processadora de imagem (GPU) desenvolvida pelo próprio grupo para busca por peptídeos $^{50}$. Empregando-se apenas modificações pós-traducionais de resíduos de cisteína carboximetilada foi gerada uma base de dados de digestão tríptica a partir de anotações do genoma da bactéria Thermmogammatispora cepa T81.

Para cada biblioteca de fragmentos, as sequências provindas de picos mais intensos não redundantes foram selecionadas. Utilizando-se a sequência de corridas padrão e o tempo de retenção da média dos peptídeos não redundantes, foram identificados os fragmentos com maiores intensidades. As proteínas identificadas com apenas uma sequência de peptídeo foram excluídas da análise. ${ }^{50}$

O método de medida para a expressão de cada proteína foi o de contadores totais de íon (total íon coint TIC), medido como a soma da intensidade dos sinais dos peptídeos para cada proteína e representados na base de escala log2. A normalização dos valores de TIC foram feitas (nTIC) para cada sequência de peptídeos provindas a partir da relação TIC por $\log 2$ com o valor da massa em quilo daltons. ${ }^{51}$ 
A diferença entre os níveis de expressão entre diferentes condições de crescimento (fonte de carbono) foram calculadas a partir de uma transformação que combina a diferença de expressão entre diferentes estágios de crescimento (Wnet) baseado nos valores de Z-score sendo medido em unidades de desvio. O procedimento de análise foi realizado como descrito por Verbeke, ${ }^{51}$ onde as comparações para inter-replicata e intra-replicata foram avaliadas entre as fases exponencial e estacionária de crescimento para cada fonte de carbono estudada.

Os níveis globais de expressão foram avaliados utilizando uma plataforma computacional própria que dispõem de grupos de proteínas e genes inseridos em um grupo de altas variáveis "higher order variables" (HOVs) e extraído do IMG-ER para genomas individuais.

\subsubsection{Seleção de candidatos para expressão heteróloga utilizando o processamento de dados, desenho dos oligonucleotídeos, amplificação gênica e clonagem.}

A partir do cruzamento de informações dos níveis globais de expressão, classificação de Cazymes e predição quanto a localização de cada proteína a partir do programa PSORTb $3.0^{47}$ foram selecionados os alvos para expressão heteróloga.

O programa Domain-Fish ${ }^{32}$ foi utilizado para identificação das regiões de clonagem delimitando as mesmas em domínios. Os alinhamentos múltiplos das sequências gênicas selecionadas para estudo foram realizados utilizando-se o programa CLUSTAL ${ }^{33}$ e análises qualitativas das sequências foram procedidas com a plataforma do ProtParam. ${ }^{52}$

O sistema de clonagem adotado foi o independente de ligase, LIC (do inglês, Ligase Independent Cloning) como já descrito. Os oligonucleotídeos utilizados para a amplificação das regiões codificadoras de genes foram sintetizados pela Exxtend Biotecnologia Ltda e estão apresentados na Tabela 8 . As bases sublinhadas referem-se à região de ligação ao incerto. 
Tabela 8 - Oligonucleotídeos utilizados na amplificação dos genes selecionados de T81.

\begin{tabular}{|c|c|}
\hline Proteína & Oligonocleotideos \\
\hline \multirow[t]{2}{*}{ T81_46750 } & 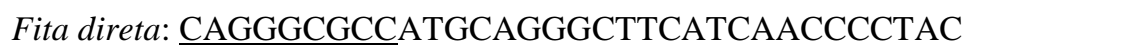 \\
\hline & Fita reversa: $\underline{\text { GACCCGACGCGGTTATTAGAAGGGCGGATAGGCG }}$ \\
\hline \multirow[t]{2}{*}{ T81_30480 } & Fita direta: CAGGGCGCCATGGCCTCAAGCGTCACCATTAACG \\
\hline & Fita reversa: $\underline{\text { GACCCGACGCGGTTACTAGACGACGCTGCAGGTCG }}$ \\
\hline \multirow[t]{2}{*}{ T81_30480 (domínio CBM) } & Fita direta: $\underline{\text { CAGGGCGCCATGGGCGCTTCCTGTCAAGTG }}$ \\
\hline & 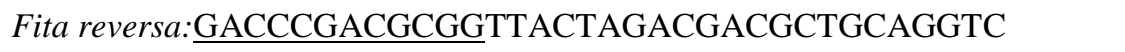 \\
\hline \multirow{2}{*}{$\begin{array}{l}\text { T81_30480 (domínio } \\
\text { catalítico) }\end{array}$} & Fita direta: CAGGGCGCCATGGCCTCAAGCGTCACCATTAACG \\
\hline & Fita reversa:GACCCGACGCGGTTAGATGACATAGGTCACCAGCGAGC \\
\hline \multirow[t]{2}{*}{ T81_22550 } & Fita direta: CAGGGCGCCATGGGAGAGCCGTTTATCCTGGG \\
\hline & 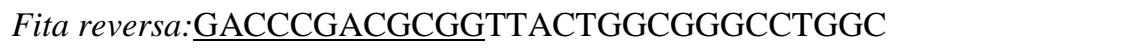 \\
\hline \multirow[t]{2}{*}{ T81_14280 } & Fita direta: $\underline{\text { CAGGGCGCCATGACATCGGGTATGCTCACTACG }}$ \\
\hline & Fita reversa:GACCCGACGCGGTTATTAGCGACAAGCATACTCCCTGAG \\
\hline
\end{tabular}

Fonte: Elaborada pelo autor. 
Os plasmídeos resultantes, gene-pET Trx-1a/Lic, foram inseridos em células de propagação Escherichia coli DH10B quimio-competente por transformação do tipo choque térmico com posterior transformação em células de expressão E. coli Rosetta (DE3) pLysS.

\subsubsection{Purificação das Proteínas}

Os procedimentos de purificação para as proteínas clonadas da bactéria Thermmogammatispora cepa $\mathrm{T} 81$, foram os mesmos descritos para as proteínas expansinas.

\subsubsection{Ensaios de Atividade}

\section{Caracterização cinética do coquetel T81}

\section{Avaliação da atividade das enzimas secretadas pela bactéria T81 no meio de cultura: Coquetel T81}

Foram preparados $150 \mathrm{~mL}$ do meio AOM1 contendo 2 g. $\mathrm{L}^{-1}$ de $\alpha$-celulose (Sigma). Após cinco dias de crescimento, fase em que a cultura do organismo encontra-se em crescimento estacionário, centrifugou-se a 4800 x g por $30 \mathrm{~min}$, e separou-se o sobrenadante, que é constituído do meio líquido e das enzimas secretadas pelo organismo, o qual foi nomeado de coquetel T81. Este coquetel teve a concentração protéica total avaliada utilizando a técnica de Bradford $^{48}$ e então foi concentrado utilizando-se o concentrador Vivaspin (GE Healthcare) com corte de massa molecular de $10 \mathrm{kDa}$ para utilização em ensaios de atividade. $\mathrm{O}$ mesmo procedimento também foi realizado substituindo a $\alpha$-celulose por glicose (Sinth). A medição da atividade enzimática foi feita através da quantificação de açúcar liberado pelo método de DNS (ácido dinitrosalicílico), que se baseia na reação entre o açúcar redutor e o ácido 3,5dinitrosalicílico. ${ }^{37}$ Todos os experimentos foram realizados em triplicatas. 


\section{Determinação da temperatura ótima de atividade do coquetel T81 para CMC}

Para avaliar a temperatura ótima de atividade do coquetel enzimático secretado pela bactéria Thermogemmatispora sp. T81 quando cultivada em meio rico em $\alpha$-celulose foi feita a aferição da atividade do coquetel em um intervalo de 40 a $85^{\circ} \mathrm{C}$ durante 60 minutos. Foi realizada também a reação de controle contendo $60 \mu \mathrm{L}$ da solução de CMC a $4 \%$ massa/volume e $20 \mu \mathrm{L}$ de tampão $20 \mathrm{mM}$ ácido cítrico-citrato de sódio, pH 4,8, e a reação enzimática contendo $60 \mu \mathrm{L}$ da solução de CMC a 4\% massa/volume e $20 \mu \mathrm{L}$ de coquetel T81.

\section{Determinação do pH ótimo de atividade}

Para avaliar o pH ótimo de atividade do coquetel enzimático secretado pela bactéria Thermogemmatispora $s p$. T81 quando cultivada utilizando $\alpha$-celulose foi preparada uma solução $1 \%$ (massa/volume) de xilano de Faia (Sigma) em tampão citrato-fosfato $50 \mathrm{mM}$ variando o $\mathrm{pH}$ entre 2 a 8. A reação padrão foi realizada para cada $\mathrm{pH}$ : $60 \mu \mathrm{L}$ da solução $1 \%$ (massa/volume) de xilano e $20 \mu \mathrm{L}$ de coquetel T81, na reação de controle foi utilizado $20 \mu \mathrm{L}$ de tampão em substituição ao coquetel T81.

\section{Estabilidade do coquetel}

Para avaliar a estabilidade do coquetel T81, foi avaliada a atividade enzimática de uma amostra recém produzida (expressa) do coquetel com outra estocada por seis meses a $10^{\circ} \mathrm{C}$. Para este experimento foram preparadas as reações controle, $40 \mu \mathrm{L}$ da solução de xilano de Faia a $1 \%$ massa/volume e $60 \mu \mathrm{L}$ de tampão ácido cítrico-citrato de sódio, e as reações enzimáticas, $40 \mu \mathrm{L}$ da solução de solução de xilano de Faia a $1 \%$ massa/volume e $40 \mu \mathrm{L}$ de tampão ácido cítricocitrato de sódio e $20 \mu \mathrm{L}$ de coquetel T81 a $0,1 \mathrm{mg} / \mathrm{mL}$, ambas com tempo de reação $30 \mathrm{~min}$, a $80^{\circ} \mathrm{C}$. 


\section{Avaliação da atividade lignocelulolíticos do coquetel T81: Painel de Substratos}

Um teste padrão para avaliar a atividade enzimática do coquetel T81 foi realizado consistindo de: tempo de reação de $120 \mathrm{~min}, 80^{\circ} \mathrm{C}, 1000 \mathrm{rpm}, 50 \mathrm{mM}$ de tampão ácido cítricocitrato de sódio a $\mathrm{pH}$ 5. A concentração enzimática do coquetel T81 utilizado foi de $1 \mu \mathrm{g}$ proteína/reação.

Foram preparadas soluções em tampão ácido cítrico-citrato de sódio a $1 \%$ (massa/volume) dos seguintes substratos: celulose microgranular (Sigma), xiloglucano (Megazyme), hidroxietil-celulose (Fluka), Sigmacell tipo 50 (Sigma), liquenano (Megazyme), laminarina (Sigma), celulose Pulver (Aldrich), CM-celulose (Sigma), Avicel pH-101 (Fluka), CMC média (Sigma), beta glucano (Megazyme), xilano de Faia (Sigma), xilano de aveia (Sigma), arabinoxilano de centeio (Megazyme) e para o substrato papel filtro $\mathrm{N}^{\circ} 1$ (Whatman) foi utilizado uma massa média de aproximadamente $3,3 \mathrm{mg}$ por reação.

Para este experimento as seguintes reações foram avaliadas: reação de controle, contendo substrato em $40 \mu \mathrm{L}$ de tampão ácido cítrico-citrato de sódio para o papel filtro ou 40 $\mu \mathrm{L}$ da solução de substrato e $60 \mu \mathrm{L}$ de tampão ácido cítrico-citrato de sódio, e reação enzimática, constituída de substrato em $40 \mu \mathrm{L}$ de tampão ácido cítrico-citrato de sódio para o papel filtro ou $40 \mu \mathrm{L}$ da solução de substrato, $40 \mu \mathrm{L}$ de tampão ácido cítrico-citrato de sódio e $20 \mu \mathrm{L}$ de coquetel T81 (1 $\mu \mathrm{g}$ proteína total).

\section{Caracterização cinética das enzimas clonadas a partir dos dados de proteômica}

\section{Avaliação da atividade lignocelulolítica de cada enzima: Painel de Substratos}

Para o teste de atividade das enzimas: A ( T81_46750 GH6), B (T81_30480 GH30_7), C (T81_30480, domínio catalítico) e E ( T81_14280 GH5_22) foram utilizadas as concentrações de 4,$3 ; 5,6 ; 6,2$ e $12,5 \mu \mathrm{M}$, respectivamente, reações por $120 \mathrm{~min}$ a $60^{\circ} \mathrm{C}, 1000$ rpm e para a enzima D (T81_05390, GT4) na concentração de $7 \mu \mathrm{M}, 720$ min a $60^{\circ} \mathrm{C}$, com 
rotação de 1000 rpm. Para identificação dos tipos de moléculas que cada enzima é capaz de clivar, os substratos pectina (Synth), sigmacell 50 (Sigma), sigmacell 20 (Sigma), CMC médio (Sigma), CMC baixa (Sigma), celulose pulver (Aldrich), celulose microgranular (Sigma), CMcelulose (Sigma), Hidroxiethil celulose (Aldrich), xilano de Faia (Sigma), xilano de aveia (Sigma), arabinogalactano de Lariço (Megazyme), arabinoxilano de centeio (Megazyme), liquenano (Sigma), galactomanano (Megazyme), arabinano (Megazyme), beta glucano (Megazyme), xiloglucano (Megazyme), 1,4B D Manano (Megazyme), Avicel PH-101 (Fluka), laminarina (Sigma) foram preparados em solução $1 \%$ massa/volume em tampão citrato-fosfato pH 5. Uma massa de 3,3 mg de papel filtro foi pesada para também utilizá-lo como substrato.

\section{Teste de temperatura e pH ótimos}

As condições ótimas de catálise das enzimas para diferentes pHs e temperaturas foram avaliadas, sendo testados as temperaturas de 40 a $90^{\circ} \mathrm{C} \mathrm{e} \mathrm{pHs} \mathrm{de} 2$ a 8 . O tampão utilizado para a variação de $\mathrm{pH}$ foi ácido cítrico-citrato de sódio $20 \mathrm{mM}$ e a variação de temperatura foi realizada no termociclador (Bio-Rad). As reações foram procedidas de acordo com o experimento de teste de atividade padrão como descrito no item painel de substratos.

\section{Gel Nativo}

Amostras foram aplicadas em gel nativo gradiente 8- $25 \%$ (PhastGel - GE Healthcare) utilizando sistema PhastSystem (GE Healthcare).

\section{Determinação dos parâmetros cinéticos (Km e Vmax) para a enzima T81_30480 GH30_7 domínio catalítico}

As reações de formação e dissociação do complexo enzima substrato $(E S)$ e formação de produto liberando a enzima podem ser representadas pelo esquema de Briggs-Haldane abaixo: 


$$
\begin{aligned}
& S+E \stackrel{K 1}{\rightarrow} E S \\
& E S \stackrel{K-1}{\rightarrow} S+E \\
& E S \stackrel{K 2}{\rightarrow} P+E
\end{aligned}
$$

Admitindo o estado estacionário de formação do complexo ES, obtém-se a equação de Michaelis-Menten (Equação 3), para uma dada concentração de enzima $[\boldsymbol{E}]_{0}$ na presença de excesso de substrato. ${ }^{53}$

$$
V o=\frac{k 2[E]_{0}[S]_{0}}{[S]_{0}+K_{m}}=\frac{V_{m a ́ x}[S]_{0}}{[S]_{0}+K_{m}}
$$

Onde,

$$
K_{m}=\frac{\left(k_{-1}+k_{2}\right)}{k_{1}} \text { e } k 2[E]_{0}=V_{\text {máx }}
$$

Os parâmetros $V_{m a ́ x}, K_{m}$ e $k 2$ significam: velocidade máxima $\left(V_{m a ́ x}\right)$ é o valor máximo da velocidade inicial quando todos os sítios ativos estão ocupados, constante de MichaelisMenten $\left(K_{m}\right)$, indica a afinidade do substrato pela enzima, quanto menor o seu valor, maior será a afinidade da enzima pelo substrato logo mais eficiente. Já $k 2(=k c a t=$ turnover number= turnover frequency) número de renovação representa o número máximo de reações enzimáticas catalisadas por segundo. Por fim, uma constante alternativa, pode ser obtida a partir da relação kcat/Km, chamada de constante de especificidade, que indica o quão eficiente uma enzima converte substrato em produto.

Para a obtenção dos $V_{\text {máx }}, K_{m}$ fez-se um ajuste não linear da curva de concentração de substrato $[\boldsymbol{S}]_{\mathbf{0}}$ vs $\mu$ mol produto/min/mg de enzima, descrito pela curva da (Equação 4), utilizando o pacote Origin.

$$
V=\frac{V_{\text {máx }}[S]_{0}^{n}}{K_{m}^{n}+[S]_{0}^{n}}
$$


Para a GH30_7 (T81_30480) os parâmetros cinéticos foram obtidos sobre o substrato xilano em tampão ácido cítrico-citrato de sódio $20 \mathrm{mM}, \mathrm{pH}$ 5, 75 $\mathrm{C}, 1000 \mathrm{rpm}$ em equipamento ThermoMixer (Eppendorf).

Primeiramente, foram preparados estoques da enzima em cinco concentrações distintas $(0,96 ; 1,92 ; 2,88 ; 5,52$ e 7,68 $\mu \mathrm{g} / \mathrm{mL})$, aplicando $20 \mu \mathrm{L}$ de cada para uma reação de $0,1 \mathrm{~mL}$ com o substrato a uma concentração final de $4 \mathrm{~g} / \mathrm{L}$. Coletou-se pontos de $0,5,10,15$ e 30 min de reação. A partir deste experimento foi definido a melhor concentração e tempo em que a enzima se encontra numa região linear (não saturante) e com absorbância mensurada dentro da curva padrão.

Desta maneira, com a concentração e tempo determinados, foram preparadas reações de $0,1 \mathrm{~mL}$ com substrato a concentrações finais de: $2 ; 3 ; 3,75 ; 5 ; 6,25 ; 7,5 ; 8,75 ; 10 ; 11,25 ; 12,5$; 13,$75 ; 15 ; 20 ; 25$ e $30 \mathrm{~g} / \mathrm{L}$ para obtermos a velocidade $\left(\mathrm{V}_{\mathrm{o}}\right)$, equação 4 .

Em seguida utilizando o programa Origin, foram obtidos os parâmetros cinéticos: constante de Michaelis-Menten (Km) e velocidade máxima (Vmáx); de posse destes valores foram calculados o Kcat e a eficiência catalítica (Kcat/Km).

\section{Cromatografia em camada delgada (CCD ou TLC (Thin-layer chromatography)) para o domínio catalítico da GH30_7}

Mesma metodologia empregada e descrita na parte A, item 4.1.7.

\section{Avaliação do CBM 2}

Foi realizado seguindo o protocolo para avaliação do efeito sinérgico sobre polissacarídeos celulósicos e hemicelulósicos descritos na parte A, sendo que a amostra de CBM utilizada estava a $2,2 \mu \mathrm{M}$. 


\subsubsection{Dicroísmo circular (CD)}

Mesma metodologia empregada e descrita na parte A, item 4.1.8.

\subsubsection{Espalhamento de Raios-X a Baixo Ângulo (SAXS).}

Os estudos de espalhamento de raios $\mathrm{X}$ a baixo ângulo constituem numa ferramenta importante para o estudo de macromoléculas biológicas. Primeiramente porque esta técnica permite informações estruturais de macromoléculas parcialmente ou completamente desordenadas, em condições bem próximas as fisiológicas bem como a análise estrutural das macromoléculas frente a variações externas como, por exemplo, a temperatura. ${ }^{29}$

Além disso, as limitações técnicas na obtenção de um bom cristal para cristalografia de raios X e a baixa massa molecular para RMN leva a necessidade de técnicas como SAXS para a obtenção de informações a nível estrutural. ${ }^{54}$

Entre as necessidades técnicas na preparação de uma amostra para SAXS temos: amostras devem formar uma solução homogênea, em tampão sem aditivos especiais e monodispersa. Isto assegura uma orientação aleatória das moléculas, o que permite, na média, considerarmos o espalhamento de uma única partícula, ${ }^{29 ;} 54$ o que é fundamental para a aplicação da teoria da técnica para obtenção dos modelos estruturais.

Os raios $X$ são fótons com comprimento de onda dado por $\lambda=1.256 / E$, sendo $\lambda$ expresso em nm e $E$ em keV. Em estudos estruturais, os raios $\mathrm{X}$ possuem energia em torno de $10 \mathrm{keV}$ ( $\lambda$ entre $0.10-0.15 \mathrm{~nm}$ ). Assim, quando uma onda plana monocromática atinge uma amostra (objeto) $k 0=|k 0|=2 \pi / \lambda$, ocorre a interação com os átomos do objeto (onda incidente) que se tornam fontes de ondas esféricas. ${ }^{29 ; 54}$ 
O esquema da Figura 9, ilustra o processo de espalhamento no qual tomando a primeira aproximação de Born pode ser descrito como a transformação do espaço "real" laboratório (objeto) em coordenadas $r$ para o espaço recíproco pelo vetor $s=k 1-k 0$.
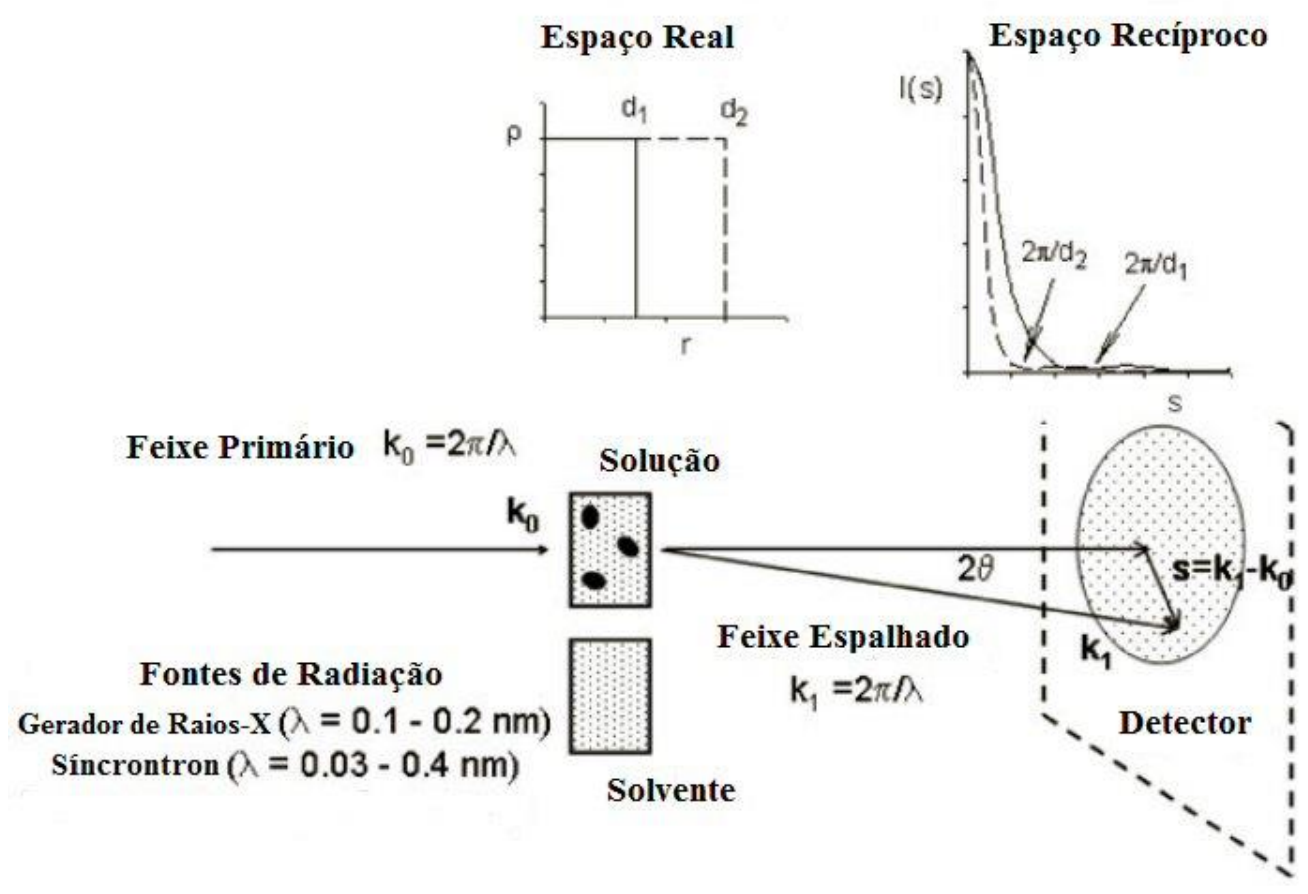

Figura 9 - Esquema do experimento de SAXS com a transformada de Fourier do espaço real para o recíproco.

Fonte: Adaptado de SVERGUN et al. ${ }^{53}$

A função transformada de Fourier aplicada a densidade de elétrons de uma átomo (esférico) é a amplitude de espalhamento dos raios X. Sendo esta densidade de elétrons escrita em função do momento transferido, $\mathrm{q}=s=4 \pi \lambda^{-1} \sin (\theta)$ onde $2 \theta$ é o ângulo de espalhamento, $\mathrm{e}$ $f(0)=f x$.

Admitindo uma densidade de espalhamento constante $\rho \mathrm{q}$ do solvente, teremos que a diferença de espalhamento para uma partícula em relação ao solvente dada por $\Delta \rho(r)=\rho(r)$ $\rho q$, que a partir da integração em todo volume pode ser descrito pela equação 5. 


$$
A(q)=\mathrm{F}[\Delta \rho(r)]=\int_{V} \Delta \rho(r) \exp (\mathbf{i} q r) \mathrm{d} r
$$

Com o experimento de espalhamento não medimos diretamente a amplitude, mas a intensidade do espalhamento por uma única partícula $I_{0}(q)$ que é dado pelo produto da amplitude espalhada pelo seu complexo conjugado, numa data direção (q), equação 6.

$$
\mathrm{I}_{0}(\mathrm{q})=\mathrm{A}(\mathrm{q}) \mathrm{A}(\mathrm{q})^{*}
$$

Tomando a média em todas as direções obtemos à fórmula de Debye.

$$
<e^{-i q r}>_{\Omega}=\frac{\operatorname{sen}(q r)}{q r}
$$

Permitindo que reescrevamos a equação $5^{29}$, na forma da equação 8 :

$$
I_{0}(q)=4 \pi \int_{0}^{\infty} \gamma(r) \frac{\operatorname{sen}(q r)}{q r} r^{2} d r
$$

A equação 8 é a representação geral para o padrão de espalhamento de partículas, sendo $\gamma(\mathrm{r})$ a função de correlação ou função característica que pode ser obtida pela transformada inversa de Fourier, este fator também por ser escrito como $\gamma(r)=P(r)$.

$$
P(r)=\gamma(r)=\frac{1}{2 \pi^{2}} \int_{0}^{\infty} I_{0}(q) q^{2} \frac{\operatorname{sen}(q r)}{q r} d q
$$

A intensidade do espalhamento para valores pequenos $(q \rightarrow 0)$, fazendo a aproximação $q$ $=\mathrm{r}=0$, o fator de Debye assume valor 1 , dessa maneira as equações 8 e 9 , serão escritas como.

$$
\begin{array}{r}
I_{0}(0)=\int_{0}^{\infty} 4 \pi^{2} \gamma(r) d r \\
P(0)=\gamma(0)=\frac{1}{2 \pi^{2}} \int_{0}^{\infty} I(q) q^{2} d q=V_{p}(\overline{\Delta \rho})^{2}
\end{array}
$$

A partir da aproximação de Guinier com a extrapolação até zero, permite a obtenção destes valores por não serem acessíveis experimentalmente. Considerando regiões de baixo q, ou seja, qr $\ll<1$, o fator de Debye pode ser aproximado utilizando a expansão de McLaurin (Equação 12). Ao substituir a equação 12 na equação 8, obtemos a equação 13. 


$$
\begin{gathered}
\frac{\operatorname{sen}(q r)}{q r} \cong 1-\frac{(q r)^{3}}{3 !}+\ldots \\
I_{0}(q)=4 \pi \int \gamma(r)\left(1-\frac{(q r)^{2}}{6}+\ldots\right) r^{2} d r \cong I_{0}(0)\left(1-\frac{q^{2} r_{g}^{2}}{3}\right)
\end{gathered}
$$

Sendo $r_{g}$, o raio de giro, obtido a partir da segunda normalização da distribuição de partícula. Uma vez que, a aproximação de Guinier é valida para baixos ângulos: qr $\ll 1 \mathrm{e}$ $e^{-x} \cong 1-x$ e a equação 12 , pode ser reescrita na forma da equação 14 .

$$
I_{0}(q) \cong I_{0}(0) e^{\left(-\frac{q^{2} r_{g}^{2}}{3}\right)}
$$

Obtemos desta foram, a equação da Lei de Guinier (Equação 14). Admitindo um sistema monodisperso ideal, o gráfico de Guinier $\left(\ln (I(q))\right.$ versus $\left.q^{2}\right)$ pode ser uma função linear, cujo intercepto na origem dá $I(0)$ e o coeficiente angular o raio de giro $R g$. Dessa maneira, a linearidade do gráfico de Guinier é um teste na avaliação da homogeneidade da amostra cujos desvios indicam interferências da interação interpartículas da mesma. ${ }^{53}$

Os resultados experimentais de espalhamento de raios- $\mathrm{X}$ a baixo ângulo foram obtidos para a GH30_7 domínio catalítico em concentrações de 1mg/mL em tampão: $150 \mathrm{mM}$ de $\mathrm{NaCl}$, $50 \mathrm{mM}$ de Tris- $\mathrm{HCl}, 5 \%$ de glicerol e pH 7,5. Foram coletados em colaboração com o pós doutorando Dr. Marco Antônio Seike Kadovak. Os dados de SAXS foram coletados na linha SAXS2 do Laboratório Nacional de Luz Síncroton (LNLS, Campinas-SP).

Os parâmetros de coleta foram comprimento de onda $\lambda=0.148 \mathrm{~nm}$, detector bidimensional (2D) e a distância amostra-detector foi de $1495.45 \mathrm{~mm}$, cobrindo um intervalo de transferência de momento de $0.01 \AA^{-1}<\mathrm{q}<0.23 \AA^{-1}$ (concentração de $1 \mathrm{mg} / \mathrm{mL}$ ).

Processamentos iniciais dos dados foram obtidos com o programa FIT2D, ${ }^{55}$ normalizando-se os dados pela intensidade do feixe e multiplicando-se pela absorção da amostra $^{56}$. Além disso, subtraiu-se o espalhamento da solução tampão da curva de espalhamento da solução de proteína. A massa molecular da proteína foi estimada usando o programa SAXS MoW. ${ }^{57}$ 
O programa $G N O M^{58}$, foi utilizado para obter a curva de distribuição de distâncias p(r), Dmáx e o raio de giro. Este último também foi obtido utilizando-se a aproximação de Guinier. ${ }^{59}$ O programa $C R Y S O L^{60}$ foi utilizado para a comparação deste resultado com modelos cristalográficos da proteína obtidos por modelagem por homologia.

Utilizamos o programa $D A M M I N^{61}$ para a geração de modelos ab Initio de baixa resolução. Para a sobreposição do modelo de átomos dummy provenientes dos programas utilizados foram sobrepostas a modelos por homologia e cristalográfico, utilizando o SUPCOMB. $^{62}$

\subsubsection{Ensaios de cristalização}

A obtenção de cristais adequados para estudos em cristalografia de raios $\mathrm{X}$ é fundamental. Para isso, exige-se que a macromolécula seja purificada até o máximo de pureza (homogeneidade). A pureza na preparação de uma amostra é um fator fundamental para a obtenção de cristais com boa capacidade de difração. ${ }^{63-64}$

O processo de cristalização requer levar a macromolécula à supersaturação. A amostra deve, portanto, ser concentrada até concentrações o mais elevadas possível, sem provocar a agregação ou precipitação da macromolécula (normalmente $2-50 \mathrm{mg} / \mathrm{mL}$ ). ${ }^{65}$

A obtenção dos cristais de proteína constitui num processo que passa por três etapas, nucleação, crescimento e cessação de crescimento. Utilizamos do método de cristalização por difusão de vapor, em particular aplicando a técnica da gota apoiada para a triagem de condições de cristalização.

A triagem de condições de cristalização foi realizada em placas de cristalização com 96 poços a $18^{\circ} \mathrm{C}$, através do método de difusão de vapor. Foram utilizados os kits comerciais Classics Suite, Classics II suíte, PEG suíte, PEG II suíte (Quiagen), Index HT e Salt RX (Hampton Research). As gotas de cristalização foram feitas em robô de cristalização Honeybee 
(Molecular Dinamics), contendo 0,7 uL de solução de proteína, utilizando o método da gota apoiada. 
5 RESULTADOS 


\subsection{PARTE A}

\subsubsection{Análises bioinformáticas}

A partir da análise das sequências gênicas codificadoras de expansinas e utilizando a base de dados NCBI, foram definidas as proteínas alvo para estudo (Tabela 9). O uso do programa Domain-Fish ${ }^{32}$ permitiu a delimitação dos domínios Rare lipoprotein e catalítico das

swoleninas (SWO1) de Trichoderma reesei (NCBI \# XM_006969163.1) e Trichoderma harzianum (JGI: \# Jgi \#87202). Além disso, foi delimitado o domínio catalítico SWO1 de $T$. harzianum a partir do gene jgi\#484109. 
Tabela 9 - Parâmetros moleculares e de clonagem das expansinas

\begin{tabular}{|c|c|c|c|c|c|}
\hline Proteína/Organismo & $\begin{array}{l}\mathbf{N}^{\circ} \\
\mathbf{A A}\end{array}$ & MM & $\begin{array}{c}\text { Plasmídeo } \\
\text { de clonagem }\end{array}$ & $\begin{array}{c}\text { Bactéria de } \\
\text { expressão }\end{array}$ & $\begin{array}{c}\mathbf{N}^{\circ} \\
\text { Cisteínas }(\mathbf{C}) \%\end{array}$ \\
\hline $\begin{array}{c}\text { Expansina de } \\
\text { Xanthomonas campestris } \\
(A A M 42805.1)\end{array}$ & 206 & 22280 & pSMT3 & $\begin{array}{c}E . \\
\text { coliRosetta } \\
\text { (DE3) }\end{array}$ & 0 \\
\hline $\begin{array}{c}\text { Expansina de Bacillus } \\
\text { licheniformis } \\
\text { GI:763044428 }\end{array}$ & 207 & 22949 & $\begin{array}{c}\text { pET } \\
\text { Trx1a/LIC }\end{array}$ & $\begin{array}{c}E . \\
\text { coliRosetta } \\
\text { (DE3) }\end{array}$ & $\mathbf{0}$ \\
\hline $\begin{array}{c}\text { SWO1 de T.harzianum jg } \\
\text { i\#484109 }\end{array}$ & 475 & 49639 & $\begin{array}{c}\mathrm{pET} \\
\text { Trx1a/LIC }\end{array}$ & $\begin{array}{c}E . \\
\text { coliRosetta } \\
\text { (DE3) }\end{array}$ & $27(5.7 \%)$ \\
\hline $\begin{array}{l}\text { SWO1-domínio catlítico de } \\
\text { T.harzianum jgi\#484109 }\end{array}$ & 232 & 24927 & $\begin{array}{c}\mathrm{pET} \\
\text { Trx1a/LIC }\end{array}$ & $\begin{array}{c}E . \\
\text { coliRosetta } \\
\text { (DE3) }\end{array}$ & $9(3.9 \%)$ \\
\hline $\begin{array}{l}\text { SWO1-domínio catalítico } \\
\text { de T.reesei GI:589114404 }\end{array}$ & 232 & 24971 & $\begin{array}{c}\text { pET } \\
\text { Trx1a/LIC }\end{array}$ & $\begin{array}{c}E . \\
\text { coliRosetta } \\
\text { (DE3) }\end{array}$ & $9(3.9 \%)$ \\
\hline $\begin{array}{c}\text { Domínio Rarelipoprotein } \\
\text { A } \\
\text { T. reesei GI:589114404 }\end{array}$ & 106 & 11341 & $\begin{array}{c}\text { pET } \\
\text { Trx1a/LIC }\end{array}$ & $\begin{array}{c}E . \\
\text { coliRosetta } \\
\text { (DE3) }\end{array}$ & $4(3.8 \%)$ \\
\hline $\begin{array}{l}\text { Cerato-platanin e fator de } \\
\text { transcrição GRAS } \\
\text { T.harzianum jgi498030 }\end{array}$ & 199 & 21596 & $\begin{array}{c}\mathrm{pET} \\
\text { Trx1a/LIC }\end{array}$ & $\begin{array}{c}E . \\
\text { coliRosetta } \\
\text { (DE3) }\end{array}$ & $8(4 \%)$ \\
\hline $\begin{array}{c}\text { Rarelipoprotein A } \\
\text { T.harzianum } \\
\text { Jgi } \# 87202\end{array}$ & 133 & 14109 & $\begin{array}{c}\mathrm{pET} \\
\text { Trx1a/LIC }\end{array}$ & $\begin{array}{c}E . \\
\text { coliRosetta } \\
\text { (DE3) }\end{array}$ & $6(4,5 \%)$ \\
\hline
\end{tabular}

Fonte: Elaborada pelo autor. 


\subsubsection{Purificação das proteínas}

As expansinas apresentadas na Tabela 9 foram clonadas e transformadas em bactéria de expressão E.coli Rosetta com a capacidade de expressão dos genes selecionados. Os perfis eletroforéticos das proteínas swolenina de T. harzianum (jgi \#484109), SWO1-domínio catalítico de T. harzianum (jgi \#484109), Cerato-platanin e fator de transcrição GRAS T. harzianum (jgi \#498030) e Rare lipoprotein A de T. harzianum (jgi \#872) são apresentados (Figura 10).

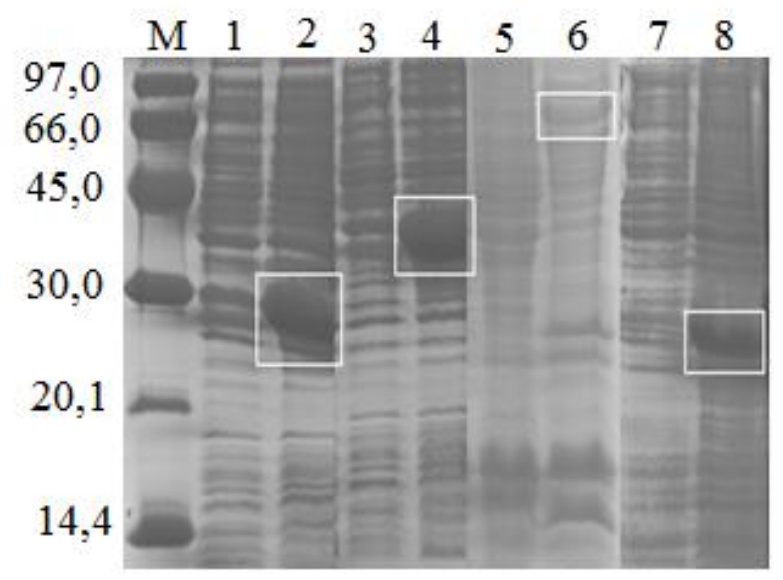

Figura 10 - Teste de expressão, perfil eletroforético em SDS-PAGE 15\%. M: marcador de massa molecular, 1: extrato bruto e 2: pós-indução de Rare lipo protein de T. harzianum.; 3: extrato bruto e 4: pós-indução de Gras transcriptor de T. harzianum; 5: extrato bruto e 6: pós-indução da SWO1 de T. harzianum; 7 extrato bruto e 8: pós indução da SWO1-dmonío catalítico de T.harzianum.

Fonte: Elaborada pelo autor.

As demais expansinas enumeradas na Tabela 9, possuem o perfil eletroforético ilustrado na Figura 11. As expansinas de Xanthomonas campestris $^{30}$ e Bacillus licheniformis GI:763044428 e SWO-domínio catalítico GI:589114404 e Rare lipoprotein A de Trichoderma reesei foram selecionadas para caracterização, devido a uma maior fração de proteínas heterologamente expressas. A purificação destas seguiu o protocolo previamente descrito em 4.1.4. Na Figura 11 está representada a primeira etapa do processo de purificação (precedente à ação da TEV protease). 


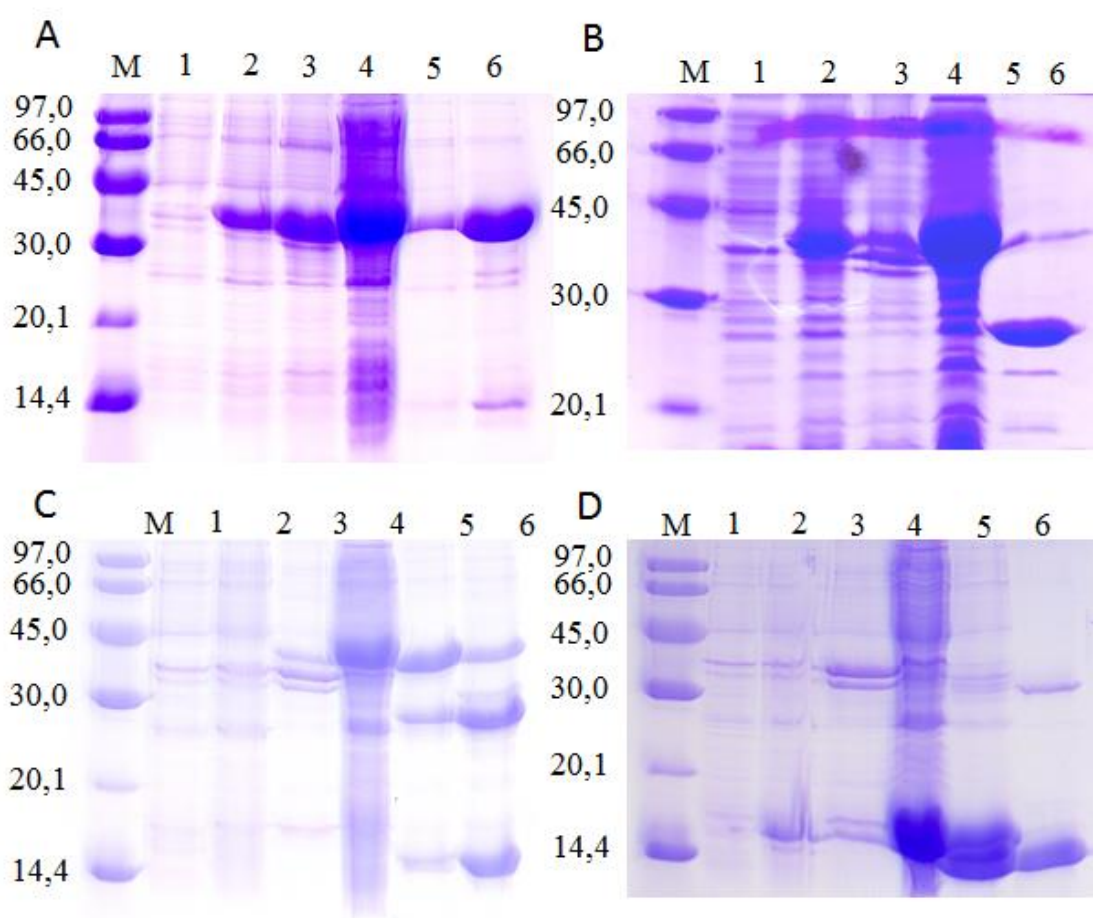

Figura 11 - Perfil eletroforético SDS-PAGE 15\%. A) Expansin-like de Bacillus licheniformis, B) Expansin-like de Xanthomonas campestris, C) Swo-domínio catalítico de Trichoderma reesei e D) Domínio de Rare lipoprotein de Trichoderma reesei. Para todas as amostras apresentadas, a ordem das linhas nos géis de poliacrilamida é: M - marcador de massa molecular, 1- fração pré-indução, 2- fração pós-indução, 3"pellet" do precipitado celular, 4- fração sobrenadante, 5 - primeira eluição (200mM imidazol) e 6segunda eluição $(500 \mathrm{mM})$ de Imidazol.

Fonte: Elaborada pelo autor.

Ao final dos processos cromatográficos, as expansinas apresentaram grau de pureza superior a 95\% (Figura 12) para a caracterização sinérgica com o coquetel Accellerase 1500 (Dupont), atividade catalítica, perfil de hidrólise de substrato (TLC) e experimentos de dicroísmo circular (CD). 


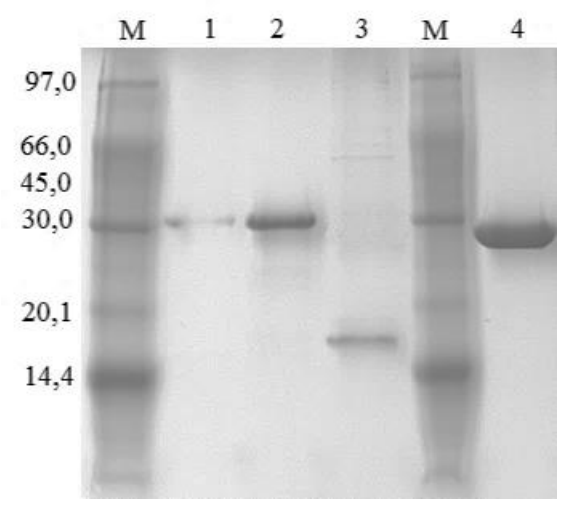

Figura 12- Perfil eletroforético da purificação das espansinas em gel SDS-PAGE 15\%. M - marcador de massa molecular, 1 - Expansina de Bacillus licheniformis, 2- SWO1-domínio catalítico de Trichoderma reesei, 3- Rare lipoprotein de Trichoderma reesei e 4- expansina de Xanthomonas campestris

Fonte: Elaborada pelo autor.

\subsubsection{Ensaios de atividade}

Avaliação da atividade sinérgica das expansinas e CBM2 (Thermogemmatispora sp. T81) associada ao coquetel enzimático Accellerase 1500 (DuPont Industrial Biosciences) sobre papel filtro $\mathrm{N}^{\circ} 1$ Whatman.

O resultado obtido neste experimento com o substrato celulósico papel filtro demonstra que a presença das expansinas e CBM2 (purificação descrita na parte B). A ação conjunta com o coquetel enzimático Accellerase 1500 (Ac) permitiu uma maior disponibilização de açúcares redutores quando comparado com a ação isolada do coquetel (Figura 13). A carga de Accelerase 1500 utilizada por reação foi de $0,007 \mathrm{~g} / \mathrm{L}$ e de expansinas foi de $0,001,0,01$ e $0,1 \mathrm{~g} / \mathrm{L}$ (estoque a $0,005 \mathrm{mg} / \mathrm{ml}$ ). A atividade catalítica isolada das expansinas ou CBM2 nesta concentração é zero, enquanto que o efeito sinérgico (Tabela 10) foi observado para a associação expansinas/CBM e o coquetel enzimático (Accelerase 1500), sendo máximo para a expansina de Xanthomonas campestris e SWO-domínio catalítico de Trichoderma reesei. 


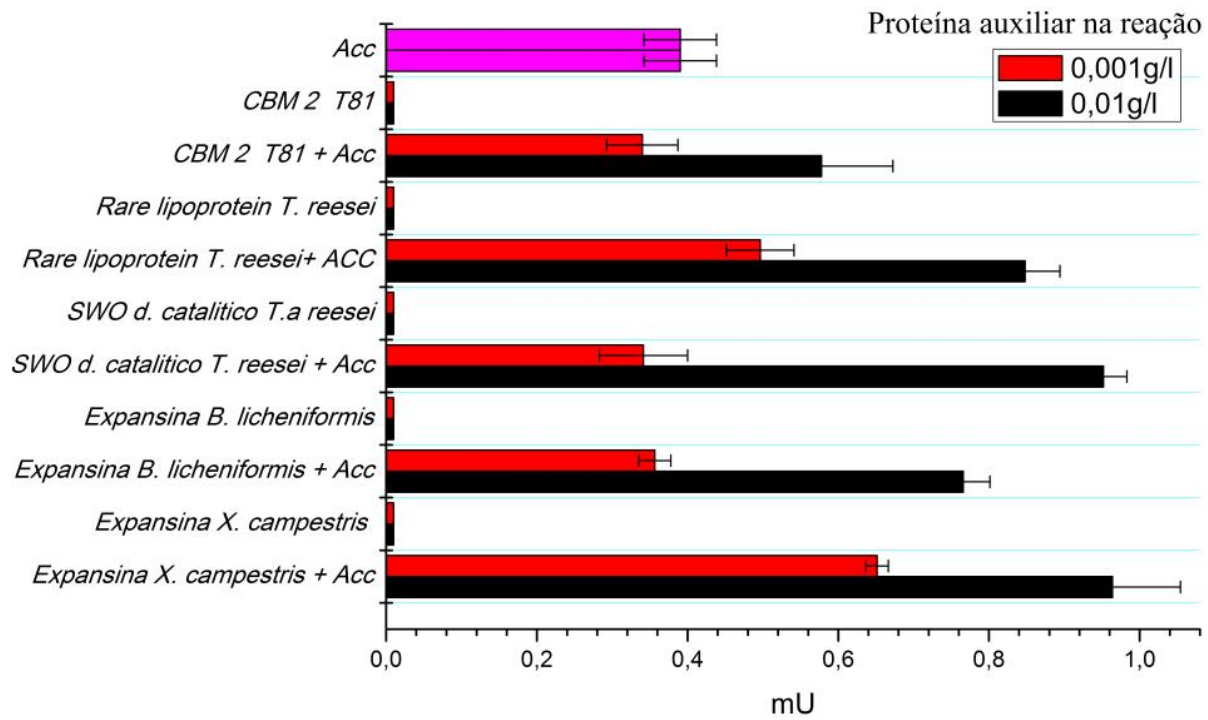

Figura 13-Avaliação da atividade relativa entre a ação do coquetel (Accellerase 1500) atuando sozinho e em conjunto com expansinas sobre papel filtro $\mathrm{N}^{\circ} 1$ da Whatman.

Fonte: Elaborada pelo autor.

O efeito sinérgico para a expansina de Xanthomonas campestris é apresentado em detalhes no APÊNDICE A: "Xanthomonas campestris expansin-like X domain is a structurally disordered beta-sheet macromolecule capable of synergistically enhancing enzymatic efficiency of cellulose hydrolysis", onde é apresentada uma descrição estrutural e de sinergismo desta proteína. 
Tabela 10 - Grau de sinergismo das expansinas em duas concentrações diferentes.

\begin{tabular}{lll}
\hline \multicolumn{1}{c}{ Proteína auxiliar } & \multicolumn{1}{c}{ Sinergismo } & \\
Expansina de Xanthomonas campestris & {[]$=0,05 \mathrm{mg} / \mathrm{ml}$} & {[]$=0,005 \mathrm{mg} / \mathrm{ml}$} \\
Expansina de Bacillus licheniformis & 2,47 & 1,69 \\
SWO1-domínio catalítico Trichoderma reesei & 1,96 & 0,92 \\
Rare lipoprotein Trichoderma reesei & 2,44 & 0,87 \\
CBM 2 Thermogemmatispora sp. T81 & 2,17 & 1,27 \\
\hline
\end{tabular}

Fonte: Elaborada pelo autor.

O mecanismo pelo qual as expansinas proporcionam este aumento na liberação de açúcares ainda não está esclarecido. Porém, existe um consenso de que proteínas sinérgicas modificam a estrutura da celulose cristalina, aumentando a acessibilidade da celulose para a celulases, ${ }^{12}$ ampliando as cavidades da parede celular a partir das ligações de polissacarídeos e perturbando ligações não-covalentes da celulose na parede celular. ${ }^{66 ; 67}$

Avaliação da atividade hidrolítica das expansinas de Xanthomonas campestris, Bacillus licheniformis, SWO1-dominio catalítico (Trichoderma reesei) e domínio de Rare lipoprotrin (Trichoderma reesei).

As atividades catalíticas das expansinas foram avaliadas sobre os substratos celulósicos (papel filtro, CMC, Sigmacell e Avicel) e hemicelulósicos (Xilano e Xiloglucano). Contudo, as proteínas estudadas apresentaram atividade hidrolítica apenas sobre Xilano como apresentado na Figura 14. 


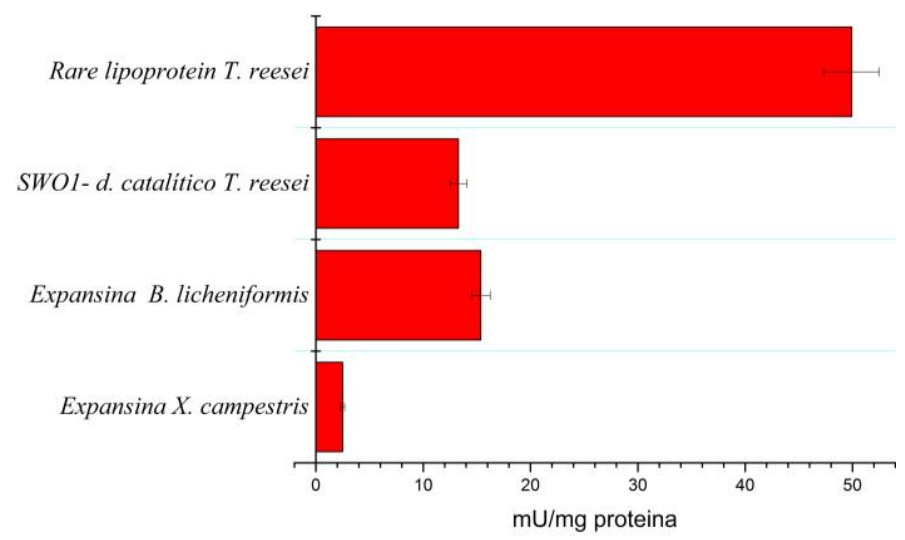

Figura 14 - Atividade hidrolítica das expansinas sobre xilano $(1 \% \mathrm{~m} / \mathrm{V})$ por $24 \mathrm{~h}, 50^{\circ} \mathrm{C}$ e $1000 \mathrm{rpm}$. Utilizando por reação de SWO1 d. catalítico T reesei, Expansina de B. licheniformis ou Expansina de X. campestris $0,08 \mathrm{mg}(=33 \mathrm{uM})$ de proteína e para a reação de Rare lipoprotein de $T$. reesei $0,02 \mathrm{mg}(=18 \mathrm{uM}) \mathrm{de}$ proteína.

Fonte: Elaborada pelo autor.

Observou-se que a atividade específica ( $\mathrm{mU} / \mathrm{mg}$ de proteína) foi máxima para o domínio de Rare lipoprotein de Trichoderma reesei e as Expansin-like de Bacillus licheniformis e Xanthomonas campestris e a Swolenina de Trichoderma reesei apresentaram respectivamente ganhos de $61 \%, 10 \%$ e $53 \%$ com relação a atividade máxima.

\subsubsection{Modelos estruturais por homologia.}

A estrutura da expansina de Xanthomonas campestris foi determinada pelos autores em trabalho anterior ${ }^{29}$. Utilizando o servidor Phyre 2 foi construído por homologia modelos estruturais das proteínas em estudo. A expansina de Bacillus subtillis obtemos um modelo com 100\% de cobertura e confiança que se baseou na estrutura PDB 3D30 (Expansinlike de Bacillus subtilis) que possui $86 \%$ de identidade sequencial. Para a SWO1-domínio catalítico de Trichoderma reesei foi obtido um modelo com $100 \%$ de confiança e $74 \%$ de cobertura, que se baseou na estrutura PDB 1N10 (Grass pollen allergen de Phleum pratense), que possui 30\% de identidade sequencial, e para o domínio de Rare lipoprotein de Trichoderma reesei foi obtido um modelo com $100 \%$ de confiança e $89 \%$ de cobertura que se baseou na 
estrutura PDB 4JCW (expansina de Clavibacter michiganensis) que possui 30\% de identidade sequencial. Na Figura 15 apresentamos a superposição entre os modelos estruturais obtidos por homologia com a GH45 de Phanerochaete chrysosporium (PcCel45A) PDB 3X2M, que será discutido a seguir. 

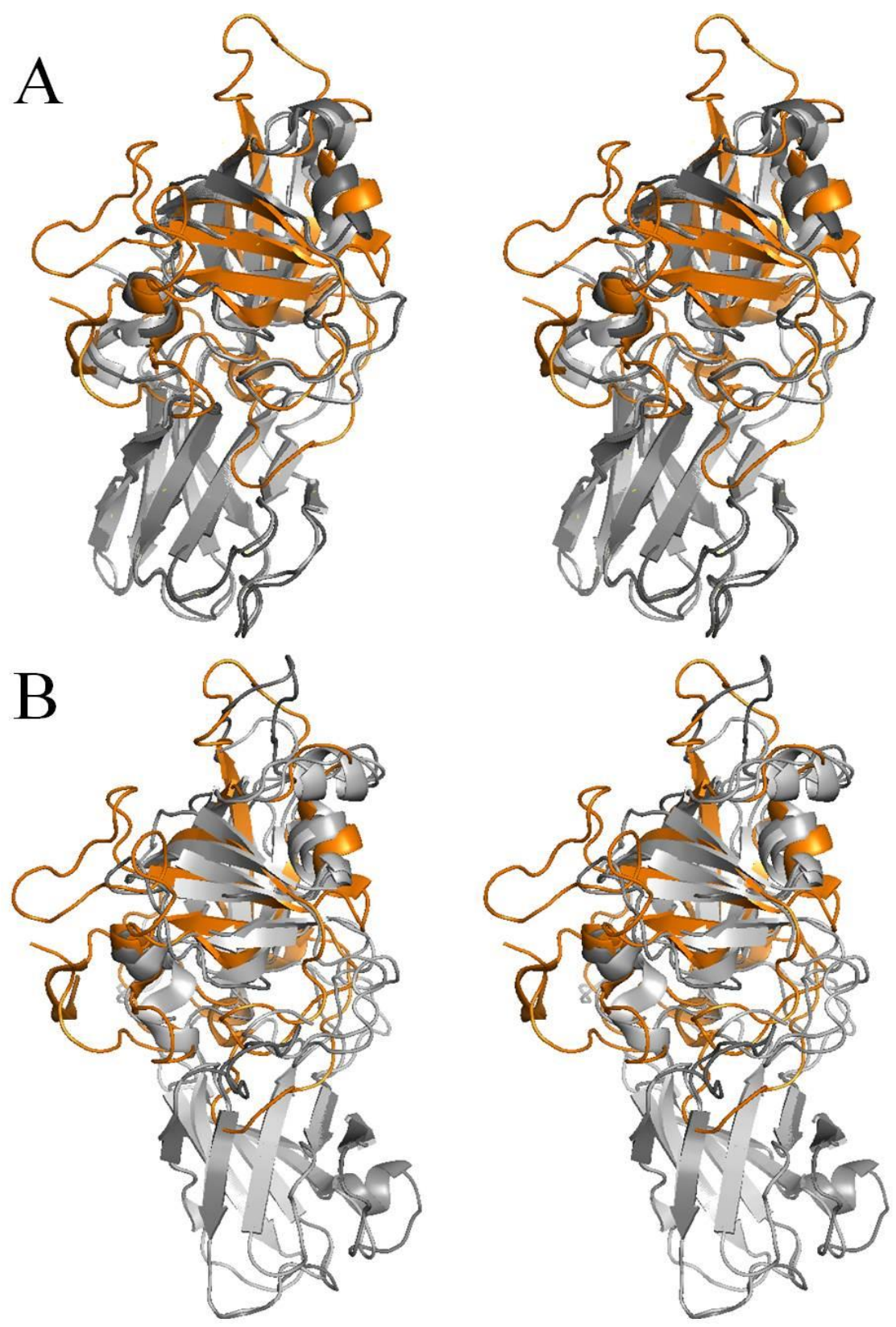

Figura 15- Visão estéreo da sobreposição entre a estrutura dos modelos obtidos por cristalografia e homologia, dando enfoque para a conservação do domínio 1 (Rare lipoprotein) conservado em expansinas e nas GH45 da família C. A - PDB 3X2M (alaranjado) e os modelos cristalográficos de expansinas bacterianas: Xanthmonas campestris (PDBid 3D30) e modelo por homologia de Bacillus licheniformis em gradiente de cinza. B - PDB 3X2M (alanranjado) e os modelos cristalográficos de expansinas fúngicas: modelo estrutural por homologia para SWO1-dominio catalítico Trichoderma reesei, modelo estrutural por homologia de Rare lipoprotein de Trichoderma reesei e PDBid 1N10 em gradiente de cinza.

Fonte: Elaborada pelo autor. 
A correlação entre as proteínas em estudo foi obtida com o programa Mega $6^{39}$ (Figura 16) na qual se observa a separação em dois grupos: bacterianas e fúngicas. As expansinas bacterianas nomeadas como proteínas semelhantes às expansinas ${ }^{27}$ (Expansin-like) apresentam como estrutura típica um domínio de Rare lipoprotein e um domínio Grass pollen alergen assim como suas homólogas de plantas nomeadas como expansinas ${ }^{27}$ (Expansin). Já para as expansinas de origem fúngica nomeadas como swoleninas ${ }^{27}$ (Swolenin), essas apresentam o domínio CBM. ${ }^{12}$

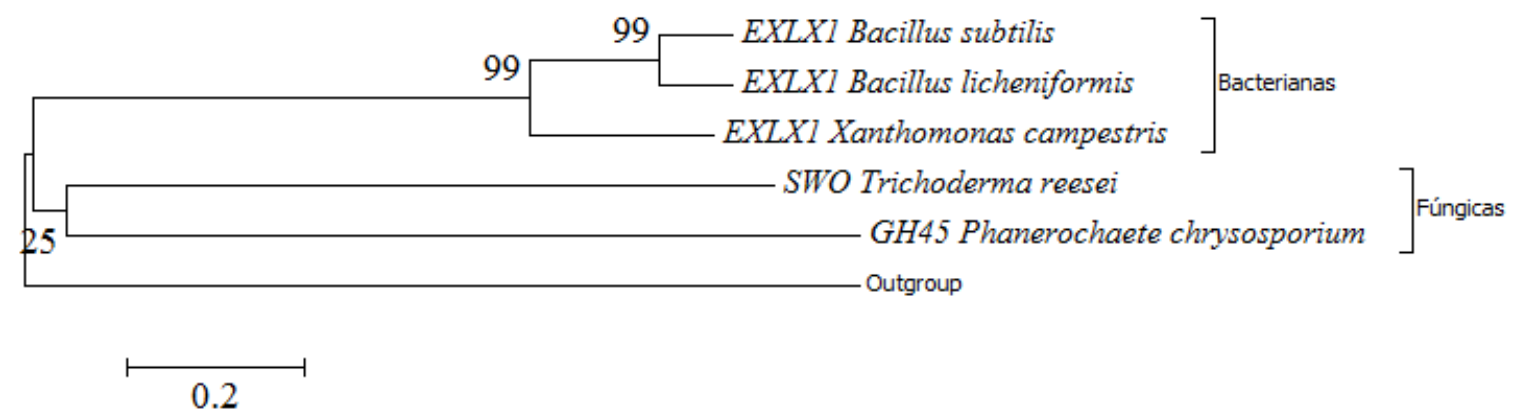

Figura 16 -Árvore de identidade sequencial obtida com o algoritmo Neighbour-joining para expansina (Expansinlike) de Bacillus lichenisformis e Xanthomonas campestris, SWO1-sítio catalítico de Trichoderma reesei e a GH 45 de Phanerochaete chrysosporium. Testes com 10000 repetições foram conduzidos com um grupo controle para examiner a qualidade do modelo.

Fonte: Elaborada pelo autor.

As arquiteturas estruturais das Expansin-like de Xanthomonas campestris, Bacillus licheniformis e da SWO1-domínio catalítico de Trichoderma reesei são compostas por dois domínios: o primeiro (D1) formado por um Duplo- $\Psi \beta$-barril de 6-fitas (6-stranded Double- $\Psi \beta$ barrel), comum em várias famílias de proteínas $^{29}$, e o segundo (D2) formado por um Ig-like $\beta$ sandwich. Já o domínio de Rare liproprotein é forma apenas pelo D1.

O domínio D1 apresenta o mesmo enovelamento estrutural das proteínas da família GH45 sub-família C. Recentemente o mecanismo de hidrólise desta família de proteínas foi proposto por Igarashi et al, ${ }^{68}$ onde a díade catalítica N92 e D114 na GH45 de Phanerochaete 
chrysosporium (PcCel45A; PDBid 3X2M) seria completada por outros 6 resíduos de aminoácidos, que em conjunto formariam uma cadeia de transferência de elétrons (Pêndulo de Newton) criando as condições para hidrólise.

A atividade hidrolítica sobre xilano (Figura 14) apresentada pelas expansinas em estudo desperta a necessidade de proposição ou explicação do mecanismo envolvido para esta atividade hidrolítica. Além disso, Saloheimo et al, ${ }^{69}$ demonstrou a presença de atividade endoglucalítica e de celobiohidrolase para a SWO1-domínio catalítica (produzida com glicosilações diferente da descrita neste trabalho, produzida em sistema bacteriano) de Trichoderma reesei, porém não propôs nenhum mecanismo envolvido ou atribuído para tal atividade.

Desta maneira, os resultados obtidos para a atividade catalítica das proteínas auxiliares e a semelhança estrutural com as GH45 da família C, que tiveram o mecanismo de hidrólise elucidado, possibilitam inferir algumas sugestões para o mecanismo de hidrólise das expansinas. Para isto, o primeiro passo foi o alinhamento sequencial das proteínas em estudo com a $P c$ Cel45A, obtidos com o servidor $\mathrm{T}$-Coffee ${ }^{40}$, o que possibilitou a identificação de resíduos conservados, ilustrados na Figura 17 para as fúngicas na Figura 18 para as bacterianas.

Os resíduos catalíticos presentes em $P c$ Cel45A estão destacados na Figura 17, observase também que os mesmos resíduos são conservados na sequência da SWO1-domínio catalítico. Já para o alinhamento das swoleninas bacterianas com $P c$ Cel45A, observa-se que o resíduo catalítico N92 encontra-se numa região ausente para as bacterianas. 
T-COFFEE, Version_11.00.d625267 (2016-01-11 15:25:41 - Revision d625267 - Build 507)

Cedric Notredame

$\mathrm{SCORE}=55$

BAD AVG GOOD

$\begin{array}{llr}\text { SWO1_d.cat_T_re } & : & 55 \\ \text { GH45_P_chrysosp } & : & 55 \\ \text { cons } & : & 5\end{array}$

SWO1_d.cat_T_re

作

GH45_P_chrysosp

ATGGYVQQATGQASFTMYSGCGSPACGKAASGFTAAINQLAFGSAPG-LGAGDACGRCFALTG

cons

. * $\quad:{ }^{*} \cdot{ }^{*}: *$
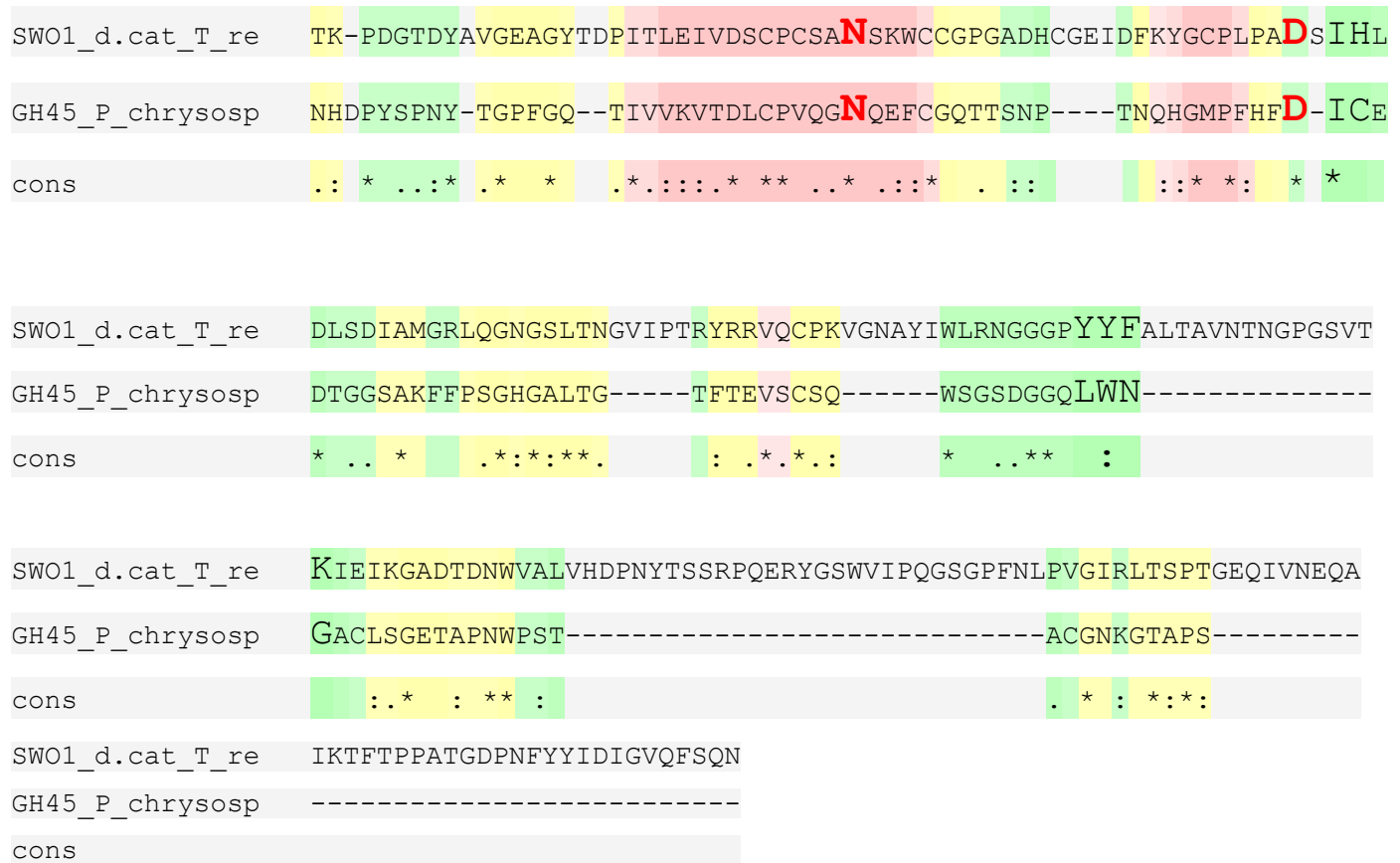

Figura 17 - Alinhamento sequencial para SWO1-domínio catalítico de Trichoderma reesei com a GH45 de Phanerochaete chrysosporium, em destaque os aminoácidos catalíticos da GH45 e os possíveis aminoácidos catalítcos das expansinas. Obtidos com o servidor T-Coffee. ${ }^{40}$

Fonte: Elaborada pelo autor. 
T-COFFEE, Version_11.00.d625267 (2016-01-11 15:25:41 - Revision d625267 - Build 507)

Cedric Notredame

$\begin{array}{lll}\text { SCORE }=99 & & \\ \text { BAD AVG GOOD } & & \\ \text { Exp_B_subtilis } & : & 99 \\ \text { Exp_X_campestri : } & 99 \\ \text { Exp_B_lichenifo : } & 99 \\ \text { GH45_P_chrysosp : } & 99 \\ \text { cons } & : & 9\end{array}$

Exp_B_subtilis ----MAYDDLHEGYATYTGSGYSGGAFLLDPIPSDMEITAINPADLNY--GGVKAALAGSYLE

Exp_X_campestri -----PWNSTFTGTATVTGSGYSGGALLLDPIPSDAFITALNPVQLNF--GGVKAALAGAYLQ

Exp_B_lichenifo ----AYNSLHTGYATYTGSGYSGGALLLDPIPSNMKITALNPTDMNY--RGVKAALAGAYLR GH45_P_chrysosp ATGGYVQQATGQASFTMYSGC-GSPACGKA---ASGFTAAINQLAFGSAPGLGAGDACGRCFA

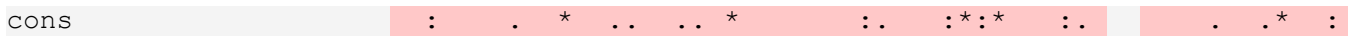

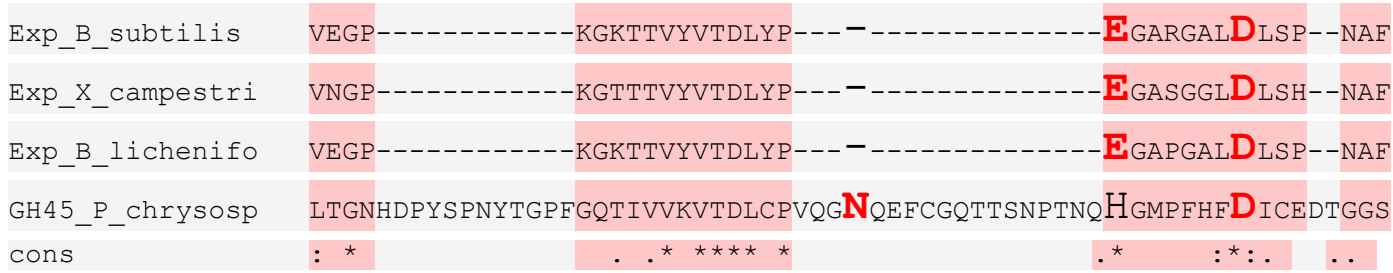

Exp_B_subtilis

Exp_X_campestri

Exp_B_lichenifo

GH $4 \overline{5}$ _ ${ }_{-}$chrysosp

cons

Exp_B_subtilis

Exp_X_campestri

Exp B lichenifo

GH $4 \overline{5}$ _ ${ }^{-}$_chrysosp

cons
RKIGNMKDGKINIKWRVVKAPITGNFTYRIKEGSSRWWAAIQVRNHKYPVMKMEYEKDGK-WI AAIGDMVQGRIPISWKVVRAPVTGNLQYRIKEGSSRWWAAIQVRNHAYPVVKLEV-KQGSTWK REIGDMKDGKIDIKWRIVKAPITGNFTYRIKEGSSQWWAAIQVRNHKY PVMKMEYYKDGK-WI AKFFPSGHGALTGTFTEVSCSQWSGSDGGQLWNGACLSGETAPNWPSTACGNKGTAPS-----

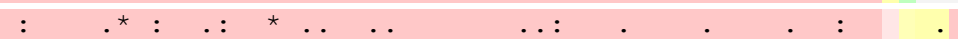

NMEKMDYNHFVSTNLGTGSLKVRMTDIRGKVVKDTI PKLPESGTSKAYTVPGHVQFPE NLQKMDYNHFLGEQLGNQPLTLRITDIRGKVLTDTLPRLPEDGSKPAYFEPGHVQFPNMEKTDYNHFVSTNLGTSPLKVRITDIRGKVVKDTIKKLPENGTSSAYTVPGKVQFPD

Figura 18 - Alinhamento sequencial para Expansin-like de Bacillus subtillis, Bacillus licheniformis, Xanthomonas campestris e a GH45 de Phanerochaete chrysosporium, em destaque os aminoácidos catalítico da GH45 e os possíveis aminoácidos catalítcos das expansinas. Obtidos com o servidor T-Coffee. ${ }^{40}$

Fonte: Elaborada pelo autor. 
A partir de um alinhamento estrutural buscou-se a conservação dos resíduos identificados como catalíticos por Igarashi ${ }^{68}$ na PcCel45A. O alinhamento estrutural do modelo SWO1domínio catalítico e do domínio de Rare lipoprotein de Trichoderma reesei com a estrutura de PcCel45A (PDBid 3X2M) não possibilitou identificar a díade catalítica. Isso provavelmente se deve à baixa identidade do molde utilizado para geração do modelo, levando a uma estrutura que não retrata a real posição dos resíduos ou pela ausência da referida díade nas expansinas fúngicas estudadas.

Já para o alinhamento estrutural das expansinas bacterianas com a estrutura de PcCel45A (PDBid 3X2M) foi possível uma melhor interpretação. O modelo estrutural da expansina de Bacillus licheniformis foi obtida utilizando-se como molde a expansina de Xanthomonas campestris $^{29}$ com identidade sequencial de $88 \%$, possibilitando uma interpretação mais realística. Assim, observando-se a sobreposição entre as expansina bacterianas e PcCel45A observa-se uma correspondência estrutural com o domínio de Rare lipoprotein (Figura 15 A e Figura 19).

Analisando a sobreposição estrutural com enfoque para o recente sítio catalítico proposto por Igarashi ${ }^{68}$ (Figura 20) tem-se que a díade catalítica identificada corresponde aos resíduos Asp 81- Glu74 na expansina de Xanthomonas campestris. Estes resíduos remetem ao mecanismo clássico de hidrólise característico da sub-família A das GH45 e de outras família de hidrolases de glicosídeos, presente na família GH 11 (presença de dois ácidos glutâmicos no sítio catalítico). 


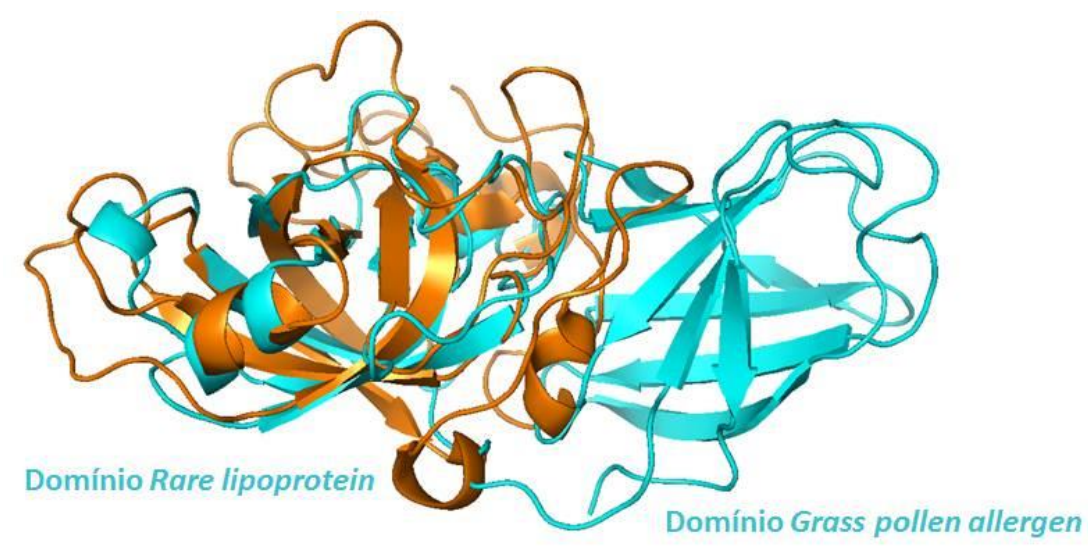

Figura 19 - Sobreposição estrutural da expansina (Expansin-like) de Xanthomonas campestris na cor ciano com a PcCel45A na cor laranja.

Fonte: Elaborada pelo autor.

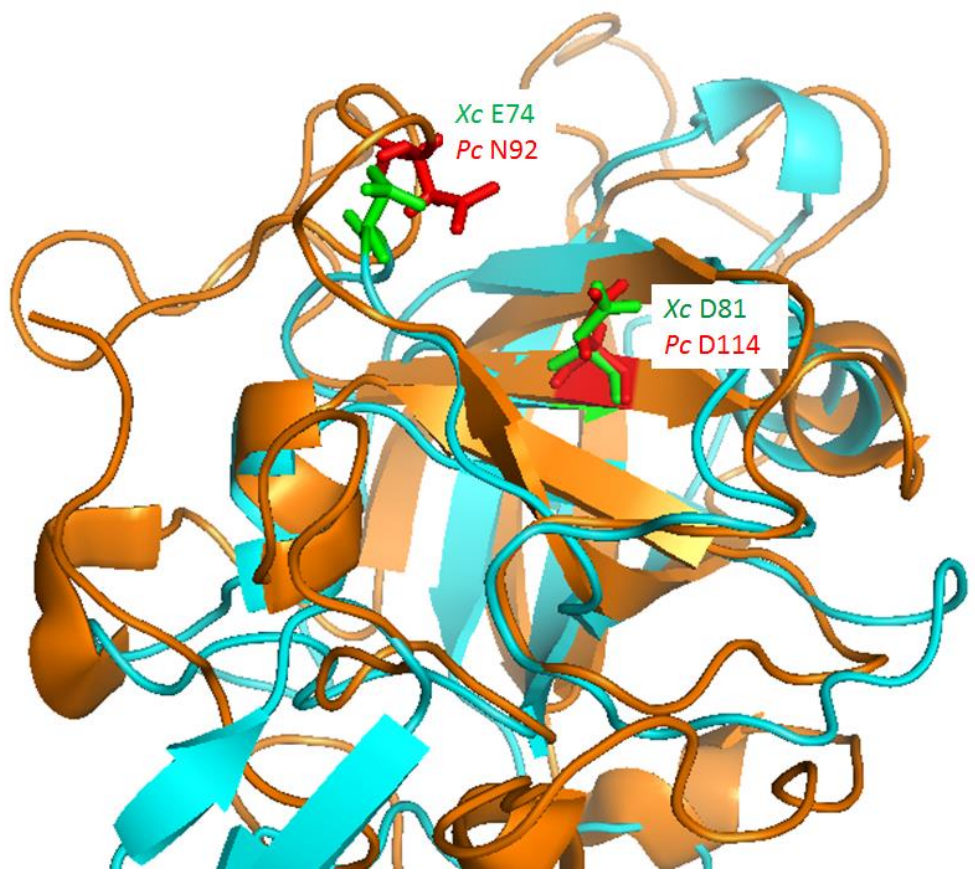

Figura 20 - Sobreposição estrutural da Expansin-like de Xanthomonas campestris na cor ciano com a PcCel45A na cor laranja, destacando em vermelho os resíduos catalíticos da GH45 de Phanerochaete chrysosporium e em verde os resíduos propostos como catalíticos em Xanthomonas campestris.

Fonte: Elaborada pelo autor. 
Igarashi e colaboradores realizaram também a mutação sítio dirigida N92D, observando que a atividade catalítica diminuía, porém uma pequena quantidade de produto ainda era detectável. Este resultado permite reforçar a hipótese de que E74 e D81 são os verdadeiros resíduos catalíticos de $X$. campestris.

\subsubsection{Cromatografia em camada delgada (CCD) ou Thin-layer chromatography (TLC)}

Os produtos de hidrólise das expansinas utilizando xilano como substrato (Figura 14) foram avaliados pela técnica de cromatografia de camada delgada ( Figura 21).

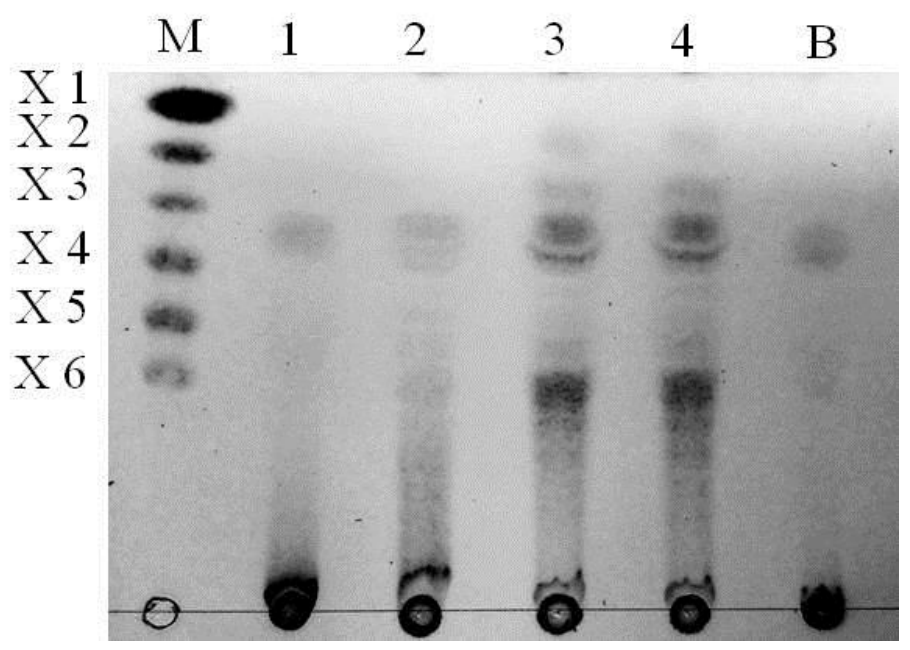

. Figura 21 - Cromatografia em camada delgada do perfil de degradação dos oligossacarídeos para as expansinas. Cada linha corresponde: M, marcadores de oligossacarídeos, X1 (xilose), X2 (xilobiose), X3( xilotriose), X4 (xilotetraose), X5(xilopentaose) e X6 (xilohaxaoese), 1: Expansin-like de Xanthomonas campestris, 2: Expansin-like de Bacillus licheniformis, 3: SWO-domínio catalítico de Trichoderma reesei, 4: Rare lipoprotein Trichoderma reesei e B: branco, substrato da reação

Fonte: Elaborada pelo autor.

A TLC da expansina (Expansin-like) de Xanthomonas campestris apresentou xilooligossacarídeos com grau de polimerização maior do que seis e sem definição para um oligo de tamanho específico. Este perfil de hidrólise se apresentou com baixa concentração em função da baixa atividade catalítica da enzima. Por outro lado, a Expansin-like de Bacillus licheniformis 
mostrou um padrão de clivagem semelhante, contudo com maior intensidade relativo a uma maior atividade enzimática.

O SWO1-dominio catalítico e Rare lipoprotein de Trichoderma reesei apresentaram padrões de xilo-oligossacarideos mais definidos para xilobiose a xilohexaose. A amostra referente ao substrato (branco) apresenta uma banda artefato correspondente à possível migração de xilotriose. 


\subsubsection{Dicroísmo circular (CD)}

Na Figura 22 temos o espectro de CD na região do UV distante para as expansinas de Xanthomonas campestris (ExX), Trichoderma reesei (ExT) e Bacillus licheniformis (ExB).

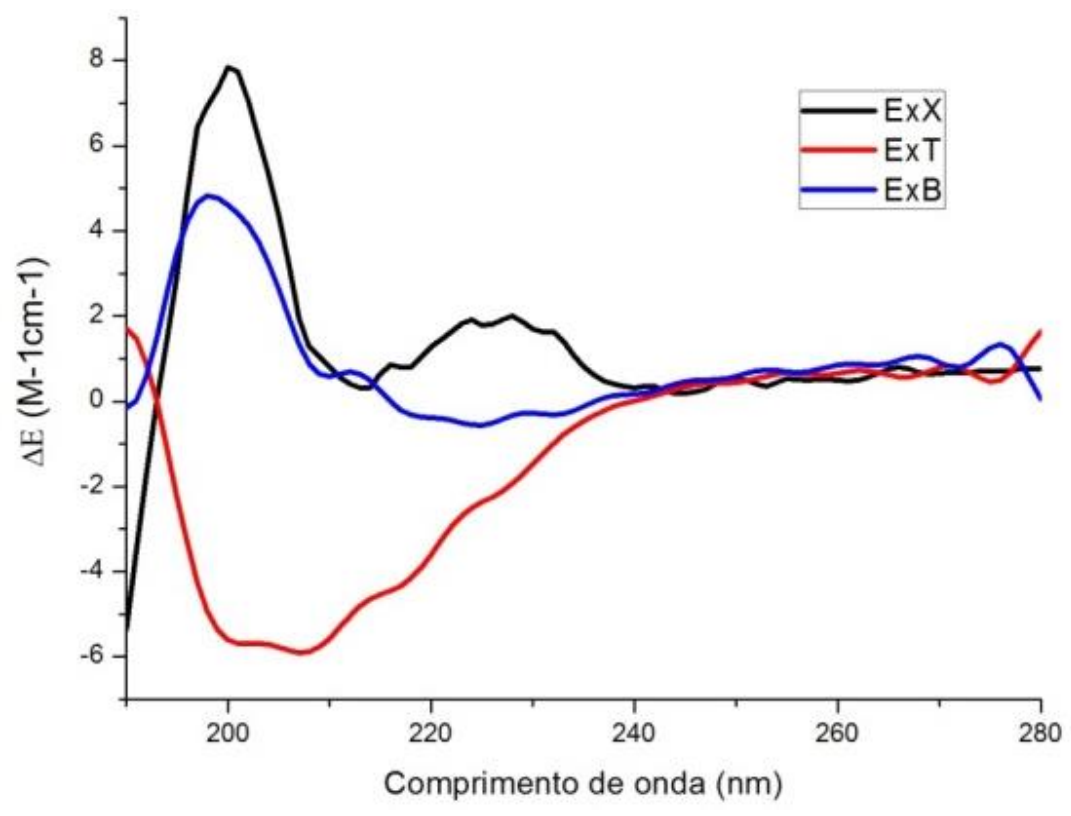

Figura 22 - Espectros de CD das proteínas similar a expansina de Xanthomonas campestris (ExX), proteína similar a expansina de Trichoderma reesei (ExT) e a proteína similar a expansina de Bacillus licheniformis $(\mathrm{ExB})$.

Fonte: Elaborada pelo autor.

A ExX foi obtida como descrita em Tomazini et. $A 1 .{ }^{29}$ No espectro de ExX observamos um mínimo evidente próximo a $208 \mathrm{~nm}$ devido a uma transição do tipo $\pi \rightarrow \pi^{*}$ e outro máximo em torno de $226 \mathrm{~nm}$. A existência deste tipo de máximo ainda não está esclarecida. Porém, uma explicação deste pico positivo em $226 \mathrm{~nm}$ seja a presença de resíduos aromáticos que contribuem para um espectro positivo entre 230 e $215 \mathrm{~nm}$. É conhecido que a interação entre aminoácidos aromáticos pode resultar em um sinal no UV distante, que alteraria as análises de estrutura secundaria por $\mathrm{CD}{ }^{70}$ 
No espectro de ExT observamos um mínimo em 208 nm, típica de uma transição fraca do $\pi \rightarrow \pi^{*}(\sim 208-210 \mathrm{~nm})$, paralela ao eixo da hélice, que consiste de uma transição característica de $\alpha$-hélice. Outra evidência do espectro é uma banda positiva entre 200 e $190 \mathrm{~nm}$ típica de contribuição de folhas $\beta$ e um perfil altamente desordenado, o que faz com que haja a diminuição do sinal de estruturas ordenadas como $\alpha$-hélice.

Tabela 11 - Proporção de estruturas secundárias obtidas a partir dos espectros de CD, desconvoluídos.

\begin{tabular}{lcccccc}
\hline \multicolumn{1}{c}{ Proteína } & $\begin{array}{c}\text { Hélices } \\
\boldsymbol{\alpha}(\boldsymbol{\%})\end{array}$ & $\begin{array}{l}\text { Folhas } \\
\boldsymbol{\beta}(\%)\end{array}$ & $\begin{array}{l}\text { Outros (voltas e } \\
\text { desordenada) } \\
(\%)\end{array}$ & RMSD & Algoritmo \\
(base de dados) \\
$\begin{array}{l}\text { Expansina- } \\
\begin{array}{l}\text { Xantomonas } \\
\text { campestris }\end{array}\end{array}$ & 9 & 51 & 32 & 0,115 & Selcon3 (database 7) \\
$\begin{array}{l}\text { SWO1- domínio } \\
\text { catalítico T. reesei }\end{array}$ & 7 & 36 & 57 & 0,160 & Contin (database 4) \\
$\begin{array}{l}\text { Expansina- Bacillus } \\
\text { licheniformis }\end{array}$ & 7 & 41 & 51 & 0,223 & Contin (SP 175) \\
\hline
\end{tabular}

Observação: Predição de estruturas desordenadas pelos programas FoldIndex e GlobPlot2 indicaram que ExX, ExT e ExB possuem 44, 50 e 53\% de estruturas desordendas, respectivamente.

Fonte: Elaborada pelo autor.

A desconvolução dos espectros de dicroísmo circular está apresentada na Tabela 11. Os resultados estão em conformidade com o esperado teoricamente para estruturas desordenadas (programas FoldIndex ${ }^{71}$ e GlobPlot $2^{72}$ ), que predisseram frações de estruturas desordenadas próximas a 50\% para as proteínas ExX, ExB e ExT.

A pequena discrepância entre as porcentagens de estruturas secundárias preditas e experimentais se deve à baixa quantidade de espectros de proteínas com estrutura altamente desordenadas nas bases de dados (SP175, database 4 e 7). Além disso, existe a correspondência entre as estruturas tridimensionais das proteínas de referência obtidas a partir da cristalografia de Raios-X e a organização estrutural das mesmas em solução aquosa. Somado a isso temos as próprias limitações técnicas na preparação da amostra como qualidade da proteína no tampão 
utilizado e até mesmo limitações do equipamento, como equilíbrio de gases na cela de coleta que podem interferir na qualidade dos dados coletados. 


\subsection{PARTE B}

\subsubsection{Bactéria e condições de crescimento}

A bactéria Thermogemmatispora sp. cepa T81 foi reativada após cinco meses estocada a $4^{\circ} \mathrm{C}$ onde encontrava-se em estado latente. O primeiro teste foi repicar a cultura em meio mínimo AOM1 liquido e sólido, contudo após diversas tentativas o microrganismo não apresentou crescimento. A Tabela 12 mostra dados referentes às tentativas iniciais, onde foi verificada a liberação de gás carbônico pela cultura de T81, medidas com o uso da cromatografia gasosa com o organismo cultivado em garrafas do tipo Penicilina seladas.

Tabela 12 - Concentração de $\mathrm{CO}_{2}$ medida utilizando a cromatografia gasosa

\begin{tabular}{ccc}
\hline Tempo (dia) & $\begin{array}{r}\text { AOM1(suplementado com 2 } \\
\text { g/L de glicose) }\left(\boldsymbol{\mu V} \text {.Minarea } \mathbf{C O}_{\mathbf{2}}\right)\end{array}$ & $\begin{array}{c}\text { AOM1(suplementado com 2 g/L } \\
\text { de celobiose }(\boldsymbol{\mu} \text { V.Minarea CO2) }\end{array}$ \\
$\mathbf{1}$ & 4,86 & 2,93 \\
$\mathbf{2}$ & 6,65 & 4,34 \\
$\mathbf{3}$ & 9,38 & 6,19 \\
$\mathbf{7}$ & 13,81 & 6,56 \\
\hline
\end{tabular}

Fonte: Elaborada pelo autor.

A concentração crescente de $\mathrm{CO}_{2}$ ao longo do tempo evidenciou a presença de metabolismo celular, contudo a cultura não apresentou nenhum ganho em termos de biomassa, permanecendo sem crescimento evidente. Buscando-se ativar o crescimento, o meio AOM1 foi preparado em $\mathrm{pH} 5,5,5$ e 6,5, e avaliadas as temperaturas de 60 e $70^{\circ} \mathrm{C}$, porém sem ganhos de biomassa no crescimento.

Procedeu-se também com a inoculação da cultura em meio sólido no qual se avaliou: meio AOM1 com ágar nos pHs 5,5 e pH 6,5 e meio AOM1 com fitagel nos pHs 5,5 e pH 6,5. Após diversos testes, foi evidenciado o crescimento de uma colônia na condição meio AOM1 com fitagel, pH 5,5. Esta colônia foi repicada em outras placas (Figura 23A) e a partir dela foi 
possível a transferência para meio líquido (Figura 23B) tratando-se do meio mínimo AOM1 com $20 \mathrm{~g} / \mathrm{L}$ de extrato de levedura.
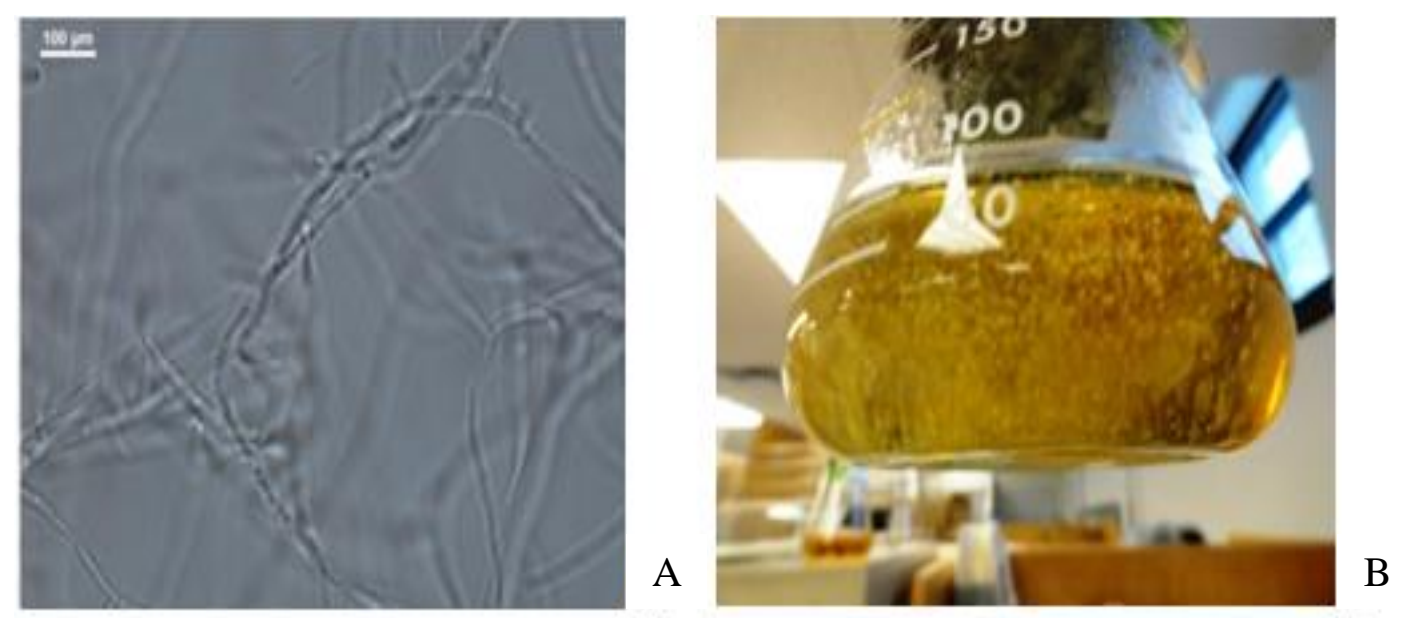

Figura 23 - Imagens da bactéria Thermogemmatispora sp. cepa T81. A) Imagem de microscopia óptica sem corantes ou fixadores, B) em meio líquido AOM1 com $20 \mathrm{~g} / \mathrm{L}$ de extrato de levedura.

Fonte: Elaborada pelo autor.

A bactéria Thermogemmatispora sp. em meio de cultura apresenta morfologia filamentosa com formações de esporo (Figura 23B).

\subsubsection{Confirmação do organismo de estudo}

\section{Extração do DNA}

O protocolo Charge Switch gDNA Mini Bacteria Kit (Life Technologies) com a modificação advinda da etapa de lise celular utilizando o Mini beadbeater (BioSpec) apresentou-se sendo o melhor meio para extração do DNA genômico da Thermogemmatispora $s p$. cepa T81. Devido à morfologia filamentosa da bactéria, o uso de um volume de $5 \mathrm{ml}$ de meio de cultura foi necessário. 


\section{PCR utilizando oligonucleotídeos universais para a sequência CPN60}

As sequências dos DNAs amplificados foram alinhadas com a sequência do locus gênico 2503255124 chaperonin GroL de T81 utilizando a ferramenta Clustal X. ${ }^{33}$ Como resultado do alinhamento obteve-se 100\% de homologia entre o amplificado e a sequência CPN60.

Com este resultado ficou confirmado que a bactéria de estudo era a Thermogemmatispora sp. cepa T81, permitindo-se a continuidade dos estudos para caracterização da bactéria.

\subsubsection{Análises Filogenéticas}

A árvore filogenética baseada na sequiência do gene universal cpn60 (UP) foi utilizada para estabelecer as relações evolutivas entre a Thermogemmatispora sp. e outras bactérias do grupo Chloroflexi, além de confirmar que Thermogemmatispora sp. T81 é um membro do filo Chloroflexi (Figura 24). 


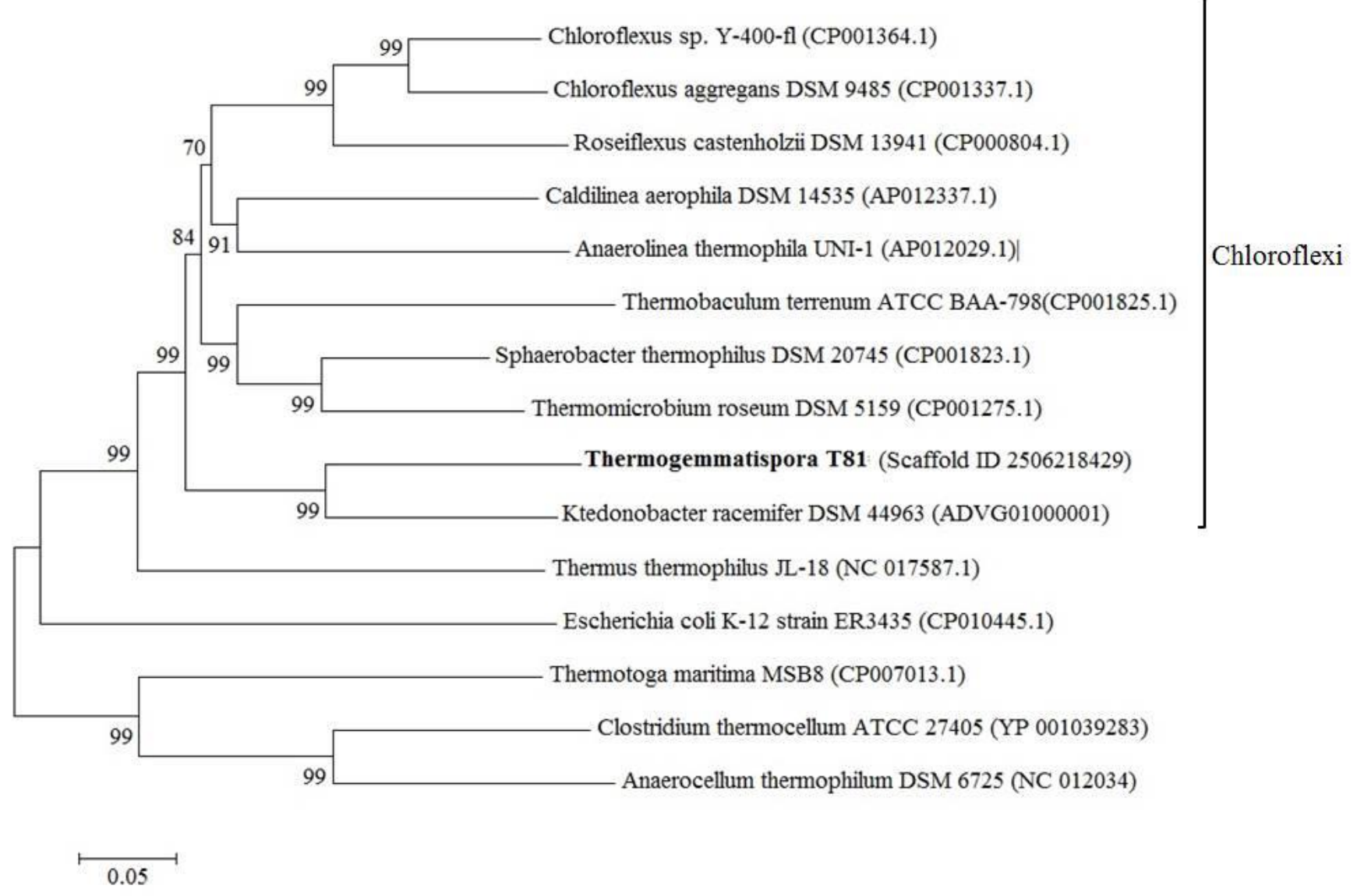

Figura 24 - Árvore filogenética utilizando o algoritmo Neighbour-joining com base nas sequências do gene cpn60 para as espécies selecionadas. Testes com 10000 repetições foram conduzidos para examinar a confiabilidade dos ramos interiores.

Fonte: Elaborada pelo autor.

\subsubsection{Análises Genômicas}

O genoma de Thermogemmatispora sp. T81 possui 5,97 megabases (Mb) com 4793 genes anotados, dos quais 4738 são codificares de proteínas. Comparando o genoma da Thermogemmatispora sp. T81 com as demais bactérias do filo Chloroflexi selecionadas (Tabela 13) tem-se que apenas o genoma de Ktedonobacter racemifer é maior com 13,66 Mb, 12147 genes preditos e 11453 genes codificadores de proteína. O menor genoma entre as bactérias 
analisadas temos a Thermotoga maritima MSB8 com um genoma 1,86 Mb com 1928 genes dos quais 1858 são codificadores de proteínas.

Tabela 13 - Características gerais dos genomas de Thermogemmatispora sp. T81 e de outras bactérias do grupo Chloroflexi (em ordem ascendente de tamanho do genoma).

\begin{tabular}{|c|c|c|c|c|}
\hline Espécie & $\begin{array}{l}\text { Tamanho do } \\
\text { genoma (Mb) }\end{array}$ & $\begin{array}{l}\% \\
\text { GC }\end{array}$ & $\begin{array}{l}\text { Número } \\
\text { de genes }\end{array}$ & $\begin{array}{l}\text { Número de genes } \\
\text { codificantes de } \\
\text { protéina }\end{array}$ \\
\hline Thermotoga maritima MSB 8 & $1,, 86$ & 46,2 & 1928 & 1858 \\
\hline Thermus thermophilus JL-18 & 2,14 & 69,3 & 2245 & 2173 \\
\hline $\begin{array}{c}\text { Thermomicrobium roseum } \\
\text { DSM } 5159\end{array}$ & 2,92 & 64,2 & 2664 & 2559 \\
\hline $\begin{array}{c}\text { Anaerocellum thermophilum } \\
\text { DSM } 6725\end{array}$ & 2,93 & 35,2 & 2803 & 2619 \\
\hline $\begin{array}{c}\text { Thermobaculum terrenum } \\
\text { ATCC BAA-798 }\end{array}$ & 3,10 & 53,5 & 2883 & 2786 \\
\hline $\begin{array}{c}\text { Anaerolinea thermophila } \\
\text { UNI-1 }\end{array}$ & 3,53 & 53,8 & 3165 & 3064 \\
\hline $\begin{array}{c}\text { Clostridium thermocellum } \\
\text { ATCC } 27405\end{array}$ & 3,84 & 39,0 & 3376 & 3224 \\
\hline $\begin{array}{c}\text { Sphaerobacter thermophilus } \\
\text { DSM } 20745\end{array}$ & 3,99 & 68,1 & 3507 & 3403 \\
\hline $\begin{array}{c}\text { Chloroflexus aggregans } \\
\text { DSM } 9485\end{array}$ & 4,68 & 56,4 & 3828 & 3679 \\
\hline $\begin{array}{c}\text { Caldilinea aerophila DSM } \\
14535\end{array}$ & 5,14 & 58,8 & 4095 & 3954 \\
\hline Chloroflexus sp Y-400-fl & 5,27 & 56,7 & 4122 & 3989 \\
\hline $\begin{array}{c}\text { Roseiflexus castenholzii } \\
\text { DSM } 13941\end{array}$ & 5,72 & 60,7 & 4601 & 4492 \\
\hline $\begin{array}{c}\text { Thermogemmatispora sp. } \\
\text { T81 }\end{array}$ & 5,97 & 59,9 & 4793 & 4738 \\
\hline
\end{tabular}

Fonte: Obtida pelo autor.

\subsubsection{Anotações de Cazymes}

A partir da anotação do genoma da Thermogemmatispora sp. T81 foi identificado um elevado número de genes codificadores de CAZymes (Carbohydrate-Active enZYmes: enzimas 
que degradam carboidratos) extracelulares em comparação com as demais Chloroflexi e com o grupo de teste (outgroup) selecionado (Tabela 14).

Tabela 14 - Analise comparativa do número de CAZymes por família codificada pelo grupo de bactérias Chloroflexi selecionada.

\begin{tabular}{|c|c|c|c|c|c|c|c|c|}
\hline Espécie & GH & GT & $\begin{array}{l}\mathbf{P} \\
\mathbf{L}\end{array}$ & $\mathrm{CE}$ & $\overline{\mathbf{A A}}$ & CBM & Total & $\begin{array}{l}\text { Genes codificadores } \\
\text { para CAZymes* } \\
\text { extracelular. }\end{array}$ \\
\hline $\begin{array}{c}\text { Chloroflexus sp Y-400- } \\
\text { fl }\end{array}$ & 50 & 100 & & 5 & & 11 & 166 & 2 \\
\hline $\begin{array}{c}\text { Chloroflexus aggregans } \\
\text { DSM } 9485\end{array}$ & 47 & 98 & & 4 & & 9 & 158 & 0 \\
\hline $\begin{array}{l}\text { Roseiflexus castenholzii } \\
\text { DSM } 13941\end{array}$ & 55 & 127 & 2 & 12 & & 9 & 205 & 0 \\
\hline $\begin{array}{c}\text { Thermobaculum } \\
\text { terrenum ATCC BAA- } \\
798\end{array}$ & 57 & 39 & 1 & 9 & & 11 & 117 & 5 \\
\hline $\begin{array}{c}\text { Sphaerobacter } \\
\text { thermophilus DSM } \\
20745\end{array}$ & 24 & 64 & & 9 & & 11 & 108 & 3 \\
\hline $\begin{array}{l}\text { Thermomicrobium } \\
\text { roseum DSM } 5159\end{array}$ & 18 & 37 & & 6 & & 2 & 63 & 0 \\
\hline $\begin{array}{c}\text { Anaerolinea } \\
\text { thermophila UNI-1 }\end{array}$ & 49 & 59 & 1 & 7 & & 7 & 123 & 0 \\
\hline $\begin{array}{l}\text { Caldilinea aerophila } \\
\text { DSM } 14535\end{array}$ & 68 & 83 & & 8 & & 43 & 202 & 4 \\
\hline $\begin{array}{c}\text { Thermogemmatispora } \\
\text { sp. T81 }\end{array}$ & 67 & 55 & 2 & 13 & & 31 & 168 & 18 \\
\hline $\begin{array}{c}\text { Thermus thermophilus } \\
\text { JL-18 }\end{array}$ & 14 & 20 & & 5 & & 5 & 44 & 0 \\
\hline $\begin{array}{c}\text { Thermotoga maritima } \\
\text { MSB8 }\end{array}$ & 49 & 22 & 1 & 5 & & 18 & 95 & 3 \\
\hline $\begin{array}{c}\text { Escherichia coli K-12 } \\
\text { MG1655 }\end{array}$ & 48 & 39 & & 9 & 2 & 15 & 113 & 4 \\
\hline $\begin{array}{c}\text { Clostridium } \\
\text { thermocellum ATCC } \\
27405\end{array}$ & 74 & 38 & 4 & 16 & & 90 & 222 & 59 \\
\hline $\begin{array}{c}\text { Anaerocellum } \\
\text { thermophilum DSM } \\
6725\end{array}$ & 60 & 29 & 3 & 5 & & 34 & 131 & 29 \\
\hline
\end{tabular}

*Baseado no programa de predição PSORTb 3.0 incluindo GHs, PLs e CEs

Fonte: Elaborado pelo autor. 
Os genes preditos como codificantes para CAZymes extracelullular foram obtidos com o programa PSORTb 3.0, incluindo hidrolases de glicosídeos (GH), liase de polissacsrídeo (PL) e esterase de carbono (CE). As famílias de enzimas putativas (CAZyme) de Thermogemmatispora sp. T81 foram analisadas e comparadas às espécies de Clostridium selecionadas a partir da anotação do genoma da Thermogemmatispora sp. T81 foi identificado um elevado numero de genes codificadores de CAZymes extracelulares em comparação com as demais Chloroflexi e com o grupo de teste selecionado (Tabela 14).

O genoma de Thermogemmatispora sp. T81 codifica um total de 168 genes de proteínas CAZymes, que é inferior ao número total de genes CAZyme de Caldilinea aerophila DSM 14535 (202) e Roseiflexus castenholzii DSM 13941 (205). Entretanto, o genoma da Thermogemmatispora sp. T81 codifica 67 CAZymes da família da hidrolases de glicosídeos (GH) semelhante a C. aerophila DSM 14535 (68) e superior a $R$. castenholzii (57).

Dezoito genes codificantes para possíveis CAZymes extracelulares foram identificados no genoma de Thermogemmatispora sp. T81, superior ao número máximo de 5 genes presentes nas outras espécies analisadas a partir da anotação do genoma da Thermogemmatispora sp. T81 foi identificado um elevado numero de genes codificadores de CAZymes extracelulares em comparação com as demais Chloroflexi e com o grupo de teste selecionado (Tabela 14): $2 \mathrm{em}$ Chloroflexus sp Y-400-fl; 5 em Thermobaculum terrenum ATCC BAA-798; 3 em Sphaerobacter thermophilus DSM 20745; 4 em Caldilinea aerophila DSM 14535; $3 \mathrm{em}$ Thermotoga maritima MSB8; e 4 em Escherichia coli K-12 subst.MG1655. 
Tabela 15 - CAZymes extracelulares preditas para Thermogemmatispora sp. T81

\begin{tabular}{ll}
\hline GH & Locus Tag T81 \\
GH3 & T81_00047160 \\
GH6 & T81_00046750 \\
PL & Locus Tag T81 \\
PL1 & T81_00040140 \\
MDP & Locus Tag T81 \\
GH5_22 & T81_00014280 \\
GH9-CBM3 & T81_00030500 \\
GH9-CBM3-CBM2 & T81_00014220 \\
GH13_2-CBM20 & T81_00004200 \\
GH16-CBM32 & T81_00047310 \\
GH16-CBM56-CBM56 & T81_00008400 \\
GH18-CBM16 & T81_00010940 \\
GH30_7-CBM2 & T81_00030480 \\
GH30_7-CBM2 & T81_00040380 \\
GH48-CBM2 & T81_00014200 \\
GH51-CBM2 & T81_00047400 \\
GH74-CBM2 & T81_00014240 \\
PL4-CBM2 & T81_00033740 \\
CBM3-GH5 & T81_00034150 \\
CBM16-GH18 & T81_00011960 \\
\hline
\end{tabular}

Fonte: Elaborado pelo autor.

O local no genoma (locus tag) das 18 CAZymes preditas como extracelular estão enumeradas na Tabela 15.

A hidrólise de material lignocelulósico envolve principalmente enzimas pertencentes às seguintes subfamílias de GH: GH1 GH1, GH3, GH5, GH10, GH11, GH39, GH45 e GH74, além disso pelo menos outras 29 subfamilias de GH estão envolvidas neste processo. ${ }^{73}$

A partir da análise das CAZymes de Thermogemmatispora sp. T81 foi constatado que o maior número de genes de hidrolases de glicosídeos $(\mathrm{GH})$ pertencem às subfamílias: GH1 (4); GH3 (8); GH5 (6); GH9 (2); GH15 (5); GH18 (5) e para a GH31 (3) (Tabela 16). Entre estes genes, algumas famílias foram encontradas apenas em Thermogemmatispora sp. T81, contudo 
genes das famílias GH39 e GH77 não foram encontradas apesar de serem reportadas para outras bactérias do filo Chloroflexi.

Hidrólise de material lignocelulósico

A hidrólise e degradação de materiais lignocelulósicos requerem CAZymes principalmente da família das $\mathrm{GH}$, que incluem, pelo menos, três tipos de enzimas celulolíticas: endoglucanases, exoglucanase e $\beta$-glucosidases. Como indicado acima, Thermogemmatispora sp. T81 apresenta vários genes para CAZymes extracelularesdas famílias GH3, GH5, GH6, GH9, GH13, GH16, GH18, GH30, GH48, GH51, GH74, PL2, PL2 e PL4. CAZymes da família GH3 são conhecidas pela atividade de $\beta$-glucosidase ${ }^{74}$ e Thermogemmatispora sp. T81 possui um gene para GH3 extracelular predita (T81_00047160).

O genoma da Thermogemmatispora sp. T81 possui dois genes preditos como pertencentes a GH5 (T81_00034150 and T81_00014280), com atividade predita como endoglucanase. $^{74}$

Base de dados de estruturas cristalográficas $(\mathrm{PDB})^{75}$ e análises com BLAST mostraram que a estrutura da endoglucanase de Acidothermus cellulolyticus (PDBid 1ECE) possui 62\% de identidade sequencial com a T81_00034150. O genoma da Thermogemmatispora sp. T81 também possui um gene predito para a família GH6 (T81_00046750) com 55\% de identidade sequencial com a Cel6b de Thermobifida fusca (PDBid 4B4F). 
Tabela 16 - Distribuição das famílias de hidrolases de glicosídeos nos genomas das bactérias do grupo Chloroflexi

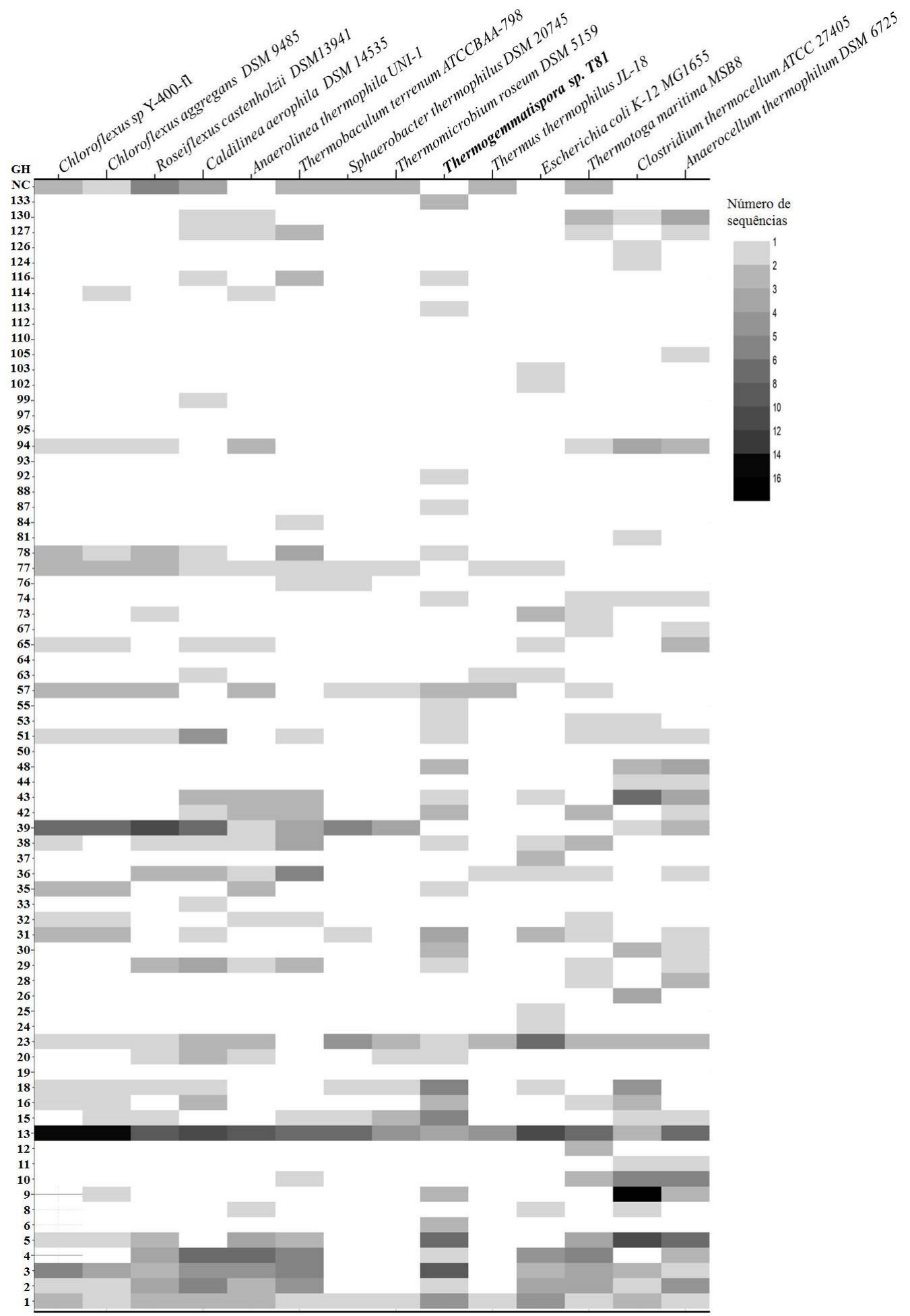

Fonte: Elaborada pelo autor. 
Para a família GH9 que possui atividade conhecida para endo- e exoglucanase ${ }^{76}$ a análise do genoma identificou dois genes (T81_00030500 e T81_00014220). O gene T81_00030500 contém o domínio CBM3 enquanto que o gene T81_00014220 contém os domínios CBM2 e CBM3. Análises com BLAST indicaram que T81_00030500 possui 48\% de identidade sequencial com a celulase de Clostridium thermocellum (PDBid 2YIK), enquanto que o gene T81_00014220 possui 59\% de identidade sequencial com a endo-exoglucanase de Clostridium thermocellum (PDBid 1JS4).

Hidrolases de glicosídeo da família GH16 estão divididas em cinco subgrupos de acordo como o substrato de preferência: transglucosilase de xiloglucano/hidrolases; (1,3)- $\beta$ galactanases; (1,4)- $\beta$-galactanases/ $\kappa$-carrageenases; "atividade não especifica" $(1,3 / 1,3 ; 1,4)-\beta$-dglucano endohidrolases; e $(1,3 ; 1,4)-\beta$-d-glucano endohidrolases. ${ }^{77} \mathrm{O}$ genoma da Thermogemmatispora sp. T81 tem genes extracelulares preditos para a família GH16 (T81_00047310 and T81_00008400).

Membros da família GH30 são descritos com cinco atividades enzimáticas conhecidas: glucosilceramidase, $\beta$-glucosidase, $\beta$-xilosidase, e endo- $\beta$-1,6-glucanase, endo- $\beta$-1,4-xilanase. ${ }^{78}$ O genoma da Thermogemmatispora $s p$. T81 possui duas sequências preditas como extracelulares (T81_00030480 and T81_00040380), sendo que cada uma contém um domínio CBM.

Membros da família GH48 são componentes de vários sistemas de degradação lignocelulósico $^{79}$. As seguintes atividades já foram reportadas para enzimas desta família: endo$\beta$-1,4-glucanase, quitinase, celulase endo-processiva, e celobiohidrolase. Celulases da família GH48 podem atuar de maneira sinérgica com celulases da família da GH 9. ${ }^{79}$

O genoma da Thermogemmatispora sp. T81 possui um gene predito como uma GH48 extracelular (T81_00014200) possuindo um domínio CBM2. Análises com o BLAST indicaram que a sequência de aminoácidos possui $59 \%$ de identidade com a celobiohidrolase de Caldicellulosiruptor bescii PDB 4L0G.

Membros da família GH51 são usualmente caracterizadas como $\alpha$-Larabinofuranosidases, mas também foram determinadas as atividades: endoglucanase, endo- $\beta$ 1,4-xilanase, e $\beta$-xilosidase (Carbohydrate Active Enzymes database, http://www.cazy.org/) ${ }^{80}$. O 
genoma da Thermogemmatispora sp. T81 foi predito com uma GH51 extracelular (T81_00047400) com um domínio CBM2.

A família GH74 é uma família fonte de enzimas muito importantes para a degradação de material lignocelulósico com algumas atividades descritas incluindo endoglucanase, celobiohidrolase específica para redução de oligo xiloglucano e xiloglucanase. ${ }^{81}$ O genoma da Thermogemmatispora sp. T81 genome foi predito com uma GH74 extracelular (T81_00014240) com um domínio CBM2. Análises de BLAST indicaram que a sequência de aminoácidos desta GH74 possui 55\% de identidade com a endoxiloglucanase de Acidothermus cellulolyticus (PDB id 4LGN).

Hidrólise de amido.

Diferentes enzimas são necessárias para a hidrólise do amido. A maioria das enzimas descritas como hidrolíticas de amido são da família GH13 ${ }^{82}$. O genoma de Thermogemmatispora sp. T81 possui um gene predito como extracelular pertencente a esta família (T81_00004200). Além disso, outros dois genes identificados no genoma Thermogemmatispora sp. T81 (T81_00004240 e T81_00007010) como pertencentes à GH13 são possivelmente intracelulares. Isto contrasta com outras bactérias do filo Chloroflexi que codificam entre 6 a 14 genes para a família GH13 (Tabela 16).

Hidrólise de quitina.

Quitinases estão agrupadas principalmente nas famílias GH18 e GH19. ${ }^{83}$ O genoma de Thermogemmatispora sp. T81 foi predito como codificante de duas quitinases extracelulares: T81_00010940 que contém um domínio de CBM16 e T81_00010940 que contém um domínio CBM18. 
Hidrólise de pectina.

Uma série de enzimas estão envolvidas na hidrólise de pectina, incluindo pectina liase, pectase liase, esterase de pectina e poligalacturonase. ${ }^{84}$ As famílias CAZymes que codificam estas enzimas são CE8, PL1, PL2, PL3, PL9, PL10, GH28, GH78, e GH88. ${ }^{73}$ O genoma da Thermogemmatispora sp. T81 possui genes codificadores para duas pectinases extracelulares: PL1 (T81_00040140) and PL4 (T81_00033740), sendo que T81_00033740 possui um domínio CBM2.

\subsubsection{Análises de Crescimento}

As células cresceram em $2 \mathrm{~g} / \mathrm{L}$ de $\alpha$-cellulose, $2 \mathrm{~g} / \mathrm{L}$ de glicose e $2 \mathrm{~g} / \mathrm{L}$ de extrato de levedura em meio AOM1, sendo o crescimento avaliado a partir da concentração de proteína quantificado pelo método de Bradford. As culturas apresentaram fase inicial, exponencial e estacionária. Os tempos de geração determinados foram de 10,3 h (Gráfico 1A); 5,8 h (Gráfico 2A ) e 8,2 h (Gráfico 3A) para $\alpha$-celulose, glicose e extrato de levedura respectivamente.

Além disso, foi avaliado o $\mathrm{pH}$ durante o crescimento, sendo que o perfil apresentado foi: acidófilico para a cultura em $\alpha$-cellulose (Gráfico 1B), acidófilico para glicose (Gráfico 2B) e acidófilico e neutrofílico para extrato de levedura (Gráfico 3B), sendo o crescimento limitado ao intervalo de $\mathrm{pH}$ de 3,15 a 8. 

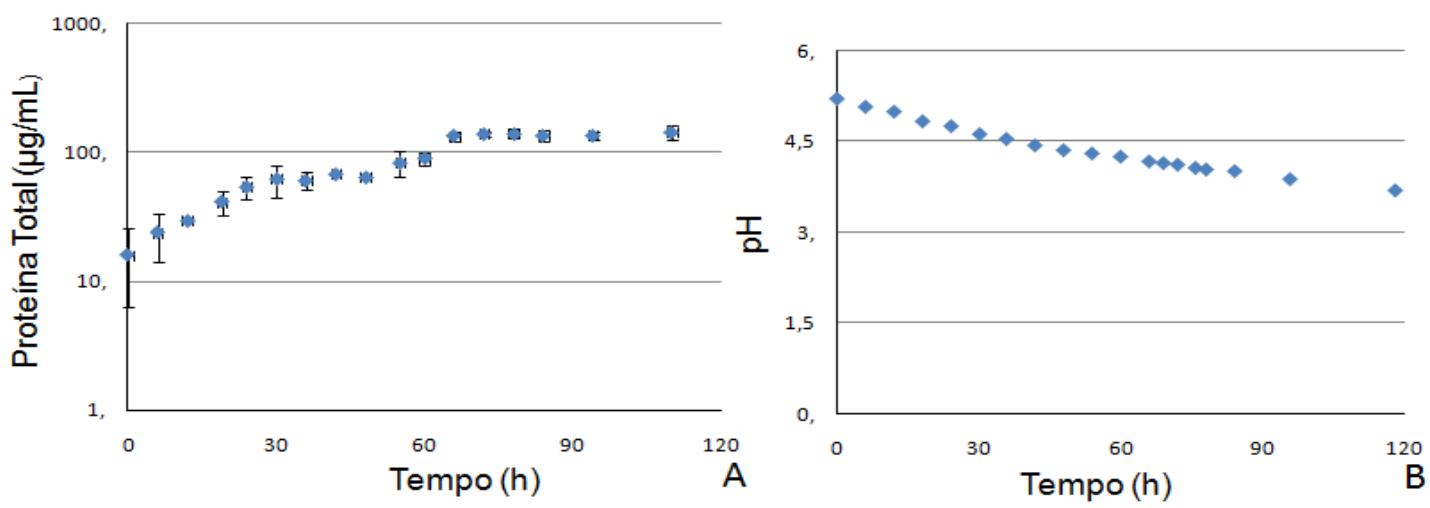

Gráfico 1 - A) Curva de crescimento utilizando $\alpha$-cellulose como fonte de carbono. B) perfil de pH da cultura Thermogemmatispora sp. cepa T81 utilizando $\alpha$-celulose como fonte de carbono.

Fonte: Elaborado pelo autor.
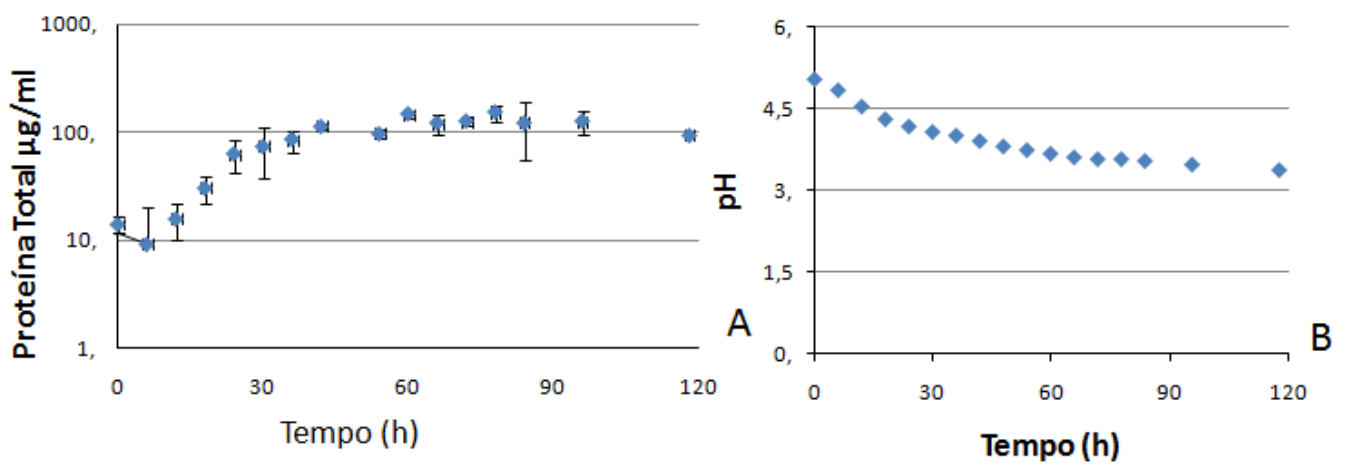

Gráfico 2 - A) Curva de crescimento utilizando glicose como fonte de carbono. B) Perfil de pH da cultura Thermogemmatispora sp. cepa T81 utilizando glicose como fonte de carbono..

Fonte: Elaborado pelo autor. 

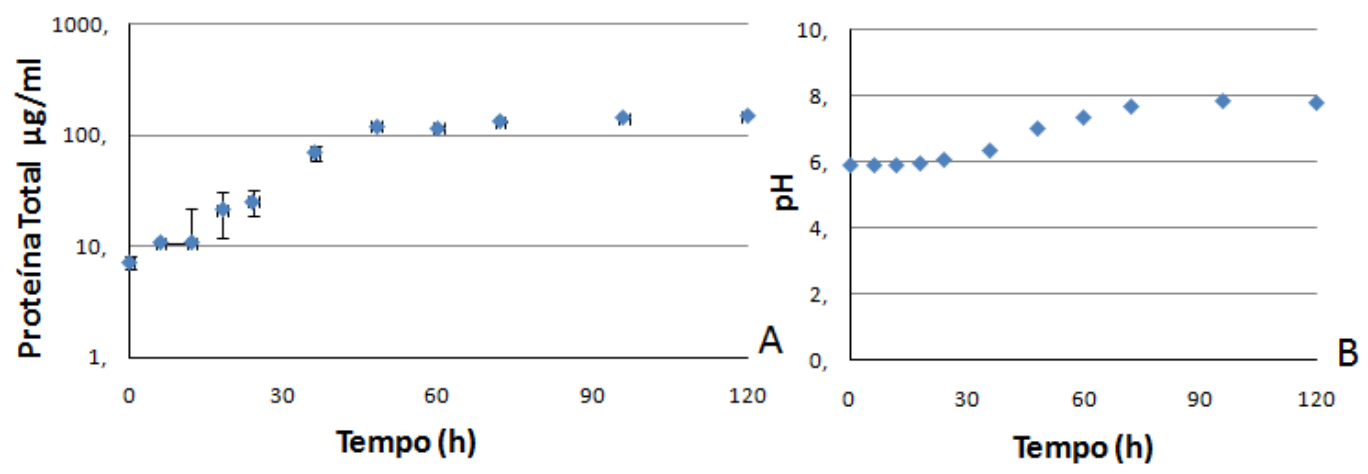

Gráfico 3 - A) Curva de crescimento utilizando extrato de levedura como fonte de carbono. B) Perfil de pH da cultura Thermogemmatispora sp. cepa T81 utilizando extrato de levedura como fonte de carbono.

Fonte: Elaborado pelo autor.

A limitação experimental foi um dos grandes problemas para a determinação das curvas de crescimento apresentadas, uma vez que devido ao caráter filamentoso e globular pelo qual as células da cultura de Thermogemmatispora sp. se organizam, a obtenção de alíquotas homogêneas e uniformes apresentou-se como um fator limitante. Este experimento foi realizado em triplicata para cada condição avaliada, sendo cada ponto coletado em triplicatas biológicas.

As fontes de carbono com as curvas de crescimento descritas acima foram escolhidas para as análises de proteômica. A fim de se avaliar ou não o aumento de biomassa (crescimento) foi medida a concentração total de proteína em cada condição, comparando à concentração de proteína no momento do inóculo e após uma semana de crescimento.

\subsubsection{Análise Proteômica}

\section{Crescimento}

Como apresentado na seção anterior, as condições de crescimento utilizando glicose, extrato de levedura e $\alpha$-celulose na concentração final de $2 \mathrm{~g} / \mathrm{L}$ foram escolhidas para determinação das curvas de crescimento (tempo de geração), com o objetivo final de análise 
proteômica. Estas análises exigem coletar a amostra protéica que permitam comparar o nível de expressão entre os substratos escolhidos e informações obtidas quanto à glicólise (glicose como fonte de carbono), gliconeogênese (extrato de levedura como fonte de carbono) e cadeia celulolítica ( $\alpha$-celulose como fonte de carbono).

\section{Extração Protéica}

A extração protéica foi conduzida como descrito na seção de materiais e métodos, na qual o tampão de lise SDT juntamente com VWR Beads Zircon MolBio 200M foram expostos ao Mini beadbeater (BioSpec) por 45 segundos seguida de centrifugação. O sobrenadante deste processo pode ser observado na Figura 25, onde observamos também as fase Mid-log e estacionárias das duplicatas biológicas para cada fonte de carbono onde foi avaliado o crescimento da Thermogemmatispora sp $\mathrm{T} 81$.
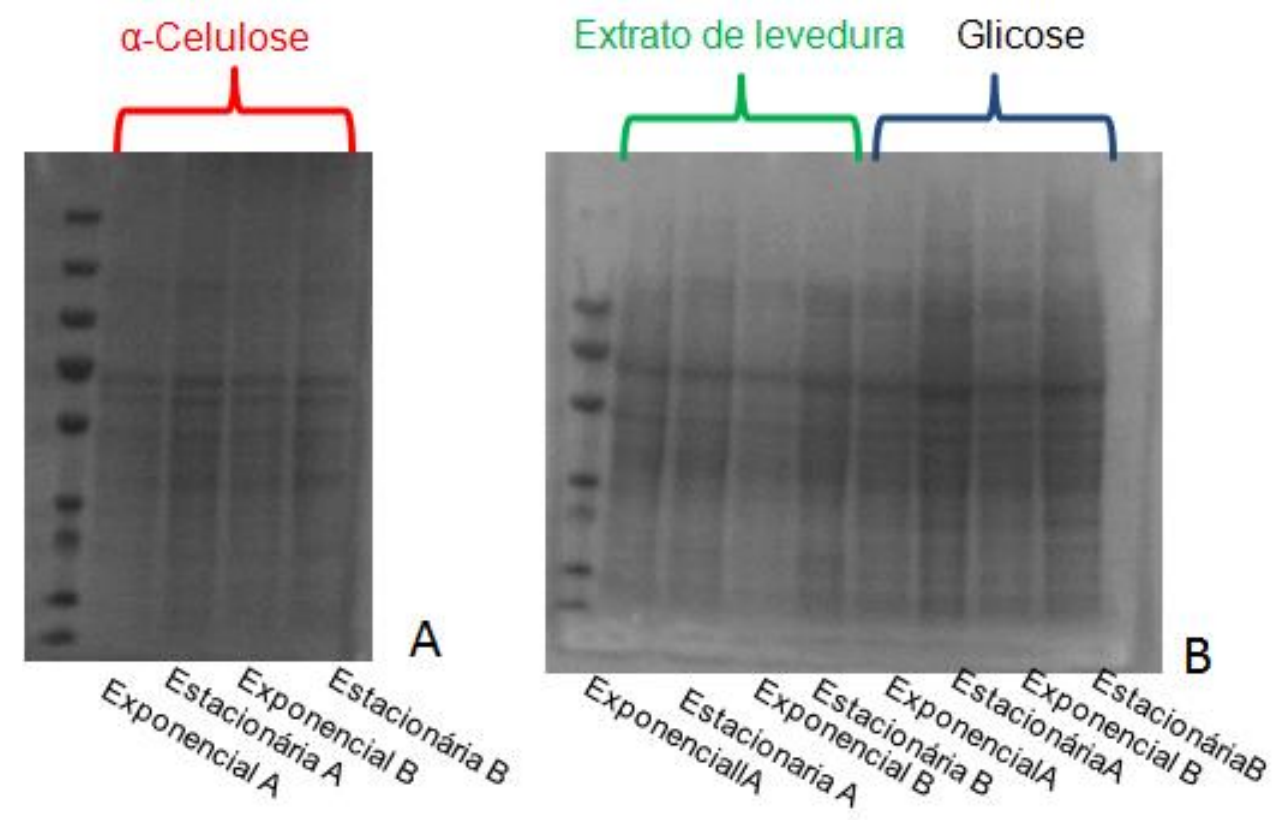

Figura 25 - SDS-PAGE das amostras da fase Mid-log (exponencial) e estacionária dos substratos avaliados como fonte de carbono, em A as amostras correspondentes a $\alpha$-celulose e em B as correspondentes ao extrato de levedura e glicose, as letras A e B junto ao exponencial e estacionário referem-se a cada duplicata do experimento.

Fonte: Elaborada pelo autor. 
O padrão de bandas apresentado no SDS_PAGE permitiu obter a quantidade mínima de proteínas necessárias para dar continuidade aos procedimentos de preparação das amostras para MS-LC. O padrão de bandas apresentou-se bem definido, homogêneo e com concentração acima de $500 \mu \mathrm{g}$. Esta quantidade é considerada mínima para a continuidade dos procedimentos, sendo as perdas advindas das inúmeras etapas do processo de preparação das amostras.

Esta etapa no processo de extração protéica é determinante, dado que a remoção do detergente SDS permitirá a ação da tripsina (tripsinização) e a ionização da amostra (LC-MS).

A adequação do protocolo apresentado exigiu testes para determinação das melhores condições para extração e purificação das amostras protéicas. Frente ao problema de remoção de SDS das amostras, conclui-se que os fatores primordiais para a remoção do mesmo está no volume de tampão de lise utilizado, sendo o volume de $1 \mathrm{~mL}$ suficiente para o processo e não volumes superiores utilizados nos primeiros testes de preparação das amostras. Isto é, uma grande quantidade de tampão de lise carrega uma quantidade maior de detergente que, mesmo com o incremento de etapas de diálise, não permite a remoção do mesmo de maneira satisfatória. Além disso, a divisão da alíquota de $1 \mathrm{~mL}$ provinda da lise celular em dois concentradores para o processo subsequente de preparação das amostras permitiu uma melhor remoção do detergente.

\section{Purificação de peptídeos e análises de MS}

Ao final do processo de tripsinização, as amostras apresentaram uma considerável diminuição na concentração protéica advindas do próprio processo de preparação. Para ilustrar são apresentadas as concentrações dos peptídeos advindos da extração da cultura crescida em $\alpha$ celulose, que foram quantificadas utilizando o espectrofotômetro NanoDrop 1000 (ThermoScientific): fase exponencial (Mid-log) 135 e $297 \mu$ g para cada duplicata biológica e na fase estacionária 297 e $189 \mu \mathrm{g}$. Ao final do processo de purificação, utilizando o sistema de HPLC, a concentração das amostras decaiu em média 60\%, passando para 65 e $70 \mu \mathrm{g}$ para as fases exponenciais e 180 e $130 \mu \mathrm{g}$ para as amostras da fase estacionária. 
Terminada a preparação das amostras, estas foram enviadas ao professor Oleg V. Krokhin que realizou as medidas LC-MS utilizando um espectrômetro de massa Triplo TOF5600 (ABSciex, Concord, ON) no Manitoba Centre for Proteomics and Systems Biology da Universidade de Manitoba, Winnipeg, Canadá.

\section{Processamento de Dados e Análises}

A partir dos espectros LC-MS obtidos e utilizando uma unidade processadora de imagem (GPU) desenvolvida pelo próprio grupo, foi possível a identificação dos peptídeos e a das proteínas presentes em cada uma das amostras estudadas. O nível de expressão foi determinado pelos contadores totais de elétrons (nTIC), como descrito na seção de materiais e métodos. Esta informação (nTIC) foi utilizada para traçar comparações inter-replicata (R) e inter-estados exponencial e estacionária de crescimento $(Z)$ para cada fonte de carbono estudada.

A diferença nos níveis de expressão entre diferentes condições de crescimento (fonte de carbono) foram calculadas a partir de uma transformação que combina a diferença de expressão em diferentes estágios de crescimento (Wnet) representada nas Tabelas de 17 a 20.

Estas correspondem a quão cada uma das CAZymes expressas estava em maior concentração na fase estacionária em comparação à fase exponencial, indicando com isso, uma expressão crescente de tal proteína durante o crescimento e que representa o papel que a mesma desempenha no metabolismo.

O sinal positivo nos valores nas Tabelas de 17 a 20 advem de uma diferença entre a fase exponencial e estacionária indicando que na fase estacionária a proteína analisada estava em maior concentração. 
Tabela 17 - Tabela de Hidrolases de Glicosídeos identificadas no proteôma da bactéria Thermogemmatispora sp. cepa T81. Os níveis de expressão é listado para cada um dos substratos. AC: $\alpha$-celulose, Gli: glicose e EL: extrato de levedura.

\begin{tabular}{cccccc}
\hline Cazy & Locus gênico & Localização & Wnet AC & Wnet GLi & Wnet EL \\
GH1 & T81_11200 & Citoplasma & 1,61 & & \\
GH1 & T81_34060 & Citoplasma & 0,23 & & \\
GH2 & T81_46850 & Citoplasma & 0,04 & $-0,51$ & \\
GH3 & T81_7110 & Citoplasma & $-0,14$ & & \\
GH4 & T81_6190 & Citoplasma & & & 0,61 \\
GH6 & T81_46750 & Extracelular & 6,50 & & \\
GH15 & T81_43780 & Citoplasma & 1,14 & 1,39 & 0,73 \\
GH15 & T81_12820 & Parede Celular & 0,43 & $-0,5$ & $-0,33$ \\
GH38 & T81_30920 & Citoplasma & 0,19 & $-0,94$ & $-1,74$ \\
GH42 & T81_9400 & Citoplasma & 0,04 & 1,84 & 0,34 \\
\hline
\end{tabular}

Fonte: Elaborada pelo autor.

Avaliações dos dados de proteôma advindas da cultura da bactéria Thermogemmatispora $s p$. T81 utilizando glicose, extrato de levedura e celulose como fonte de carbono permitem informações respectivamente aos processos como glicólise, neogliconeogênese e atividade celulolítica, por exemplo. Além disso, permitiu a obtenção de informações com relação aos processos regulatórios de $\mathrm{pH}$, uma vez que, como observado nos Gráficos 1B, $2 \mathrm{~B}$ e $3 \mathrm{~B}$, a bactéria possui mecanismo para sobrevivência na faixa de $\mathrm{pH}$ de 3,15 a 8 . 
Tabela 18 - Tabela de Transferases de glicosídeos identificadas no proteôma da bactéria Thermogemmatispora sp. cepa T81. Os níveis de expressão é listado para cada um dos substratos. AC: $\alpha$-celulose, Gli: glicose e EL: extrato de levedura.

\begin{tabular}{|c|c|c|c|c|c|}
\hline Cazy & Locus gênico & Localização & Wnet AC & Wnet GLi & Wnet EL \\
\hline GT2 & T81_16680 & $\begin{array}{c}\text { Membrana } \\
\text { citoplasmática }\end{array}$ & 1,06 & 0,04 & $-0,19$ \\
\hline GT2 & T81_18800 & Citoplasma & 1,41 & 0,01 & \\
\hline GT2 & T81_23720 & $\begin{array}{c}\text { Membrana } \\
\text { citoplasmática }\end{array}$ & 1,63 & & \\
\hline GT4 & T81_17320 & $\begin{array}{c}\text { Membrana } \\
\text { citoplasmática }\end{array}$ & $-1,39$ & $-0,06$ & \\
\hline GT4 & T81_22530 & Desconhecido & $-1,40$ & $-0,10$ & \\
\hline GT4 & T81_22550 & Citoplasma & 2,33 & & 0,82 \\
\hline GT4 & T81_25130 & Citoplasma & $-0,70$ & 0,48 & $-0,90$ \\
\hline GT5 & T81_15670 & Citoplasma & 0,29 & 0.51 & 0,03 \\
\hline GT20 & T81_24470 & Citoplasma & 0,04 & 0,18 & 1,18 \\
\hline GT28 & T81_27540 & $\begin{array}{c}\text { Membrana } \\
\text { citoplasmática }\end{array}$ & $-0,97$ & $-0,25$ & $-1,04$ \\
\hline GT35 & T81_12790 & Citoplasma & $-0,14$ & 0,75 & 0,53 \\
\hline
\end{tabular}

Fonte: Elaborada pelo autor.

Tabela 19 - Tabela de Esterase de Carboidratos identificadas no proteôma da bactéria da bactéria Thermogemmatispora sp.cepa T81. Os níveis de expressão é listado para cada um dos substratos.AC: $\alpha$-celulose, Gli:glicose e EL: extrato de levedura.

\begin{tabular}{cccccc}
\hline Cazy & Locus gênico & Localização & Wnet AC & Wnet GLi & Wnet EL \\
CE14 & T81_5750 & Citoplasma & -1.91 & $-1,06$ & $-0,03$ \\
CE14 & T81_12220 & Citoplasma & 0,24 & $-0,51$ & 0,62 \\
CE14 & T81_19620 & Citoplasma & 0,81 & 2,16 & 0,28 \\
CE14 & T81_25110 & Citoplasma & 0,11 & 0,27 & 0,12 \\
\hline
\end{tabular}

Fonte: Elaborada pelo autor. 
Tabela 20 - Tabela de Proteínas Multidomínio identificadas no proteôma da bactéria Thermogemmatispora sp. cepa T81. Os níveis de expressão é listado para cada um dos substratos. AC: $\alpha$-celulose, Gli: glicose e EL: extrato de levedura..

\begin{tabular}{cclccc}
\hline Cazy & Locus gênico & Localização & Wnet AC & Wnet GLi & Wnet EL \\
GH5_22 & T81_14280 & Extracellular & $-1,91$ & & \\
GH30_7-CBM2 & T81_30480 & Extracellular & 0,24 & & \\
\hline
\end{tabular}

Fonte: Elaborada pelo autor.

\subsubsection{Seleção de candidatos para expressão heteróloga}

Tomando-se como objeto principal desta pesquisa as CAZymes, os dados de proteôma foram correlacionados com as proteínas preditas por Henrissat, permitindo a construção das tabelas de 17 a 20, para os três substratos analisados (celulose, glicose e extrato de levedura) apenas as celulases.

Assim sendo, estas foram classificadas de acordo com a descrição de CAZymes. As tabelas de 17 a 20, representam as 27 CAZymes obtidas aplicando o filtro COG de um total de 96 enzimas que haviam sido preditas por Henrissat. É importante salientar que o proteoma foi obtido a partir das células e do substrato (enzimas secretadas que estavam aderidas ao substrato e vieram durante o processo de centrifugação com o maciço celular). Para o entendimento completo dos níveis de expressão, demandaria a realização do proteôma a partir do sobrenadante. Contudo, devido aos problemas na adaptação do protocolo para a remoção do SDS e tempo para conclusão do trabalho, não foi possível a execução da mesma. A partir do conjunto de dados obtidos, selecionou-se quatro alvos para estudo (Tabela 21) .

Empregando as ferramentas do Swiss-Prot ${ }^{34}$ e da base de dados do Protein Data Bank ${ }^{75}$ foi determinada uma pré-caracterização destes alvos (Tabela 21) para a etapa seguinte de superexpressão heteróloga. 
Tabela 21 - Alvos selecionados para estudo com caracterização baseada no Swiss-Prot (http://web.expasy.org/protparam/) e Protein Data Bank (PDB; http://www.rcsb.org/pdb/).

\begin{tabular}{|c|c|c|c|c|}
\hline Cazy & Locus & Localização & $\begin{array}{l}\text { Peso } \\
\text { Molecular } \\
\text { (PM) kDa }\end{array}$ & $\begin{array}{l}\text { pdb, identidade com } \\
\text { T81, Classificação } \\
\text { catalítica }\end{array}$ \\
\hline GH 6 & T81_46750 & Extracelular & 41,68 & $\begin{array}{l}\text { Pdb : 4AVO|A , } \\
(218 / 396) 55 \%, \\
\text { Celobiohidrolase Cel6b } \\
\text { (Exoglucanase) }\end{array}$ \\
\hline GH30_7_CBM2 & T81_30480 & Extracelular & 51,4 & $\begin{array}{l}\text { Pdb: 1VJZ|A, (73/280) } \\
26 \% \text {, } \\
\text { Endoglucanase }\end{array}$ \\
\hline $\begin{array}{l}\text { CBM2 de } \\
\text { GH30_7 }\end{array}$ & T81_30480 & & & \\
\hline $\begin{array}{c}\text { D.catalítico de } \\
\text { GH30_7 }\end{array}$ & T81_30480 & & & $\begin{array}{l}\text { Pdb: 1NOF|A, } \\
\text { (115/406) } 28 \%, \\
\text { Xilanase }\end{array}$ \\
\hline GT 4 & T81_22550 & Citoplasma & 17,63 & $\begin{array}{l}\text { Pdb: 4FMV|A, } \\
\text { (124/453) 27\%, } \\
\text { Endoxilanase }\end{array}$ \\
\hline GH5_22 & T81_14280 & Extracelular & 53,98 & $\begin{array}{l}\text { Pdb: 1VJZ|A, }(73 / 280) \\
26 \% \text {, } \\
\text { Endoglucanase }\end{array}$ \\
\hline
\end{tabular}

Fonte: Elaborada pelo autor.

A partir da análise do gene T81_30480 com o programa Domain-Fish ${ }^{32}$ foram delimitadas duas outras construções: uma referente ao domínio T81_30480_CBM2 e outra referente apenas ao domínio catalítico T81_30480_domínio catalítico. Assim, as quatro ORFs selecionadas e as suas construções gênicas truncadas foram clonadas para expressão heteróloga nos vetores pET Trx-1a/Lic com posterior transformação em células de expressão E. coli Rosetta (DE3).

\subsubsection{Purificação das Proteínas}

Na Figura 26, é apresentada a primeira etapa do processo de cromatografia de afinidade utilizada para a purificação das proteínas selecionadas para expressão heteróloga de Thermogemmatispora sp. cepa T81. Observa-se que as seis construções foram expressas na 
fração solúvel. Após a ação da TEV protease, estas proteínas apresentaram grau de pureza satisfatório para ensaios cinéticos e também para experimentos de dicroísmo circular (CD) (Figura 27).
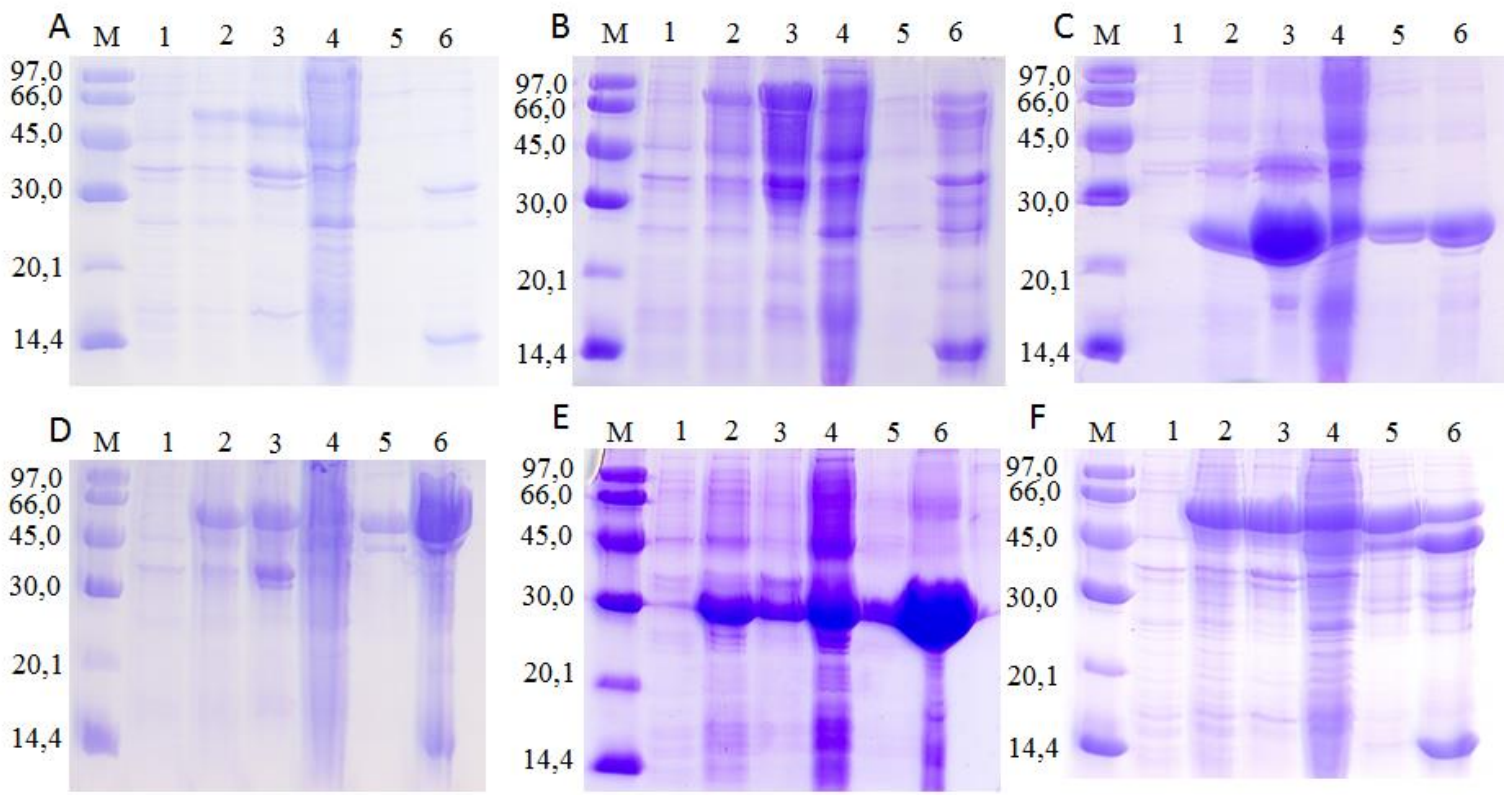

Figura 26 - Perfil eletroforético SDS-PAGE 15\% referente às etapas de purificação. A (T81_49580 GH6), B (T81_30480 GH30_7), C (T81_30480 domínio CBM2) D (T81_30480, domínio catalítico) E (T81_22550, GT4) e F ( T81_14280 GH5_22). Para todas as amostras apresentadas, a ordem das linhas nos géis de poliacrilamida é a seguinte: M - marcador de massa molecular, 1 - fração antes de indução, 2- fração pós-indução, 3- "pellet” precipitado celular, 4- fração sobrenadante, 5 - primeira eluição (200mM imidazol) e 6- segunda eluição $(500 \mathrm{mM})$ de Imidazol.

Fonte: Elaborada pelo autor

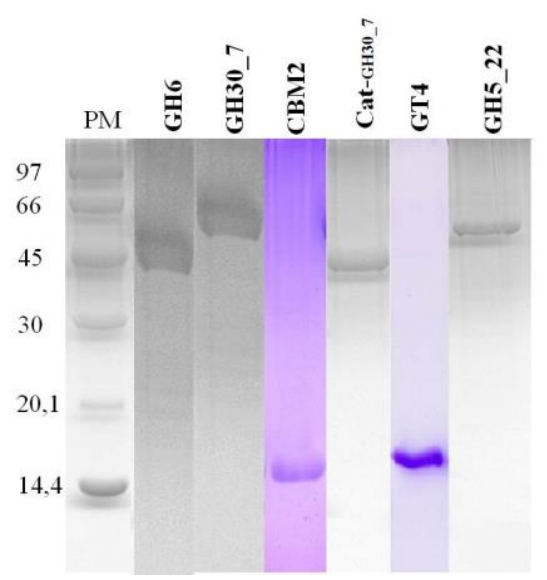

Figura 27 - Perfil eletroforético em SDS-PAGE 15\% dos alvos purificados

Fonte: Elaborada pelo autor. 


\subsubsection{Ensaios de Atividade}

(1)

\section{Caracterização cinética do coquetel T81}

\section{Determinação da temperatura ótima de atividade do coquetel T81}

Para determinar a temperatura ótima do coquetel T81 utilizando CMC como substrato, o mesmo foi testado variando-se a temperatura reacional entre $40^{\circ} \mathrm{C}$ e $85^{\circ} \mathrm{C}$ (Figura 28A).

A partir deste resultado, observou-se que a atividade do coquetel enzimático foi melhor nas temperaturas entre 65 e $80^{\circ} \mathrm{C}$, com atividade máxima em $80^{\circ} \mathrm{C}$. Porém, os picos a 65,70 e $75^{\circ} \mathrm{C}$ podem, na verdade, indicam que diferentes enzimas que constituem o coquetel apresentam diferentes temperaturas ótimas.
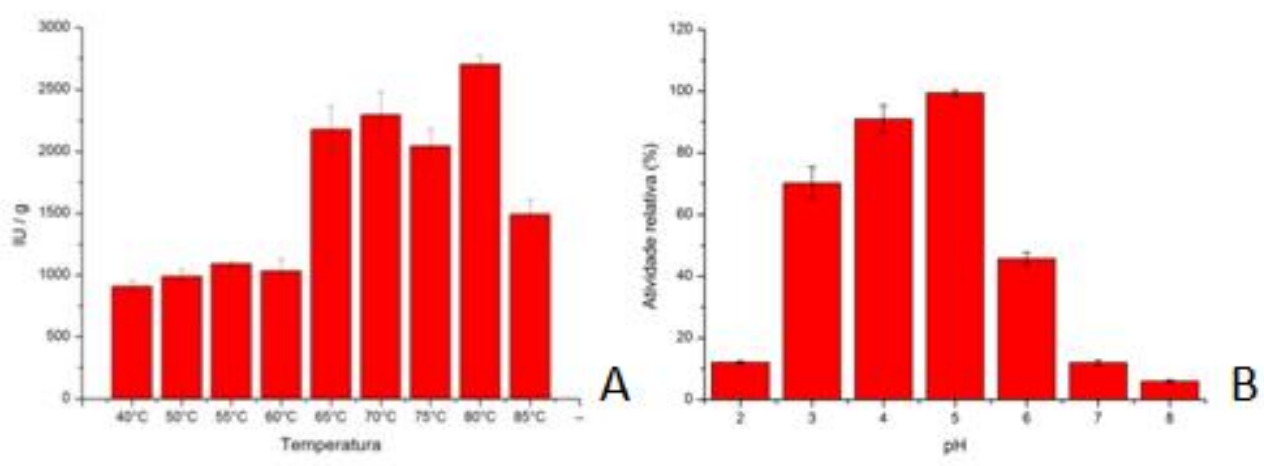

Figura 28 - A Varredura de temperaturas de ação do coquetel de Thermogemmatispora sp. T81 sobre CMC, B Varredura de pHs de ação do coquetel de T81 sobre Xilano de faia.

Fonte: Elaborada pelo autor.

Como referencial comparativo da atividade enzimática do coquetel, foi utilizado o coquetel comercial ACCELLERASE® 1500 (DuPont ${ }^{\circledR}$ ), que possui um valor de 2200 a 2800 CMC U/g de atividade endoglucanase nas mesmas condições experimentais usadas nesse estudo. Uma unidade de CMC correspondente a $1 \mu \mathrm{mol}$ de açúcar redutor liberado a $50^{\circ} \mathrm{C} \mathrm{e} \mathrm{pH}$ 
4,8. No coquetel de T81, observou-se um ganho máximo de aproximadamente $2800 \mathrm{U} / \mathrm{g}$, um rendimento semelhante ao apresentado pela ACCELERASE® 1500 (DuPont $\left.{ }^{\circledR}\right)$, o que evidencia o potencial enzimático do coquetel T81.

\section{Painel de substrato do coquetel T81}

A partir de uma varredura de substratos, demonstrou-se que o coquetel apresenta alta atividade para degradação de hemicelulose (Figura 29), pois foi capaz de hidrolizar ligações $\beta(1$ 4) entre resíduos de glicoses dos substratos xiloglucano, xilano e arabinoxilano. Além disso, também apresenta atividade na hidrólise do mesmo tipo de ligações em liquenano, CMC, $\beta$ glucano, Avicel e papel filtro.

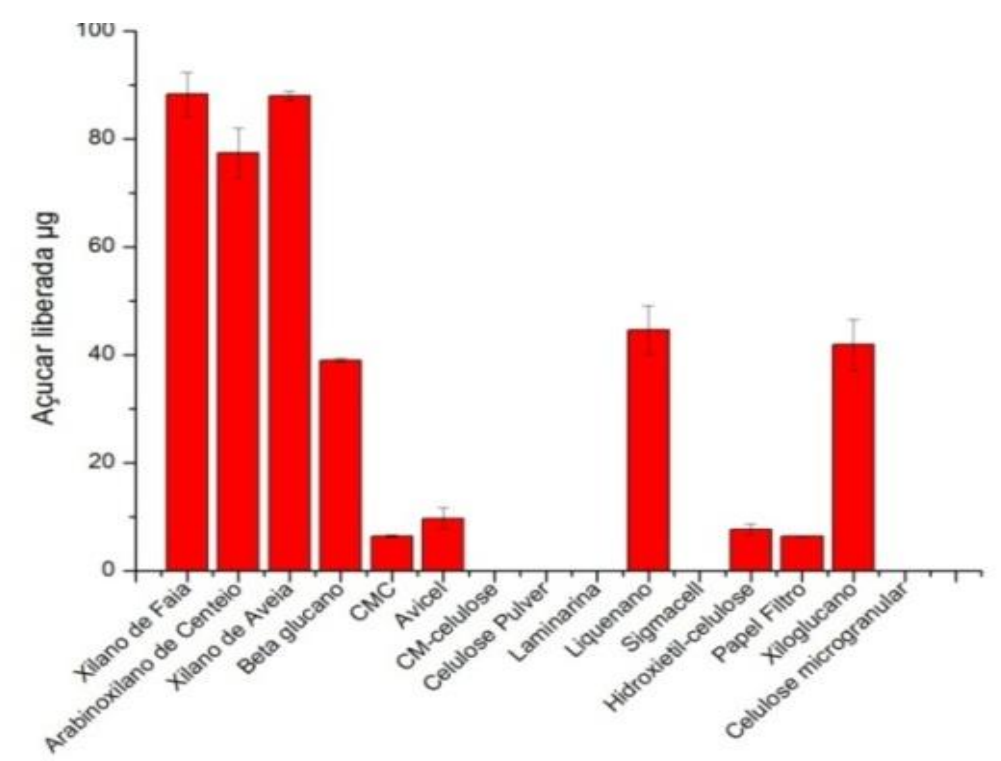

Figura 29 - Varredura de substratos para ação do coquetel T81.

Fonte: Elaborada pelo autor.

A estabilidade do coquetel estocado a $10^{\circ} \mathrm{C}$ por seis meses foi avaliada a partir da comparação entre a quantidade de xilose liberada utilizando o coquetel fresco e o coquetel 
armazenado (Figura 30A). Nota-se que houve uma variação pouco significativa, ao redor de 10 $\mu \mathrm{g}$ entre os dois coquetéis, o que demonstra a sua estabilidade nas condições de estocagem, mesmo para períodos longos como seis meses.

Além disso, foi avaliado o perfil de secreção das enzimas de T81 durante sete dias, a partir da coleta diária de frações do meio de cultura, monitorando a ação enzimática destas frações em solução contendo xilano de Faia (Figura 30B).

Observa-se que existe um aumento na quantidade de xilose liberada para frações mais tardias, o que pode ser resultado da crescente concentração de xilanases disponível ao longo dos dias, seja pelo próprio aumento devido ao maior número de células ou devido à diminuição de substrato para clivagem com a consequente disponibilização de mais enzimas no meio.

A atividade enzimática do meio de cultura (enzimas secretadas) quando a Thermogemmatispora sp. T81 cresceu utilizando glicose ou xilano foi nula, confirmando que enzimas lignocelulolíticas são estimuladas frente à fonte de carbono exposta para a cultura bacteriana.
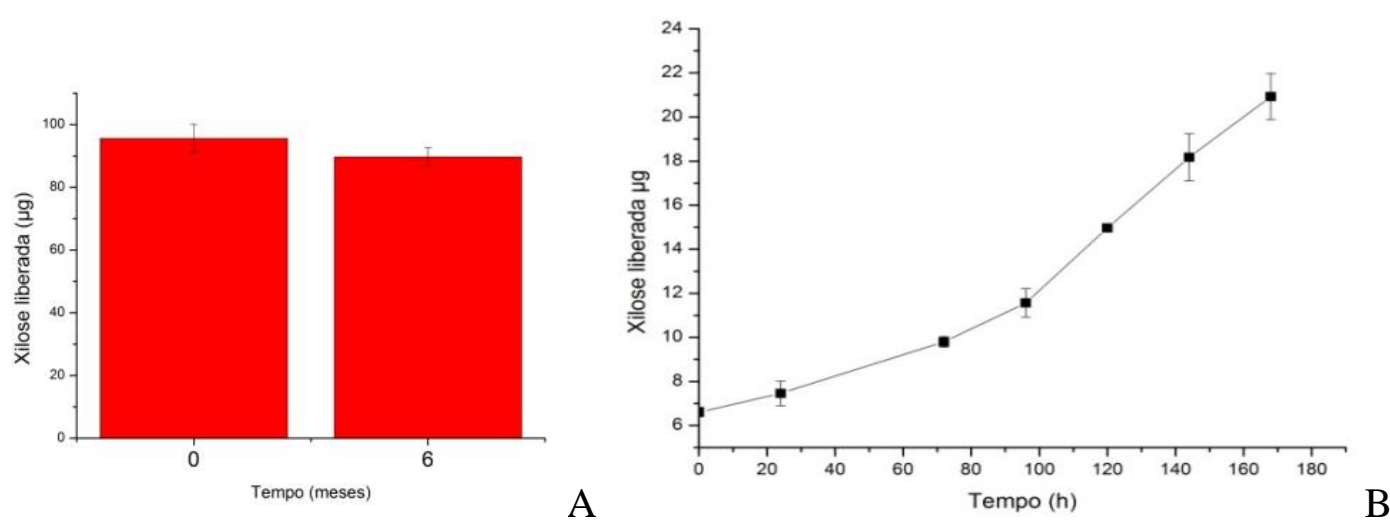

Figura 30 - A Atividade do coquetel recém produzido e do coquetel armazenado por 6 meses B Atividade das enzimas secretadas ao longo do período de crescimento da cultura de T81.

Fonte: Elaborada pelo autor. 


\section{Caracterização cinética das enzimas clonadas a partir dos dados de proteôma}

\section{Avaliação da atividade lignocelulolíticos de cada enzima: Painel de Substratos}

Para cada uma das enzimas clonadas da bactéria T81, foi avaliada a atividade lignocelulósica apresentados na Figura 31. Desta maneira, pode-se correlacionar a atividade predita pela avaliação de Henrissat com a real atividade verificada para cada uma delas.

A enzima T81_46750 foi predita como uma GH6, família cujas enzimas são endoglucanases (EG, EC 3.2.1.4) e celobiohidrolases (CBH, EC 3.2.1.91). ${ }^{85}$ Os resultados mostram que esta enzima de fato apresenta atividade endoglucalítica (Figura $31 \mathrm{~A}$ ), todavia, os resultados ainda são inconclusivos acerca da atividade celobiohidrolitíca. Esta é a enzima mais secretada pela bactéria Thermogemmatispora sp. cepa T81, de acordo com os resultados apresentados pelo proteoma, o que confirma o descrito na literatura em que enzimas da família GH6 são os principais componentes em coquetéis enzimáticos utilizados para a degradação de biomassa . ${ }^{86}$

No caso da T81_30480, foi predito que essa pertence à família GH30, subfamília 7. Enzimas pertencentes à subfamília 7 são descritas pela atividade exo- $\beta$-1,4-xilanase (EC 3.2.1.), o que é condizente com os resultados obtidos a partir do painel de substratos ilustrado (Figura 31B). O mesmo espectro de ação também é obtido quando se usa o domínio catalítico desta enzima (Figura 31C)

A enzima T81_22550 foi predita como GT4, contudo não foram realizados experimentos específicos para verificar a atividade de transferase. Porém, a atividade hidrolítica foi avaliada e constatada, como ilustrado na Figura 31D.

No caso da T81_14280, foi predito que essa pertence à família GH5, subfamília 22. Enzimas desta subfamília possuem atividade de celulase (endoglucanase) ${ }^{87}$. Além disso, para a família 5 é descrita atividade xilanolítica que foi identificada para a enzima em questão (Figura $31 \mathrm{E})$. 


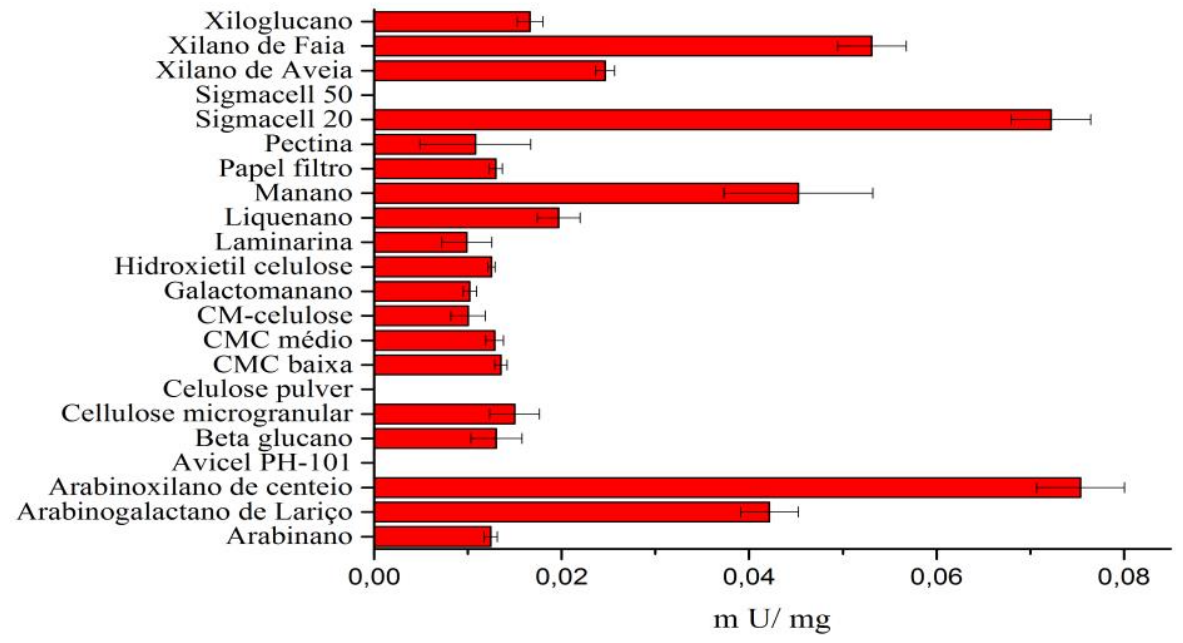

B

Xiloglucano Xilano de Faia Xilano de Aveia

Sigmacell 50

Sigmacell 20 Pectina

Papel filtro Manano

Liquenano Laminarina Hidroxietil celulose Galactomanano

CM-celulose

CMC médio

CMC baixa

Celulose pulver

Cellulose microgranular

Beta glucano

Avicel PH-101

Arabinoxilano de centeio Arabinogalactano de Lariço

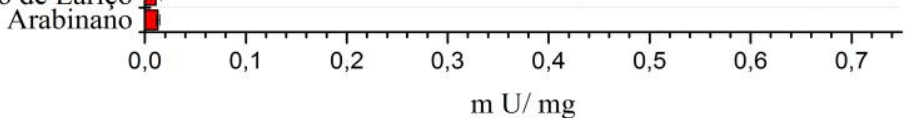

(continua) 


\section{(continuação)}

C

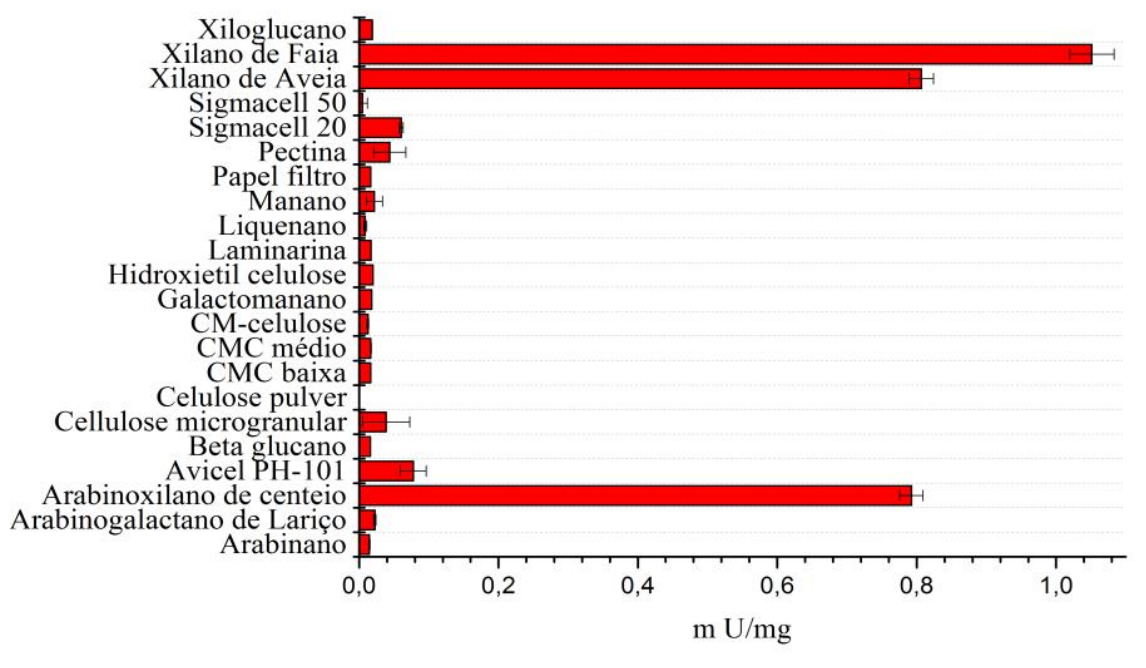

D

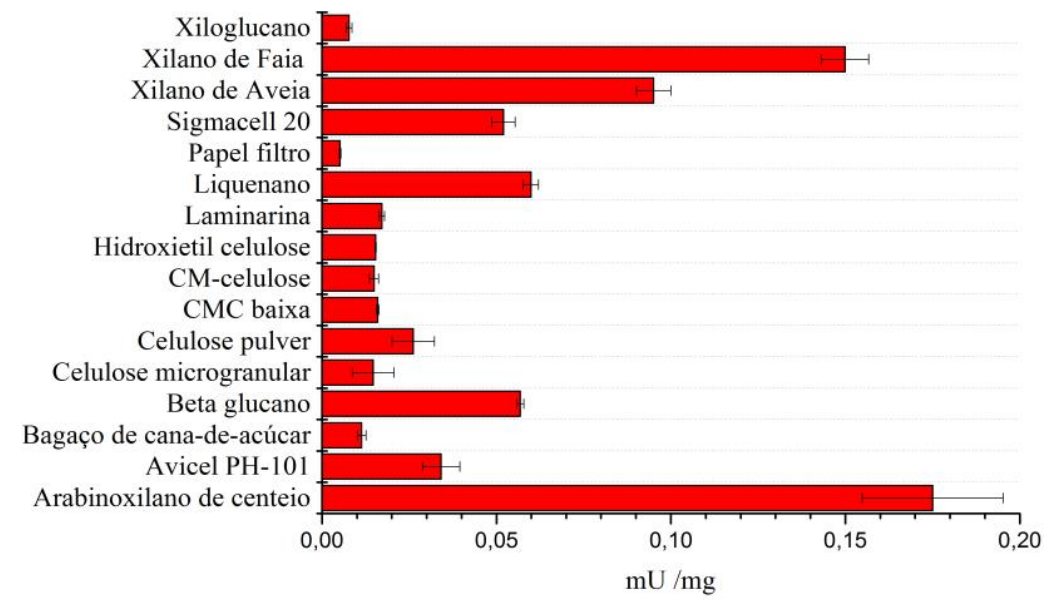

(continua) 
(continuação)

$\mathrm{E}$

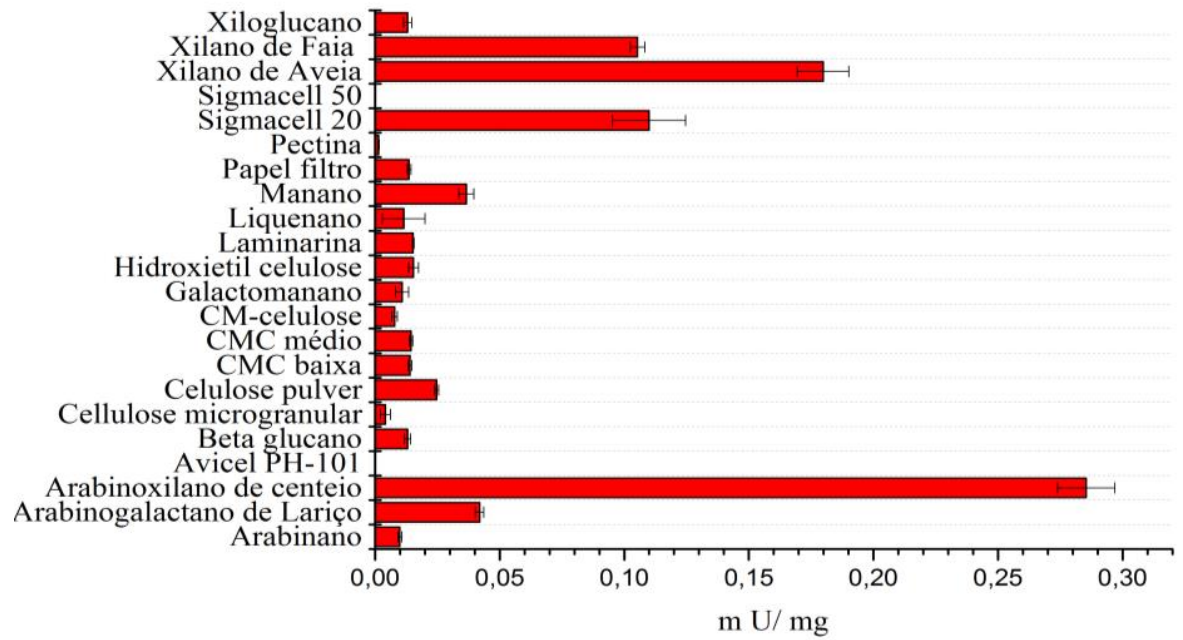

Figura 31 - Painel de substratos para as enzimas clonadas de T81: A ( T81_46750 GH6), B (T81_30480 GH30_7), C (T81_30480, domínio catalítico) e E ( T81_14280 GH5_22) foram utilizadas as concentrações de 4,$3 ; 5,6 ; 6,2$ e $12,5 \mu \mathrm{M}$, respectivamente, reações por $120 \mathrm{~min}$ a $60^{\circ} \mathrm{C}, 1000 \mathrm{rpm}$ e para a enzima $\mathrm{D}$ (T81_05390, GT4) na concentração de $7 \mu \mathrm{M}, 720 \mathrm{~min}$ a $60^{\circ} \mathrm{C}$, com rotação de $1000 \mathrm{rpm}$.

Fonte: Elaborada pelo autor.

\section{Teste de temperatura e pH ótimos}

As condições ótimas de catálise da enzima T81: 30480, 30480 domínio catalítico e 22550 sobre o substrato xilano de Faia estão apresentadas nas Figuras de 32 a 34.
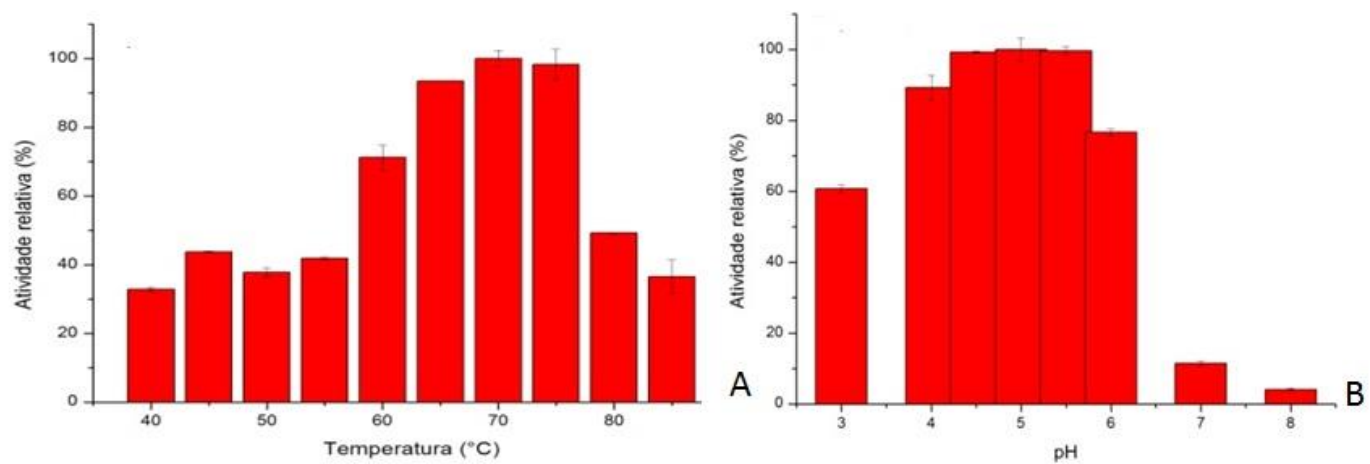

Figura 32 - Avaliação dos substratos para a enzima (T81_30480 GH30_7): A temperatura ótima e B pH. Fonte: Elaborada pelo autor. 

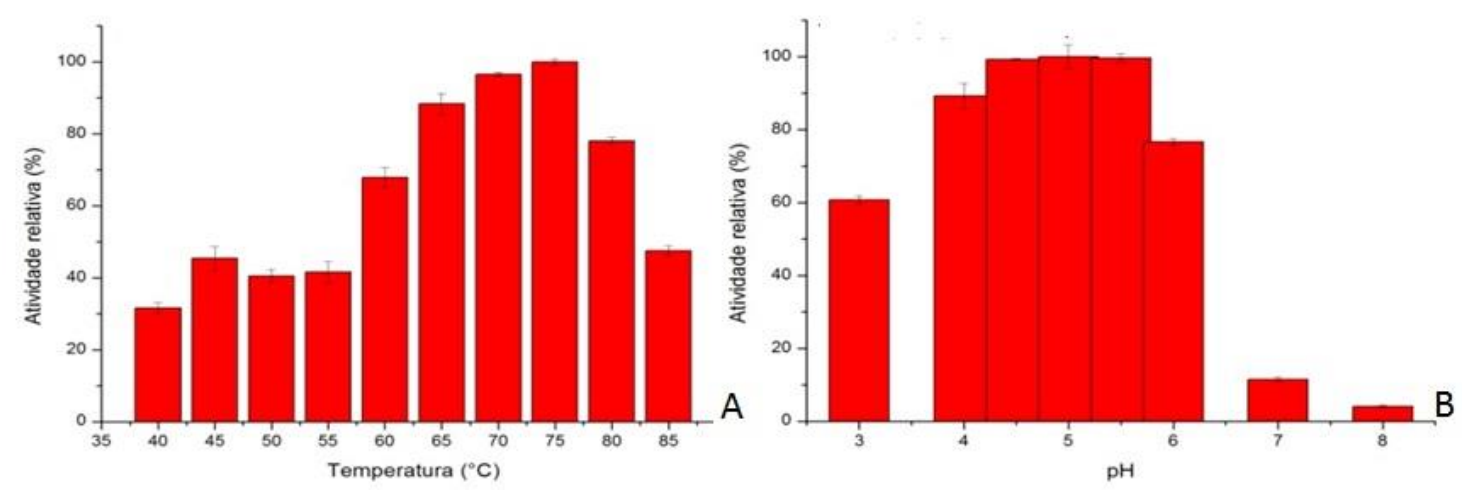

Figura 33 - Avaliação das condições ótimas para a enzima C(T81_30480 GH30_7 domínio catalítico). A. temperatura e B. $\mathrm{pH}$.

Fonte: Elaborada pelo autor.
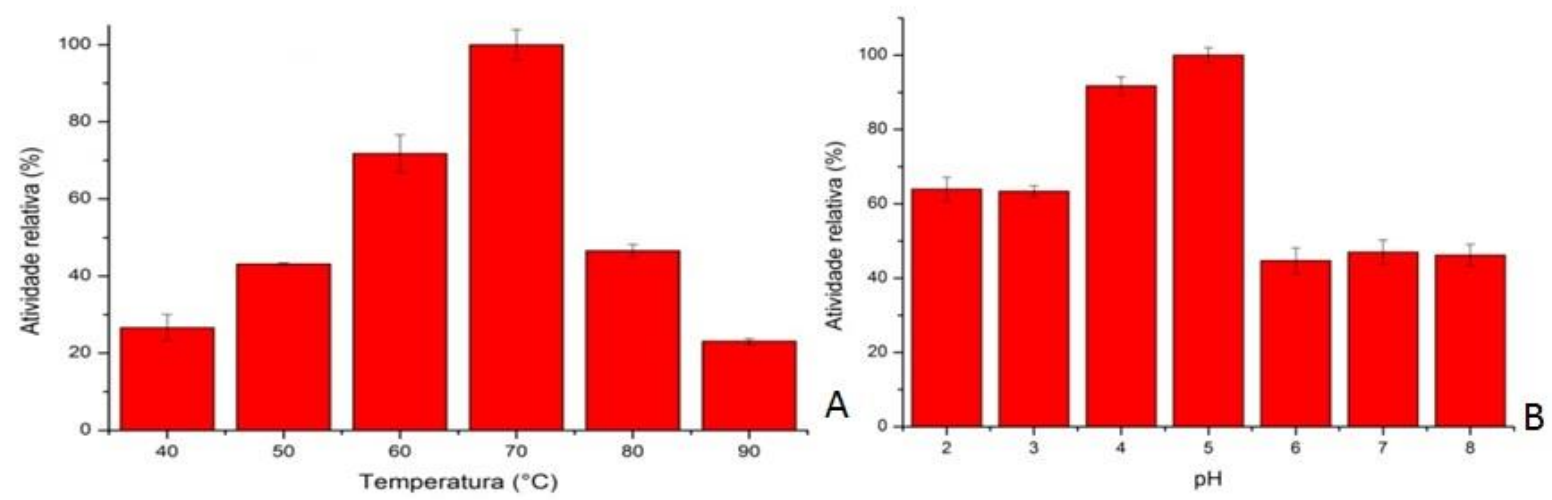

Figura 34 - Avaliação das condições ótimas para da enzima E (T81_22550, GT4): A. temperatura ótima de $70^{\circ} \mathrm{C}$ e B. pH. de 5.

Fonte: Elaborada pelo autor.

Para as enzimas T81_30480, GH30_7 e T81_22550, GT4, as condições ótimas de atividade foram em temperatura de $70^{\circ} \mathrm{C}$ e pH 5. Já para a enzima T81_30480 GH30_7 domínio catalítico as condições ótimas de atividade foram $75^{\circ} \mathrm{C} \mathrm{e} \mathrm{pH} 5$. 


\section{Determinação dos parâmetros cinéticos ( Km e Vmax) para a enzima T81_30480 GH30_7 domínio catalítico}

Como a determinação dos terminais redutores da ação enzimática sobre o substrato dá-se de maneira indireta, método colorimétrico (DNS), a determinação dos parâmetros cinéticos dáse em tempos específicos (End point) e não em tempo real.

Para isto, o experimento avaliando a enzima em condição de excesso de substrato e que possa ser mensurada adequadamente é o primeiro passo para a determinação das constantes cinéticas. Assim, foi variada a concentração da enzima GH30_7 domínio catalítico (T81_30480) em cinco concentrações e a atividade enzimática foi seguida no tempo (Figura 34), buscando-se a melhor condição experimental.

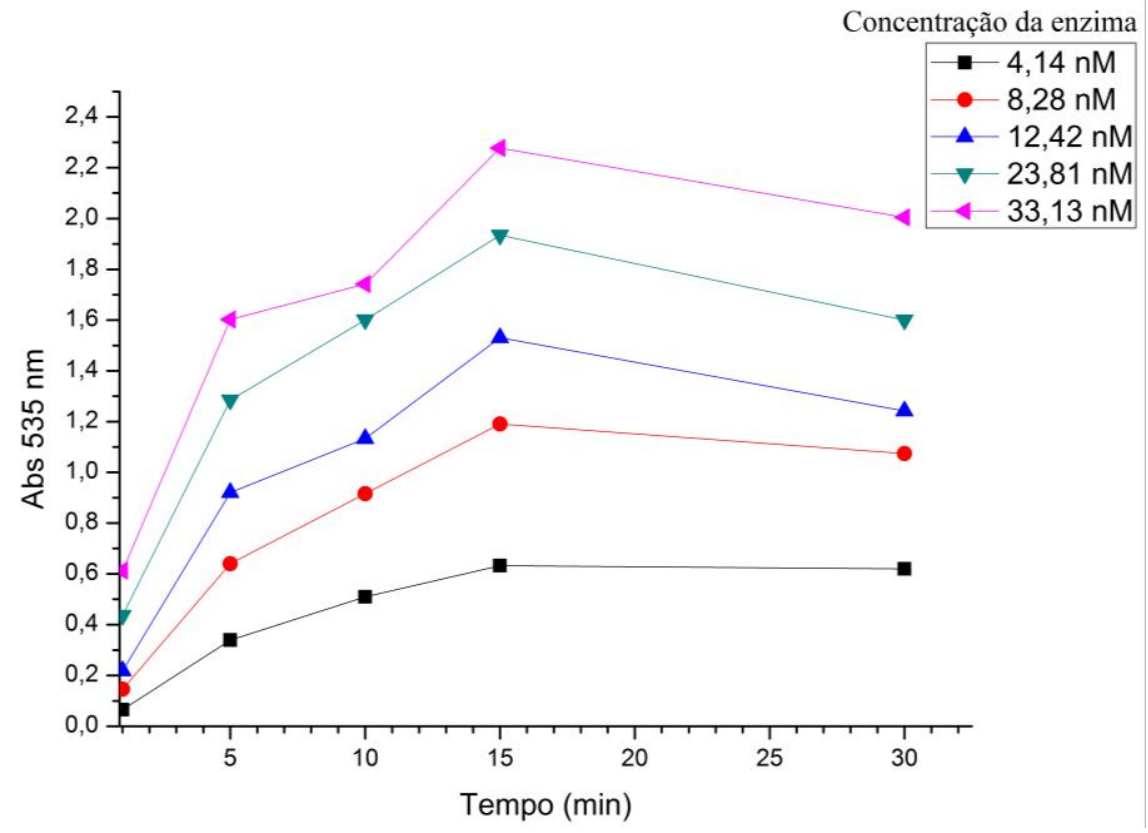

Figura 34 - Determinação da concentração ideal de enzima e do tempo reacional para a enzima GH30_7 domínio catalítico (T81_30480).

Fonte: Elaborada pelo autor. 
Como se observa na Figura 34, a enzima atinge o patamar de saturação em menos de 15 minutos. Desta maneira, utilizando o tempo de 2,5 min e uma concentração de $33 \mathrm{nM}$ (estoque a $7,68 \mathrm{ug} / \mathrm{ml}$ ) com variação da concentração do substrato e obtem-se a velocidade de ação da enzima.

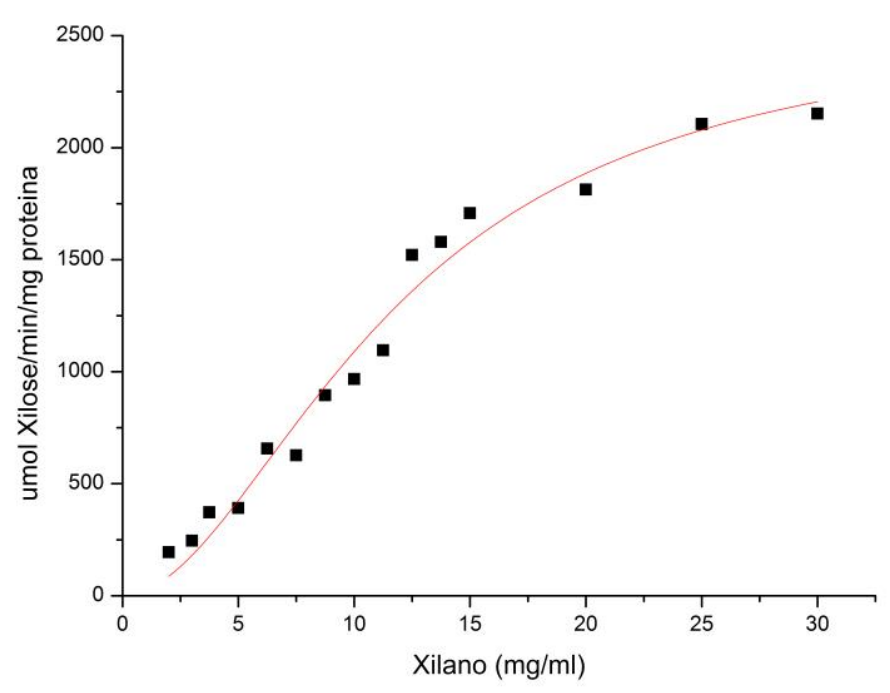

Figura 35 - Gráfico da velocidade de formação de xilose em função da concentração de xilano para a enzima GH30_7 domínio catalítico (T81_30480).

Fonte: Elaborada pelo autor.

Utilizando o programa Origin, os parâmetros cinéticos foram determinados: constante de Michaelis-Menten $(\mathrm{Km})$ de $(11,8 \pm 1,5) \mathrm{mg} / \mathrm{mL}$ e velocidade máxima Vmáx de $(2585,5 \pm 248,0)$ $\mu$ mol de xilose/min/mg proteína. A partir destes parâmetros foram calculados o Kcat e a eficiência da enzima (Tabela 22). Jadhav e Kamble ${ }^{88}$ descreveram uma xilanase do organismo termofílico Bacillus sp DSM 15340 que atuando sobre xilano de faia, apresentou Km e Vmax de $5,26 \mathrm{mg} / \mathrm{mL}$ e $277,7 \mu \mathrm{mol} / \mathrm{min} / \mathrm{mg}$, respctivamente. 
Tabela 22 - Parâmetros cinéticos de caracterização da enzima GH30_7 domínio catalítico (T81_30480).

\begin{tabular}{|c|c|c|}
\hline Parâmetro & Valor & \\
\hline $\begin{array}{l}\text { Vmáx } \\
\text { Km }\end{array}$ & $\begin{array}{c}(2.585 \pm 248) \mu \mathrm{mol} \text { de xilose } / \mathrm{min} / \mathrm{mg} \\
\text { proteína* } \\
(11,82 \pm 1,48) \mathrm{mg} / \mathrm{ml}\end{array}$ & $\begin{array}{c}(0,39 \pm 0,04) \mu \mathrm{mol} \mathrm{de} \\
\text { xilose } / \mathrm{min} \\
(0,37 \pm 0,05) \mathrm{mM}\end{array}$ \\
\hline Kcat & $1967 \mathrm{~s}^{-1}$ & \\
\hline Kcat $/ \mathrm{Km}$ & $\left(5,31 \times 10^{6}\right) \mathrm{M}^{-1} \mathrm{~s}^{-1}$ & \\
\hline Kcat/km & $116(\mathrm{ml} / \mathrm{mg} / \mathrm{s})$ & \\
\hline
\end{tabular}

* $\mu$ mol de xilose/min/mg proteína = U/mg de proteína

Fonte: Elaborada pelo autor.

Além disso, Wang et al. ${ }^{89}$ descreveram uma xilanase (GH11) de Bacillus sp. NTU-06 que hidrolisa xilano de Faia com $\mathrm{Km}$ e Vmax de 3,45 mg/mL e 387,3 umol/min/mg, respectivamente. Já Xu et. al ${ }^{90}$ caracterizaram quatro xilanases de Penicillium oxalicum GZ-2 pertencentes às famílias GH10 e GH11 que hidrolisam xilano de Faia com Km de 3 a 4,7 mg/ml, Vmax de 247 a 3476 umol/min/mg, Kcat de 86,9 a $2176^{\text {s-1 }}$ e Kcat/Km de 28,7 a 467,8 $(\mathrm{ml} / \mathrm{mg} / \mathrm{s})$.

Dessa maneira, quando comparados os parâmetros cinéticos das xilanases acima descritas com a xilanase de Thermogemmatispora sp. T81 (GH30_7 domínio catalítico (T81_40520)) (Tabela 22), conclui-se que a mesma possui parâmetros cinéticos bem próximos aos das mais eficientes descritas. A constante de especificidade (kcat $/ \mathrm{km})$ expressa o quão eficientemente uma enzima converte substrato em produto em baixas concentrações de substrato. O kcat $/ \mathrm{km}$ foi de $116 \mathrm{~mL} / \mathrm{mg} / \mathrm{s}$ para a enzima de estudo, evidenciando uma boa capacidade de conversão mesma em baixas concentrações de xilano.

Para avaliar o estado oligomérico da proteína GH30_7 domínio catalítico (T81_30480) a mesma foi submetida a eletroforese em gel nativo (gradiente de $8-25 \%$ ) para avaliação do perfil oligomérico da mesma. Observa-se que em sua maior parte a enzima encontra-se monomérica com uma banda próxima a $66 \mathrm{kDa}$, condizente com a massa 
teórica calculada para o monômero de 46358,2 Da (Figura 36). Uma banda minoritária correspondente ao estado de dímero também é observada próxima a $140 \mathrm{kDa}$

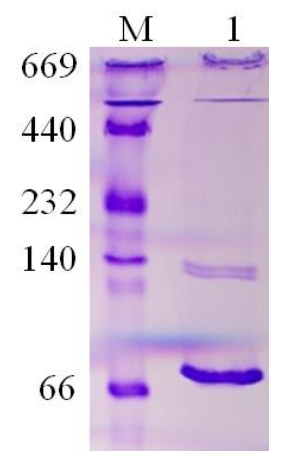

Figura 36 - Perfil eletroforético em gel nativo da enzima GH30_7 domínio catalítico (T81_30480). Gel nativo (gradiente de 8-25\%), M - corresponde ao padrão de massa molecular, 1- corresponde a proteína.

Fonte: Elaborada pelo autor.

\section{Cromatografia em camada delgada (CCD) ou Thin-layer chromatography (TLC) para o domínio catalítico da GH30_7}

O perfil de hidrólise da xilanase sobre xilano de Faia em 2,5 min de reação está apresentado na TLC da Figura 37. Observa-se que os xilo-oligossacarídeos majoritários no processo de hidrólise são xilotetraose e xilohaxaose.

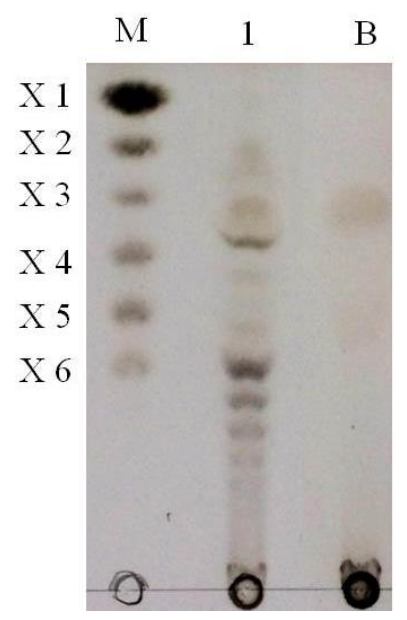

Figura 37 - Cromatografia em camada delgada do perfil de degradação dos oligossacarídeos para GH30_7 domínio catalítico (T81_30480). Cada linha corresponde: M, marcadores de oligossacarídeos, X1 (xilose), X2 (xilobiose), X3( xilotriose), X4 (xilotetraose), X5(xilopentaose) e X6 (Xilohaxaoese), 1: tempo de 2,5 min e B: branco, substrato da reação.

Fonte: Elaborada pelo autor. 
A partir deste perfil de hidrólise pode-se inferir o tipo de atividade hidrolítica da enzima, uma vez que a ausência de xilose como produto de clivagem descarta atividade (Figura 4) do tipo $\beta$-D-xilosidase. Xilanases são conhecidas pela baixa capacidade ou ausência de xilotriose ${ }^{90}$ o que foi confirmado no TLC. Além disso, o perfil de degradação apresenta oligossacarídeos indefinidos com taxa de retenção na sílica com tempo característicos entre os padrões utilizados.

\section{Avaliação do CBM 2}

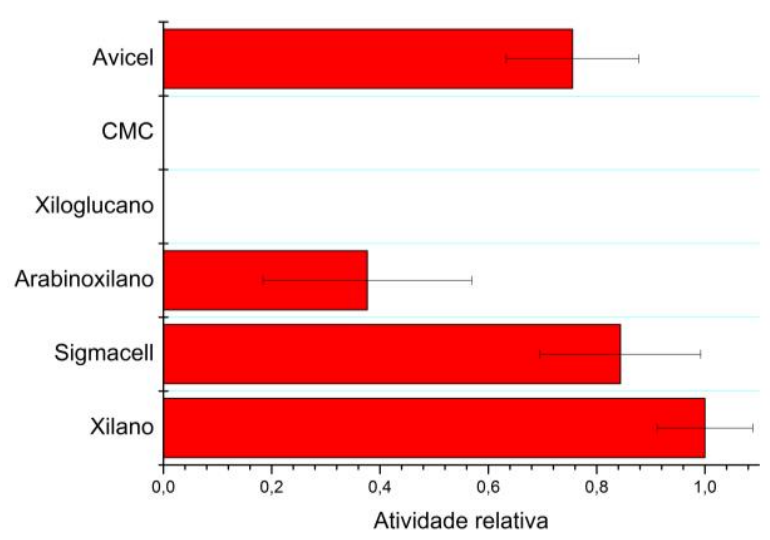

Figura 38 - Atividade relativa do CBM2, reação $24 \mathrm{~h}, 70^{\circ} \mathrm{C}, 100 \mathrm{rpm} .$.

Fonte: Elaborada pelo autor.

A atividade catalítica do domínio de ligação à celulose está apresentada na Figura 38, onde se observa uma atividade sobre substratos hemicelulósicos (xilano e arabinoxilano) e celulósicos (Avicel e Sigmacell).

\subsubsection{Espectroscopia de CD - proteínas de T81}

Na Figura 39 temos os espectros de CD obtidos utilizando-se as proteínas p1( T81_46750 GH6), p2 (T81_30480 GH30_7), p3 (T81_30480, domínio CBM), p5 (T81_30480, domínio catalítico), p7(T81_22550, GT4) e p8( T81_14280 GH5_22). 


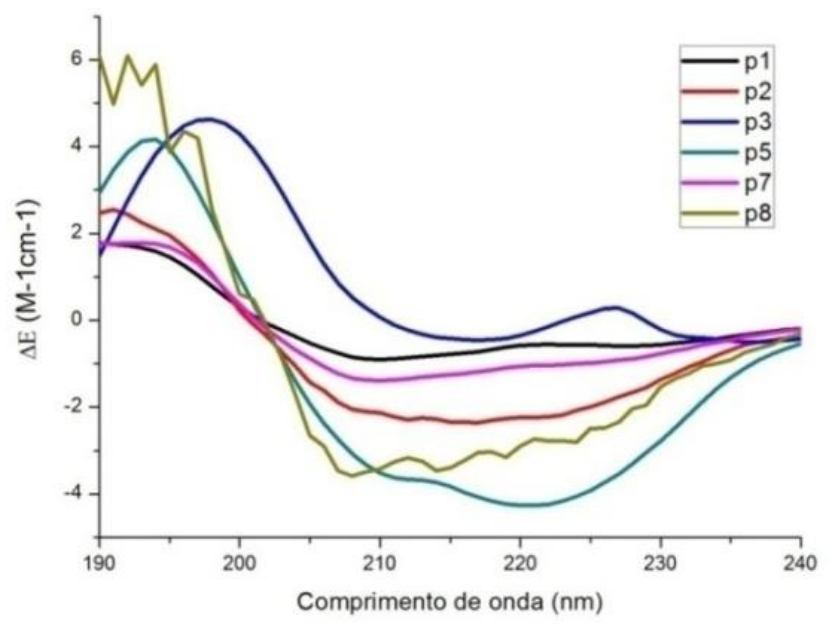

Figura 39 - Espectros de CD obtidos para as proteínas p1( T81_46750 GH6), p2 (T81_30480 GH30_7), p3 (T81_30480, domínio CBM), p5 (T81_30480, domínio catalítico), p7(T81_22550, GT4) e p8( T81_14280 GH5_22).

Fonte: Elaborada pelo autor.

A composição de estruturas secundárias obtidas a partir da deconvolução dos espectros de CD está apresentada na Tabela 23. Os resultados para voltas foram agrupadas com as estruturas desordenadas, haja vista a alta flexibilidade das mesmas e a própria limitação da técnica. Seja observando um mínimo na proximidade de $216 \mathrm{~nm}$ ou consultando a tabela fica evidente que folhas do tipo $\beta$ constituem a fração de estruturas ordenadas mais evidentes entre as proteínas estudadas.

Contudo, para as proteínas p5 e p8 existe um equilíbrio entre a quantidade de $\alpha$ hélice e folhas $\beta$, além de evidenciar a condição bem estruturada destas proteínas. Para a proteína $\mathrm{p} 3$ observamos um pico deslocado para $225 \mathrm{~nm}$ como o apresentado pela ExX. Isto evidencia a semelhança estrutural entre elas e cuja semelhança funcional também foi evidenciada pelos experimentos funcionais. 
Tabela 23 - Proporção de estruturas secundárias obtidas para os dados (CD) deconvoluidos.

\begin{tabular}{cccccc}
\hline Proteína & $\begin{array}{c}\text { Hélices } \\
\boldsymbol{\alpha}(\mathbf{\%})\end{array}$ & $\begin{array}{c}\text { Folhas } \\
\boldsymbol{\beta}(\%)\end{array}$ & $\begin{array}{c}\text { Outros (voltas } \\
\mathbf{e} \\
\text { desordenada) } \\
(\boldsymbol{\%})\end{array}$ & RMSD & $\begin{array}{c}\text { Algoritmo (base de } \\
\text { dados) }\end{array}$ \\
p1(T81_46750) & 9 & 38 & 53 & 0,073 & Contim (SP 175) \\
p2(T81_30480) & 14 & 31 & 55 & 0,051 & CDSSTR (database 4) \\
p3(T81_30480) & 11 & 41 & 48 & 0,175 & Contin (database 4) \\
p5(T81_30480) & 30 & 26 & 44 & 0,097 & Contin (SP175) \\
p7(T81_22550) & 13 & 35 & 52 & 0,089 & Contin (SP175) \\
p8(T81_14280) & 26 & 28 & 46 & 0,041 & CDSSTR (database 4) \\
\hline
\end{tabular}

Fonte: Elaborada pelo autor.

Utilizando o programa de predição de estruturas secundárias $\left.(\mathrm{GOR} 4)^{91}\right)$, foi predito que p1 teria ( $\alpha$-hélice $19 \%$, folhas $\beta 21 \%$ e desordenadas $60 \%$ ), p2 teria ( $\alpha$-hélice $10 \%$, folhas $\beta$ 27\% e desordenadas 63\%), p3 ( $\alpha$-hélice $0 \%$, folhas $\beta 36 \%$ e desordenadas $64 \%$ ), p5 ( $\alpha$-hélice $13 \%$, folhas $\beta 27 \%$ e desordenadas $60 \%$ ), p7 ( $\alpha$-hélice $46 \%$, folhas $\beta 21 \%$ e desordenadas $33 \%$ ) e p8 ( $\alpha$-hélice 34\%, folhas $\beta 15 \%$ e desordenadas 51\%). Confrontando os valores teóricos com os dados experimentais obtidos por espectroscopia de CD das proteínas, observamos que a porcentagem entre estruturas secundárias ( $\alpha$-hélice e folhas $\beta$ ) e outras (voltas e desordenadas) mantém próximas o que evidencia a confiança em programas de predição da quantidade de estruturas ordenadas ou não.

A estabilidade térmica da proteína p5 (T81_30480) foi avaliada por CD, no intervalo de $25^{\circ} \mathrm{C}$ a $95^{\circ} \mathrm{C}$, com uma variação de $5^{\circ} \mathrm{C}$, sendo a taxa de aquecimento de $1^{\circ} \mathrm{C}$.min- ${ }^{1}$. A reversibilidade estrutural pós desnaturação térmica foi analisada adquirindo o espectro de $\mathrm{CD}$ durante o fresfriamento de $95^{\circ} \mathrm{C}$ até atingir $25^{\circ} \mathrm{C}$, com taxa de resfriamento proporcional à de aquecimento. 
Para tanto, monitoramos as estruturas do tipo hélices $\alpha$ em 190, 208 e $222 \mathrm{~nm}$. Em 190 nm, a fotomultiplicadora atingiu saturação na detecção já em $40^{\circ} \mathrm{C}$, $\operatorname{logo}$ não foi possível avaliar este comprimento de onda.
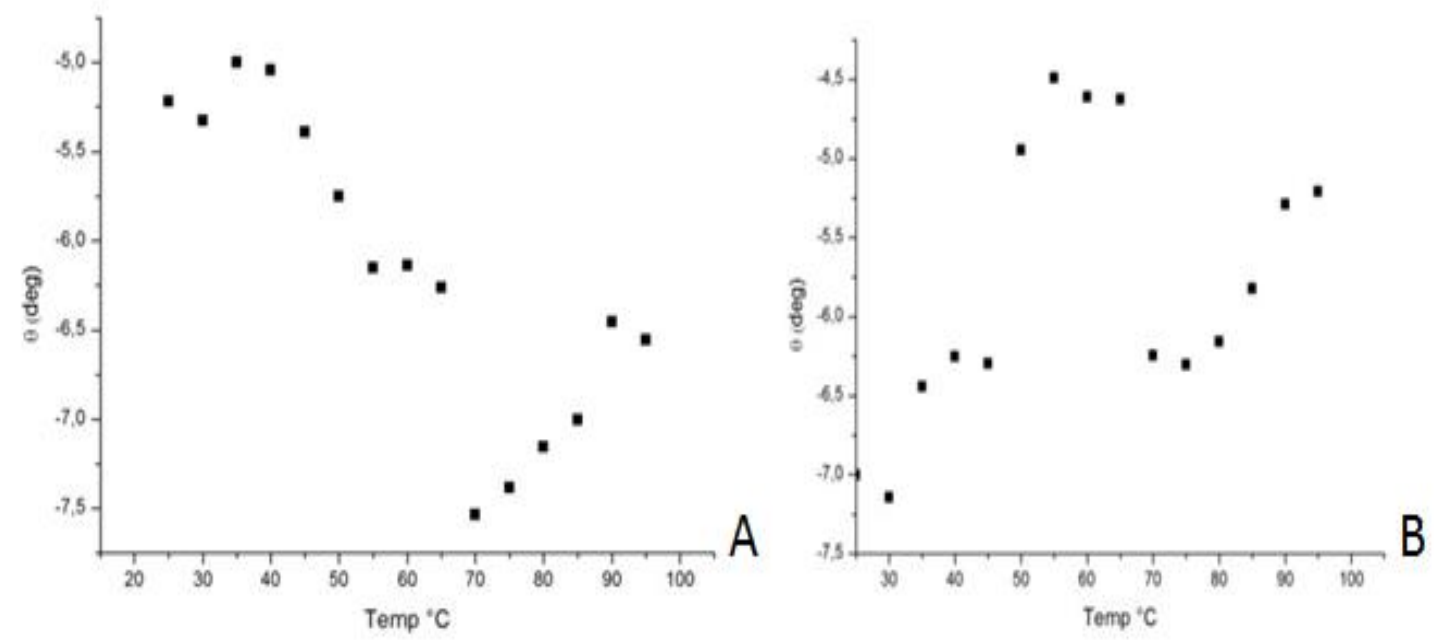

Figura 40 - A Monitoramento em 208nm para a proteína p5 (T81_30480), B Monitoramento em 222nm para a proteína p5 (T81_30480).

Fonte: Elaborada pelo autor.

Com a desnaturação térmica por $\mathrm{CD}$, associado aos dados de cinética, foi possível correlacionar uma reorganização dos elementos de estrutura secundária a partir dos $65^{\circ} \mathrm{C}$ até $75^{\circ} \mathrm{C}$ observada nos comprimentos de onda monitoramento $208 \mathrm{~nm}$ (Figura 40A) e $222 \mathrm{~nm}$ (Figura 40B), com a condição ótima de atividade da mesma que ocorre aos $75^{\circ} \mathrm{C}$. Assim, uma reordenação estrutural torna a enzima ótima para a atividade. 


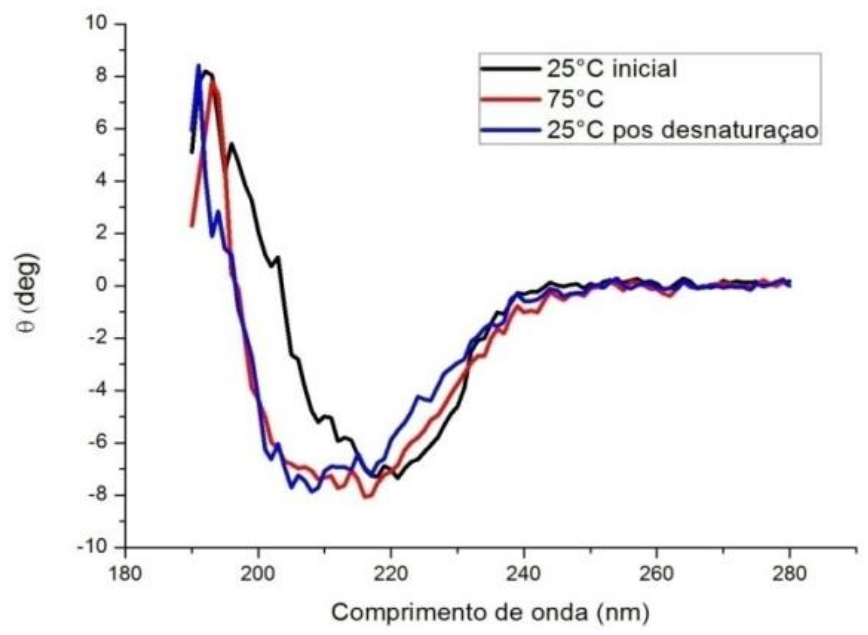

Figura 41 - Espectro de dicroísmo circular da p5 em $25^{\circ} \mathrm{C}$ inicial, $75^{\circ} \mathrm{C}$ e $25^{\circ} \mathrm{C}$ pós desnaturação térmica. Fonte: Elaborada pelo autor.

A reversibilidade estrutural com a desnaturação térmica não foi verificada (Figura 41) uma vez que além da mudança do espectro entre a amostra, antes e pós desnaturação analisados a $25^{\circ} \mathrm{C}$, ocorreu uma perda funcional em $95 \%$, verificada em teste cinético.

\subsubsection{Modelo por homologia da proteína T81_30480_domínio catalítico}

Utilizando o servidor Phyre 2 foi construído por homologia um modelo estrutural para a proteína GH30_7 tendo-se como molde a estrutura da $\beta$-glicosidade de Homo sapiens (PDBid 2F61) com $22 \%$ de identidade sequencial e $91 \%$ cobertura. Este modelo permite gerar hipóteses sobre o enovelamento típico de enzimas desta família e permite correlacionar o mesmo com dados estruturais obtidos a partir de modelos de baixa resolução obtidos com a técnica de SAXS. Na figura 42 apresenta-se o modelo obtido para a GH30_7. 

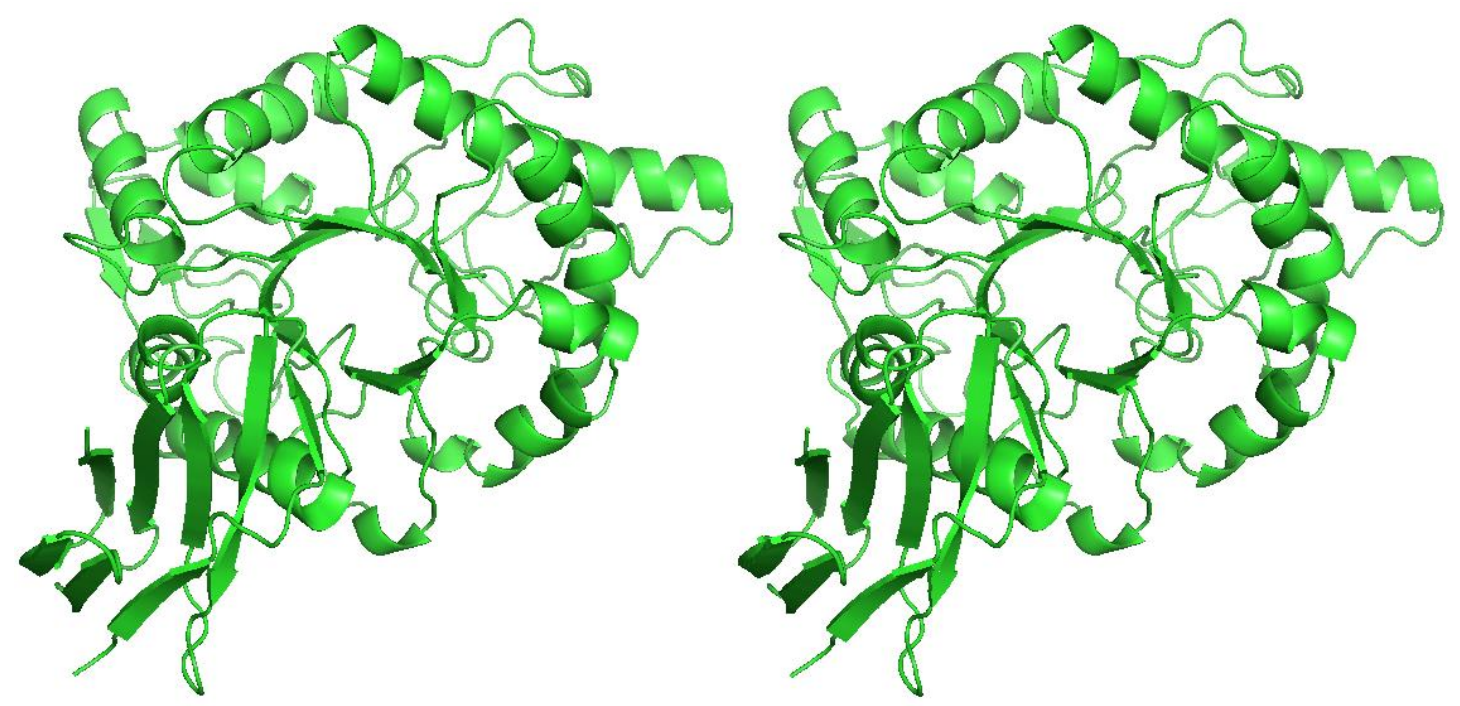

Figura 42 -Imagem estéreo do modelo para GH30_7_domínio catalítico (T81_30480) obtido por homologia. Fonte: Elaborada pelo autor.

\subsubsection{SAXS}

As curvas de espalhamento de GH30_7 domínio catalítico em solução assim como de seu tampão foram coletados em 2 etapas de 300 segundos para monitoramento dos danos causados pela radiação à amostra, além da estabilidade do feixe. De maneira sistemática foi realizada a subtração dos dados pela radiação de fundo no mesmo tempo de exposição, em seguida, normalizando-os pela intensidade do feixe incidente e multiplicando-os pela absorção da amostra. O espalhamento da solução tampão foi subtraído da curva de espalhamento da solução de proteína.

Em seguida, o padrão de espalhamento bidimensional da proteína foi integrado em $2 \Theta$ obtendo-se por fim a curva de espalhamento a baixo ângulo. O raio de giro $\left(R_{g}\right)$ foi obtido por dois métodos distintos, utilizando a equação de Guinier ${ }^{92}$ (Figura 43) e pelo método de Transformada Inversa de Fourier implementado no programa Gnom $^{58}$, onde também foi gerado a função de distribuição de distâncias $p(r)$ e a $D_{\operatorname{máx}}$ das proteínas foi estimada. 


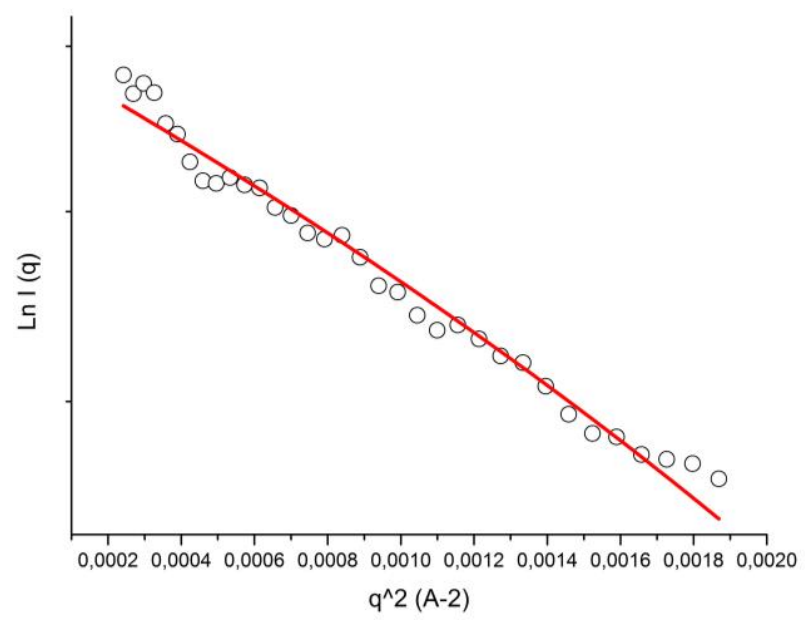

Figura 43 - Obtenção do raio de giro pelo método de Guinier

Fonte: Elaborada pelo autor

A partir da aproximação de Guinier sobre a curva de espalhamento (qR $\mathrm{g}_{\mathrm{g}}<1,3$ ) obtivemos o raio de giro da proteína igual a $(23,5 \pm 0,2) \AA$ que concorda com o determinado pelo Gnom de 23,2 . Ao aplicar o Gnom, os pontos iniciais da curva de espalhamento foram eliminados devido à evidência de pequenos agregados na solução protéica medida.

A estimativa da massa molecular da proteína GH30_7 (domínio catalítico) em solução foi estimada utilizando o servidor SAXS MoW $W^{93}$ como sendo de 39,28 kDa. Este dado indica a predominância de monômeros em solução com erro relativo para a massa molecular teórica de 15\%. A predominância do estado monomérico da proteína foi confirmada pela técnica de eletroforese em gel nativo Figura 36.

A distribuição de frequência de distâncias $p(r)$ da proteína é uma gaussiana deslocada para esquerda. Sendo $D_{\text {máx }}$ de $68 \AA$ (Figura 44). Os valores de $R g, D_{\max }$ foram calculados para um intervalo de q entre $0,00968 \AA^{-1}$ e $0,20922 \AA^{-1}$ com uma resolução de $30,01 \AA$. 


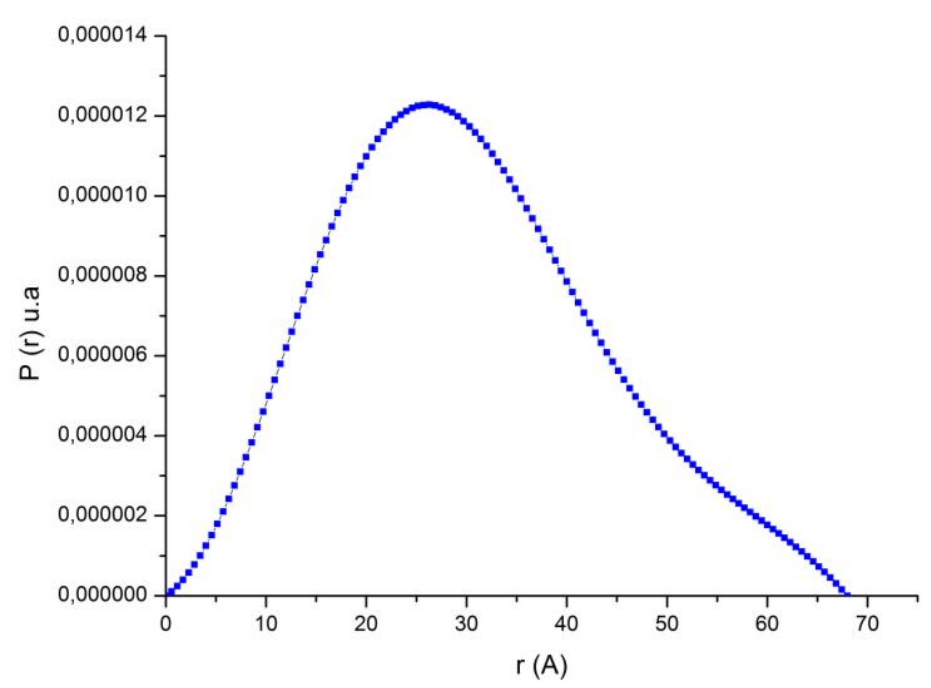

Figura 44 - Função de distribuição de distâncias para os dados experimentais da GH30_7 domínio catalítico.

Fonte: Elaborada pelo autor.

Os modelos de envelope molecular do tipo dummy atoms foram obtidos utilizando o programa Dammin. ${ }^{94}$ Para atestar a unicidade do modelo, simulações independentes partindo de diferentes parâmetros iniciais e sem imposição de simetria foram realizadas. O envelope mergeado e normalizado pelo volume está representado na Figura 46. A sobreposição da curva de espalhamento experimental sobre a curva simulada do modelo de átomos dummy mostra que o mesmo representa adequadamente os dados experimentais da GH30_7. A curva de espalhamento teóricas dos modelos de átomo dummy e do modelo por homologia foram calculadas utilizando o programa $\mathrm{Crysol}^{60}$ (Figura 45). 


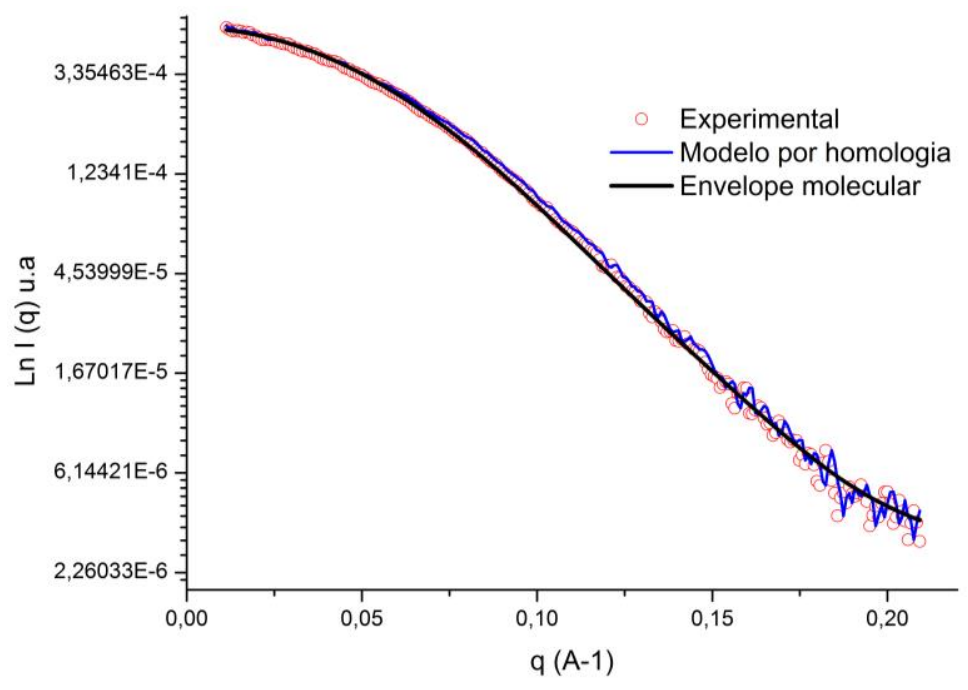

Figura 45 - Curva de espalhamento de raios-X a baixo ângulo da proteína GH30_7 domínio catalítico. Para o modelo de envelope molecular, DAM (Dammin), modelo cristalográfico por homologia e para a curva experimental.

Fonte: Elaborada pelo autor.

O modelo a baixa resolução da GH30_7 (domínio catalítico) obtido pelo modelo de átomos de dummy foi posicionado sobre o modelo por homologia obtido com o uso do servidor Phyre $2^{38}$ utilizando o programa supcomb20. O modelo de envelope molecular sobrepõe bem o modelo por homologia (Figura 46). Os parâmetros estruturais obtidos a partir dos dados de SAXS do DAM e do PDB por homologia podem ser visualizados na Tabela 24. O valor de NSD foi de $(0,57 \pm 0,02)$ e o de $\chi=(3,54 \pm 0,02)$.

Tabela 24 - Parâmetros estruturais da GH30_7 domínio catalítico, obtidos por SAXS.

\begin{tabular}{lccc}
\hline \multicolumn{1}{c}{ Parâmetros } & Exp. ${ }^{*}$ & PDB. ${ }^{\dagger}$ & DAM. $\$$ \\
$\mathrm{D}_{\text {máx }}(\AA)$ & 68 & 75,39 & 76,53 \\
$\mathrm{R}_{\mathrm{g}}(\AA)$ & 23,2 & 22,52 & 23,33 \\
Resolução $(\AA)^{\epsilon}$ & 30,01 & --- & 30,01 \\
\hline
\end{tabular}

* Exp., calculado a partir dos dados experimentais a $1 \mathrm{mg} / \mathrm{ml}$ para a $\mathrm{GH30 \_} 7$

$†$ PDB id: gerado por modelagem utilizando o program Phyre2 tendo como molde o PDB $2 f 61$

\#DAM, parâmetros do modelo de átomos dummy (DAM) gerado sem imposição de simetria no programa Dammin.

$\epsilon$ Resolução $2 \pi / q_{\text {máx.. }}$

Fonte: Elaborada pelo autor 

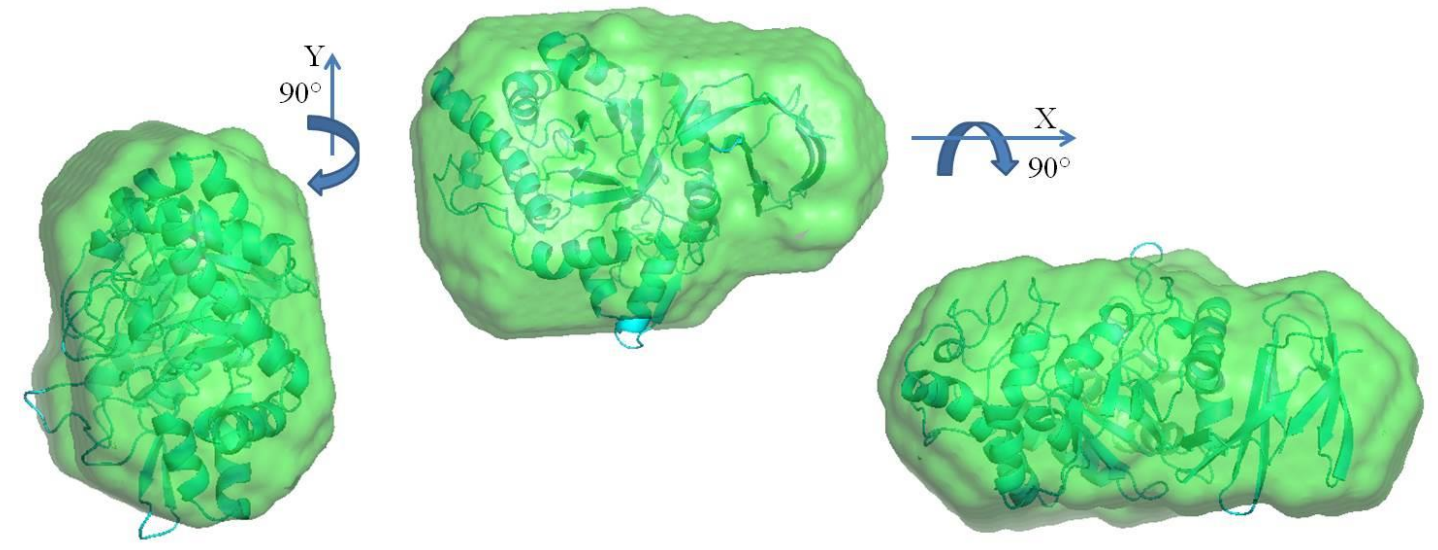

Figura 46 - Sobreposição do DAM para GH30_7 com o modelo por homologia. A partir do modelo central temos: a imagem a direita provinda de uma rotação de $90^{\circ}$ no eixo x e a da esquerda a partir de uma rotação de $90^{\circ}$ com relação ao eixo y. Tomando como coordenadas o plano cartesiano xyz.

Figura: Elaborada pelo autor.

\subsubsection{Ensaios de cristalização.}

A varredura inicial de condições de cristalização (descrita na seção de materiais e métodos) foi realizada para os seguintes alvos: T81_30480 (GH30_7), T81_30480 (domínio CBM), T81_30480 (domínio catalítico), T81_22550 (GT4) e T81_14280 (GH5_22), com amostras protéicas a $10 \mathrm{mg} / \mathrm{mL}$. Contudo, apenas para T81_30480 (domínio catalítico) foi obtida uma condição satisfatória. Os cristais foram obtidos na condição: $0,1 \mathrm{M}$ de hepes pH 7,5 e 70\% MPD após 15 dias de equilíbrio, morfologicamente possuem o formato de agulhas (Figura 47). 


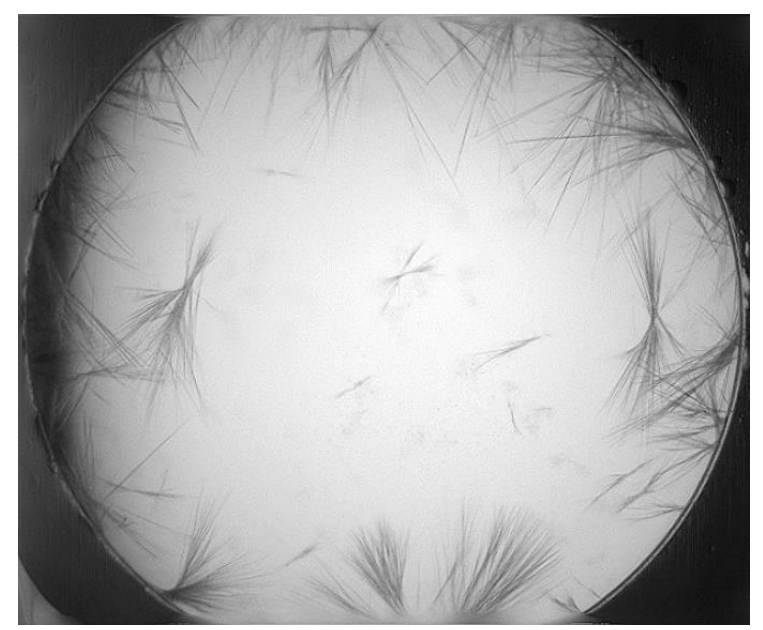

Figura 47 - Cristais do sítio catalítico da GH30_7 de T81.

Fonte: Obtida pelo autor

Devido ao formato apresentado, o refinamento da condição de cristalização determinada, possibilitara a obtenção de cristais com simetria melhor definida. Para isso, a variação de precipitante, $\mathrm{pH}$, concentração de proteína e temperatura são fatores fundamentais para variação. 


\section{CONCLUSÃO}

Neste trabalho foram apresentados os resultados obtidos para a clonagem e estudos estruturais e funcionais das expansinas de Xanthomonas campestris, Bacillus licheniformis e Trichoderma reesei. Também foram realizadas análises do genoma, proteôma, clonagem e caracterização bioquímica dos melhores genes expressos pela cepa T81 de Thermogemmatispora sp. utilizando substrato celulósico: $\alpha$-celulose. As atividades foram desenvolvidas nos laboratórios de pesquisa do Instituto de Física de São Carlos, Laboratório Nacional de Luz Síncrotron em Campinas e na Universidade de Manitoba em Winnipeg no Canadá.

Para o estudo de expansinas: através do emprego de ferramentas de bioinformática foram definidos os genes alvos; o produto de expressão foi obtido com um rendimento de $20 \mathrm{mg} / \mathrm{L}$ de cultura, possibilitando os estudos sinérgicos e cinéticos. Os experimentos de sinergismo das expansinas estudadas atuando em conjunto com o coquetel enzimático Accelerase 1500, permitiram observar que há um aumento do número de açúcares redutores livres disponíveis para a reação, sendo os graus de sinergismo obtidos de 2,47 para a expansina de Xanthomonas campestris, 1,96 para a expansina de Bacillus licheniformis, 2,44 para o SWO1-domínio catalítico de Trichoderma reesei e 2,17 para o domínio de Rare lipoprotein de Trichoderma reesei.

A expansina de Xanthomonas campestris teve sua caracterização estrutural e efeito sinérgico descritos e publicados no artigo "Xanthomonas campestris expansin-like $\mathrm{X}$ domain is a structurally disordered beta-sheet macromolecule capable of synergistically enhancing enzymatic efficiency of cellulose hydrolysis" em anexo, e teve sua atividade catalítica comprovada. A expansina de Bacillus licheniformis, o SWO1 domínio catalítico e o domínio de Rare lipoprotein de Trichoderma reesei também tiveram sua atividade catalítica comprovada sobre o substrato hemicelulósico xilano de Faia, com padrão de degradação demonstrado com a técnica de cromatografia em camada delgada (com destaque para a predominância de xilooligossacarideos de 4 e 6 monômeros). Além disso, com as sobreposições estruturais da 
expansina de Xanthomonas campestris e a PcCel45A (PDB 3X3M) foi possível a identificação dos aminoácidos possivelmente responsáveis pelo efeito catalítico em expansinas.

A análise do genoma anotada para a bactéria Thermogemmatispora sp. T81 possibilitou a identificação de um potencial lignocelulolítico, principalmente devido ao alto número (18) quando comparado às outras bactérias do filo Chloroflexi de CAZymes extracelulares preditas, o que engloba as principais famílias de GH envolvidas na hidrólise de material lignocelulósico. A partir dos estudos de proteômica desta bactéria cultivada com glicose, $\alpha$-celulose e extrato de levedura, foram identificados quatro genes com alto índice de expressão sobre material celulósico. Estes foram então selecionados para clonagem, expressão e caracterização bioquímica e estrutural.

Para os genes selecionados a partir dos dados de proteômica, foram determinados a atividade hidrolítica específica, $\mathrm{pH}$ e temperatura ótimos de atividade. Dentre estes alvos selecionados da Thermogemmatispora sp. T81, a proteína GH30_7 (T81_30480) foi extensamente caracterizada neste projeto, com estudos de espalhamento de raios- $\mathrm{X}$ a baixo ângulo (SAXS), determinação dos parâmetros cinéticos e determinação de condições de cristalização. O modelo de SAXS obtido para a GH30_7 (T81_30480) explica bem o enovelamento estrutural obtido utilizando técnicas de modelagem por homologia, além disso, os parâmetros cinéticos determinados, $\mathrm{Km}=11,82 \mathrm{mg} / \mathrm{mL}$ e Vmáx $=2585,5 \mu \mathrm{mol}$ de xilose/min/mg proteína, classificam esta enzima entre as melhores xilanases dentre as GHs. Adicionalmente, trata-se de uma das primeiras xilanases com parâmetros cinéticos determinados na família GH30.Para tanto a condição de cristalização da mesma foi determinada, permitindo futuros estudos estruturais de difração de raios-X em monocristal.

As porcentagens de estrutura secundária para as expansinas e para os produtos de genes selecionados da Thermogemmatispora sp. T81 foram condizentes com o previsto teoricamente, a partir dos resultados de dicroísmo circular. Além disso, para expansinas de Xanthomonas campestris ainda foi discutido a influência de aminoácidos aromáticos no desvio do plano da luz polarizada. 
Desta maneira, os objetivos iniciais propostos neste projeto foram concluídos. Para as expansinas foi determinado o grau de sinergismo e proposição de um mecanismo de hidrólise para as mesmas, já que por mais de 20 anos tiveram sua atividade definida exclusivamente como enzimas acessórias. Devido às propriedades termoestáveis das enzimas expressas pela bactéria Thermogemmatispora sp. T81 foram identificados e selecionados genes com aplicação biotecnológica, entre esses o gene da proteína GH30_7 (xilanase) cuja caracterização bioquímica e estrutural confirmam sua alta estabilidade, atividade e eficiência em relação às outras enzimas dessa família descritas na literatura. 


\section{REFERÊNCIAS}

1 BRASKEN. O. Etanol. 2015. Disponível em: <http://www.braskem.com.br/site.aspx/Etanol >. Acesso em: 20 maio 2015.

2 BEG, Q. K. et al. Microbial xylanases and their industrial applications: a review. Applied Microbiology and Biotechnology, v. 56, n. 3-4, p. 326-338, 2001.

3 ROGER, P. et al. Cell wall chemistry. In: ROWELL, R. M. (Ed.). Handbook of wood chemistry and wood composites. Boca Raton: CRC Press, 2005

4 TAIZ, L.; ZEIGER, E. Plant physiology. 5th ed. Sunderland, MA: Sinauer Associates, 2010. cap. 15 , p.425-452.

5 SPLETTSTOESSER, T. Lignocellulose - SciStyle. scientific illustration and animation service. $2011 . \quad$ Disponível em: <http://portfolio.scistyle.com/filter/illustration/Lignocellulose >. Acesso em: 26 jul. 2015.

6 CASTRO, A. M. D.; PEREIRA JUNIOR, N. Produção, propriedades e aplicação de celulases na hidrólise de resíduos agroindustriais. Química Nova, v. 33, n. 1, p. 181-188, 2010.

7 YANG, B.; WYMAN, C. E. Cellulosic ethanol for sustainable transportation. Disponível em:

$<$ http://www.calrecycle.ca.gov/organics/conversion/events/techforum06/Presentatns/BinY ang.pdf $>$. Acesso em: 30 jun. 2015.

8SIU, R. G. H. Microbial decomposition of cellulose. New York: Reinhold Publishing Corporation, $1951.531 \mathrm{p}$.

9 COLlins, T.; GERDAY, C.; FELlER, G. Xylanases, xylanase families and extremophilic xylanases. FEMS Microbiology Reviews, v. 29, n. 1, p. 3-23, 2005.

10 GALLARDO, Ó. et al. Characterization of a family GH5 Xylanase with activity on neutral oligosaccharides and evaluation as a pulp bleaching Aid. Applied and Environmental Microbiology, v.76, n. 18, p.6290-6294, 2010.

11 CANTAREL, B. L. et al. The carbohydrate-active enzymes database (CAZy): an expert resource for glycogenomics. Nucleic Acids Research, v. 37, p. D233-D238, 2009. doi: $\underline{10.1093 / \mathrm{nar} / \mathrm{gkn} 663}$. 
12 KIM, I. J. et al. Synergistic proteins for the enhanced enzymatic hydrolysis of cellulose by cellulase. Applied Microbiology and Biotechnology, v. 98, n. 20, p. 8469-8480, 2014

13 KOSHLAND JR, D. E. Stereochemistry and the mechanism of enzymatic reactions. Biological Reviews, v. 28, n. 4, p. 416-436, 1953.

14 JONGKEES, S. A.; WITHERS, S. G. Unusual enzymatic glycoside cleavage mechanisms. Accounts of Chemical Research, v. 47, n. 1, p. 226-235, 2014.

15 DAVIES, G.; HENRISSAT, B. Structures and mechanisms of glycosyl hydrolases. Structure, v. 3, n. 9, p. 853-859, 1995.

16 PIERETTI, I. et al. The complete genome sequence of Xanthomonas albilineans provides new insights into the reductive genome evolution of the xylem-limited Xanthomonadaceae. BMC Genomics, v. 10, n. 1, p. 616, 2009.

17 AGENCY, U. S. E. P. Bacillus Licheniformis final risk assessment. Disponível em: < http://www.epa.gov/biotech_rule/pubs/fra/fra005.htm >. Acesso em: 05 set. 2012.

18 Bacillus licheniformis final risk assessment. 1997. Disponível em: < http://www.epa.gov/biotech_rule/pubs/fra/fra005.htm >. Acesso em: 05 set. 2012.

19 HARMAN, G. E. et al. Trichoderma species--opportunistic, avirulent plant symbionts. Nature Reviews Microbiology, v. 2, n. 1, p. 43-56, 2004.

20 ADAMS, M. W. W.; KELLY, R. M. Enzymes from microorganisms in extreme environments. Chemical \& Engineering News, v. 73, n. 51, p. 32-42, 1995.

21 BHALLA, A. et al. Improved lignocellulose conversion to biofuels with thermophilic bacteria and thermostable enzymes. Bioresource Technology, v. 128, p. 751-759, 2013. doi: 10.1016/j.biortech.2012.10.145.

22 HARRIS, P. V. et al. Stimulation of lignocellulosic biomass hydrolysis by proteins of glycoside hydrolase family 61: structure and function of a large, enigmatic family. Biochemistry, v. 49, n. 15, p. 3305-3316, 2010

23 STOTT, M. B. et al. Isolation of novel bacteria, including a candidate division, from geothermal soils in New Zealand. Environmental Microbiology, v. 10, n. 8, p. 20302041, 2008. 
24 STOTT, M. B.; DUNFIELD, P. F.; CROWE, M. A. New Class of Chloroflexi-like thermophilic cellulose degrading bacteria. USA. US 2011/0091951 2011.

25 RUGGIERO, M. A. et al. A higher level classification of all living organisms. PLoS One, v. 10, n. 4, p. e0119248, 2015.

26 MORGAN, X. C. et al. Thermogemmatispora sp. tikiterensis sp. nov., a thermophilic isolate of class Ktedonobacteria, and emended description of the clade Thermogemmatispora sp. gen. nov. (Yabe et al., 2011). International Journal of Systematic and Evolutionary Microbiology. 2014. In press.

$27 \mathrm{KENDE}, \mathrm{H}$. et al. Nomenclature for members of the expansin superfamily of genes and proteins. Plant Molecular Biology, v. 55, n. 3, p. 311-314, May 2004. ISSN 01674412. Disponível em: < <Go to ISI >://WOS:000225690200001 >.

28 KIM, E. S. et al. Functional characterization of a bacterial expansin from bacillus subtilis for enhanced enzymatic hydrolysis of cellulose. Biotechnology and Bioengineering, v. 102, n. 5, p. 1342-1353, 2009.

29 TOMAZINI JUNIOR, A. Caracterização estrutural da glicosilhidrolase de xanthomonas campestris contendo os domínios: catalítico da familía GH5 e similar à expansina. 2012. 143 p. Dissertação (Mestrado em Ciências) - Instituto de Física de São Carlos, Universidade de São Paulo, São Carlos, 2012.

30 TOMAZINI JUNIOR, A. et al. Xanthomonas campestris expansin-like $\mathrm{X}$ domain is a structurally disordered beta-sheet macromolecule capable of synergistically enhancing enzymatic efficiency of cellulose hydrolysis. Biotechnology Letters, v. 37, n. 12, p. 24192426, 2015.

31 ALTSCHUL, S. F. et al. Basic local alignment search tool. Journal of Molecular Biology, v. 215, n. 3, p. 403-410, 1990.

32 CONTRERAS-MOREIRA, B.; BATES, P. A. Domain fishing: a first step in protein comparative modelling. Bioinformatics, v. 18, n. 8, p. 1141-1142, 2002.

33 HIGGINS, D. G.; SHARP, P. M. Clustal: a package for performing multiple sequence alignment on a microcomputer. Gene, v. 73, n. 1, p. 237-244, 1988. 
34 GASTEIGER, E. et al. Protein identification and analysis tools on the ExPASy server. In: WALKER, J. M. (Ed.). The proteomics protocols handbook. New Jersey: Humana Press, 2005. p. 571-607.

35 CAMILO, C. M.; POLIKARPOV, I. High-throughput cloning, expression and purification of glycoside hydrolases using Ligation-Independent Cloning (LIC). Protein Expression and Purification, v. 99, p. 35-42, 2014. doi: 10.1016/j.pep.2014.03.008

36 SCHÄGGER, H.; JAGOW, G. V. Tricine-sodium dodecyl sulfate-polyacrylamide gel electrophoresis for the separation of proteins in the range from 1 to $100 \mathrm{kDa}$. Analytical Biochemistry, v. 166, n. 2, p. 368-379, 1987.

37 MILLER, G. L. Use of dinitrosalicylic acid reagent for determination of reducing sugar. Analytical Chemistry, v. 31, n. 3, p. 426-428, 1959.

38 KELLEY, L. A. et al. The Phyre2 web portal for protein modeling, prediction and analysis. Nature Protocols, v. 10, n. 6, p. 845-858, 2015.

39 TAMURA, K. et al. MEGA6: molecular evolutionary genetics analysis version 6.0. Molecular Biology and Evolution, v. 30, n. 12, p. 2725-2759, 2013.

40 DI TOMMASO, P. et al. T-Coffee: a web server for the multiple sequence alignment of protein and RNA sequences using structural information and homology extension. Nucleic Acids Research, v. 39, p. W13-W17, 2011. doi: 10.1093/nar/gkr245.

41 MOREIRA, A. D. S.; SOUZA, A. S., VENDRUSCOLO, C. T. Determinação da composição de biopolímero por cromatografia em camada delgada: metodologia. Current Agricultural Science and Technology, v. 4, n. 3, p. 222-224, 1998. Disponível em: <https://periodicos.ufpel.edu.br/ojs2/index.php/CAST/article/viewFile/228/220 >. Acesso em: 09 jul. 2015.

42 WHITMORE, L.; WALLACE, B. A. DICHROWEB, an online server for protein secondary structure analyses from circular dichroism spectroscopic data. Nucleic Acids Research, v. 32, n. 2, p. W668-W673, 2004

43 GREENFIELD, N. J. Analysis of Circular Dichroism Data. Methods in Enzymology, v. 383, 2004. Disponível em: < http://dx.doi.org/10.1016/S0076-6879(04)83012-X >.

44 CHANG, Y. et al. PCR assay of the groEL gene for detection and differentiation of Bacillus cereus group cells. Applied and Environmental Microbiology, v. 69, n. 8, p. 4502-4510, 2003. 
45 HILL, J. E. et al. cpnDB: a chaperonin sequence database. Genome Research, v. 14, n. 8, p. 1669-1675, 2004.

46 MARKOWITZ, V. M. et al. IMG ER: a system for microbial genome annotation expert review and curation. Bioinformatics, v. 25, n. 17, p. 2271-2278, 2009.

47 GARDY, J. L.; BRINKMAN, F. S. Methods for predicting bacterial protein subcellular localization. Nature Reviews Microbiology, v. 4, n. 10, p. 741-751, 2006.

48 BRADFORD, M. M. A rapid and sensitive method for the quantitation of microgram quantities of protein utilizing the principle of protein-dye binding. Analytical Biochemistry, v. 72, n. 1-2, p. 248-254, 1976.

49 SMITH, P. K. et al. Measurement of protein using bicinchoninic acid. Analytical Biochemistry, v. 150, n. 1, p. 76-85, 1985.

50 MCQUEEN, P. et al. Information-dependent LC-MS/MS acquisition with exclusion lists potentially generated on-the-fly: case study using a whole cell digest of Clostridium thermocellum. Proteomics, v. 12, n. 8, p. 1160-1169, 2012.

51 VERBEKE, T. J. et al. Thermoanaerobacter thermohydrosulfuricus WC1 shows protein complement stability during fermentation of key lignocellulose-derived substrates. Applied and Environmental Microbiology, v. 80, n. 5, p. 1602-1615, 2014.

52 GASTEIGER, E. et al. Protein identification and analysis tools on the ExPASy server. In: WALKER, J. M. (Ed.). The proteomics protocols handbook. Totowa: Humana Press, 2005.

53 CARVALHO, N. M. et al. Uso de equações lineares na determinação dos parâmetros de Michaelis-Menten. Química Nova, v. 33, n. 7, p. 1607-1611, 2010.

54 SVERGUN, D. I. et al. Small-angle scattering studies of biological macromolecules in solution. Reports on Progress in Physics, v. 66, n. 10, p. 1735, 2003

55 HAMMERSLEY, A. P. FIT2d: an introduction and overview. Grenoble: ESRF, 1997.

56 ROSA E SILVA, I. Estudos biofíscos de selenofosfato sintetase de Escherichia coli e investigação de seu papel na via de biossíntese de Selenocisteínas. 2012. 140 p. Dissertação (Mestrado em Ciências) - Instituto de Física de São Carlos: Universidade de São Paulo, São Carlos, 2011. 
57 FISCHER, H. D. O. N., M.NAPOLITANO,H. B.POLIKARPOV, I.CRAIEVICH,A. F. Determination of the molecular weight of proteins in solution from a single smallangle X-ray scattering measurement on a relative scale: Journal of Applied Crystallography. 43: 101-109 p. 2010.

58 SVERGUN, D. I. Determination of the regularization parameter in indirect-transform methods using perceptual criteria. Journal of Applied Crystallography, v. 25, n. 4, p. 495-503, 1992.

59 SVERGUN, D. I. Small-angle X-ray and neutron scattering as a tool for structural systems biology. Biological Chemistry, v. 391, n. 7, p. 737-743, 2010.

60 SVERGUN, D.; BARBERATO, C.; KOCH, M. H. J. CRYSOL - a program to evaluate $\mathrm{x}$-ray solution scattering of biological macromolecules from atomic coordinates. Journal of Applied Crystallography, v. 28, n. 6, p. 768-773, 1995.

61 SVERGUN, D. I. Restoring low resolution structure of biological macromolecules from solution scattering using simulated annealing. Biophysical Journal, v. 76, n. 6, p. 2879-2886, 1999

62 KOZIN, M. B.; SVERGUN, D. I. Automated matching of high- and low-resolution structural models. Journal of Applied Crystallography v. 34, pt. 1, p. 33-41, 2001.

63 MCPHERSON, A. Introduction to protein crystallization. Methods, v. 34, n. 3, p. 254 265,2004

64 DRENTH, J. Principles of protein x-ray crystallography. New York: Springer, 2007.

65 DESSAU, M. A.; MODIS, Y. Protein crystallization for x-ray crystallography. Journal of Visualized Experiments, v. 47, 2011. doi: 10.3791/2285.

66 SAMPEDRO, J.; COSGROVE, D. J. The expansin superfamily. Genome Biology, v. 6, n. 12, p. 245, 2005.

67 GEORGELIS, N.; NIKOLAIDIS, N.; COSGROVE, D. J. Biochemical analysis of expansin-like proteins from microbes. v. 100, n. 1, p. 17-23, 20142014.

68 NAKAMURA, A. et al. "Newton's cradle" proton relay with amide-imidic acid tautomerization in inverting cellulase visualized by neutron crystallography. Science Advances, v. 1, n. 7, p. e1500263, 2015. 
69 ANDBERG, M.; PENTTILA, M.; SALOHEIMO, M. Swollenin from Trichoderma reesei exhibits hydrolytic activity against cellulosic substrates with features of both endoglucanases and cellobiohydrolases. Bioresour Technol, v. 181, p. 105-13, Apr 2015. ISSN 0960-8524. Disponível em: < http://dx.doi.org/10.1016/j.biortech.2015.01.024 >.

70 ANDBERG, M.; PENTTILA, M.; SALOHEIMO, M. Swollenin from Trichoderma reesei exhibits hydrolytic activity against cellulosic substrates with features of both endoglucanases and cellobiohydrolases. Bioresource Technology, v. 181, p. 105-113, 2015. doi: 10.1016/j.biortech.2015.01.024

71 PRILUSKY, J. et al. FoldIndex: a simple tool to predict whether a given protein sequence is intrinsically unfolded. Bioinformatics, v. 21, n. 16, p. 3435-3438, 2005.

72 LINDING, R. et al. GlobPlot: exploring protein sequences for globularity and disorder. Nucleic Acids Research, v. 31, n. 13, p. 3701-3708, 2003.

73 ZHAO, Z. et al. Comparative analysis of fungal genomes reveals different plant cell wall degrading capacity in fungi. BMC Genomics, v. 14, p. 274, 2013. doi: 10.1186/1471-2164-14-274.

74 BERLEMONT, R.; MARTINY, A. C. Phylogenetic distribution of potential cellulases in bacteria. Applied and Environmental Microbiology, v. 79, n. 5, p. 15451554, 2013.

75 BERMAN, H. M. et al. The protein data bank. Nucleic Acids Research, v. 28, n. 1, p. 235-242, 2000.

76 POIDEVIN, L. et al. Insights into exo- and endoglucanase activities of family 6 glycoside hydrolases from Podospora anserina. Applied and Environmental Microbiology, v. 79, n. 14, p. 4220-4229, 2013.

77 STROHMEIER, M. et al. Molecular modeling of family GH16 glycoside hydrolases: potential roles for xyloglucan transglucosylases/hydrolases in cell wall modification in the poaceae. Protein Science, v. 13, n. 12, p. 3200-1323, 2004.

78 ST JOHN, F. J. et al. A novel member of glycoside hydrolase family 30 subfamily 8 with altered substrate specificity. Acta Crystallographica D, v. 70, n. pt 11, p. 2950-2958, 2014.

79 SUKHARNIKOV, L. O. et al. Sequence, structure, and evolution of cellulases in glycoside hydrolase family 48. Journal of Biological Chemistry, v. 287, n. 49, p. 410684177, 2012. 
80 LOMBARD, V. et al. The carbohydrate-active enzymes database (CAZy) in 2013. Nucleic Acids Research, v. 42, p. D490-D495, 2014. doi: 10.1093/nar/gkt1178

81 YAOI, K. et al. Tandem repeat of a seven-bladed beta-propeller domain in oligoxyloglucan reducing-end-specific cellobiohydrolase. Structure, v. 12, n. 7, p. 12091217, 2004.

82 LABES, A. et al. Novel members of glycoside hydrolase family 13 derived from environmental DNA. Applied and Environmental Microbiology, v. 74, n. 6, p. 19141921, Mar 2008.

83 BEIER, S.; BERTILSSON, S. Bacterial chitin degradation-mechanisms and ecophysiological strategies. Frontiers in Microbiology v. 4, p. 149, 2013. doi: 10.3389/fmicb.2013.00149.

84 ABBOTT, D. W.; BORASTON, A. B. Structural biology of pectin degradation by enterobacteriaceae. Microbiology and Molecular Biology Reviews, v. 72, n. 2, p. 301316, 2008.

85 LIU, Y. et al. Characterization of glycoside hydrolase family 6 enzymes from coprinopsis cinerea. Bioscience, Biotechnology, and Biochemistry, v. 73, n. 6, 2014. doi: 10.1271/bbb.80888.

86 PAYNE, C. M. et al. Fungal cellulases. Chemical Reviews v. 115, n. 3, p. 1308$1448,2015$.

87 WANG, Y. Exploring glycoside hydrolase family (GH5) enzymes. 2013. Ph. D. Thesis (Licentiate in Biotechnology) - School of Biotechnology, Royal Institute of Technology, Stockholm, 2013.

88 KAMBLE, R. D. et al. Isolation, purification, and characterization of xylanase produced by a new species of bacillus in solid state fermentation. International Journal of Microbiology, v. 2012, 2012 doi: 10.1155/2012/683193.

89 WANG, C.-Y. et al. Production, purification and characterisation of a novel halostable xylanase from Bacillus sp. NTU-06. Annals of Applied Biology, v. 156, n. 2, p. 187-197, $2010>$.

90 LIAO, H. et al. Functional diversity and properties of multiple xylanases from Penicillium oxalicum GZ-2. Scientific Reports, v. 5, p. 12631, 2015. doi: $10.1038 /$ srep 12631 
91 SREERAMA, N.; WOODY, R. W. Estimation of protein secondary structure from circular dichroism spectra: comparison of CONTIN, SELCON, and CDSSTR methods with an expanded reference set. Analytical Biochemistry, v.287, n. 2, p.252-260, 2000.

92 GLATTER, O.; KRATKY, O. Small angle X-ray scattering. New York: Academic Press, 1982.

93 FISCHER, H. D. O. N., M.NAPOLITANO,H. B.POLIKARPOV, I.CRAIEVICH,A. F. Determination of the molecular weight of proteins in solution from a single small-angle Xray scattering measurement on a relative scale. Journal of Applied Crystallography. v. 43, pt 1, p. 101-109, 2010.

94 SVERGUN, D. I. Restoring low resolution structure of biological macromolecules from solution scattering using simulated annealing. Biophysical Journal, v. 77, n. 5, p. 2896-2896, 1999.

95 Pozharski, E. et al. Ligand Bound Structures of a Glycosyl Hydrolase Family 30 Glucuronoxylan Xylanohydrolase. Journal of Molecular Biology, v. 407, n. 1, p. 92-109, 2011.

$96 \mathrm{Liu}, \mathrm{Z}$. et al. Synergism of cellulase, xylanase, and pectinase on hydrolyzing sugarcane bagasse resulting from different pretreatment technologies. Bioresource Technology, v. 155, p. 258-265, 2014. 


\section{APÊNDICE A -}

"Xanthomonas campestris expansin-like X domain is a structurally disordered beta-sheet macromolecule capable of synergistically enhancing enzymatic efficiency of cellulose hydrolysis". 


\title{
Xanthomonas campestris expansin-like X domain is a structurally disordered beta-sheet macromolecule capable of synergistically enhancing enzymatic efficiency of cellulose hydrolysis
}

\author{
At'1lio Tomazini Junior · Luciano Graciani Dolce • \\ Mario de Oliveira Neto · Igor Polikarpov
}

Received: 18 April 2015 / Accepted: 4 August 2015 / Published online: 14 August 2015

(C) Springer Science+Business Media Dordrecht 2015

\begin{abstract}
Objectives To biochemically characterize an expansin-like X protein domain from Xanthomonas campestris (XcEXLX1) and to study its synergy with cellulases in cellulose depolymerization.

Results The protein was purified using a combination of ion exchange and size exclusion chromatography rendering about $30 \mathrm{mg}$ pure protein/l culture medium. Circular dichroism spectroscopy and smallangle X-ray scattering studies of XcEXLX1 reveal that it is a strongly disordered $b$-sheet protein. Its low resolution envelope fits nicely the crystallographic structure of the homologous protein EXLX1 from Bacillus subtillis. Furthermore, we demonstrate that XcEXLX1 shows a synergistic, $\mathrm{pH}$-dependent effect when combined with a commercial enzymatic preparation (Accellerase 1500), enhancing its hydrolytic activity on a cellulosic substrate. The strongest effect
\end{abstract}

Electronic supplementary material The online version of this article (doi:10.1007/s10529-015-1927-9) contains supplementary material, which is available to authorized users.

A. T. Junior · L. G. Dolce · I. Polikarpov (\&)

Departamento de F'́sica e Ciência Interdisciplinar,

Instituto de F'isica de São Carlos, Universidade de São

Paulo, Avenida Trabalhador 8 São Carlense 400 - Centro,

São Carlos, SP 13560-970, Brazil

e-mail: ipolikarpov@ifsc.usp.br

M. de Oliveira Neto

Instituto de Biociências, Universidade Estadual Paulista,

Distrito de Rubião Jr. s/n, Botucatu, SP 18618970, Brazil was observed in acid $\mathrm{pHs}$ with an increase in sugar release of up to $36 \%$.

Conclusion The synergistic effect arising from the action of the expansin-like protein was considerable in the presence of significantly larger amounts of the commercial enzymatic cocktail then previously observed (0.35 FPU of Accellerase 1500/g substrate).

Keywords Accellerase $\cdot$ Biofuel $\cdot$ Cellulase $\cdot$

Cellulose depolymerization - Expansin synergism ·

Xanthomonas campestris

Introduction

Renewable fuels, especially biofuels from lignocellulosic biomass, are considered an important, sustainable alternative to fossil fuels. The conversion of lignocellulosic material, such as, agricultural and forest residues, into fermentable sugars can be achieved by a combination of physical or chemical pretreatment and enzymatic hydrolysis (Saha 2004).

Although enzymatic hydrolysis has been extensively studied until recently the role of auxiliary proteins has not received enough attention. Expansins are responsible for the loosening of the cellulosic cell walls thereby allowing the plants to grow (Cosgrove 2000).

Although expansins cause plant cells expansion and modify their cell wall mechanical properties, the 
capacity of expansins to enhance efficiency of the cellulosic biomass remains controversial. Some reports have concluded that although lacking hydrolytic activity, expansins in general, including those from microbial origin, are capable of promoting improvements in the enzymatic hydrolysis of crystalline cellulose by synergizing with cellulases (Cosgrove 2000). Other studies have reached the opposite conclusions and suggested that microbial expansins do not act synergistically with selected cellulases for soluble sugar release from cellulose (Georgelis et al. 2014).

Here, we describe the cloning, expression and biophysical characterization of an expansin-like X domain from Xanthomonas campestris (XcEXLX1) and its synergistic effect on the hydrolysis of cellulosic substrates by a commercial cellulase mixture. We show that XcEXLX1 is a naturally disordered $b$-sheet protein, capable of boosting the enzymatic hydrolysis of cellulosic substrates by up to $36 \%$.

\section{Materials and methods}

Construction of the expression plasmid

The expansin-like X gene of X. campestris EXLX1Xc was amplified using PCR and inserted into the IPTGinducible expression vector pSMT3 (provided by Prof. Lawrence Shapiro, Columbia University, NY-USA) (see supporting information).

Expression of the protein and its purification process

The culture of $E$. coli Rosetta (DE3) pLysS was grown in lysogeny broth and purified using Ni-NTA Agarose column (Qiagen) and ÄKTA purifier 10 system (GE Healthcare Life Sciences) (see supporting information).

\section{Circular dichroism spectroscopy}

CD spectra of XcEXLX1 in $20 \mathrm{mM} \mathrm{NaCl}, 10 \mathrm{mM}$ Tris/ $\mathrm{HCl}, \mathrm{pH} 8$ were recorded on a Jasco J-720 spectral polarimeter using $0.1 \mathrm{~cm}$ path length cuvettes (Jasco, Tokyo, Japan). The spectra were collected from 190 to $280 \mathrm{~nm}$ with $100 \mathrm{~nm} \mathrm{~min}^{-1}$ increment step, $10 \mathrm{~s}$ averaging time, $1 \mathrm{~nm}$ bandwidth and a response time of $0.5 \mathrm{~s}$.
Solvent contributions were subtracted from the original spectra curves. We deconvoluted the CD spectra using the Dichroweb webserver (Whitmore and Wallace 2004) to obtain the estimates of the protein secondary structure composition.

\section{Small angle X-ray scattering (SAXS)}

Small angle X-ray scattering experiments were conducted at the D02A-SAXS2 Laboratório Nacional de Luz S'incrontron (LNLS) using a bi-dimensional detector (MarResearch, EUA). A distance of $1000 \mathrm{~mm}$ between it by the sample and the detector was used, covering arange of momentum transfer $0.013 \mathrm{~A}^{\circ} \mathbf{- 1} \mathrm{W}$ $\mathrm{qW} 0.33 \AA^{-1} \quad(\mathrm{q}=4 \mathrm{p} \sin (\mathrm{h}) / \mathrm{k})$, where $2 \mathrm{~h}$ is the scattering angle and $\mathrm{k}=0.148 \mathrm{~nm}$ is the $\mathrm{X}$-ray wavelength. The protein samples were measured at 2 and $5 \mathrm{mg} / \mathrm{ml}$ in $10 \mathrm{mM} \mathrm{Tris} / \mathrm{HCl}, 20 \mathrm{mM} \mathrm{NaCl}, \mathrm{pH} 8$ buffer.

The data was analyzed using a FIT2D program

(Hammersley 1997), normalizing the data by the intensity of the beam and multiplying it by sample absorption. The scattering of the buffer was subtracted from the scattering curve of the protein's solution. The radius of gyration $(\mathrm{Rg})$ was calculated using the slope of a Guinier plot.

The estimate of XcEXLX1 molecular mass was obtained with a SAXS MoW webtool (Fischer 2010). The distance distribution function $\mathrm{p}(\mathrm{r})$, the maximum diameter Dmax and Rg were computed from the entire scattering patterns using a GNOM package (Svergun 1992). These results were compared with the homologous structure of expansin-like protein $\mathrm{X}$ from Bacillus subtilis (Kerff et al. 2008);(PDB id 3d30). A theoretical SAXS curve from the model structure was generated and compared with the experimental curve using a Crysol program (Svergun et al. 1995). We also used the experimental curve to build dummy atom models (DAMs) of XcEXLX1 using the DAMMIN program (Svergun 1999).

\section{Enhancement of enzymatic cellulose hydrolysis}

The effect of XcEXLX1 addition on the cellulose enzymatic hydrolysis on filter paper Whatman No. 1 substrate was measured using the protocol described by Kim et al. (2009) with some adaptations. The commercial enzyme preparation, Accellerase 1500 (DuPont Industrial Biosciences), diluted to 0.35 FPU (Adney and Baker 1996) per g substrate was used, 
whereas the XcEXLX1 was diluted to $0.7 \mathrm{mg} / \mathrm{g}$ of substrate, and the bovine serum albumin (BSA) was diluted to $0.23 \mathrm{mg} / \mathrm{g}$ substrate. The reaction time varied from $30 \mathrm{~min}$ to $24 \mathrm{~h}$, and it was carried out at $50{ }^{\circ} \mathrm{C}$ in $50 \mathrm{mM}$ sodium citrate buffer using $3.3 \mathrm{mg}$ filter paper per reaction. The determination of $\mathrm{pH}$ optimum was conducted in the $\mathrm{pH}$ range from 3 to 6 was analyzed. The released sugars were measured using 3,5-dinitrosalicylic acid (DNS) method.

Results and discussion

Identification of the expansin-like $\mathrm{x}$ domain

An expansin-like $X$ domain was identified within $X$. campestris Xcc 3535 gene sequence accession number AAM42805.1 using the Domain-Fish program (Contreras-Moreira and Bates 2002) and refined by Clustal program (Higgins and Sharp 1988) using amino acid sequence with both BsEXLX1 (expansin-like from $B$. subtillis) amino acid sequence and with the sequence of expansin from Zea mays (Kim et al. 2009). A specific region of the protein, corresponding to the amino acids 385-607 (Supplementary Fig. 1), displayed characteristics that matched two characteristic expansin domains: a rare lipoprotein domain and a pollen allergen domain.

This gene was classified as expansin-like $X 1$ from $X$. campestris (XcEXLX1) according to the nomenclature

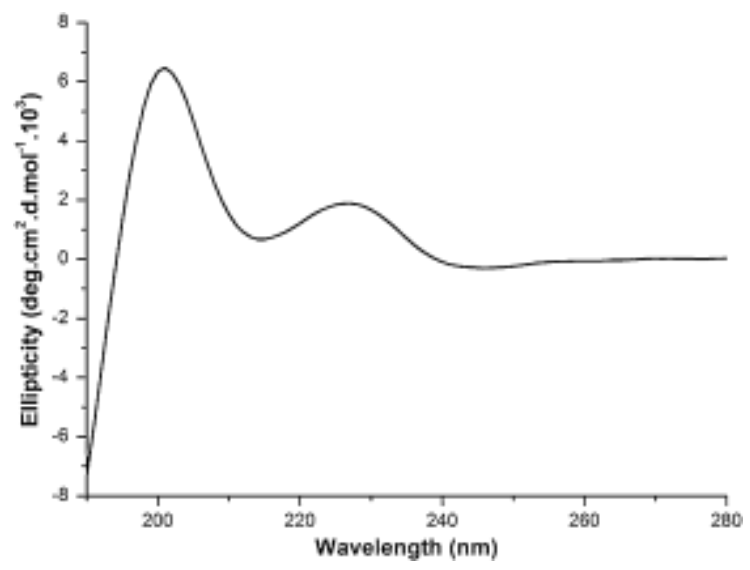

Fig. 1 Structural characterization of XcEXLX1 by CD spectroscopy. The far-UV spectrum was recorded in $20 \mathrm{mM}$ $\mathrm{Na}_{2} \mathrm{HPO}_{4}, 20 \mathrm{mM} \mathrm{NaCl}, \mathrm{pH} 8$, using an optical path length of $1 \mathrm{~mm}$ for members of the expansin superfamily of genes and proteins (Kende et al.2004).

Cloning, expression and purification of the protein

The ORF corresponding to XcEXLX1 was amplified from genomic DNA of $X$. campestris and cloned into the pSMT3 vector as described in "Materials and methods" section. The XcEXLX1-pSMT3 plasmid was sequenced and compared with the original XcEXLX1 sequence using the ContigExpress software (a component of Advance Vector NTI 11.0, Invitrogen Corporation), revealing no cloning errors or artifacts.

XcEXLX1 was expressed with a His 6 -Sumo affinity tag to facilitate purification and the tag was subsequently removed via proteolytic cleavage with ULP1. The expression and purification protocol (see supporting information) rendered an average of $30 \mathrm{mg}$ pure protein/l cell culture.

\section{Circular dichroism spectroscopy}

The CD spectra (Fig. 1) shows a negative minimum around $208 \mathrm{~nm}$ due to $\mathrm{p}-\mathrm{p}^{*}$ transitions and a positive maximum around $226 \mathrm{~nm}$. Why the later peak appears in the CD spectra is not quite clear. However, one possible explanation of the appearance of the positive peak around $226 \mathrm{~nm}$ could be due to the presence of aromatic residues which contribute to the positive region of the spectrum between 215 and $230 \mathrm{~nm}$. It is known that specific interaction between certain aromatic amino acids could result in a signal at far UV, which may affect the analysis of secondary structures by CD (Andersson et al. 2001).

The secondary structure composition, calculated from the XcEXLX1 spectra (Fig. 1) using the algorithm CDSSTR with the SP175 dataset (Lees et al. 2006) resulted in $3 \%$ a-helices, $47 \%$ b-sheets, $9 \%$ turns and $41 \%$ disordered secondary structures. The RMSD of our analysis was $6.3 \%$. These results show that XcEXLX1 is a predominantly b-sheets protein with a considerable fraction of disordered regions.

Small angle X-ray scattering (SAXS) studies

The experimental SAXS curves did not display any spatial correlation effects within the studied 
concentration range ( 2 and $5 \mathrm{mg} / \mathrm{ml}$ ). For this reason, subsequent analyses were performed using SAXS data collected from samples at $5 \mathrm{mg} / \mathrm{ml}$.

The flexibility of the protein can be evaluated using the Kratky plot (Fig. 2a). XcEXLX1 small-angle scattering curve is consistent with a partially folded protein (Rambo and Tainer 2011). In this case the initial parabolic peak is followed by an elevated baseline at high $\mathrm{q}$ that is typical for random coil structures. These data are coherent with our CD spectroscopy results that also showed a large portion of disordered regions in the structure of the protein. This behavior can also be evaluated using a Porod plot (Fig. 2b), in which the slope at high $\mathrm{q}_{\mathrm{s}}$ give us a Porod constant equal to $4.391 \mathbf{1}^{-5}$. A non-flexible system would give a slope close to zero (constant).

The radius of gyration $\left(\mathrm{R}_{\mathrm{g}}\right)$ value was calculated using the Guinier plot (Fig. 3a, insert) and its value is consistent with a monomeric state of XcEXLX1 in solution. An independent $\mathrm{R}_{\mathrm{g}}$ estimate was obtained from the analysis of the distance distribution function (p(r)) analyses (Fig. 3b; Table 1), which also demonstrates that there is no interference among the protein particles in solution. The $\mathrm{R}_{\mathrm{g}}$ and $\mathrm{D}_{\max }$ values were calculated using the GNOM program. A new value of $\mathrm{q}_{\max }=0.29 \AA^{-1}$ was adjusted to eliminate regions with weak scattering signal. (Fig. 3a; Table 1). The SAXS-based estimate of XcEXLX1 molecular mass,
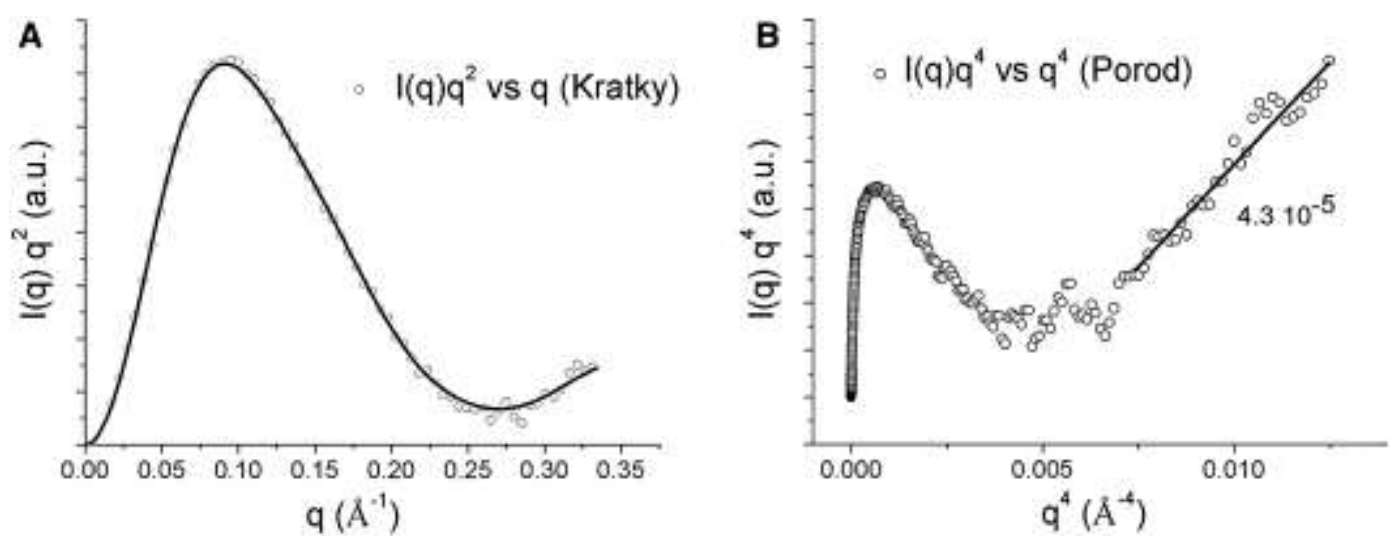

Fig. 2 a Small-angle X-ray scattering curve of XcEXLX1. A Kratky plot of scattering data illustrating changes in the behavior of the curve for partially folded protein. $\mathrm{b}$ Porod plot of same scattering data
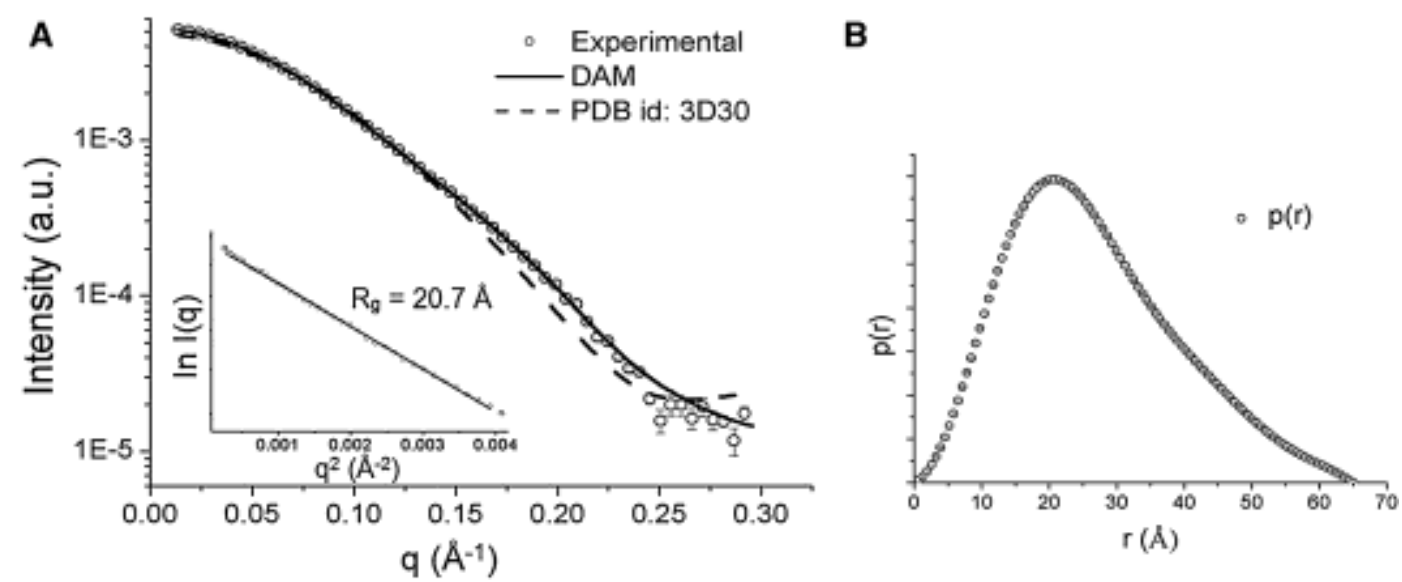

Fig. 3 a Small-angle X-ray scattering curve for XcEXLX1 $(\log I$ (q) 9 q) results of fitting procedure: experimental curve (circle), the high resolution model of the pdb id 3D30 (dashed line) and the simulated scattering DAM (Dammin) (solid line). The insert shows the Guinier adjustment for obtaining the $\mathrm{R}_{\mathrm{g}}$. $\mathrm{b}$ The $\mathrm{p}(\mathrm{r})$ plot 
Table 1 Structural parameters derived from SAXS for XcEXLX1

\begin{tabular}{llll}
\hline Parameters & Exp.* & PDB $\dagger$ & DAM. \\
\hline $\mathrm{D}_{\text {máx }}(\AA)$ & $65 \pm 5$ & 66.03 & 66.46 \\
$\mathrm{R}_{\mathrm{g}}(\AA)$ & 20.7 (Guinier) & & \\
$20.68 \pm 0.01($ Gnom) & 18.98 & 20.63 & \\
MW (kDa) & 22.6 & & \\
Resolution $(\AA)^{€}$ & 21.24 & - & 21.24 \\
\hline
\end{tabular}

* Exp., calculated from the experimental data $3 \mathrm{mg} / \mathrm{ml}$

$\dagger$ PDB id: PDB 3D3O $60 \%$ sequence identity with XcEXLX1

\$ DAM, parameters of the (DAM) without symmetry obligation in the program Dammin

$€$ Resolution $2 \mathrm{p} / \mathrm{q}_{\max }$

obtained using the SAXS MoW server, was $22.6 \mathrm{kDa}$ with a relative error of $1.2 \%$. This value is very close to a theoretical molecular weight of XcEXLX1 and confirms that XcEXLX1 exists in solution predominantly in a monomeric state.

The Dammin program was used to calculate ten independent low-resolution protein models, consis-

tently generating similar molecular envelopes. The average $\mathrm{v}$ value for the simulated 10 models was 2.30.

An experimental X-ray scattering curve and two theoretical SAXS curves (one simulated from an average DAM and another one computed from the homology model [(Kerff et al. 2008); PDB id: 3D30] overlap closely (Fig. 3a). The small difference between the experimental curve and the simulated curve derived from the PDB id 3D30 could be attributed to the flexibility effect yielding a curve that represents an average of different molecular conformations in solution. As a following step we used the Subcomb program to superpose the DAM with a high-resolution structure of the homologous protein BsEXLX1 [(Kerff et al. 2008); PDB id 3D30] (Fig. 4). The high-resolution X-ray structure fits nicely into the low-resolution SAXS envelope reconstructed for XcEXLX1.

Activity tests: enhancement of the enzymatic hydrolysis of cellulose

To evaluate whether XcEXLX1 is capable of boosting the efficiency of cellulolytic enzymatic preparations, we applied it in a combination with Accellerase 1500 (DuPont Industrial Biosciences) to filter paper enzymatic hydrolysis. The hydrolysis reaction was performed in a sodium citrate buffer using $0.7 \mathrm{mg}$ XcEXLX1 per g substrate and 0.35 FPU of Accellerase $1500 / \mathrm{g}$ substrate in the $\mathrm{pH}$ range of 3-6 (Fig. 5a). The concentration of the substrate was kept at $3.3 \mathrm{mg}$ per reaction and the reaction volume was kept at 6011. The mass ratio between the total protein mass of Accellerase 1500 and XcEXLX1 was 4 (i.e., there were four times more cellulase enzymes in terms of their weight). Since XcEXLX1 is much smaller than a typical cellulase and, assuming that the average molecular weight of the cellulase in the Accellerase 1500 is equal to the molecular mass of Trichoderma reesei Cel7A (the major enzymatic component of the $T$. reesei supernatant which corresponds to approximately $60 \%$ of the total secreted protein), the molar relation between the cellulases and the XcEXLX1 was 1.7 (i.e. there were 1.7 times more cellulase enzymes in terms of their molarity). Our results clearly demonstrate the synergistic effect between Accellerase 1500 and the XcEXLX1 protein, which resulted in an increase of the relative activity of the commercial enzymatic preparation.

Most of the fungal-derived industrial enzymatic mixtures which are available commercially such as Accellerase 1500 function best at acidic pHs between $\mathrm{pH} 4$ and 6. The optimal $\mathrm{pH}$ for the mixture of XcEXLX1 with Accellerase 1500 was found to be 5 and at this $\mathrm{pH}$, the addition of XcEXLX1 increased the enzymatic hydrolysis efficiency by approximately $36 \%$ after 30 min of reaction (Fig. 5a) and by $20 \%$ after $24 \mathrm{~h}$ of reaction performed at $\mathrm{pH} 5$ (Fig. 5b). Furthermore, our experimental results show that the synergistic effect of XcEXLX1 is pH-dependent with a tendency to become stronger at acidic pHs (Fig. 5a) and less relevant or non-existent at $\mathrm{pHs}$ equal or higher than 6. This might indicate that XcEXLX1 could synergize even better with more acidic enzymatic preparation with optimum pHs between 4 and 5 (Fig. 5a). However, we also cannot exclude a hypothesis that XcEXLX1 might have some stabilizing effect on the enzymes which are typically non-active under very acid conditions. It is important to note that under optimum conditions XcEXLX1 had stronger effect on the enhancing of cellulase activity than a commonly used test protein, BSA (Fig. 5a).

Why does BSA, which is not secreted by plant biomass-degrading fungi, enhance cellulose degradation by cellulases? BSA is known to bind to 
Fig. 4 Superposition of the crystallographic model of BsEXLX1 [(Kerff et al. 2008); PDB id 3D30] with the low-resolution model generated by DAMMIN. Center and right models were rotated $90^{\circ}$ around $y$ axis and $90^{\circ}$ around $x$-axis from the orientation shown on the left panel
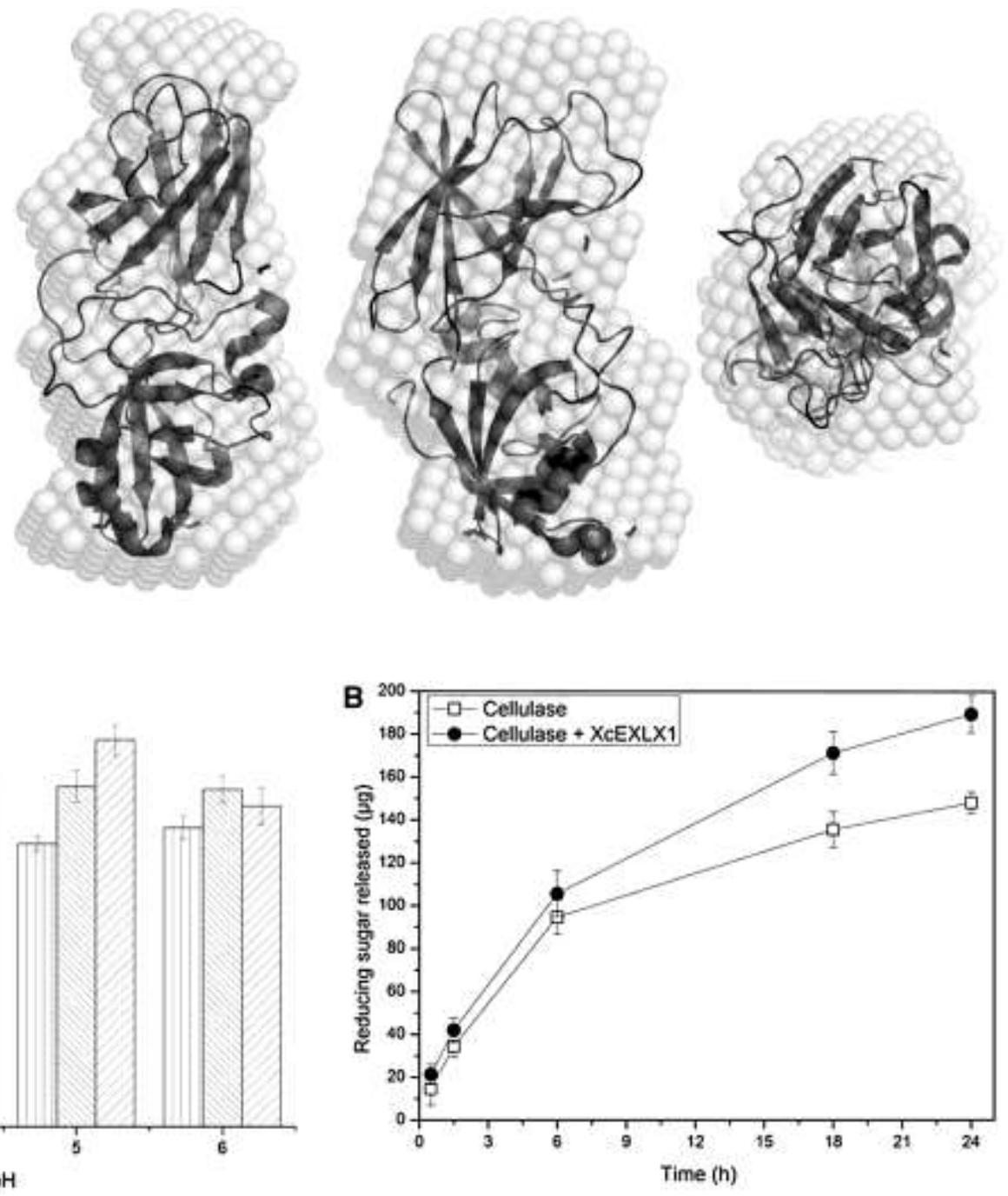

of synergism between the XcEXLX1 and cellulase (Accellerase $1500)$ at $\mathrm{pH}$ 5. The experiments were performed in triplicate with 0.35 FPU of Accellerase 1500 and $0.7 \mathrm{mg}$ of XcEXLX1 per $\mathrm{g}$ of substrate

degradation by cellobiohydrolases. Two cellobiohydrolases (Cel7A and Cel6A) of $T$. reesei-based enzymatic mixtures, such as Accellerase 1500, are the major components of the cellulose preparate and correspond to approx. 60 and $20 \%$ of the total protein mass secreted by $T$. reesei, respectively (Zhang and Lynd 2004). Both of them consist of a catalytic domain (CD) connected through a linker peptide to the carbohydrate-binding module (CBM) ((Jung et al. 2013; Kuras in and Va“ ljamäe 2011; Lehtio“ et al. 2003). Cel7A binds to the hydrophobic (110) face of cellulose
The most plausible explanation comes from the

consideration of the molecular mechanism of cellulose hydrophobic surfaces (Jeyachandran et al. 2009) and thus might prevent unspecific binding between cellustrates such as lignin (for example, see Brethauer et al. 2011). It can also stabilize cellulases in solution thus reducing the enzyme denaturation during hydrolysis (Eriksson et al. 2002) and also relieve sugar inhibition of enzymatic hydrolysis of biomass materials (Wang et al. 2015). 
(Lehtio" et al. 2003; Liu et al. 2011). Cel7A and Cel6A hydrolyze glycosidic bonds, respectively, from the reducing and none-reducing ends of the cellulose chain in a processive manner (Igarashi et al. 2009). Cel7A typically performs $61 \pm 14$ catalytic acts before dissociating from the cellulose (Kuras in and Valjamäe 2011). The enzyme is only able to begin to cleave cellulose if the catalytic domain is at the hydrophobic surface of the cellulose and its active site recognized the free end of the cellulose chain and is in the proper conditions for the catalysis (Igarashi et al. 2009; Jalak and Valjamae 2014; Jung et al. 2013). However, exoglucanases are guided to the hydrophobic surface of cellulose by CBMs and their interaction with cellulose is mediated by both the CBMs and CDs. The CBM can bind to the hydrophobic surface of cellulose without the $\mathrm{CD}$ productively interacting with the available free chain ends, thus engaging in a nonproductive binding (Igarashi et al. 2009; Jalak and Valjamae 2014; Jung et al. 2013). This would deplete active cellulase pool available in solution, without them effectively being involved in cellulose hydrolysis. BSA binding to the same hydrophobic surface of cellulose crystals (Jeyachandran et al. 2009) would hinder none-productive binding of cellulases hence avoiding their unproductive interactions with the substrate, increasing concentration of free cellulases and enabling a larger number of cellulases to get involved in the processive enzymatic cleavage of the substrate. Consequently, the BSA mechanism of action might somewhat resembles that of surfactants that also have been widely employed to increase efficiency of cellulase hydrolysis of cellulosic substrates (Eriksson et al. 2002). Molecular mechanisms by which expansins enhance cellulose hydrolysis deserve further investigations.

Thus our results contrast with a previous study in which expansin-like proteins from microbes have been reported to have no effect on the enhancement of the soluble sugars release from filter paper by cellulases (Georgelis et al. 2014) but confirm several other studies that found a boosting effect of expansins on cellulase activities (Kim et al. 2009; Lin et al. 2013).

Acknowledgments We thank Livia Regina Manzine, Andressa Alves Pinto, Derminda I. de Moraes, Joci Neuby Alves Macedo, Ethel Schuster and Jose' Luis Lopes for the technical support. This research was supported by Fundac,a o de Amparo a Pesquisa do Estado de São Paulo (FAPESP) via research Grants \# 2008/56255-9, 2007/08706-9, 2010/52362-5 and 2009/05349-6, by Coordenaca o de Aperfeic,oamento de Pessoal de N'ivel Superior (CAPES) and by Conselho Nacional de Desenvolvimento Cient '́fico e Tecnoló gico (CNPq) via INCT do Bioetanol and Grant \# 471834/2009-2, 301981/2011-6 and 550931/2011-2.

Supporting information Supplementary methods. Construction of the expression plasmid, Expression of the protein and its purification process.

Supplementary Fig. 1-Aligned sequences of gene (1) Xcc3535, (2) 2BH0 (BsEXLX1) and (3) 2HCZ (expansin of Zea mays), using the multiple alignment Clustal program (Higgins and Sharp 1988).

Supplementary Fig. 2-Size-exclusion chromatogram of XcEXLX1.

\section{References}

Adney B, Baker J (1996) Measurement of ellulase activities. National Renewable Energy Laboratory

Andersson D, Carlsson U, Freskgard PO (2001) Contribution of tryptophan residues to the $\mathrm{CD}$ spectrum of the extracellular domain of human tissue factor: application in folding studies and prediction of secondary structure. Eur J Biochem 268:1118-1128

Brethauer S, Studer MH, Yang B, Wyman CE (2011) The effect of bovine serum albumin on batch and continuous enzymatic cellulose hydrolysis mixed by stirring or shaking. Bioresour Technol 102:6295-6298

Contreras-Moreira B, Bates PA (2002) Domain fishing: a first step in protein comparative modelling. Bioinformatics 18:1141-1142

Cosgrove DJ (2000) Loosening of plant cell walls by expansins. Nature 407:321-326

Eriksson T, Borjesson J, Tjerneld F (2002) Mechanism of surfactant effect in enzymatic hydrolysis of lignocellulose. Enzym Microb Technol 31:353-364

Fischer H (2010) Determination of the molecular weight of proteins in solution from a single small-angle X-ray scattering measurement on a relative scale. J Appl Crystallogr 43:101-109

Georgelis N, Nikolaidis N, Cosgrove DJ (2014) Biochemical analysis of expansin-like proteins from microbes. Carbohydr Polym 100:17-23

Hammersley AP (1997) FIT2d: an introduction and overview. E.S.R.F, Grenoble

Higgins DG, Sharp PM (1988) CLUSTAL: a package for performing multiple sequence alignment on a microcomputer. Gene 73:237-244

Igarashi K, Koivula A, Wada M et al (2009) High speed atomic force microscopy visualizes processive movement of Trichoderma reesei cellobiohydrolase I on crystalline cellulose. J Biol Chem 284:36186-36190

Jalak J, Valjamae P (2014) Multi-mode binding of cellobiohydrolase Cel7A from Trichoderma reesei to cellulose. PLoS One 9:e108181

Jeyachandran YL, Mielczarski E, Rai B, Mielczarski JA (2009) Quantitative and qualitative evaluation of adsorption/ 
desorption of bovine serum albumin on hydrophilic and hydrophobic surfaces. Langmuir 25:11614-11620

Jung J, Sethi A, Gaiotto T et al (2013) Binding and movement of individual Cel7A cellobiohydrolases on crystalline cellulose surfaces revealed by single-molecule fluorescence imaging. J Biol Chem 288:24164-24172

Kende H, Bradford KJ, Brummell DA et al (2004) Nomenclature for members of the expansin superfamily of genes and proteins. Plant Mol Biol 55:311-314

Kerff F, Amoroso A, Herman R et al (2008) Crystal structure and activity of Bacillus subtilis YoaJ (EXLX1), a bacterial expansin that promotes root colonization. Proc Natl Acad Sci USA 105:16876-16881

Kim ES, Lee HJ, Bang W-G et al (2009) Functional characterization of a bacterial expansin from Bacillus subtilis for enhanced enzymatic hydrolysis of cellulose. Biotechnol Bioeng 102:1342-1353

Kurašin M, Väljamäe P (2011) Processivity of cellobiohydrolases is limited by the substrate. J Biol Chem 286:169-177 Lees JG, Miles AJ, Wien F, Wallace BA (2006) A reference database for circular dichroism spectroscopy covering fold and secondary structure space. Bioinformatics 22:1955-1962

Lehtio. J, Sugiyama J, Gustavsson M et al (2003) The binding specificity and affinity determinants of family 1 and family 3 cellulose binding modules. Proc Natl Acad Sci USA 100:484-489

Lin H, Shen Q, Zhan JM et al (2013) Evaluation of bacterial expansin EXLX1 as a cellulase synergist for the saccharification of lignocellulosic agro-industrial wastes. PLoS One 8:e75022
Liu YS, Baker JO, Zeng Y et al (2011) Cellobiohydrolase hydrolyzes crystalline cellulose on hydrophobic faces. J Biol Chem 286:11195-11201

Rambo RP, Tainer JA (2011) Characterizing flexible and intrinsically unstructured biological macromolecules by SAS using the Porod-Debye law. Biopolymers 95:559-571 Saha BC (2004) Lignocellulose biodegradation and applications in biotechnology. Lignocellulose biodegradation. American Chemical Society, pp 2-34

Svergun DI (1992) Determination of the regularization parameter in indirect-transform methods using perceptual criteria. J Appl Crystallogr 25:8

Svergun DI (1999) Restoring low resolution structure of biological macromolecules from solution scattering using simulated annealing. Biophys J 76:2879-2886

Svergun D, Barberato C, Koch MHJ (1995) CRYSOL-a program to evaluate X-ray solution scattering of biological macromolecules from atomic coordinates. J Appl Crystallogr 28:768-773

Wang H, Kobayashi S, Hiraide $\mathrm{H}$ et al (2015) The effect of nonenzymatic protein on lignocellulose enzymatic hydrolysis and simultaneous saccharification and fermentation. Appl Biochem Biotechnol 175:287-299

Whitmore L, Wallace BA (2004) DICHROWEB, an online server for protein secondary structure analyses from circular dichroism spectroscopic data. Nucleic Acids Res 32:W668-W673

Zhang YH, Lynd LR (2004) Toward an aggregated understanding of enzymatic hydrolysis of cellulose: noncomplexed cellulase systems. Biotechnol Bioeng 88:797-824 